UNIVERSIDADE DE SÃO PAULO

FACULDADE DE ECONOMIA, ADMINISTRAÇÃO E CONTABILIDADE DEPARTAMENTO DE ECONOMIA PROGRAMA DE PÓS-GRADUAÇÃO EM ECONOMIA

DEMANDA POR MOEDA E PERCEPÇÃO DE RISCO: -EVIDÊNCIAS DA ECONOMIA DOS EUA-

Eduardo Alvarenga de Melo

Orientador: Prof. Dr. Joe Akira Yoshino 
Prof. Dr. Marco Antônio Zago Reitor da Universidade de São Paulo

Prof. Dr. Adalberto Américo Fischmann Diretor da Faculdade de Economia, Administração e Contabilidade

Prof. Dr. Hélio Nogueira da Cruz Chefe do Departamento de Economia

Prof. Dr. Márcio Issao Nakane Coordenador do Programa de Pós-Graduação em Economia 


\title{
DEMANDA POR MOEDA E PERCEPÇÃO DE RISCO: -EVIDÊNCIAS DA ECONOMIA DOS EUA-
}

\author{
Dissertação apresentada ao Departamento de \\ Economia da Faculdade de Economia, \\ Administração e Contabilidade da \\ Universidade de São Paulo como requisito \\ para a obtenção do título de Mestre em \\ Ciências.
}

Orientador: Prof. Dr. Joe Akira Yoshino

Versão Corrigida

(Versão original disponível na Faculdade de Economia, Administração e Contabilidade)

\section{SÃO PAULO}




\section{FICHA CATALOGRÁFICA}

Elaborada pela Seção de Processamento Técnico do SBD/FEA/USP

Melo, Eduardo Alvarenga de

Demanda por moeda e percepção de risco: evidências da economia dos EUA / Eduardo Alvarenga de Melo. -- São Paulo, 2014.

$151 \mathrm{p}$.

Dissertação (Mestrado) - Universidade de São Paulo, 2014.

Orientador: Joe Akira Yoshino.

1. Economia monetária 2. Teoria monetária 3. Econometria 4. Economia - Estados Unidos I. Universidade de São Paulo. Faculdade de Economia, Administração e Contabilidade. II. Título.

CDD - 332.46 


\section{RESUMO}

A influência da percepção de risco sobre as decisões de demanda por moeda é o tema central que este trabalho busca explorar. Para isso, um modelo de demanda por moeda a ser testado empiricamente foi proposto, com a inclusão de variáveis de volatilidade do mercado de ações, das taxas de juros e do produto interno bruto, além do spread sobre a taxa de juros de política monetária, ao modelo padrão na literatura, com produto e taxa de juros como variáveis independentes. Em seguida, o modelo foi estimado para a economia dos Estados Unidos no período entre 1959 e 2013, utilizando sete diferentes agregados monetários como variável dependente. Para que fosse corretamente considerada a cointegração entre as variáveis envolvidas, foi utilizada a técnica de estimação por modelos ARDL (Autoregressive Distributed Lags), cuja aplicação na literatura durante a última década em modelos com variáveis de distintas ordens de integração é crescente. Os resultados obtidos são animadores no sentido de sugerir a existência desta relação entre risco e demanda por moeda, particularmente para o período de maior inovação financeira recente, porém dão margem a novas pesquisas que possam aperfeiçoar a metodologia teórica e econométrica a fim de melhor estimar a dimensão e o mecanismo desta relação. 


\begin{abstract}
The influence of perceived risk on the decisions of the demand for money is the central theme that this paper seeks to explore. With this goal, we propose a model of demand for money to be tested empirically, with the inclusion of volatilities of the stock market, interest rates and gross domestic product, in addition to the spread on the monetary policy interest rate, to the standard model in the literature, with product and interest rate as independent variables. This model was then estimated for the United States economy in the period between 1959 and 2013, using seven different monetary aggregates as the dependent variable. In order to properly consider the cointegration between the variables involved, we made use of ARDL (Autoregressive Distributed Lags) modeling technique, whose application in the literature over the last decade, in models with variables of different orders of integration, is increasing. The results are encouraging in the sense of suggesting the existence of such relationship between risk and demand for money, particularly for the most recent period of financial innovation, but leaves room to new research that could improve the theoretical and econometric methodology in order to better estimate the dimension and the mechanism of this relationship.
\end{abstract}




\section{SUMÁRIO}

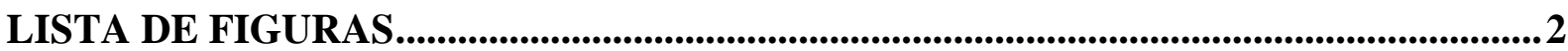

LISTA DE TABELAS ...................................................................................................

1 INTRODUÇÃO ...........................................................................................................5

2 A DEMANDA POR MOEDA NA LITERATURA ECONÔMICA ..................................7

2.1 Evolução do conceito de demanda por moeda ................................................................................7

2.2 Literatura empírica e metodologia econométrica...............................................................................10

2.2.1 A produção empírica impulsionada pelas mudanças nas décadas de 1970/80 .................................... 10

2.2.2 Cointegração entre variáveis e os modelos de demanda por moeda ................................................ 13

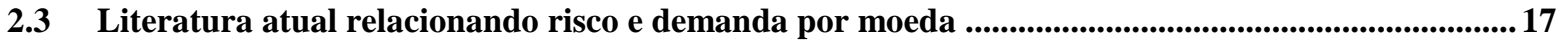

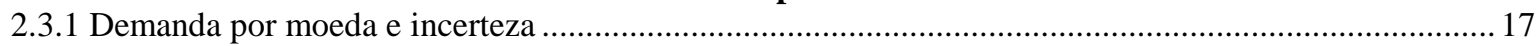

2.3.2 Volatilidade da taxa de juros e do spread bancário: ...................................................................... 21

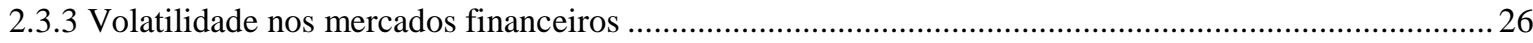

2.3.4 Volatilidade do desempenho da economia real (PIB) ..................................................................... 30

3 MODELO PROPOSTO E DISCUSSÃO DAS VARIÁ VEIS...........................................33

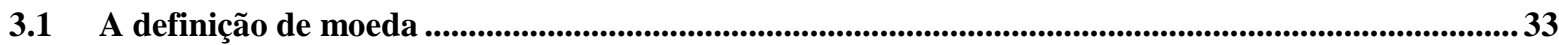

3.2 Variáveis de escala e de custo de oportunidade ..................................................................................35

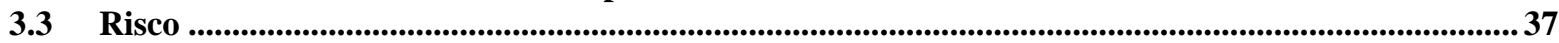

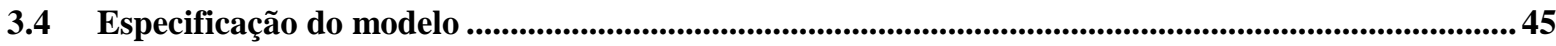

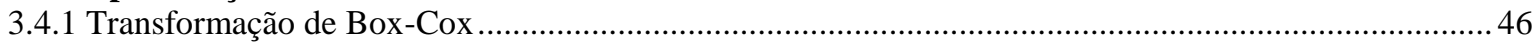

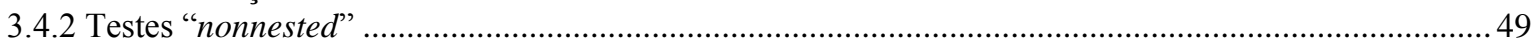

3.4.3 Seleção por critérios de informação e ajuste dos modelos ..........................................................51

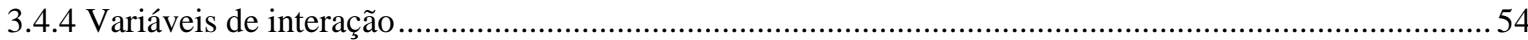

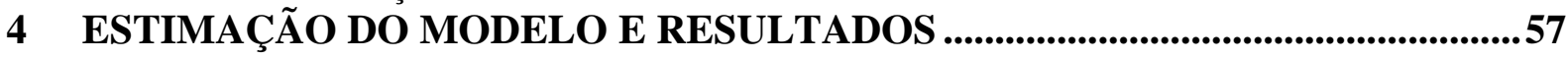

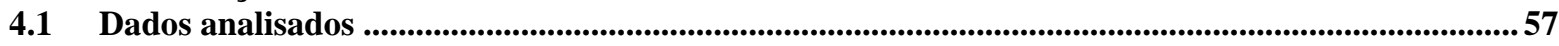

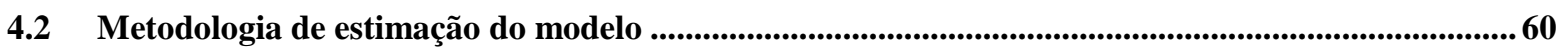

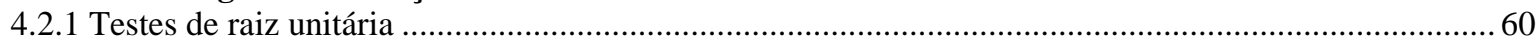

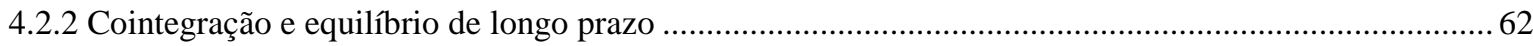

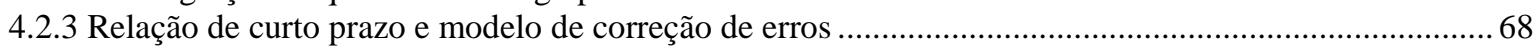

4.3 Resultados: demanda por moeda padrão ..................................................................................69

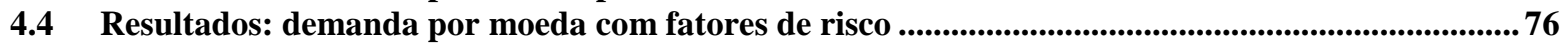

4.4.1 Abordagem de "bounds-testing" para cointegração .................................................................. 76

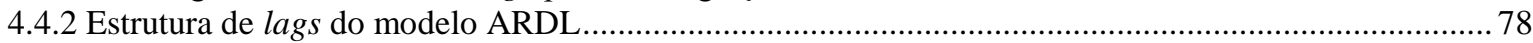

4.4.3 Estimação ECM irrestrito e equações de longo prazo..................................................................... 79

4.4.4 Modelos ECM restritos e dinâmica de curto prazo ........................................................................ 89

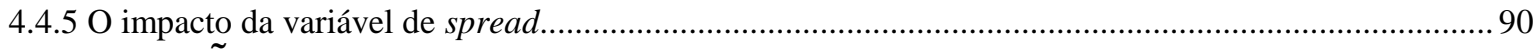

5 EXTENSÕES AO MODELO PROPOSTO............................................................ 105

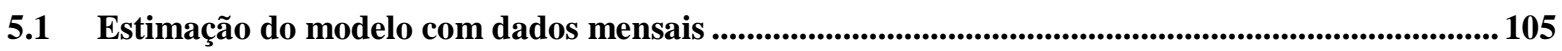

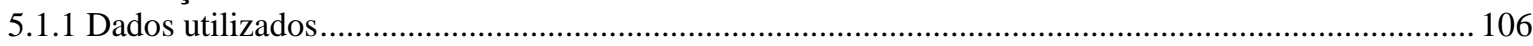

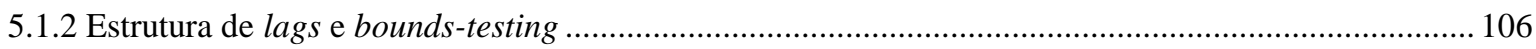

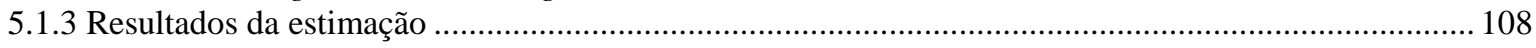

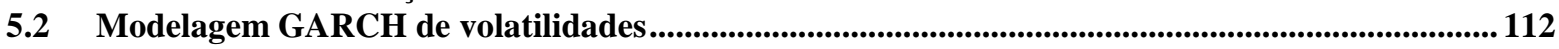

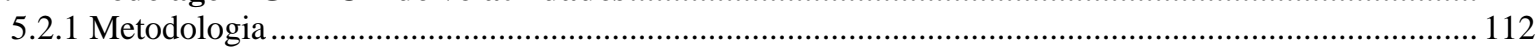

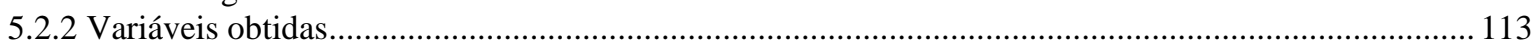

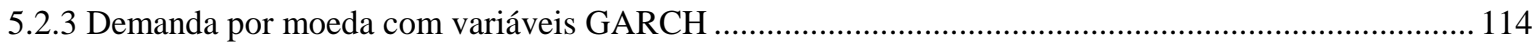

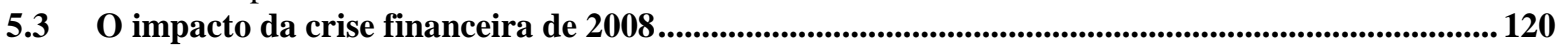

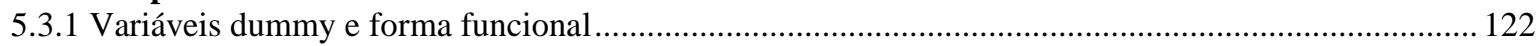

5.3.2 Variáveis relacionadas à atuação do Federal Reserve ...................................................................... 123

6 CONCLUSÕES ............................................................................................................. 127

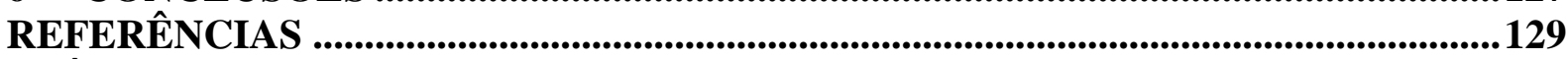

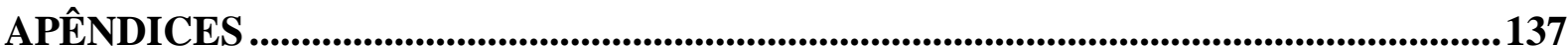




\section{LISTA DE FIGURAS}

Figura 1- M1/PIB vs. Juros de curto prazo - 1959-85(círculo) e 1986-2013(cruz) .................. 11

Figura 2 - EUA: agregados monetários em termos reais (bilhões de US\$ de 2009) ................ 35

Figura 3 - Índice de Sharpe a partir de dados mensais, janela móvel de 24 meses ................. 38

Figura 4 - Gráficos de dispersão: Sharpe x $\log (\mathrm{M} 1)$ (esquerda) e Sharpe $\mathrm{x} \log (\mathrm{M} 2)$............. 38

Figura 5 - Taxas de juros dos "Treasury Bills" com maturidade de 3 meses (em \% ao ano) e sua Volatility.....

Figura 6 - EUA: PIB real trimestral (bilhões de US\$ de 2009) e Vol(PIB) ............................ 40

Figura 7 - Gráficos de dispersão: Vol_rt vs. $\log (\mathrm{M} 1)$ (esquerda) e $\log (\mathrm{M} 2)$ (direita) ............. 41

Figura 8 - Gráficos de dispersão: Vol_PIBt vs. $\log (\mathrm{M} 1)$ (esquerda) e $\log (\mathrm{M} 2)$ (direita) ........ 41

Figura 9 - Spread-loan, Ted-Spread e Spread-T30 - 1960 a 2013 ........................................ 42

Figura 10 - Ted-Spread e componentes - dados mensais de 1986 a 2013 ............................. 43

Figura 11- Gráficos de dispersão: Spread-loan vs. $\log (\mathrm{M} 1)$ (esquerda) e $\log (\mathrm{M} 2)$ (direita) ... 43

Figura 12- Gráficos de dispersão: TED Spread vs. $\log (\mathrm{M} 1)$ (esquerda) e $\log (\mathrm{M} 2)$ (direita) ... 43

Figura 13- Gráficos de dispersão: T30 Spread vs. $\log (\mathrm{M} 1)$ (esquerda) e $\log (\mathrm{M} 2)$ (direita) .... 44

Figura 14 - Termo de erro do modelo padrão para M1 e variáveis de risco............................77

Figura 15 - Termo de correção de erros (logs), modelos com agregado M1 .......................... 83

Figura 16 - Termo de correção de erros (logs), modelos com agregado M2 .......................... 83

Figura 17 - Termo de correção de erros (logs), modelos com agregado M1RS.......................83

Figura 18 - Termo de correção de erros (logs), modelos com agregado DV ...........................84

Figura 19 - Termo de correção de erros (logs), modelos com agregado PMPP .......................84

Figura 20 - Termo de correção de erros (logs), modelos com agregado BM...........................84

Figura 21 - Termo de correção de erros (logs), modelos com agregado RES .......................... 85

Figura 22 - Termo de correção de erros: modelos per capita com risco................................87

Figura 23 - Termo de correção de erros: modelos com Spread-Loan e TED-Spread...............95

Figura 24 - Termo de correção de erros: modelos com Spread-Loan e Spread-T30 ............. 101

Figura 25 - Termo de correção de erros: modelos com dados mensais.................................. 110

Figura 26 - Evolução temporal: GARCH_rt, GARCH_Yt e GARCH_dowt .......................... 114

Figura 27 - Termos de erro: modelos com variáveis GARCH .........................................119

Figura 28 - Agregados Monetários - 2000 a 2013 (em US\$ bi de 2009)............................. 121

Figura 29 - Variáveis de risco - 2006 a 2013 (2006Q1=100) ............................................. 122

Figura 30 - Termo ECt do modelo com risco para M1RS com dummy da crise e semi-log. 123 Figura 31 - Termo ECt do modelo com risco para M1RS e volatilidade das reservas totais 124 Figura 32 - Termos de correção de erros: modelo com risco anterior e modificado..............126 


\section{LISTA DE TABELAS}

Tabela 1 - Correlações das variáveis, em pares $(*=5 \%$ sign.) ..............................................4

Tabela 2 - Resultados das regressões com transformações de Box-Cox ............................... 48

Tabela 3 - Teste J: resultados para modelos selecionados ..................................................50

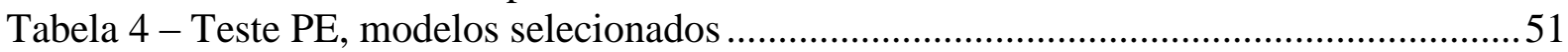

Tabela 5 - Critérios de informação para modelos no formato ARDL (agregado M1) ............53

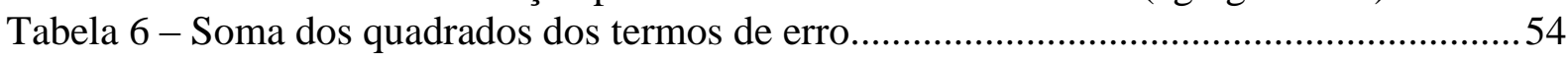

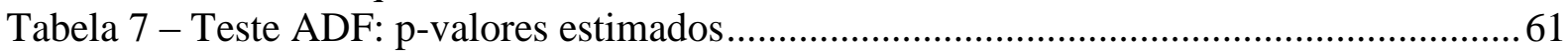

Tabela 8 - Valores do teste F com diferentes defasagens no modelo ARDL padrão - M1 .....69

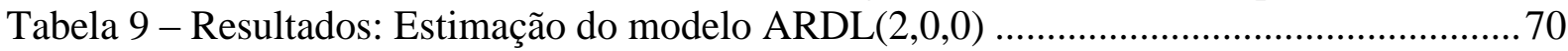

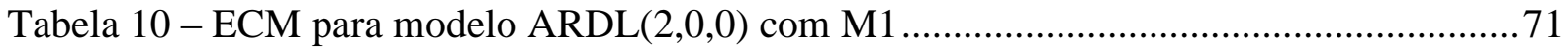

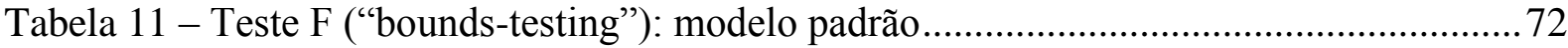

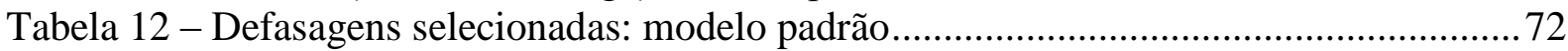

Tabela 13 - Coeficientes estimados para os modelos ARDL selecionados ............................ 73

Tabela 14 - Teste F (“bounds-testing”): modelo padrão com variáveis per capita....................75

Tabela 15 - Defasagens selecionadas: modelo padrão com variáveis per capita.....................75

Tabela 16 - Resultados: modelo padrão com variáveis per capita........................................ 75

Tabela 17 - Teste F ("bounds-testing"): modelo com variáveis de risco................................77

Tabela 18 - Teste F ("bounds-testing"): modelo com risco e com variáveis per capita ...........78

Tabela 19 - Defasagens selecionadas: modelo com variáveis de risco...................................79

Tabela 20 - Defasagens selecionadas: modelo com risco e com variáveis per capita .............79

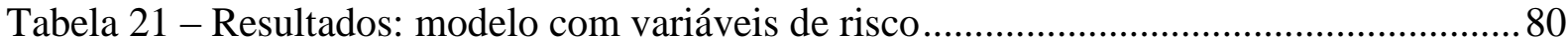

Tabela 22 - Resultados: modelo com risco e com variáveis per capita ................................. 85

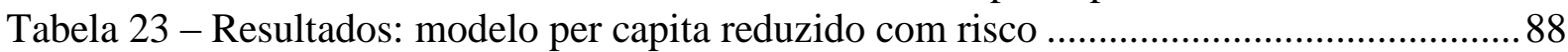

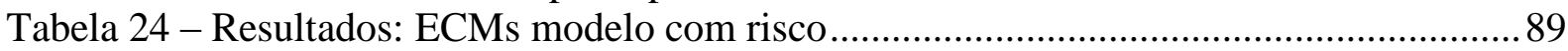

Tabela 25 - Resultados: ECMs modelo per capita com risco ............................................. 89

Tabela 26 - Defasagens selecionadas: modelo com variáveis de risco e TED Spread............. 90

Tabela 27 - Defasagens selecionadas: modelo per capita com variáveis de risco e TED

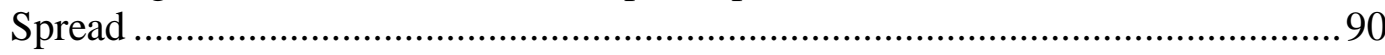

Tabela 28 - Teste F (“bounds-testing”): modelo com variáveis de risco e TED Spread .........91

Tabela 29 - Teste F ("bounds-testing"): modelo per capita com risco e TED Spread.............91

Tabela 30 - Resultados: modelo com risco e com TED_Spread ..........................................92

Tabela 31 - Resultados: ECM modelo com risco e com TED_Spread ....................................93

Tabela 32 - Resultados: modelo per capita com risco e com TED_Spread .............................95

Tabela 33 - Resultados: ECM modelo per capita com risco e com TED_Spread ..................96

Tabela 34 - Defasagens selecionadas: modelo com variáveis de risco e Spread T30 .............97

Tabela 35 - Defasagens selecionadas: modelo per capita com variáveis de risco e Spread

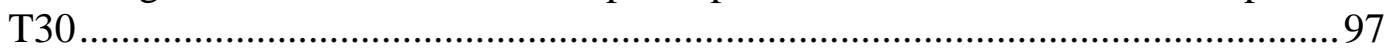

Tabela 36 - Teste F (“bounds-testing”): modelo com variáveis de risco e Spread T30 ..........97

Tabela 37 - Teste F ("bounds-testing”): modelo per capita com variáveis de risco e Spread $\mathrm{T} 30$.

Tabela 38 - Resultados: modelo com risco e com Spread T30 ….......................................98

Tabela 39 - Resultados: ECM modelo com risco e com Spread T30 ....................................99

Tabela 40 - Resultados: modelo per capita com risco e com Spread T30 ........................... 101

Tabela 41 - Resultados: ECM modelo per capita com risco e com Spread T30 .................. 102

Tabela 42 - Teste F ("bounds-testing”): modelo com variáveis mensais ............................. 107 
Tabela 43 - Teste F (“bounds-testing”): modelo per capita com variáveis mensais.............. 107

Tabela 44 - Defasagens selecionadas: modelo com variáveis mensais ................................. 108

Tabela 45 - Defasagens selecionadas: modelo per capita com variáveis mensais ..................108

Tabela 46 - Resultados: modelo com risco e variáveis mensais............................................. 109

Tabela 47 - Resultados: modelo per capita com risco e variáveis mensais ............................. 111

Tabela 48 - Resultados: Estimação dos modelos GARCH(1,1) .........................................113

Tabela 49 - Teste F ("bounds-testing"): modelo com variáveis GARCH ............................. 115

Tabela 50 - Teste F ("bounds-testing"): modelo per capita com variáveis GARCH.............115

Tabela 51 - Defasagens selecionadas: modelo com variáveis GARCH ............................. 115

Tabela 52 - Defasagens selecionadas: modelo per capita com variáveis GARCH ...............116

Tabela 53 - Resultados: modelo com variáveis GARCH ..................................................... 116

Tabela 54 - Resultados: modelo per capita com variáveis GARCH ................................... 119

Tabela 55 - Coeficientes e p-valores das variáveis incluídas ................................................ 125

Tabela 56 - Coeficientes de modelos com inclusão de variáveis MBST e RRA....................126 


\section{INTRODUÇÃO}

Dentre os seus vários alertas gerados para a necessidade de revisão dos rumos da pesquisa econômica, a crise global iniciada em 2008 reacendeu, em particular, a relevância da pesquisa sobre a demanda por moeda, em contraposição à tendência iniciada em torno dos anos 1980, em que as teorias macroeconômicas em desenvolvimento minimizavam o papel dos agregados monetários na transmissão da política monetária. Neste período recente, por outro lado, a inovação financeira e os produtos dela derivados afetaram o modo em que efetuamos pagamentos e alocamos riquezas em uma velocidade e intensidade inéditas. Este contexto nos apresenta o desafio de modelar empiricamente as relações de demanda por moeda, que se encontram em forte movimento e apresentam destacada relevância em uma conjuntura em que a política monetária com foco exclusivo nas taxas de juros se mostra incompleta.

Neste contexto, uma importante e pouco explorada abordagem teórica ao tema é o papel das variáveis de risco na determinação da relação de demanda por moeda; que será o assunto explorado neste trabalho. Mais detalhadamente, na exposição que se segue serão realizados estudos empíricos da função de demanda por moeda nos EUA, durante os últimos cinquenta anos, com a inclusão de variáveis representativas do nível de risco na economia, com foco em distintos mercados. As regressões utilizarão da metodologia de uso dos modelos ARDL (Auto Regressive Distributed Lags) para variáveis cointegradas, e com os resultados das mesmas buscaremos observar o suporte estatístico dado à hipótese de que as variáveis de risco têm importância direta na decisão individual dos níveis de agregados monetários a serem demandados.

É importante destacar aqui que a análise empírica a ser realizada nos capítulos seguintes é inteiramente baseada em dados da economia dos EUA. Esta escolha foi feita com base em duas razões. A primeira é o alto nível de disponibilidade e confiabilidade de dados econômicos neste país, o que permitiu que a abordagem a seguir fosse realizada em vários níveis de detalhe (dos agregados monetários, por exemplo) e para um grande horizonte de tempo. Esta condição não se observaria em um trabalho que se baseasse no Brasil, que, por ser o país de origem desta pesquisa, poderia ser uma escolha natural para origem dos dados da mesma. Em segundo lugar, e que consideramos ser de maior importância, podemos seguramente afirmar que os EUA possuem a economia com maior grau de desenvolvimento 
de produtos e serviços financeiros envolvidos na alocação e dispêndio de riquezas. Conforme analisamos no capítulo seguinte, é esperado que conforme se eleve a importância desse fenômeno, maior deverá ser a relevância da consideração, por parte dos indivíduos, de fatores de percepção de risco sobre sua decisão de demanda por ativos monetários.

Dados os objetivos acima, podemos afirmar em consequência que a principal contribuição desta dissertação para a literatura relacionada ao tema é, para além da análise consolidada dos trabalhos existentes, a apresentação de uma modelagem de demanda por moeda mais abrangente, que considera, simultaneamente, o risco econômico em uma ampla gama de mercados. Em outras palavras, em oposição aos trabalhos que procuram captar efeitos de risco apenas no mercado de ações ou no mercado monetário sobre a demanda por moeda, neste trabalho buscou-se captar efeitos, sobre a demanda por diversos agregados monetários, de mudanças da percepção de risco nos mercados monetário, mercado de ações e no setor "real" da economia.

Buscou-se subdividir este trabalho de modo a seguir uma cadeia natural de raciocínio para o tema: após apresentarmos o contexto em torno do mesmo, é proposta uma hipótese a ser testada e, em seguida, são apresentados os resultados obtidos neste teste. Mais detalhadamente, o Capítulo 2, seguinte a essa introdução, apresenta um breve resumo da literatura econômica relacionada à demanda por moeda, tanto em seu âmbito teórico quanto em suas questões empíricas. Particular atenção foi dispensada à literatura relacionando a percepção de risco e a demanda por moeda, a qual constituirá a base para a elaboração do trabalho que seguirá.

No Capítulo 3, é desenvolvido em detalhes o modelo teórico a ser estimado empiricamente, abrangendo tanto as variáveis envolvidas quanto a forma funcional a ser utilizada. Em seguida, no Capítulo 4, são apresentados os resultados principais da estimação do modelo, precedidos dos detalhes com relação à metodologia econométrica utilizada, que se mostrou a mais adequada, em termos de adequação às suas bases teóricas, às particularidades envolvidas na estimação do modelo proposto.

O Capítulo 5 apresenta três complementos ao capítulo anterior, de modo que nele foi possível concentrar maiores esforços em três questões particulares: duas envolvendo variações na metodologia de estimação e outra considerando o forte efeito da crise global iniciada em 2008 sobre a demanda por moeda. No capítulo seguinte, por sua vez, serão apresentadas algumas considerações e conclusões finais com relação aos resultados obtidos. 


\section{A DEMANDA POR MOEDA NA LITERATURA ECONÔMICA}

Neste capítulo inicial, será feita uma breve síntese da literatura sobre demanda por moeda de maior relevância para o desenvolvimento do presente trabalho. Na primeira seção, será brevemente apresentada a origem e evolução inicial do conceito de demanda por moeda na literatura econômica. Já uma parte da literatura empírica de aplicação deste arcabouço teórico e as dificuldades e metodologias econométricas associadas a esta produção acadêmica serão tema da segunda seção deste capítulo. Na terceira e última seção, serão explorados alguns trabalhos recentes que investigam especificamente a relação entre incerteza e percepção de risco sobre a demanda por moeda, a qual também consiste, em seu enfoque próprio, o objeto de investigação deste trabalho.

\subsection{Evolução do conceito de demanda por moeda}

Uma das primeiras abordagens amplamente difundidas para a demanda por moeda é a da teoria quantitativa da moeda. A mesma parte da identidade contábil conhecida como a versão de transações da equação de trocas, válida para uma economia monetária (Serletis, 2007, cap.7):

$$
M^{S} V \equiv P T
$$

Na qual $M^{S}$ é a quantidade de moeda ofertada, V é a velocidade de sua circulação, $\mathrm{P}$ é o nível de preços e T, o volume de transações nesta economia. Portanto, esta identidade deriva do uso da moeda como meio de troca para a realização das transações em uma economia. A teoria quantitativa da moeda surgiria, partindo da equação 2.1, da hipótese de que o termo $\mathrm{V}$, por ser determinado por fatores tecnológicos e institucionais, poderia ser considerado relativamente constante. Com isso, a identidade anterior daria lugar a uma função de demanda por moeda (Goldfeld \& Sichel, 1990), se supormos, adicionalmente, que o mercado monetário está em equilíbrio (isto é, a oferta e a demanda por moeda são iguais, $M^{s}=M^{d}$ ): 


$$
M^{d}=\frac{1}{V}(P Y) \text { ou } \frac{M^{d}}{P}=k Y
$$

Na qual utilizamos o produto real $Y$ em lugar da variável de transações da versão anterior. A segunda versão é interpretada como demanda por moeda em termos reais, com $k=\frac{1}{V}$. Observe que a equação implica em uma elasticidade-renda da demanda por moeda igual à unidade ${ }^{1}$.

Keynes (1936) retrabalharia esta relação buscando englobar tanto teorias de demanda por moeda com foco no nível de transações quanto de alocação de ativos, distinguindo entre três motivos pelos quais os agentes determinariam sua demanda por moeda: motivo transação, motivo precaução e motivo especulação. A demanda por motivo transação seria, segundo o autor, representável como na equação (2.2), isto é, seria função do nível de renda (transações). A demanda por motivo precaução, por sua vez, seria função, além da renda, do nível de incerteza com relação ao futuro. Quanto ao motivo especulação, o diferencial maior de sua análise, a demanda por moeda seria vista como uma alternativa à demanda por ativos com retorno financeiro em geral. Portanto, a demanda por moeda por esta ótica seria uma função negativa da taxa nominal de juros.

Combinando os três motivos, portanto, temos a função keynesiana de preferência pela liquidez, que descreve a demanda por moeda total:

$$
\frac{M^{d}}{P}=\phi(r, Y)
$$

Em que $r$ representa a taxa nominal de juros e a função $\phi(\cdot)$ é tal que $\phi_{r}<0$ e $\phi_{Y}>$ 0 , sendo $\phi_{x}$ a derivada parcial de $\phi$ com relação à variável $x$. Observe que nesta relação a velocidade da moeda ( $\frac{Y}{M / P}$ ) não mais é constante, mas sim uma função de $r$.

A teoria da demanda por moeda de Friedman (1956), por sua vez, expressa a demanda por moeda de um indivíduo em termos de sua posse de riquezas:

$$
\frac{M^{d}}{P}=\phi\left(Y_{p}, r_{b}-r_{m}, r_{e}-r_{m}, \pi^{e}-r_{m}\right)
$$

${ }^{1}$ Elasticidade-renda: $\eta\left(\frac{M^{d}}{P}, Y\right)=\frac{d \log \left(M^{d} / P\right)}{d \log (Y)}=1$. 
Em que $r_{b}, r_{m}$ e $r_{e}$ são as taxas de retorno esperadas sobre bonds, moeda e equities, respectivamente; e $\pi^{e}$ é a inflação esperada. A variável $Y_{p}$ representa a renda permanente real, um conceito que representa um nível de renda constante hipotético em que o valor presente dos fluxos de renda passados e futuros seriam iguais.

A teoria de Friedman trazia duas inovações principais. Em primeiro lugar, ao assumir que a demanda por moeda depende dos incentivos para a posse de ativos em geral relativamente à posse de moeda, a mesma se tornava pouco sensível à taxa de juros no "money market", e, portanto, a renda permanente seria o único determinante da demanda por moeda. Além disso, adicionando-se a definição de renda permanente ao fato anterior, tem-se a conclusão de que a função de demanda por moeda conta com uma forte estabilidade no tempo (Serletis, 2007).

A produção teórica após Keynes no campo da demanda por moeda assumiu dois campos teóricos distintos: as teorias de demanda por moeda por transações e as de portfólio. As teorias de transações enfatizavam o papel da moeda como meio de troca, enquanto as teorias de portfólio se apoiavam na função de reserva de valor da moeda. Posteriormente, com o objetivo de descrever o papel da moeda em modelos microfundamentados, foram desenvolvidos modelos teóricos em que uma demanda por moeda denominada em termos dinâmicos era obtida como resultado do processo de maximização de utilidade de um agente representativo. Um trabalho considerado pioneiro neste sentido é o de Sidrauski(1967), que utiliza uma abordagem money-in-the-utility-function, a qual ainda mantém sua relevância na literatura. $^{2}$

De forma geral, toda a produção teórica no assunto conclui que a demanda por moeda possui um importante papel na análise macroeconômica, particularmente em seu uso na seleção das ações de política monetária mais apropriadas por parte das autoridades envolvidas, e também influenciando indiretamente variáveis centrais no contexto macroeconômico, como a taxa de câmbio. Portanto, a importância do correto entendimento dos mecanismos envolvidos no conceito de demanda por moeda, e a razão pela qual acreditamos na relevância da análise contida nesta dissertação, é de que a demanda por moeda constitui um componente crítico da formulação da política monetária, e uma função de demanda por moeda estável é considerada um pré-requisito para o uso de agregados monetários na condução dessa política (Goldfeld \& Sichel, 1990).

\footnotetext{
${ }^{2}$ Uma descrição detalhada da produção teórica dos movimentos citados pode ser encontrada, por exemplo, em Serletis (2007) e Walsh (2010).
} 


\subsection{Literatura empírica e metodologia econométrica}

Como visto na seção anterior, as diferentes teorias monetárias propõem, de modo geral, uma função de demanda por moeda que apresenta a seguinte especificação básica:

$$
\frac{M_{t}}{P_{t}}=f\left(R_{t}, Y_{t}\right)
$$

Em que $M_{t}$ é o agregado monetário cuja demanda é analisada, $P_{t}$ é o índice de preços usado para converter o agregado nominal em saldos reais, $R_{t}$ é o custo de oportunidade relevante da posse de moeda e $Y_{t}$ é a variável de escala relevante que busca relacionar o nível de atividade do lado real da economia. Já a forma funcional de $f$ determinada pelas diferentes teorias é um dos principais fatores de diferenciação entre as mesmas. No capítulo 3 serão definidas detalhadamente as variáveis a serem utilizadas na investigação empírica do presente trabalho, bem como a forma funcional a ser utilizada, com base na forma geral descrita pela equação (2.5).

Como explorado por Lucas (2000) e Ireland (2009), as duas especificações mais utilizadas para a função de demanda por moeda, logarítmica (equação (2.6)) e semilogarítmica (equação (2.7)) implicam em comportamentos bastante distintos da demanda por moeda sob taxas de juros baixas (em ambas, $m$ representa a razão dos balanços monetários nominais e renda nominal). Na primeira, à medida que a taxa de juros $r$ se aproxima de zero, a demanda por saldos reais se torna arbitrariamente grande. ${ }^{3}$ Já a segunda especificação implica que os balanços reais atingem um ponto de saciedade finito quando expressos como fração da renda (Ireland, 2009).

$$
\begin{gathered}
\ln (m)=\ln (A)-\eta \ln (r) \\
\ln (m)=\ln (B)-\xi r
\end{gathered}
$$

\subsubsection{A produção empírica impulsionada pelas mudanças nas décadas de 1970/80}

Lucas (1988) realiza a estimação da seguinte equação de demanda por moeda para os EUA, utilizando dados até o ano de 1985:

\footnotetext{
${ }^{3}$ Uma modelagem teórica da demanda por moeda com foco em situações de baixas taxas de juros pode ser encontrada em Mulligan \& Sala-i-Martin (2000).
} 


$$
\ln \left(\frac{M 1_{t}}{P_{t}}\right)=a+b \ln \left(Y_{t}\right)+c r_{t}+u_{t}
$$

Os resultados encontrados pelo autor podem ser considerados como representativos da problemática de estimação da demanda por moeda à época: Lucas conclui pela existência de uma relação estável entre saldos reais, renda e taxa nominal de juro, em que a elasticidade da renda (termo $b$ ) seria próxima de 1 , e a semi-elasticidade dos juros (termo $c$ ) estaria entre 0,05 e 0,1 .

Entretanto, a literatura que se seguiria observa que esta relação estável teria sido alterada a partir da grande queda na velocidade de circulação da moeda da década de 1980 , como observam Goldfeld \& Sichel (1990), que apresentam estimações para a demanda por moeda padrão utilizando diferentes períodos, selecionados com base nos anos de presumida quebra estrutural, bem como testes estatísticos da estabilidade dos parâmetros estimados. Tal fato pode ser observado na Figura 1, abaixo. Este gráfico plota os dados da razão ${ }^{4}$ entre o agregado (em termos reais) M1 e o PIB real em dado período, no eixo das ordenadas, e a taxa de juros dos títulos dos "treasury bills" com vencimento de três meses do período correspondente. Observe que os pontos cinza no gráfico, correspondentes aos dados do período entre 1959 e 1985, aparentam seguir uma relação decrescente relativamente estável que não mais se observa no período entre 1986 e 2013 (pontos em cruz no gráfico).

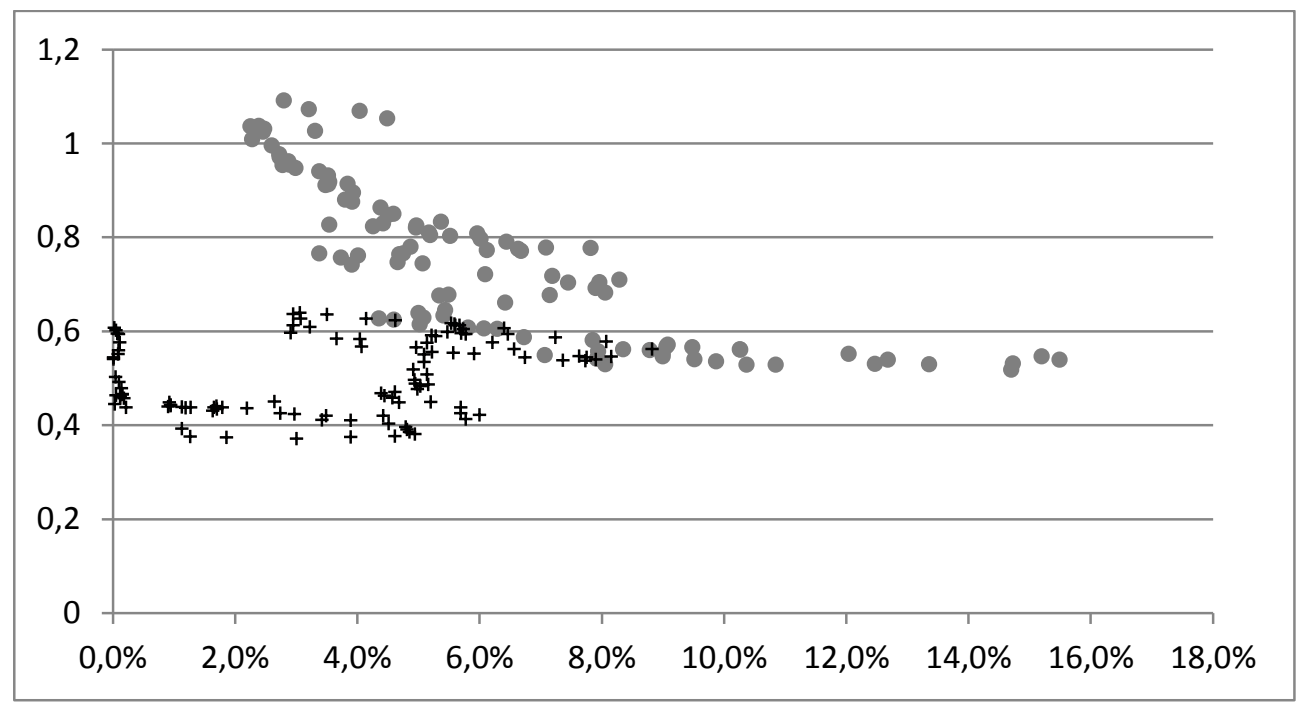

Figura 1- M1/PIB vs. Juros de curto prazo - 1959-85(círculo) e 1986-2013(cruz)

\footnotetext{
${ }^{4}$ Observe que, aplicando a igualdade $b=1$ na Equação (2.8), podemos reescrever a relação de modo que o logaritmo desta razão seja função linear simples da taxa de juros.
} 
Segundo Goldfeld \& Sichel (1990), essa mudança impulsionaria novas pesquisas empíricas voltadas ao aperfeiçoamento da função de demanda por moeda em face aos novos dados. Uma das linhas de investigação dos novos trabalhos se basearia na revisão das variáveis utilizadas na estimação, da forma funcional e da dinâmica da relação entre as variáveis. Uma segunda linha de pesquisas, por sua vez, dedicaria-se a modificar a relação funcional padrão de modo a considerar mudanças provocadas pela inovação financeira e a maior desregulação, que se intensificavam no período.

De fato, como afirmado por Duca \& Vanhoose (2004), a ideia de que a demanda pelo agregado M1 está sujeita a deslocamentos relacionados a movimentos de inovação financeira se intensificou com o período do "missing money", em meados dos anos 1970, em que os modelos de demanda por moeda convencionais nos EUA superestimavam sistematicamente os níveis dos balanços monetários. Entretanto, como observam Goldfeld \& Sichel (1990), a estabilidade da especificação convencional da demanda por moeda, quando considerados os dados da década de 1970, poderia ser restaurada satisfatoriamente com o uso de uma variável dummy de intercepto e dummies de inclinação multiplicando as variáveis de escala e custo de oportunidade.

O impacto das inovações financeiras a partir dos anos 1980, porém, passou a requisitar maior atenção dos pesquisadores com relação aos impactos específicos dos diferentes fatores sobre os agregados monetários. Com relação aos agregados com definição mais restrita ("narrow money"), vários fatores passavam a tornar menos apropriado seu uso como instrumento de investigação do trabalho empírico em demanda por moeda, como o uso crescente das MMDAs ("money market deposit account", depósitos remunerados com alta liquidez) e da posse do dólar em espécie em vários países, além dos EUA. Atenção especial é requerida com o advento e crescimento do uso das sweep accounts, que reduziam fortemente as medições dos depósitos à vista (e consequentemente do M1), por transferirem, ao final dos dias contábeis, tais saldos disponíveis para aplicações que seriam resgatadas no começo do dia seguinte. Por controlar para esta inovação financeira, o uso do agregado M1RS (M1 + sweep accounts) seria então mais adequado para as estimações dos equilíbrios de longo prazo da demanda por moeda a partir dos anos 1990 (Duca \& Vanhoose, 2004; Dutkowsky \& Cynamon, 2003). Outra mudança importante foi a tendência de rápida alteração na composição dos depósitos entre pessoas jurídicas relativamente às pessoas físicas. Uma visão formada entre a literatura para explicar a falta de estabilidade na relação de demanda por moeda seria, portanto, de que as constantes mudanças tecnológicas e regulatórias faziam com 
que as próprias medições dos agregados monetários utilizados nos trabalhos empíricos devessem ser ajustadas de acordo com essa dinâmica (Teles \& Zhou, 2005).

Com o início dos anos 1990 e as dificuldades descritas acima com os agregados mais restritos, o uso do agregado M2 na função de demanda passou a ser visto como de maior estabilidade nos dados, particularmente por absorver as alterações de portfólio entre ativos inclusos no M2, mas fora do cálculo do M1, e os componentes do M1. O uso do agregado M2 na especificação da demanda por moeda, porém, enfrentaria seus próprios problemas, como o aumento da substituição nos portfólios entre ações e ativos "broad money" (Duca \& Vanhoose, 2004).

Sriram (2001) realiza uma coleta e organização dos resultados obtidos em um grande número de trabalhos de estimação da função de demanda por moeda com aplicação de modelos de correção de erros publicados durante a década de 1990, incluindo resultados tanto de países industrializados quanto de economias em desenvolvimento. Como exploraremos na discussão dos capítulos subsequentes, a principal vantagem do uso dos modelos de correção de erros é que os mesmos possibilitam que o equilíbrio de longo prazo seja especificado pela teoria econômica e a dinâmica de curto prazo seja definida pelos dados utilizados (Sriram, 1999 e 2001). Utilizando dados trimestrais até o final da década de 1980, os três trabalhos referentes aos EUA considerados naquele compêndio apresentam, para o agregado M1, uma elasticidade-renda média de 0,83 e uma semi-elasticidade média da taxa de juros de -6,36. Para o agregado M2, os valores médios são de, respectivamente, 1,154 e -1,75 (um dos trabalhos calcula a elasticidade-juros em -0,092). Considerando os trabalhos relativos a todos os países, o autor calcula a elasticidade-renda média dos trabalhos considerados de 0,98 sobre agregados restritos (como o M1) e 1,22 sobre agregados amplos (como o M2).

\subsubsection{Cointegração entre variáveis e os modelos de demanda por moeda}

Concomitantemente à busca do aperfeiçoamento da relação de demanda por moeda pelas linhas de pesquisa acima, eram desenvolvidas novas técnicas no campo da econometria que buscavam dar conta da estimação de modelos em que as variáveis envolvidas apresentavam uma relação de equilíbrio de longo prazo, um fenômeno que seria mais tarde chamado de cointegração.

O conceito estatístico de cointegração é relativamente recente, tendo sido introduzido por Engle \& Granger (1987). Nas últimas décadas, porém, várias técnicas de cointegração foram desenvolvidas em resposta ao interesse em testar empiricamente a existência de 
relações de longo prazo entre variáveis. Um vetor $\boldsymbol{y}_{t}$ é dito cointegrado se cada uma de suas séries componentes individuais possui uma raíz unitária (i.e., são I(1)), enquanto uma combinação linear $\boldsymbol{a}^{\prime} \boldsymbol{y}_{t}$ das mesmas é estacionária para um vetor não nulo $\boldsymbol{a}$ de mesma dimensão (Hamilton, (1994)).

Fazendo $\boldsymbol{y}_{t}=\left[\begin{array}{l}y_{t} \\ x_{\boldsymbol{t}}\end{array}\right]$, a seguinte estimação da regressão de cointegração pode ser feita, segundo Engle \& Granger (1987):

$$
y_{t}=\boldsymbol{b}^{\prime} \boldsymbol{x}_{t}+\epsilon_{t}
$$

E um teste com hipótese nula de ausência de cointegração (contra sua existência) seria o equivalente a um teste para a existência de raiz unitária nos resíduos da estimação de (2.9) por OLS, $\hat{\epsilon}_{t}$.

Granger (1983 e 1986) demonstrou que o conceito de equilíbrio estável de longo prazo entre séries temporais é o equivalente estatístico do conceito de cointegração. De acordo com o Teorema da Representação de Granger (Granger, 1983 e 1986; Engle \& Granger, 1987), a toda relação de longo prazo entre variáveis corresponderá uma representação em termos de um modelo de correção de erros (Error Correction Model - ECM), que demonstra o padrão de comportamento das variáveis cointegradas no tempo, em resposta a eventuais choques que as desloquem da trajetória de equilíbrio de longo prazo. O ECM tem, portanto, o propósito de demonstrar a dinâmica de curto prazo entre as variáveis consistente com um equilíbrio de longo prazo. No presente contexto, o modelo de correção de erros associado à variável $y_{t}$ tem a seguinte forma:

$$
\Delta \mathrm{y}_{\mathrm{t}}=\alpha_{1}+\alpha_{\mathrm{y}} \hat{\epsilon}_{\mathrm{t}-1}+\sum_{\mathrm{j}=1}^{\mathrm{r}} \alpha_{11}(\mathrm{j}) \Delta \mathrm{y}_{\mathrm{t}-\mathrm{j}}+\sum_{\mathrm{j}=1}^{\mathrm{s} 1} \alpha_{12}(\mathrm{j}) \Delta \mathrm{x}_{1, \mathrm{t}-\mathrm{j}}+\cdots+\mathrm{u}_{\mathrm{yt}}
$$

Em que $u_{y t}$ é um ruído branco e $\hat{\epsilon}_{t-1}$ o termo de erro estimado no período anterior.

Considere o seguinte modelo de demanda por saldos monetários reais de longo prazo adaptado da discussão anterior, com variáveis em logs:

$$
\mathrm{m}_{t}-\mathrm{p}_{t}=\beta_{0}+\beta_{1} \mathrm{y}_{t}+\beta_{2} \mathrm{r}_{t}+\varepsilon_{t}
$$


Se as variáveis acima se relacionam em um equilíbrio de longo prazo no mercado monetário, haverá uma combinação linear tal que $\varepsilon_{t}$, abaixo, será estacionária:

$$
\varepsilon_{t}=\left(\mathrm{m}_{t}-\mathrm{p}_{t}\right)-\beta_{0}-\beta_{1} \mathrm{y}_{t}-\beta_{2} \mathrm{r}_{t}
$$

$\mathrm{Ou}$, em notação matricial:

$$
\varepsilon_{t}=\boldsymbol{\beta}^{\prime} \boldsymbol{X}_{t}=\left[\begin{array}{llll}
1 & -\beta_{0} & -\beta_{1} & -\beta_{2}
\end{array}\right]\left[\begin{array}{c}
\left(\mathrm{m}_{t}-\mathrm{p}_{t}\right) \\
1 \\
\mathrm{y}_{t} \\
\mathrm{r}_{t}
\end{array}\right]
$$

Em que o vetor $\boldsymbol{\beta}^{\prime}$, portanto, é o vetor de cointegração ${ }^{5}$.

$\mathrm{Na}$ literatura empírica atual, as duas abordagens mais comumente utilizadas para o teste de relações de equilíbrio de longo-prazo entre variáveis em nível são o procedimento de duas etapas baseado na análise dos resíduos de Engle-Granger (Engle \& Granger, 1987), e o procedimento de sistema de equações de Johansen (1988) e Johansen \& Juselius (1990). Ambas as abordagens se desenvolvem a partir da hipótese de que as séries temporais envolvidas são integradas de primeira ordem (i.e., I(1)). Como observado, por exemplo, em Sriram (2001), a grande maioria dos estudos empíricos de demanda por moeda com especificação padrão de uma variável de atividade econômica e uma variável de custo de oportunidade como determinantes daquela têm sua metodologia de estimação baseada nestas duas abordagens.

Recentemente, em face às dificuldades encontradas com a estimação da demanda por moeda pelos métodos para séries temporais existentes, como a existência de cointegração e o impacto do período amostral selecionado, foram realizados trabalhos que adotavam uma abordagem alternativa para o problema, através da estimação com dados cross-section. Além de evitar os problemas de ordem econométrica associados às estimações com séries temporais, o método tem a vantagem de permitir um tratamento consistente das diferentes estruturas dos sistemas financeiros de cada país, como também de permitir o uso de variáveis adicionais não disponíveis na forma de séries temporais (Serletis, 2007).

Em um dos primeiros esforços neste sentido, Mulligan \& Sala-i-Martin (1992) realizam uma estimação da função de demanda por moeda para os EUA utilizando as unidades federativas do país como unidades amostrais, encontrando estimativas para a

\footnotetext{
${ }^{5}$ Note que, se $\boldsymbol{X}_{t}$ contem $n$ variáveis, podem existir até $n-l$ vetores de cointegração linearmente independentes.
} 
elasticidade-renda da demanda por moeda com valores maiores que a unidade. Considerando este e outros trabalhos neste sentido, Serletis (2007) adota a abordagem cross-country para realizar estimações com 48 países, utilizando uma observação para cada variável por país, referente a algum instante temporal entre 1980 e 1995. Quatro modelos são estimados, representados pela forma geral:

$$
\log \left(\frac{M}{P}\right)=\boldsymbol{a}^{\prime} \boldsymbol{X}+\boldsymbol{b}_{\boldsymbol{i}}{ }^{\prime} \boldsymbol{Y}_{\boldsymbol{i}}+\varepsilon_{i}
$$

Em que o vetor $\boldsymbol{X}$ contém as variáveis tradicionais dos logaritmos do PIB real e da taxa de juros nominal de curto prazo. $\mathrm{O}$ vetor $\boldsymbol{Y}_{\boldsymbol{i}}$ assume variáveis distintas para os quatro modelos i. O primeiro modelo é o de demanda por moeda padrão, isto é, sem o vetor $\boldsymbol{Y}_{\boldsymbol{i}}$. No segundo modelo, este vetor representa variáveis institucionais que medem estabilidade macroeconômica, abertura comercial e estabilidade política. Em outro modelo, $\boldsymbol{Y}_{\boldsymbol{i}}$ representa a estrutura financeira do país, sendo valores maiores associados a uma economia market-based e valores menores associados a uma economia bank-based. Já no quarto modelo, este vetor contém uma medida de desenvolvimento financeiro (ver Serletis (2007) e Levine (2002) para descrição detalhada das variáveis usadas).

O autor realiza a estimação dos quatro modelos via OLS (Ordinary Least Squares) com erros-padrão consistentes para heterocedasticidade e para os agregados monetários M1 e M2 como variáveis dependentes. Na estimação do modelo tradicional, as estimativas da elasticidade-renda da demanda por ambos os agregados são pouco maiores que a unidade (1,012 e 1,061 para M1 e M2, respectivamente) e significativas a 1\% de confiança. Além disso, o teste com hipótese nula de que esta elasticidade é igual a um não pôde ser rejeitado a $5 \%$ de confiança. Já a elasticidade-juros da demanda por moeda estimada é negativa e significativa a 5\% (-0,108 e -0,102 para M1 e M2, respectivamente).

Nas estimações realizadas com variáveis institucionais, Serletis encontra coeficiente significativo a 5\% e com sinal esperado (negativo) apenas para a variável de escolaridade na demanda pelo agregado M1. Já no modelo com variáveis de estrutura financeira, o autor encontra coeficientes significativos a $10 \%$ para alguns dos índices usados, com a implicação de que algumas medidas de estrutura financeira indicam que a demanda por moeda é negativamente relacionada às economias market-based. Por fim, as estimações com variáveis de desenvolvimento financeiro retornam coeficientes positivos e significativos (a 10\%) para as quatro variáveis utilizadas por Serletis na determinação da demanda pelo agregado M2, 
porém nenhum dos coeficientes é significativo na estimação com o agregado M1. Tais resultados poderiam sugerir, segundo o autor, que ainda que um maior desenvolvimento financeiro possa trazer consigo uma maior gama de serviços financeiros, os benefícios destes seriam superados pelos custos, de modo que em verdade os custos de transações acabariam por se elevar, considerados os países envolvidos.

\subsection{Literatura atual relacionando risco e demanda por moeda}

A queda das estimativas de elasticidade-renda da demanda por moeda nos estudos empíricos a partir da década de 1990 e a recorrente conclusão empírica de ausência de cointegração nesta relação, quando inclusos dados do período iniciado na década de 1980, levantavam, dentre a literatura sobre o assunto, a hipótese de ausência de variáveis importantes ("missing variables") na equação de demanda por moeda comumente estimada (Choi \& Oh, 2003). Ainda que a importância da inclusão da inovação financeira na especificação da demanda por moeda venha se tornando cada vez mais clara, a modelagem econométrica desse fenômeno se mostra extremamente difícil, de modo que a maioria das evidências dos efeitos dessa inovação é dada de forma indireta (Goldfeld \& Sichel, 1990).

Entretanto, em face à crescente facilidade de acesso aos diversos produtos financeiros como alternativas à manutenção de riqueza em moeda, uma proposta que se impõe naturalmente neste caso é a inclusão de variáveis de risco e incerteza na determinação da demanda por moeda. Alguns dos trabalhos empíricos que compartilham desta conclusão serão apresentados nesta seção, na qual buscaremos destacar algumas similaridades com o trabalho que será aqui desenvolvido, particularmente com relação à metodologia utilizada.

\subsubsection{Demanda por moeda e incerteza}

Em uma aplicação de desenvolvimentos recentes no campo da econometria de dados em painel, Bianconi et al. (2014) estimam uma função de demanda por moeda aumentada com a incorporação de fatores como a inovação financeira, fatores institucionais e risco econômico, político e de câmbio. Utilizando dados para 140 países no período de 2004-2011, os autores propõem a seguinte especificação do modelo: 


$$
\mathrm{m}_{i t}-\mathrm{p}_{i t}=\beta_{1} \mathrm{y}_{i t}+\beta_{2} \mathrm{R}_{i t}+\beta_{3} \mathrm{Z}_{i t}+\varepsilon_{t}
$$

A ser estimado através do modelo ARDL $(1,1,1,1)$ :

$$
\begin{gathered}
\mathrm{m}_{i t}-\mathrm{p}_{i t}=\delta_{0 i} \mathrm{y}_{i t}+\delta_{1 i} \mathrm{y}_{i, t-1}+\theta_{0 i} \mathrm{R}_{i t}+\theta_{1 i} \mathrm{R}_{i, t-1}+\lambda_{0 i} \mathrm{Z}_{i t}+\lambda_{1 i} \mathrm{Z}_{i, t-1}+\alpha_{i}\left(\mathrm{~m}_{i, t-1}\right. \\
\left.-\mathrm{p}_{i, t-1}\right)+\varepsilon_{t}
\end{gathered}
$$

Sendo $\mathrm{m}_{i t}-\mathrm{p}_{i t}$ o logaritmo de um dos agregados monetários M1 e M2 em termos per capita e deflacionados pelo CPI (Consumer Price Index) para o país $i$ no período $t$; y $y_{i t}$ o logaritmo do PIB per capita, $\mathrm{R}_{i t}$ a taxa de juros sobre empréstimos bancários divulgada pelo World Bank; e $\mathrm{Z}_{i t} \mathrm{o}$ fator extra a ser incorporado na função. Como fatores de inovação financeira, são utilizados o número de agências bancárias por 100 mil habitantes e o número de ATMs (Automated Teller Machines, caixas bancários automáticos) por 100 mil habitantes. É esperado que o coeficiente associado a essas variáveis seja negativo, pois quanto maior este número, menor o custo envolvido na retenção de moeda. Como fatores institucionais são utilizados índices, calculados pelo PRS Group, de burocracia, educação, corrupção e percepção de risco econômico, político e de dívida externa. O uso de fatores institucionais é apoiado na ideia de que os países com maior estabilidade deverão exibir menor incerteza e, consequentemente, menor demanda por moeda.

Para prosseguir à estimação do modelo, os autores utilizam metodologia que restringe os coeficientes de longo prazo a serem iguais entre os países $i$, enquanto os coeficientes de curto prazo são estimados individualmente. Para o modelo padrão de demanda por moeda $\left(\operatorname{com} \beta_{3}=0\right)$ as estimativas da elasticidade-renda são 0,357 (M1) e 0,384 (M2). Já a semielasticidade dos juros estimada é de -1,156 (M1) e -1,117 (M2).

$\mathrm{Na}$ estimação do modelo aumentado para sofisticação financeira, os coeficientes associados às novas variáveis estimados são negativos, porém não são significativos, para os dois agregados monetários. A estimação da demanda por moeda com fatores institucionais (escolaridade e burocracia), por sua vez, demonstra um aumento na elasticidade-renda com a inclusão das novas variáveis. O coeficiente associado à variável de escolaridade (taxa de adesão escolar) estimado é, novamente, negativo e não-significativo. O coeficiente estimado associado ao índice de qualidade da burocracia local, por outro lado, é positivo e significativo (a 5\%). No modelo com fatores de risco, o termo de risco econômico não é significativo no longo prazo, porém no curto prazo é significativo para o agregado M2. Já os termos de risco 
político e risco na taxa de câmbio são significativos no longo prazo para o agregado M1 e, no curto prazo, para ambos os agregados.

Em outra importante abordagem empírica, Schmidt (2007) introduz medidas de variância condicional $\operatorname{GARCH}(1,1)$ para renda real, inflação e taxa de juros como variáveis condicionantes no modelo VEC (vector error correction) de demanda por moeda M1 tradicional. Os resultados obtidos pelo autor sugerem que essa inclusão de variáveis torna a obtenção de estimativas confiáveis do vetor de demanda pelo agregado M1 possível durante os períodos de instabilidade da função de demanda por moeda apontados pela literatura, como o período do "missing money" (1975-76), do declínio da velocidade de circulação (1982-83) e da “explosão do M1" (1985-86).

Seguindo a abordagem proposta por alguns dos trabalhos explorados a seguir, Greiber \& Lemke (2005) propõem, por sua vez, uma base teórica para uma função de demanda por moeda aumentada para uma medida mais abrangente de incerteza econômica. No ambiente teórico proposto pelos autores, o agente representativo pode dividir seu poder de compra entre moeda, um ativo sem risco e outro com risco, contando com uma função de utilidade MIU (Money-in-the-utility), de modo que seu problema de decisão é escolher um consumo real $C_{t}$ e um nível de moeda $M_{t}$ tais que:

$$
\max E_{0}\left[\sum_{t=0}^{\infty} \beta^{t}\left(\frac{C_{t}^{1-\sigma}-1}{1-\sigma}+b_{t}^{\delta} \frac{\left(M_{t} / P_{t}\right)^{1-\gamma}-1}{1-\gamma}\right)\right]
$$

Em que $\sigma$ e $\gamma$ representam os coeficientes de aversão ao risco com respeito ao consumo e aos saldos monetários reais, respectivamente. O termo aleatório $b_{t}^{\delta}$ é uma variável de deslocamento de preferências com o termo $\delta$ definindo seu impacto sob a utilidade derivada da posse de saldos reais.

A restrição orçamentária enfrentada pelo consumidor representativo e a relação de Fischer assumidas são, respectivamente:

$$
\begin{gathered}
C_{t}+q_{t} Q_{t}+\frac{B_{t}}{P_{t}}+\frac{M_{t}}{P_{t}}=\left(q_{t}+d_{t}\right) Q_{t-1}+R_{t-1} \frac{B_{t-1}}{P_{t}}+\frac{M_{t-1}}{P_{t}}+Y_{t} \\
R_{t}=\frac{P_{t}}{P_{t+1}}\left(1+i_{t}\right)
\end{gathered}
$$


Em que $Y_{t}$ é a renda real recebida pelo agente no período $t$, e $d_{t}$ e $R_{t}$ os dividendos reais e o retorno real recebidos sobre as ações $Q_{t-1}$ e os títulos de um período $B_{t-1}$, respectivamente. $\mathrm{O}$ preço de venda das ações é $q_{t}$, e os títulos e a moeda têm preço real unitário. Por sua vez, $i_{t}$ é a taxa de juros nominal.

Finalmente, efetuando a maximização em (2.17), sujeita a (2.18), aplicando a relação de Fischer definida e resolvendo para os níveis de saldos monetários reais, temos uma função de demanda por moeda da forma:

$$
\ln \left(\frac{M_{t}}{P_{t}}\right)=\frac{\sigma}{\gamma} \ln \left(C_{t}\right)-\frac{1}{\gamma} \ln \left(\frac{i_{t}}{1+i_{t}}\right)+\frac{\delta}{\gamma} \ln \left(b_{t}\right)
$$

De modo que os balanços reais são, portanto, determinados pelo consumo (que é igual ao produto em equilíbrio) e a taxa de juros sobre o ativo risk-free, além do termo de preferência pela liquidez $b_{t}$.

Como esta última variável não é mensurável, duas importantes hipóteses são adotadas pelos autores: a de que a variação de longo prazo na preferência pela liquidez é determinada pelo nível de incerteza macroeconômica e de que esta pode ser essencialmente capturada por um ou dois fatores não observáveis. Com isso, os autores prosseguem à especificação geral do modelo empírico para a medida de incerteza partindo de uma aplicação do procedimento do Filtro de Kalman com um vetor $n \times 1$ de variáveis observáveis $x_{t}$ determinadas por um vetor de fatores comuns $u n c_{t}$ com dimensão $p<n$, em um procedimento que é a principal inovação do trabalho em relação à literatura.

Após efetuar o procedimento para os dados da União Europeia, o autor se volta ao caso dos EUA, propondo um vetor de medida $x_{t}$ com dados do período entre 1975 e 2004, composto de seis variáveis:

1. Uma medida de volatilidade nos retornos de ações (janela móvel da variância, em três anos, dos retornos pelo índice S\&P500),

2. Uma medida de perdas neste mesmo mercado (janela móvel do quantil inferior de 5\% dos retornos no mesmo índice no período passado de três anos),

3. Correlação entre retornos de ações e títulos (correlação com horizonte de três anos, usando índice de performance dos preços de títulos para compor seus retornos),

4. Retorno real de três anos sobre ações (utilizando deflator do PIB), 
5. Spread entre rendimentos de títulos corporativos (com classificação Moody AAA) e governamentais (de longo prazo),

6. Índice de confiança do consumidor divulgado pela Universidade de Michigan.

Efetuando a regressão de uma função semi-log da demanda de longo prazo pelo agregado M2, pelo método DOLS (Dynamic Ordinary Least Squares) para cointegração entre as variáveis, os resultados obtidos pelos autores mostram que, mesmo aumentando a relação padrão de demanda com a variável de incerteza, não é restaurada a cointegração entre as variáveis de moeda, produto e custo de oportunidade existente até o início dos anos 1990, de modo que é rejeitada a importância da variável de incerteza para este agregado.

Por outro lado, a estimação do modelo para o agregado $\mathrm{M} 2 \mathrm{M}^{6}$ demonstra que a adição da variável de incerteza reestabelece a relação de cointegração do período pré-1990 para as estimativas com amostras ampliadas para 2001 e 2004, além de contar com coeficiente positivo e significativo nas estimações com tais amostras. A regressão com o uso do agregado $\mathrm{MZM}^{7}$, por sua vez, produz resultados similares que auxiliam a conclusão do autor de que o desenvolvimento recente dos níveis de incerteza contribuiu em alguma medida para o aumento recente nos níveis de liquidez nos EUA.

\subsubsection{Volatilidade da taxa de juros e do spread bancário:}

A relação entre a volatilidade da taxa de juros e a demanda por moeda é, possivelmente, a mais explorada pela literatura atualmente disponível. As diferentes teorias, entretanto, apresentam relações tanto diretas quanto inversas entre as duas variáveis. Garner (1986) e Choudhry (1999) apresentam algumas motivações teóricas pelas quais poderíamos sugerir que a volatilidade da taxa de juros afetaria a demanda por moeda, afirmando que tanto a teoria de demanda por ativos e de demanda por transações implicam que uma maior incerteza ${ }^{8}$ sobre as taxas de juros poderiam aumentar os balanços monetários desejados. Nas teorias monetárias de portfólio, uma maior incerteza acerca dos retornos dos ativos com pagamento de juros leva, considerando os investidores como avessos ao risco, a uma maior demanda pelo ativo

\footnotetext{
${ }^{6}$ Definido pelo valor do agregado M2 menos depósitos à prazo de baixo valor. A variável é calculada e divulgada pelo Federal Reserve Bank de St. Louis.

7 "Money Zero Maturity", definido pelo valor do agregado M2 menos depósitos à prazo de baixo valor e adicionados os fundos monetários institucionais. A variável é calculada e divulgada pelo Federal Reserve Bank de St. Louis.

${ }^{8}$ É importante observar que volatilidade das taxas de juros e incerteza sobre as taxas de juros são dois conceitos distintos. Entretanto, a volatilidade é geralmente aceita como um bom proxy da incerteza pois, na prática, esta última não é quantitativamente mensurável.
} 
monetário. Similarmente, a demanda por moeda por motivo transação depende positivamente do nível de transações e negativamente dos juros abdicados pela posse de moeda em lugar de ativos, e, portanto, o incentivo a reter moeda aumenta quando o risco de reter ativos alternativos aumenta.

Quanto ao impacto macroeconômico de tal correlação, vale observar que, se o aumento da volatilidade da taxa de juros afeta positivamente a demanda por moeda, então aumentos na incerteza dos agentes com relação à taxa de juros elevarão a taxa de juros esperada para períodos posteriores (incluindo as taxas de juros de longo prazo, via aumento do prêmio de risco) (Garner, 1986). Segundo o autor, o aumento desta volatilidade durante a década de 1980 nos EUA, por exemplo, estaria diretamente conectado ao aumento do risco associado às decisões de investimento. Neste caso, o aumento da variabilidade dos juros teria sido causado pelos movimentos acentuados no crescimento do produto, pela alta volatilidade inflacionária do período, e pela intensificação da desregulação dos bancos comerciais no país. Assim, a estimação deste impacto é de considerável interesse para a autoridade monetária, pois tais aumentos poderiam desencorajar decisões de investimento e afetar o mercado de câmbio.

Por outro lado, uma das razões para uma possível relação inversa entre a demanda por moeda e a volatilidade da taxa de juros é de que muito da volatilidade das taxas de juros nominais pode se dever à volatilidade da taxa de inflação. ${ }^{9}$ De fato, um aumento na volatilidade (i.e., da incerteza) da inflação eleva o risco de todos os ativos determinados nominalmente, pois seus valores em termos de bens tornam-se menos previsíveis. Consequentemente, isso pode induzir os agentes a transferirem maiores partes de suas riquezas para ativos tangíveis (Choudhry, 1999).

Já em artigo de 1983, Slovin \& Sushka argumentam que os detentores de balanços monetários em geral têm padrões de decisão sensíveis não só às taxas de juros de política monetária em si, mas também à volatilidade percebida às taxas no open market como medida de risco implícito na posse de ativos monetários, de modo que quanto maior esta volatilidade, maior seria a demanda por moeda no período (Slovin \& Sushka, 1983).

Para ilustrar o argumento, os autores utilizam um inventory theoretic model simples da demanda por moeda, com escolha entre moeda e ativos, baseado no modelo clássico de Tobin (1958). Nele, um investidor representativo encontra-se na posição de alocar um fluxo de renda $\mathrm{T}$, estando sujeito a um taxa b para transferir fundos, em lotes de tamanho K, em moeda. É

\footnotetext{
${ }^{9}$ De acordo com a conhecida equação de Fischer, sabemos que as taxas de juros nominais são dadas, aproximadamente, pela soma da taxa de juros real com a taxa de inflação.
} 
assumido também que os ativos só são vendidos quando os saldos monetários se esgotam, de modo que o balanço monetário médio é de $\mathrm{K} / 2 \mathrm{e}$, portanto, o valor médio de posse de ativos é de $(\mathrm{T}-\mathrm{K}) / 2$. O problema do indivíduo nessa situação seria então o da escolha do tamanho ótimo do lote $\mathrm{K}$, sujeito a uma função de utilidade quadrática com o retorno médio de sua carteira como variável de escolha. Sendo r a taxa de retorno no open Market, com primeiro e

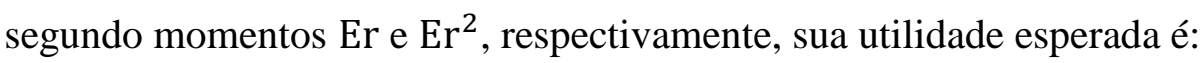

$$
\mathrm{EU}=\mathrm{aE}\left[\mathrm{r} \frac{\mathrm{T}-\mathrm{K}}{2}-\frac{\mathrm{bT}}{\mathrm{K}}\right]^{2}+\mathrm{cE}\left[\mathrm{r} \frac{\mathrm{T}-\mathrm{K}}{2}-\frac{\mathrm{bT}}{\mathrm{K}}\right]
$$

Diferenciando a expressão acima em relação ao segundo momento da taxa r, temos:

$$
\frac{\mathrm{dK}}{\mathrm{dEr} r^{2}}=\frac{\mathrm{a}(\mathrm{T}-\mathrm{K}) / 2}{(\mathrm{a} / 2) \mathrm{Er}^{2}-2\left(\mathrm{abT}^{2} / \mathrm{K}^{3}\right) \mathrm{Er}+6\left(\mathrm{ab}^{2} \mathrm{~T}^{2} / \mathrm{K}^{4}\right)-2\left(\mathrm{cbT} / \mathrm{K}^{3}\right)}>0
$$

Em outras palavras, um aumento na volatilidade das taxas do open market levaria a um maior lote ótimo K, e, portanto, um aumento nos balanços monetários.

Em seguida à apresentação teórica, os autores buscam apresentar evidências empíricas da afirmação de que a demanda por moeda é influenciada por alterações na volatilidade das taxas de juros do open market. Utilizando a técnica de Cochrane-Orcutt de ajuste para autocorrelação nos resíduos, e dados trimestrais para o período de 1954 a 1974, os autores prosseguem à estimação de uma função tradicional de demanda por moeda com a adição da variável de volatilidade na taxa de juros. Diferenciando-se da maioria dos estudos empíricos, a variável dependente utilizada é o logaritmo dos depósitos à vista (demand deposits), tendo seu uso justificado pela ideia, apresentada por Goldfeld (1973), de que os estudos empíricos apontam ser a elasticidade-juros (no open market) da demanda pelo M1 baixa em relação à mesma elasticidade dos depósitos à vista. Por sua vez, a variável de volatilidade adotada $\operatorname{Vol}(\mathrm{r})_{t}$ é calculada da seguinte maneira:

$$
\operatorname{Vol}(\mathrm{r})_{t}=\log \left[\sqrt{\frac{1}{7} \sum_{j=t-8}^{t-1}\left(r_{j}-\bar{r}\right)^{2}}\right]
$$


Em que $r_{j}$ é a taxa de juros dos commercial papers no período j. Logo, Vol(r) $t$ é o logaritmo do desvio padrão desta taxa nos 8 trimestres anteriores ao momento $t$ correspondente. Os autores observam que tal procedimento é, portanto, baseado na hipótese de que o público forma expectativas acerca de tal volatilidade pela observação dos dados passados. Os autores obtêm estimativas do coeficiente associado a essa variável de, em média, 0,0042; significativas a 5\% de confiança. Em outras palavras, os resultados sugerem que um aumento de $1 \%$ no desvio padrão das taxas de juros dos últimos 8 trimestres está associado a um aumento de $0,42 \%$ na demanda por depósitos à vista, em termos reais, no período investigado.

Em um artigo que se estabeleceu como referência na abordagem do problema de “missing variables" para obtenção de uma relação estável de demanda pelo agregado M1 nos EUA, resultados quantitativos similares são encontrados por Baba et al. (1992) utilizando janela móvel do desvio padrão dos retornos sobre títulos de longo prazo do Tesouro dos EUA como variável de volatilidade. A função de demanda por moeda proposta pelos autores inclui inflação, renda real, juros de longo prazo (e seu desvio padrão), taxas de juros das T-bills e retornos da curva de aprendizado sobre instrumentos nos agregados M1 e M2. Utilizando uma estimação na forma de um modelo de correção de erros dinâmico, o modelo estimado apresenta satisfatória estabilidade no período "missing money", para o qual a literatura anterior apresentava estimativas com grande instabilidade da demanda pelo agregado M1.

Adicionalmente a esta especificação funcional, os autores realizam novas estimações com uma variável de volatilidade da taxa de inflação calculada similarmente à volatilidade anterior. A ideia dessa adição é avaliar se a resposta da demanda por depósitos à vista à volatilidade das taxas de juros nominais seria devida à volatilidade da taxa de inflação associada. Os resultados, porém, indicam que, dada $\operatorname{Vol}(r)_{t}$, a volatilidade da inflação não tem impacto positivo significativo sobre a demanda por depósitos à vista.

Inspirado no trabalho de Slovin \& Sushka, Garner (1986) realiza estimações com dados trimestrais para a demanda pelo agregado M1 nos EUA em dois períodos: 1959 a 1973 e 1976 a 1984. Além da variável dependente, a principal diferença do trabalho de Garner é o uso de uma variável de volatilidade relativa das taxas de juros, definida pelo autor como o desvio padrão do logaritmo da taxa de juros de interesse (taxa sobre commercial paper). Em contraste ao resultado obtido pelo trabalho anterior, os resultados encontrados por Garner em sua estimação não apoiam a hipótese de que um aumento na volatilidade relativa das taxas de juros leve a um aumento na demanda por moeda. No período de 1959-1973, o coeficiente associado à variável de volatilidade estimado é negativo e estatisticamente significativo (a 5\% 
de confiança), em oposição ao sinal previsto pela teoria. Já no período 1976-1984, o mesmo coeficiente tem o sinal positivo esperado, porém não é estatisticamente significativo.

Considerando os resultados e metodologia dos dois trabalhos citados acima, Choudhry (1999) propõe-se a investigar o efeito da volatilidade da taxa de juros e da taxa de inflação sobre a demanda pelo agregado M1 no período pós-segunda guerra nos EUA, diferenciandose dos trabalhos anteriores pelo uso da variância condicional da primeira diferença do logaritmo da taxa de juros como variável de volatilidade. A estimação desta variável se dá por um modelo GARCH(1,1) (Generalized Autoregressive Condicional Heteroscedasticity) em que a primeira diferença da taxa de juros $\mathrm{y}_{t}$ é apresentada por:

$$
\begin{gathered}
\left\{\begin{array}{r}
\mathrm{y}_{t} \equiv \log \left(r_{t} / r_{t-1}\right)=\mu_{t}+\epsilon_{t} \\
\epsilon_{t} / \Omega_{t-1} \sim N\left(0, \mathrm{~h}_{t}\right)
\end{array}\right. \\
\mathrm{h}_{t}=\omega^{\prime}+\beta_{1} \mathrm{~h}_{t-1}+\alpha_{1} \epsilon_{t-1}^{2}
\end{gathered}
$$

Em que $\Omega_{t-1}$ representa a informação disponível no período anterior, $r_{t}$ é a taxa de juros (o autor utiliza uma taxa de curto prazo - T-Bill de três meses - e uma de longo prazo - taxa de títulos do governo de longo prazo) e as devidas restrições de desigualdade para variância positiva são impostas. Os testes para efeito $\mathrm{ARCH}$ encontrados são significativos, e o coeficiente do termo de erro defasado é menor que um em todos os casos, indicando que os choques à volatilidade não são explosivos.

Após testar a existência de raiz unitária em todas as variáveis, o autor utiliza a metodologia de Johansen (1988) e Johansen \& Juselius (1990) e dados trimestrais do período entre 1954 e 1996 para estimar o vetor de cointegração associado a uma demanda por moeda padrão adicionada da variável de volatilidade obtida pelo procedimento acima, utilizando ainda variáveis dummy para correção de dados sazonais e para mudanças na política monetária. Os resultados indicam que, diferentemente da especificação padrão da demanda por moeda, a especificação com variável de volatilidade (tanto na taxa de juros quanto na taxa de inflação) está associada a um vetor de cointegração, a um nível de significância de $5 \%$. Os coeficientes estimados de longo prazo (normalizando-se o vetor de cointegração estimado) associados à variável de volatilidade nas taxas de juros de curto e longo prazo são, respectivamente, $-0,079$ e $-0,003$, ambos significativos a 5\%. Esta relação inversa entre demanda por moeda e volatilidade dos juros encontrada na estimação é, portanto, oposta ao resultado encontrado por Slovin \& Sushka (1983). 


\subsubsection{Volatilidade nos mercados financeiros}

Com a crescente importância dos mercados de ações como instrumento para a reserva de riquezas por parte das famílias (households) nos EUA, a ideia de que o desempenho destes mercados tem efeito direto significativo sobre a demanda por saldos monetários, especialmente para agregados monetários mais amplos, já possui alguma tradição na literatura econômica, em comparação à relação desta demanda com a volatilidade dos níveis de produção, por exemplo. Em uma aplicação simples da modelagem ARDL, Carlson \& Schwarz (1999) se propõem a estimar o efeito dos movimentos nos preços dos mercados de ações (utilizando os índices Wilshire 5000 e S\&P 500) na determinação de curto prazo da demanda pelo agregado M2, mantendo-se a relação padrão de longo prazo com variáveis de custo de oportunidade e atividade econômica. Os resultados das estimações levam os autores a concluir que, ainda que o efeito dos preços nos mercados de ações sobre a demanda pelo M2 seja estatisticamente significativo, os ganhos de desempenho preditivo em relação ao modelo padrão de demanda por moeda são apenas marginais, particularmente com relação aos períodos de maior flutuação recentes.

$\mathrm{O}$ argumento geral proposto como justificativa da investigação sobre possíveis efeitos da percepção de risco nos mercados financeiros sobre a demanda por moeda é de que esta seria parte constituinte do portfólio dos investidores e, portanto, é determinada levando-se em conta os retornos (e riscos associados) esperados sobre os ativos alternativos.

Choi \& Cook (2007) afirmam que a posse de ativos monetários nos Estados Unidos tornou-se bastante suscetível às flutuações no mercado financeiro desde o começo da década de 1990, e se propõem a investigar essa ligação utilizando duas medidas do risco no mercado financeiro. $\mathrm{O}$ argumento utilizado é de que a posse de saldos monetários (em definições mais amplas como o M2) é parte do portfólio geral dos investidores e, portanto, são suscetíveis ao risco no mercado financeiro. Os autores concluem que, controlando para tais fatores de risco nos mercados financeiros, a função de demanda por moeda recupera sua estabilidade perdida desde as décadas de 1980/90.

A primeira variável proposta pelos autores é uma medida agregada de liquidez no mercado de ações (stock markets). A iliquidez da ação $j$ no mês $t$ (com $\left.N_{t} \operatorname{dias}\right), I L L I Q_{t}^{j}$, é definida como a razão média do valor absoluto dos retornos diários em relação ao turnover:

$$
\operatorname{ILLIQ}_{t}^{j}=\frac{1}{N_{t}} \sum_{n=1}^{N_{t}} \frac{\mid \text { Retorno }_{t, n}^{j} \mid}{\text { Turnover }_{t, n}^{j}}
$$


Por sua vez, a medida agregada da iliquidez no mês t é a média de $I L L I Q_{t}^{j}$ em um conjunto de ações listadas na American Stock Exchange (AMEX) ou na New York Stock Exchange (NYSE). Após normalização e suavização da série com o uso de médias móveis, é obtida a variável Liquidity Risk $_{t}$.

A segunda variável de risco utilizada no trabalho é de risco nos mercados de títulos (bond markets), definida como o spread entre os retornos de títulos de classificação BAA, $i_{t}^{B A A}$, e o retorno de títulos AAA, $i_{t}^{A A A}$ :

$$
\text { Default } \text { Risk }_{t}=\log \left(\frac{1+i_{t}^{B A A}}{1+i_{t}^{A A A}}\right)
$$

De posse das duas variáveis acima definidas, os autores propõem o seguinte modelo de demanda por moeda com risco financeiro:

$$
\ln \left(\frac{M_{t}}{P_{t}}\right)=\beta_{0}+\beta_{1} \ln \left(\frac{Y_{t}}{P_{t}}\right)+\beta_{2} o c_{t}+\beta_{3} \text { Liquidity Risk }_{t}+\beta_{4} \text { Default Risk } k_{t}+\omega_{t}
$$

Em que $Y_{t}$ é o produto interno bruto nominal trimestral, $M_{t}$ o agregado monetário, $P_{t} \mathrm{o}$ deflator do PIB, e $o c_{t}$ o custo de oportunidade do agregado monetário, definido pelo logaritmo da razão entre as taxas de juros sobre T-bills com vencimento em 3 meses e a taxa de juros própria do agregado monetário. Os autores afirmam ser esperado que os coeficientes $\beta_{3}$ e $\beta_{4}$ sejam positivos, pois os indivíduos substituem por moeda os ativos com pior nível de liquidez e maior risco de crédito (Choi \& Cook, 2007).

Utilizando dados trimestrais entre 1970 e 2005, e as metodologias ${ }^{10}$ de Johansen (Johansen \& Juselius, 1990) e DOLS (Dynamic Ordinary Least Squares, proposto por Saikkonnen, 1992 e Stock \& Watson, 1993); o agregado monetário M2 e algumas definições alternativas propostas para o mesmo, os autores reportam coeficientes estimados $\widehat{\beta}_{3}$ e $\widehat{\beta}_{4}$ positivos e significativos (a altos níveis de confiança) em quase todas as estimações. Os autores observam que as estimativas para $\beta_{1}$ e $\beta_{2}$ são similares para o modelo da equação (2.28) e para suas estimativas de um modelo padrão de demanda por moeda (i.e., o modelo (2.28) com a restrição $\beta_{3}=\beta_{4}=0$ ), de modo que as diferenças nas estimativas do termo de

${ }_{10}$ Aplicando inicialmente o teste ADF, os autores não rejeitam a hipótese de existência de raiz unitária em nenhuma das variáveis, a um nível de confiança de $90 \%$. 
erro $\widehat{\omega}_{\mathrm{t}}$ das duas especificações sejam basicamente atribuíveis às duas variáveis de risco. Comparando os dois modelos em termos de seu desempenho na previsão da demanda por moeda (e em comparação aos valores amostrais, i.e., calculando-se o termo de correção de erros), com essa observação em vista, os autores concluem que o modelo com risco financeiro supera claramente o modelo tradicional no período a partir de 1990, em termos de poder preditivo. Entretanto, é afirmado também que o modelo com risco financeiro deriva termos de erro de alto valor e maior volatilidade durante a década de 1970.

Adicionalmente, o autor realiza estimações com especificações diferentes para as variáveis de risco. Em lugar da variável Liquidity Risk $_{\mathrm{t}}$, é usada a variável Stock_Premium composta pelo spread entre os dividendos recebidos associados ao S\&P500 e o retorno sobre letras do tesouro com maturidade de 5 anos. Já em lugar da variável Default Risk $\mathrm{t}_{\mathrm{t}}$ é definida a variável Corporate Spread $_{t}$, composta pela diferença entre o retorno de títulos com classificação de risco AAA e o mesmo retorno sobre letras do tesouro da variável anterior. Ambas as novas variáveis apresentam coeficientes positivos e significativos a $1 \%$ de confiança nas estimações dos modelos modificados.

Em seguida, Choi \& Cook se propõem a realizar uma investigação a respeito da demanda por moeda setorial. A partir da observação dos dados, os autores demonstram que a participação da demanda por moeda entre os setores de negócios aumentou a partir dos anos 1990, em relação à demanda pelas famílias. São efetuadas então novas estimações do modelo com risco financeiro para os dois setores em separado, de modo a investigar possíveis diferenças de importância das variáveis de risco na determinação da demanda por moeda de ambos. Os resultados obtidos sugerem que o modelo com risco financeiro aparenta ser válido em menor escala para a demanda por moeda das famílias do que para a demanda por moeda agregada, porém o uso de uma dummy para o início da década de 1990 (de redução nos custos de transações financeiras) provém grande estabilidade ao modelo. Já os resultados para a demanda por moeda no setor de negócios mostram que os termos de risco utilizados explicam satisfatoriamente as flutuações de longo prazo na mesma, enquanto o modelo padrão de demanda por moeda não se ajusta bem aos dados do setor.

Choi \& Cook concluem que a sensibilidade da demanda por moeda ao risco nos mercados financeiros se elevou sensivelmente a partir da década de 1990, e oferece dois fatores que poderiam ter promovido essa mudança. Em primeiro lugar, o custo para investir em ações e títulos aos poupadores "comuns" se reduziu de modo que a posse de tais ativos se tornou mais ampla entre a população como alternativa de reserva de valor. Em segundo lugar, a análise dos dados setoriais sugere que o fenômeno anterior levou a uma queda na posse de 
saldos monetários por parte das famílias (households) em relação aos setores de negócios, mais sensíveis aos movimentos de risco nos mercados.

Em outro estudo, Carpenter \& Lange (2003) introduzem dois indicadores das condições nos mercados de ações no modelo tradicional de demanda por moeda: a volatilidade dos preços de ações e as revisões das expectativas de retornos de analistas. Os autores destacam que, assumindo que os agentes são, em geral, avessos ao risco, tal volatilidade tende a reduzir a atratividade desses ativos, podendo então levar os investidores a uma busca por alternativas de menor risco. Além disso, sendo os preços de ações uma função de seus retornos futuros descontados, mudanças nas previsões destes retornos constituiriam uma alteração no custo de oportunidade da posse de moeda.

Considerando que o grande aumento na importância dos mercados de ações sobre os portfólios das famílias se deu dos anos 1980 para os anos 1990, e evitando o período anterior de mudanças na velocidade de circulação monetária, os autores utilizam dados a partir da década de 1990. A estimação do equilíbrio de longo prazo é feita com o uso do logaritmo da velocidade de circulação do agregado M2 como variável dependente, o que implica uma elasticidade unitária da variável de produção, e adicionando uma variável de volatilidade dos preços das ações (com base no índice $\mathrm{S} \& \mathrm{P} 100$ ) à variável de custo de oportunidade $O C_{t} . \mathrm{O}$ índice de volatilidade é obtido invertendo-se uma relação dada por um modelo de precificação e inferindo o nível de volatilidade associado aos preços observados ${ }^{11}$.

$$
\ln \left(\frac{y_{t}}{m_{t}}\right)=\alpha_{0}+\alpha_{1} \ln O C_{t}+\alpha_{2} \text { vol }_{t}+\varepsilon_{t}
$$

A variável de revisões dos retornos previstos, por sua vez, é adicionada à relação da dinâmica das variáveis (error corection model). A estimação do modelo gera um coeficiente negativo e estatisticamente significativo (a 5\%) associado à volatilidade dos preços nos mercados de ações, o que, de acordo com a especificação acima, sugere que aumentos nesta volatilidade se traduzem em aumentos nas possessões monetárias de equilíbrio. Também a variável de revisões de previsões obtém valor negativo e significativo na equação de dinâmica de curto prazo estimada.

Em vista a tais resultados, Carpenter \& Lange concluem que o modelo tradicional de demanda por moeda pode ser melhorado com a inclusão de variáveis representantes da situação nos mercados de ações, ainda que, pela decomposição das contribuições das

\footnotetext{
${ }^{11}$ Detalhes sobre tal modelo, entretanto, não são fornecidos pelos autores.
} 
variáveis no modelo, tenha sido observado que a maior parte dos movimentos no agregado M2 são ainda atribuíveis à variável de escala e às taxas de juros.

\subsubsection{Volatilidade do desempenho da economia real (PIB)}

Com o objetivo de adaptar a função clássica de demanda por moeda aos episódios do "missing money" da década de 1970, a queda da velocidade de circulação da década de 1980 e o comportamento anormal da mesma no início da década de 1990; Choi \& Oh (2003) propõem a introdução de novas variáveis na análise da demanda por moeda. De fato, os autores interpretam os resultados empíricos encontrados para as elasticidades-renda nos trabalhos que consideram os dados desse período (cada vez menores que a unidade) como um problema de variáveis omitidas.

Os autores derivam uma função de demanda por moeda teórica a partir de uma abordagem de equilíbrio geral com a incorporação de uma função de utilidade com moeda ("Money-in-the-utility function" - MIUF) no seguinte formato:

$$
\mathrm{U}\left(X_{t}, \frac{\overline{L_{t-1}}}{P_{t}}\right)=\frac{\left\{X_{t}^{s}\left(\overline{\frac{L_{t-1}}{P_{t}}}\right)^{1-s}\right\}^{1-\gamma}}{(1-\gamma)} \quad, \operatorname{para} \gamma \neq 1
$$

Sendo $\mathrm{X}_{\mathrm{t}}$ e $\mathrm{P}_{\mathrm{t}}$, respectivamente, o consumo real e o nível de preços, $\overline{\mathrm{L}_{\mathrm{t}-1}}$ a liquidez nominal efetiva definida pela soma da moeda em posse no período anterior e o serviço financeiro $\mathrm{F}$ nominal do período anterior como substituto imperfeito da moeda (i.e., $\overline{\mathrm{L}_{\mathrm{t}-1}} \equiv$ $\left.\mathrm{L}_{\mathrm{t}-1}+\mathrm{nP}_{\mathrm{t}-1} \mathrm{~F}_{\mathrm{t}-1} \operatorname{com} 0<\mathrm{n}<1\right)$. Já $\gamma$ é o termo de aversão relativa ao risco e $0<\mathrm{s}<1$.

Log-linearizando o resultado da otimização dinâmica do modelo com as devidas condições de equilíbrio e equações de movimento adicionais, o autor encontra a seguinte relação de demanda por moeda:

$$
\begin{aligned}
\ln \left(\frac{M_{t}}{P_{t+1}}\right)=\alpha_{0} & +\alpha_{y} E_{t}\left(\ln \left(X_{t+1}\right)\right)+\alpha_{r} \ln R_{t}+\alpha_{f} \ln \frac{F_{t}}{E_{t}\left(\pi_{t+1}\right)}+\alpha_{\lambda} \sigma_{\lambda, t}^{2} \\
& +\alpha_{\mu} \sigma_{\mu, t}^{2}+\varepsilon_{t+1}
\end{aligned}
$$

Em que $R_{t}$ é a taxa de juros nominal, $\pi_{t}$ a taxa de inflação, e $\sigma_{\lambda, t}^{2}$ e $\sigma_{\mu, t}^{2}$ a variância do crescimento do produto e da oferta monetária, respectivamente. Portanto, na inovação 
principal proposta pelo modelo, os dois últimos termos da equação propõem que a variação da oferta monetária e do nível de produção, cujo efeito seria medido pelos coeficientes $\alpha_{\lambda}$ e $\alpha_{\mu}$, seriam fatores diretamente determinantes da demanda por moeda, bem como o termo do fluxo de serviços financeiros $F_{t}$.

Em seguida à determinação teórica do modelo, os autores prosseguem à estimação empírica do modelo encontrado para dados trimestrais da economia dos EUA entre 1959 e 1996. O agregado monetário investigado é o M1, e a construção das medidas de incerteza monetária e do produto é feita através do emprego de um modelo VAR bivariado.

Estimando os vetores de cointegração por diversos métodos derivados do princípio dos estimadores de mínimos quadrados, Choi \& Oh destacam, entre outros resultados, que a elasticidade-renda estimada para o modelo na especificação padrão da demanda por moeda apresenta valor baixo, enquanto na especificação completa proposta por seu modelo teórico a mesma elasticidade estimada é próxima da unidade. Além disso, é observado que a elasticidade para serviços financeiros $\alpha_{f}$ é negativa e significativa, bem como a elasticidade $\alpha_{\lambda}$. Já a elasticidade da incerteza monetária $\alpha_{\mu}$ estimada é positiva e significativa.

Em uma avaliação final da adequação do modelo proposto pela análise do termo de erro das diferentes especificações da demanda por moeda estimadas no período em estudo, Choi \& Oh observam que, de fato, o modelo aumentado proposto tem resultados superiores (em termos de desvios em relação ao agregado M1 observados menores) durante os quatro períodos considerados como de instabilidade da função de demanda por moeda pela literatura. Consequentemente, os autores concluem que os "puzzles" da demanda pelo agregado M1 nos EUA durante certos episódios são devidos principalmente aos erros de especificação (variáveis omitidas) na função de demanda por moeda, e não a movimentos no comportamento econômico.

Em termos gerais, este capítulo constituiu uma base teórica sobre a demanda por moeda e a evolução da literatura relacionada, que será aplicada no capítulo seguinte de forma a construir um modelo teórico adequado, de acordo com a investigação proposta. Por outro lado, da análise da literatura existente que explora a relação entre risco e demanda por moeda, concluímos pela ausência de um estudo que considere simultaneamente a percepção de risco em mercados distintos. Portanto, no próximo capítulo será definida a forma como esta questão será tratada, tomando por base as iniciativas distintas exploradas no presente capítulo, bem como o arcabouço teórico geral cuja evolução também está aqui apresentada. 


\section{MODELO PROPOSTO E DISCUSSÃO DAS VARIÁVEIS}

Neste capítulo, serão discutidas as variáveis a serem utilizadas no modelo de demanda por moeda a ser estimado, bem como as formas funcionais mais adequadas para a presente investigação; de modo que, ao final deste, seja apresentado o modelo econométrico proposto que constituirá a base sobre a qual o próximo capítulo será constituído.

$\mathrm{Na}$ primeira seção, serão discutidos e selecionados os agregados monetários adequados à presente investigação; o que será feito, também, para as variáveis de escala e custo de oportunidade, na segunda seção. Na terceira seção deste capítulo, apresentaremos em detalhes as variáveis de risco a serem utilizadas, sua metodologia de cálculo e justificativa de uso. Na quarta e última seção, utilizaremos diversos métodos econométricos para definirmos a forma funcional mais adequada a ser utilizada no capítulo seguinte.

\subsection{A definição de moeda}

Em qualquer estudo empírico que explore a relação de demanda por moeda, uma das primeiras dificuldades enfrentadas (e à qual ainda hoje não podemos dizer que conta com uma recomendação consensual) é a seleção do conceito de moeda a ser utilizado. Como apontado por Serletis (2007), estudos apoiados nas teorias com foco no papel da moeda em transações geralmente trabalham com conceitos mais limitados para a moeda, como o papel moeda em posse do público em geral e os depósitos à vista. Já as abordagens com foco mais distante da participação monetária nas transações utilizam-se de conceitos mais amplos: situação na qual a questão de método de agregação tem sua importância aumentada.

Os agregados monetários divulgados pelos bancos centrais utilizam a soma simples como método de agregação dos ativos em geral, isto é, o agregado $M_{t}$ é a soma simples dos $n$ ativos $m_{j, t}$ no período $\mathrm{t}$, conforme a equação:

$$
M_{t}=\sum_{j=1}^{n} m_{j, t}
$$


O fato de este método implicar o uso de pesos iguais para a diferente gama de ativos é a principal crítica apresentada a seu uso. Algumas abordagens de agregação alternativas que buscam levar em conta esta questão vêm sendo desenvolvidas nas últimas décadas, porém em vista às limitações em termos de disponibilidade de dados, estes não serão utilizados no presente trabalho (Maiores detalhes podem ser encontrados em Serletis (2007) e Goldfeld \& Sichel (1990)).

No capítulo anterior observamos que, em meio ao rápido advento de inovações financeiras desde meados da década de 1970, a ligação empírica entre a moeda e a variável de atividade econômica começou a enfraquecer-se, e a demanda por moeda na forma tradicional ficava cada vez mais sujeita à instabilidade. Esse fenômeno levaria, inclusive, à transferência da ênfase despendida por parte das autoridades monetárias mundiais, dos agregados monetários para as regras de política de taxas de juros (Leeper \& Roush, 2003).

Nos EUA, a definição do agregado M1 na base de dados do "Board of Governors of the Federal Reserve System" engloba os "fundos prontamente acessíveis ao dispêndio": 1) depósitos à vista, 2) traveler's checks, 3) moeda exterior ao U.S. Treasury, aos Federal Reserve Banks e às outras instituições de depósito e 4) outros depósitos observáveis ${ }^{12}$. Goldfeld \& Sichel (1990), por outro lado, argumentam que alguns dos componentes do agregado M2 não inclusos em M1 também possuem um forte apelo de uso em transações. Alguns desses componentes são as MMDAs (Money Market Deposit Accounts), MMMFs (Money Market Mutual Funds) e os RPs (Repurchase Agreements). Os dois primeiros surgiram e ganharam grande importância na década de 1970 como substitutos, em certo nível de liquidez, aos depósitos à vista (demand deposits), com pagamento de juros. Como discutido na seção anterior, a motivação teórica para o presente estudo sugere o uso de agregados monetários com conceitos mais limitados. Especificamente, estudaremos os efeitos das variáveis de risco sobre o agregado monetário M1 e seus componentes, além da base monetária e das reservas totais nos EUA. Em vista aos comentários acima, utilizaremos também os dados do agregado M2 e o agregado M1RS, apresentado no capítulo anterior. Todos os agregados selecionados são exibidos na Figura 2 abaixo, denominados em termos reais (bilhões de US\$ de 2009), disponíveis na economia norte-americana no período de 1959 a 2013 (exceto M1RS, cujos dados estão disponíveis a partir de 1967. Ver detalhes na seção 4.1).

\footnotetext{
${ }^{12}$ Ver Goldfeld \& Sichel (1990), tabela 8.6, para detalhes e dimensões de outros agregados.
} 


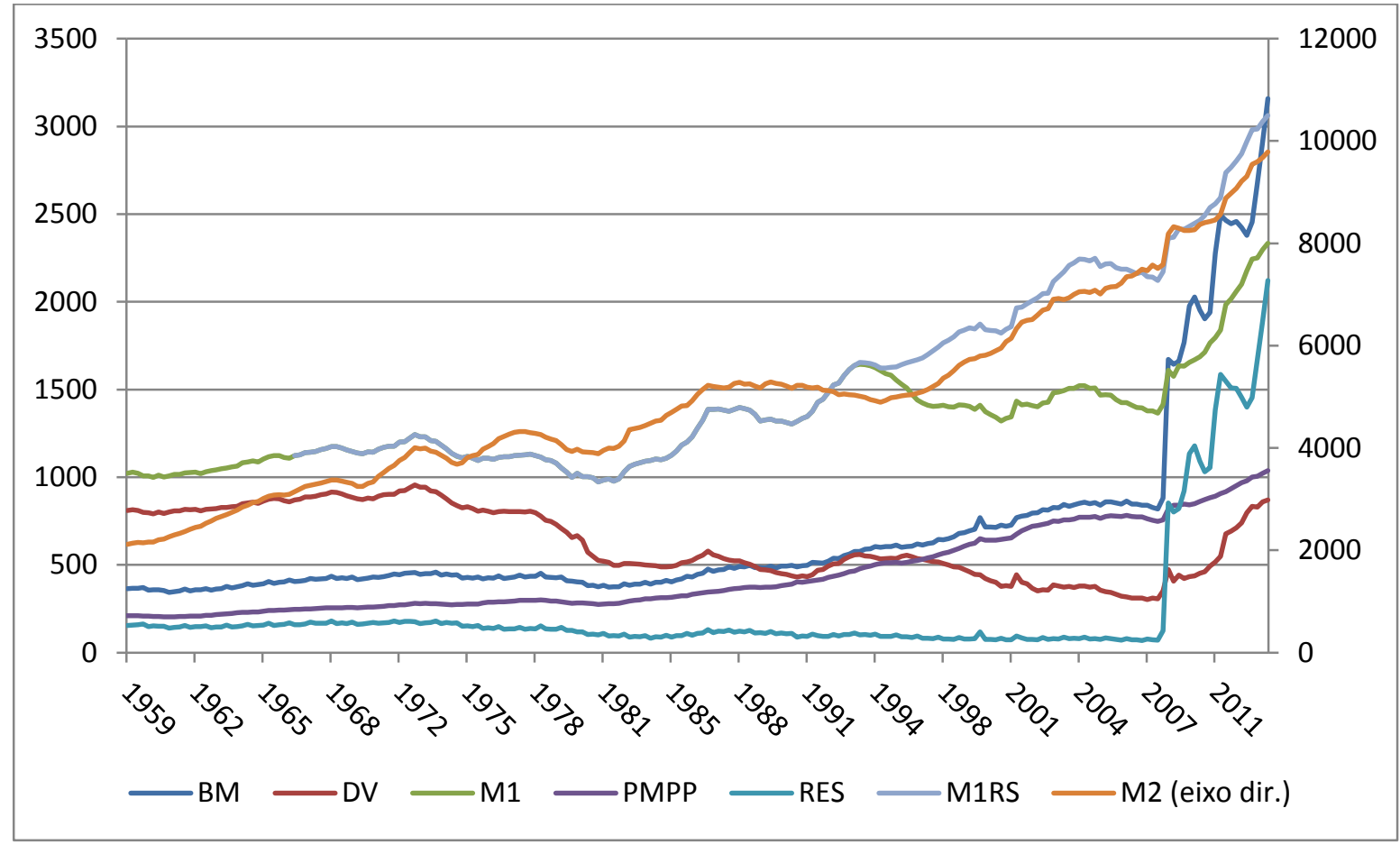

Figura 2 - EUA: agregados monetários em termos reais (bilhões de US\$ de 2009) Dados: Board of Governors of the Federal Reserve System.

Aumentos de grande dimensão em alguns dos agregados podem ser vistos claramente nos últimos anos representados na Figura 2 acima. Este corresponde ao período de "quantitative easing", que seguiu à eclosão da crise financeira de 2008, caracterizado por massivos aumentos da oferta monetária na economia dos EUA por parte do Federal Reserve, a título de combate à intensificação da crise econômica. Tendo em vista a esperada importância deste fator como uma quebra estrutural nos dados em consideração, esta questão será tratada com especial atenção no capítulo 5.

$\mathrm{Na}$ discussão a seguir, representaremos por $M_{t} / P_{t}$ as variáveis de agregados monetários denominadas em termos reais, de modo geral. Quando da estimação dos modelos e da discussão específica dos resultados, será indicado de modo explícito qual dos agregados a serem analisados está sendo considerado.

\subsection{Variáveis de escala e de custo de oportunidade}

A escolha da variável de escala apropriada a um modelo de demanda por moeda é a escolha da medida das transações relativas à atividade econômica (Goldfeld \& Sichel, 1990). 
Um ponto negativo no uso de variáveis como PIB e PNB é de que estas não descrevem propriamente o número de transações na economia, pois, em seu cálculo, são excluídas as transações com bens intermediários e com bens já existentes, bem como transações financeiras e outras transferências; as quais certamente contribuem para a determinação da demanda por moeda (Goldfeld \& Sichel, 1990). A disponibilidade e confiabilidade de dados para estas duas variáveis, entretanto, faz com que as duas sejam as mais utilizadas (em termos reais) em estudos empíricos. Duas outras variáveis utilizadas amplamente são os índices de produção industrial e o consumo real agregado (Mankiw \& Summers (1986), por exemplo, afirmam que este é muito mais intensivo em transações com moeda que o PIB). Estudos de maior horizonte temporal e menor foco na demanda por motivos transacionais utilizam também de medidas de riqueza como a renda permanente, que por sua vez são calculados com base em valores da renda bruta em diferentes períodos passados (Goldfeld \& Sichel, (1990)).

Com isto em vista, utilizaremos neste trabalho, como variável de escala, o produto interno bruto em termos reais, o qual será representado por $Y_{t}$ nas descrições dos procedimentos deste trabalho a seguir. No capítulo 5, porém, serão feitas estimações a partir de dados denominados mensalmente e, portanto, utilizaremos dados do Índice de Produção Industrial dos EUA.

A variável de custo de oportunidade representa o retorno do qual o indivíduo abre mão ao decidir-se pela posse de determinado valor na forma de papel moeda ou de depósitos à vista. Portanto, é a diferença entre o retorno dos ativos alternativos à moeda e sua própria taxa de retorno, que é considerada nula nos estudos empíricos (visto a natureza subjetiva do retorno sobre a posse de moeda). Em estudos com foco em países com economias menores e de maior nível de abertura, grande ênfase é despendida também no uso de variáveis como taxas de juros externas e taxas de câmbio. Como neste trabalho nosso foco será na economia dos Estados Unidos, porém, não serão utilizadas estas variáveis.

Na presente análise, a variável de custo de oportunidade $r_{t}$ será constituída pela taxa de juros dos títulos do tesouro norte-americano (treasury bills) com maturidade de três meses. A fonte dos dados utilizados e a definição precisa da taxa de juros utilizada será detalhada na seção 4.1 . 


\subsection{Risco}

Quatro variáveis de risco da economia dos EUA serão incluídas no modelo a ser estimado, com as quais buscaremos captar o risco associado ao mercado de ações, ao "Money Market" e ao mercado de bens em geral. Ao incluirmos as mesmas em um modelo de demanda por moeda "padrão" e efetuarmos sua estimação com as técnicas econométricas adequadas, buscaremos realizar testes estatísticos para averiguarmos evidências acerca da importância de tais variáveis na determinação da moeda nos EUA.

O Índice de Sharpe (Sharpe ratio), proposto por Sharpe (1966) e revisto em Sharpe (1994), é uma medida de retorno (em excesso ao retorno risk-free) por unidade de risco de algum determinado investimento financeiro $i$ :

$$
\operatorname{Sharpe}_{i, t}=\frac{\bar{R}_{t}^{e}}{\sigma_{t}^{e}}
$$

Sendo:

$$
\begin{gathered}
\bar{R}_{t}^{e}=\frac{1}{n} \sum_{j=t-(n-1)}^{t}\left(R_{j}-R F_{j}\right) \\
\sigma_{t}^{e}=\sqrt{\frac{1}{n-1} \sum_{j=t-(n-1)}^{t}\left(R_{j}-R F_{j}-\bar{R}_{j}^{e}\right)^{2}}
\end{gathered}
$$

Em que $n$ é o número de períodos anteriores a serem considerados no cálculo do índice (i.e., o índice será uma janela móvel), $R_{j}$ é o retorno (variação porcentual) do investimento em questão no período $j$ e $R F_{j}$ é o retorno do investimento livre de risco relevante (i.e., a medida do custo de oportunidade do investimento de risco) em $j$. Desse modo, $\bar{R}_{t}^{e}$ é uma média móvel do retorno em excesso ao ativo risk-free e $\sigma_{t}^{e}$ o desvio padrão (em janela móvel) do mesmo retorno em excesso.

Para utilizarmos o Índice de Sharpe como medida de risco do mercado de ações de um país, aquele será calculado com base em um dos principais índices de bolsa de valores daquela economia. Em outras palavras, o retorno $R_{j}$ a ser utilizado na descrição acima é a variação percentual do índice do mercado de ações em determinado intervalo de tempo. 
No presente estudo, dado nosso interesse na economia dos Estados Unidos, será utilizado o "Dow Jones Industrial Average", índice divulgado desde 1896 que representa o desempenho no mercado dos papéis de 30 das maiores companhias norte-americanas de capital aberto. ${ }^{13} \mathrm{O}$ retorno será calculado em termos mensais, e utilizado então para o cálculo do índice de Sharpe levando em conta os últimos 24 meses (i.e., a janela móvel descrita pela equação (3.3) é calculada com $n=24$ ). A série temporal adimensional obtida, doravante denominada Sharpe $_{t}$, possui valores mensais no período de Janeiro de 1949 a Outubro de 2013 e sua evolução temporal é exibida na Figura 3 abaixo.

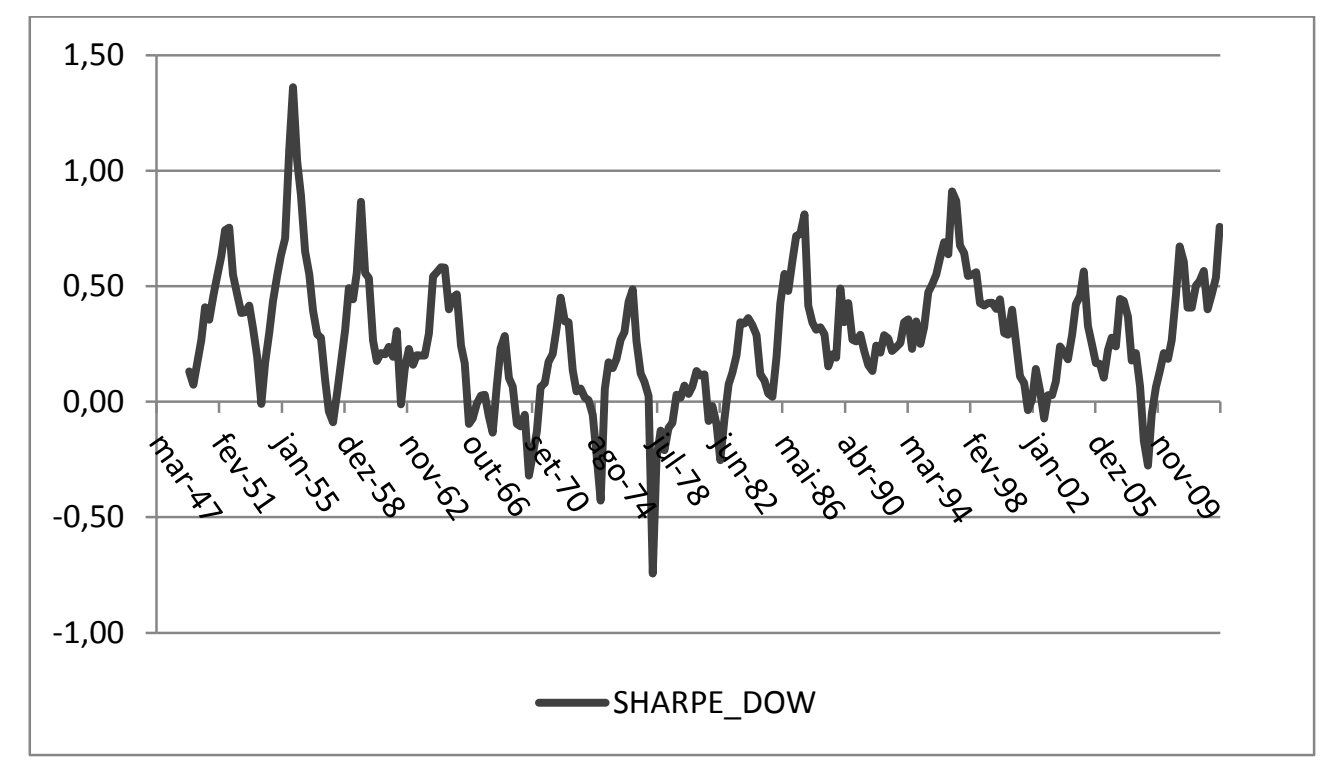

Figura 3 - Índice de Sharpe a partir de dados mensais, janela móvel de 24 meses Dados: S\&P Dow Jones Indices LLC

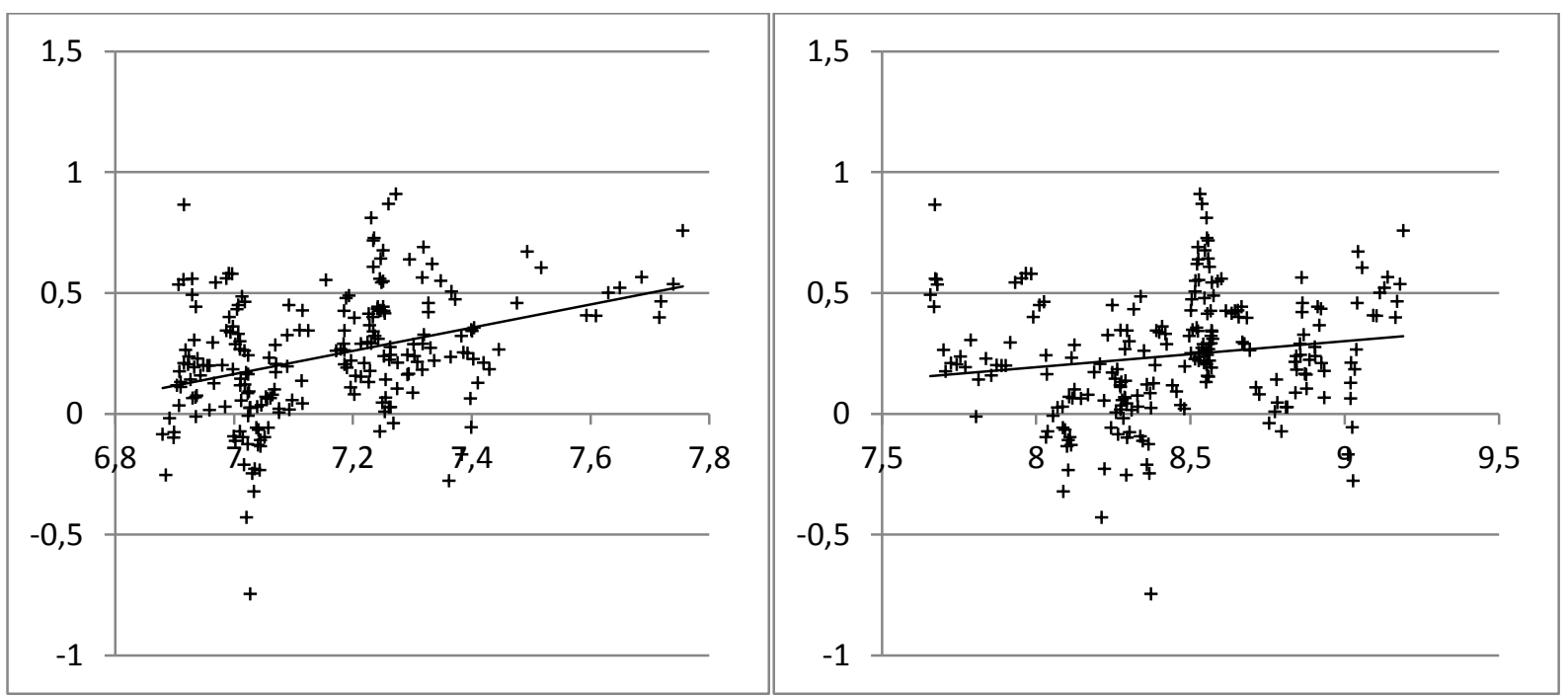

Figura 4 - Gráficos de dispersão: Sharpe $x \log (M 1)($ esquerda) e Sharpe $x \log (M 2)$

13 Dow Jones Industrial Average Fact Sheet. Disponível em: http://www.djindexes.com/mdsidx/downloads/ fact_info/Dow_Jones_Industrial_Average_Fact_Sheet.pdf. 
As volatilities são medidas da variabilidade de determinada variável da perspectiva de determinado instante de tempo $t$, calculada utilizando-se os valores da mesma entre $t-n$ e $t$, sendo n o número de períodos passados que deseja-se incluir no cálculo. A literatura atual propõe várias fórmulas para seu cálculo, mas que geralmente apenas propõem pequenas alterações ao cálculo do desvio padrão simples, que é a forma que utilizaremos no presente trabalho, conforme a equação abaixo:

$$
\operatorname{Vol}(X)_{t}=\sqrt{\frac{1}{n-1}\left(\sum_{j=t-(n-1)}^{t}\left(X_{j}-\bar{X}_{J}\right)^{2}\right)}
$$

Sendo $X_{j}$ o valor, no instante $j$, da variável cuja volatilidade está sendo calculada, e $\bar{X}_{j}$ a média simples, em janela móvel, da variável no intervalo de tempo considerado, de $t-(n-$ 1) a $t$.

Considerando a literatura apresentada anteriormente, utilizaremos as volatilities de duas variáveis: taxa de juros nominal e crescimento do PIB real. Desse modo, efetuamos os cálculos de $\operatorname{Vol}(X)_{t}$ sendo $X \in(r, P I B)$, de modo que obteremos amostras (janelas móveis) que irão compor os vetores $\overrightarrow{\operatorname{Vol}(r)} e \overrightarrow{\operatorname{Vol}(P I B)}$. Para as volatilities da taxa de juros, cuja disponibilidade de dados é mensal, utilizamos $n=24$ (i.e., a janela móvel é de 24 meses). Já com relação ao PIB real, cuja disponibilidade é trimestral, e visando evitar a perda de amostras utilizáveis na estimação, utilizamos n=12 (i.e., a janela móvel será de 12 trimestres).

Desse modo, os valores obtidos para as volatilities da taxa de juros, doravante Vol_r $r_{t}$, correspondem ao período de Janeiro de 1949 a Outubro de 2013. Já os valores trimestrais obtidos das volatilities do PIB real, doravante $V o l_{-} P I B_{t}$, correspondem ao período do $1^{\circ}$ Trimestre/1950 ao $3^{\circ}$ Trimestre/2013.

A Figura 5, abaixo, mostra a evolução temporal das taxas de juros dos "Treasury Bills" (ou "T-Bills") com maturidade de três meses, $r_{t}$ (em \% ao ano, eixo da esquerda) e da sua volatility correspondente, $V_{0} \_r_{t}\left(V \_i\right.$, denominada no eixo à direita).

Já a Figura 6, abaixo, mostra a evolução temporal do PIB real trimestral dos EUA, $Y_{t}$ (em bilhões de US\$ de 2009, eixo da esquerda), e da volatility correspondente às suas taxas de crescimento, $V o l \_P I B_{t}\left(V_{-}\right.$rgdp, denominada no eixo à direita). 


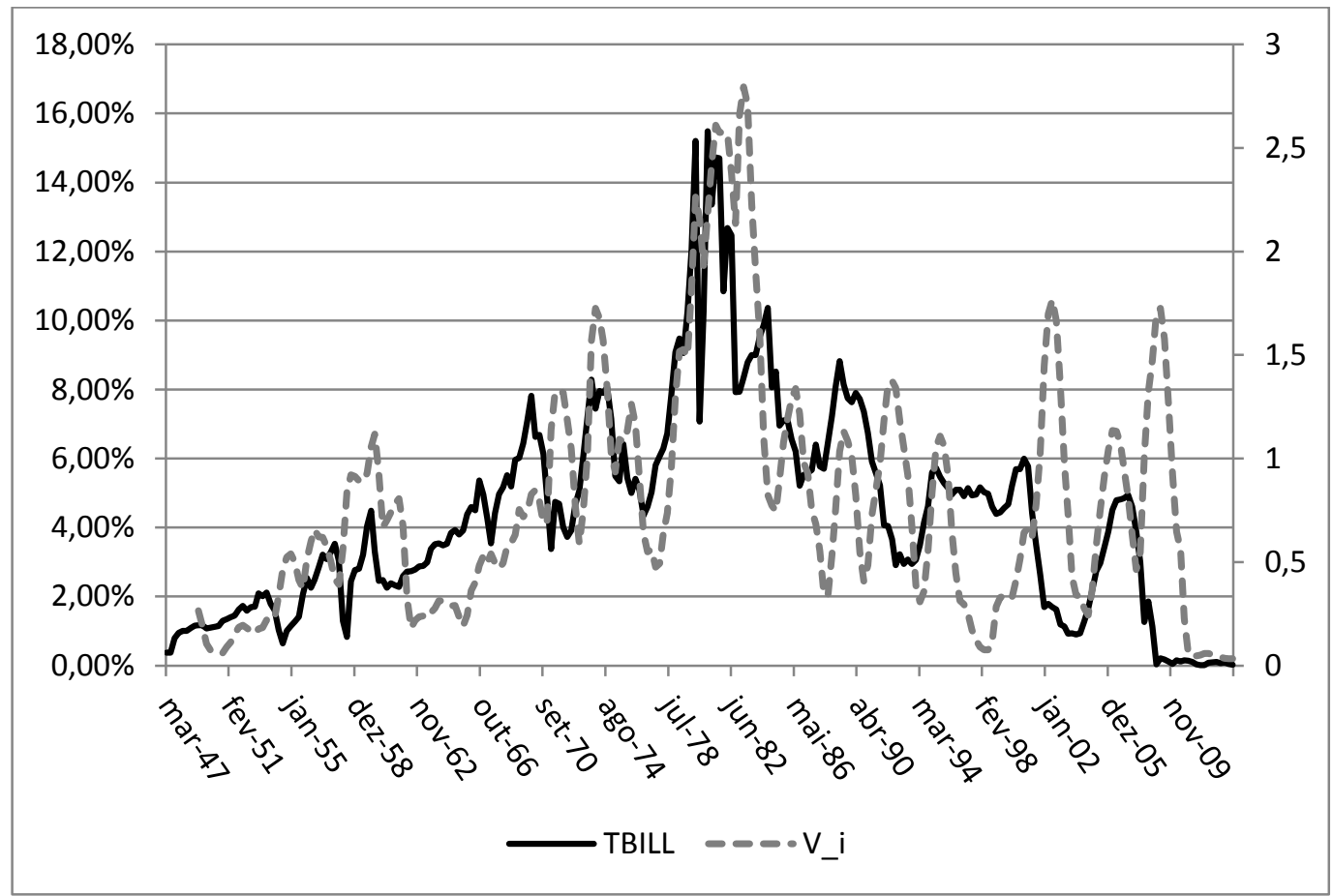

Figura 5 - Taxas de juros dos "Treasury Bills" com maturidade de 3 meses (em \% ao ano) e sua Volatility

Dados: Board of Governors of the Federal Reserve System.

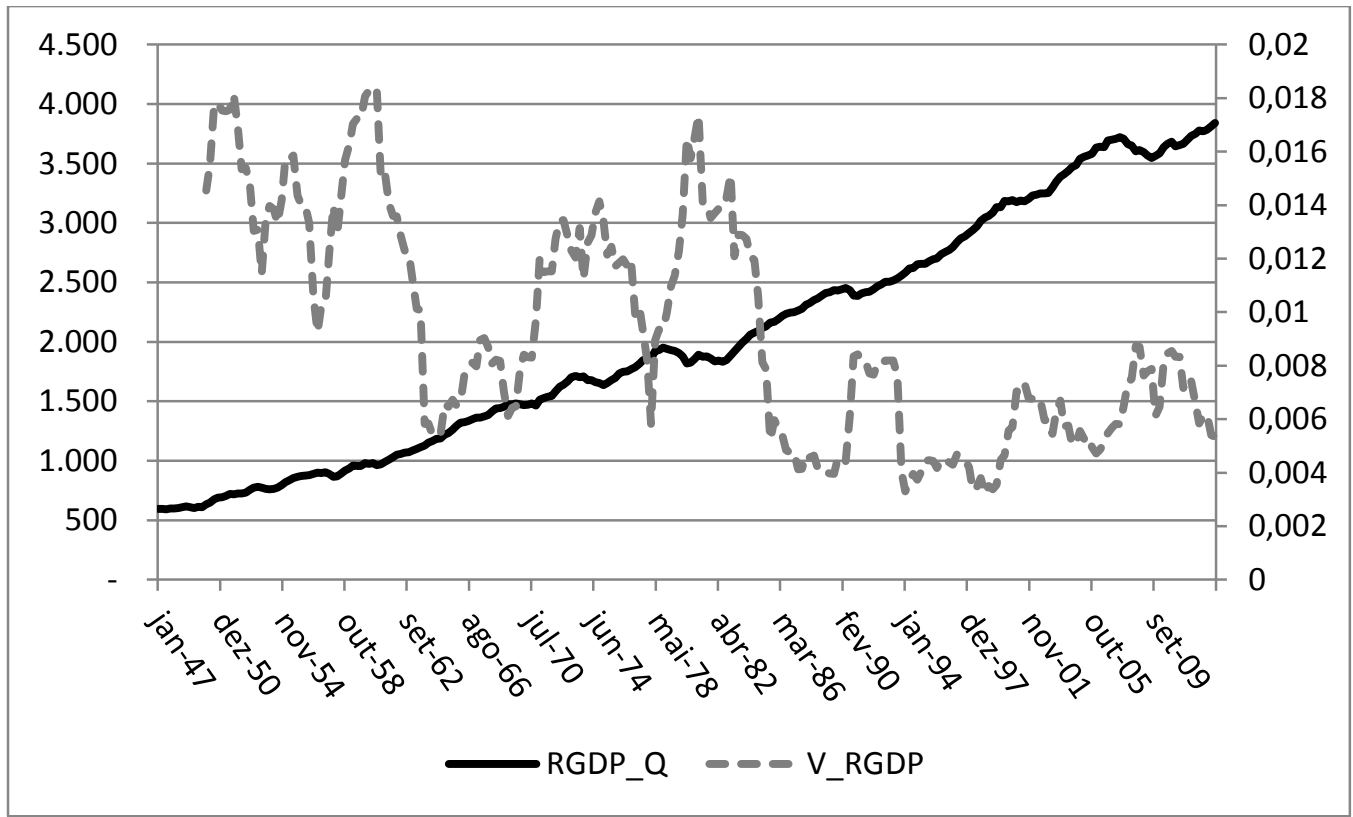

Figura 6 - EUA: PIB real trimestral (bilhões de US\$ de 2009) e Vol(PIB)

Dados: U.S. Department of Labor: Bureau of Labor Statistics e OECD.Stat. 


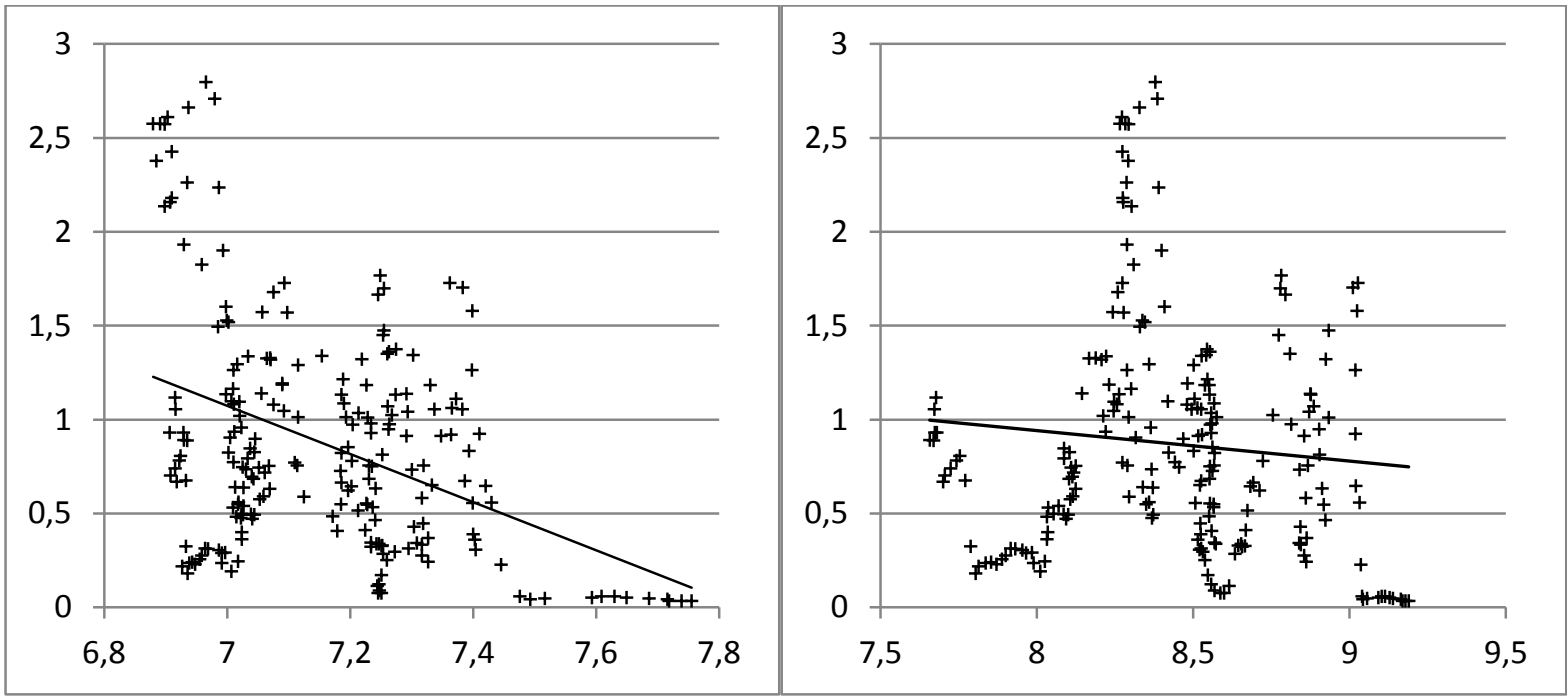

Figura 7 - Gráficos de dispersão: $V o l \_r_{t}$ vs. $\log (\mathrm{M1})$ (esquerda) e $\log (\mathrm{M} 2)$ (direita)
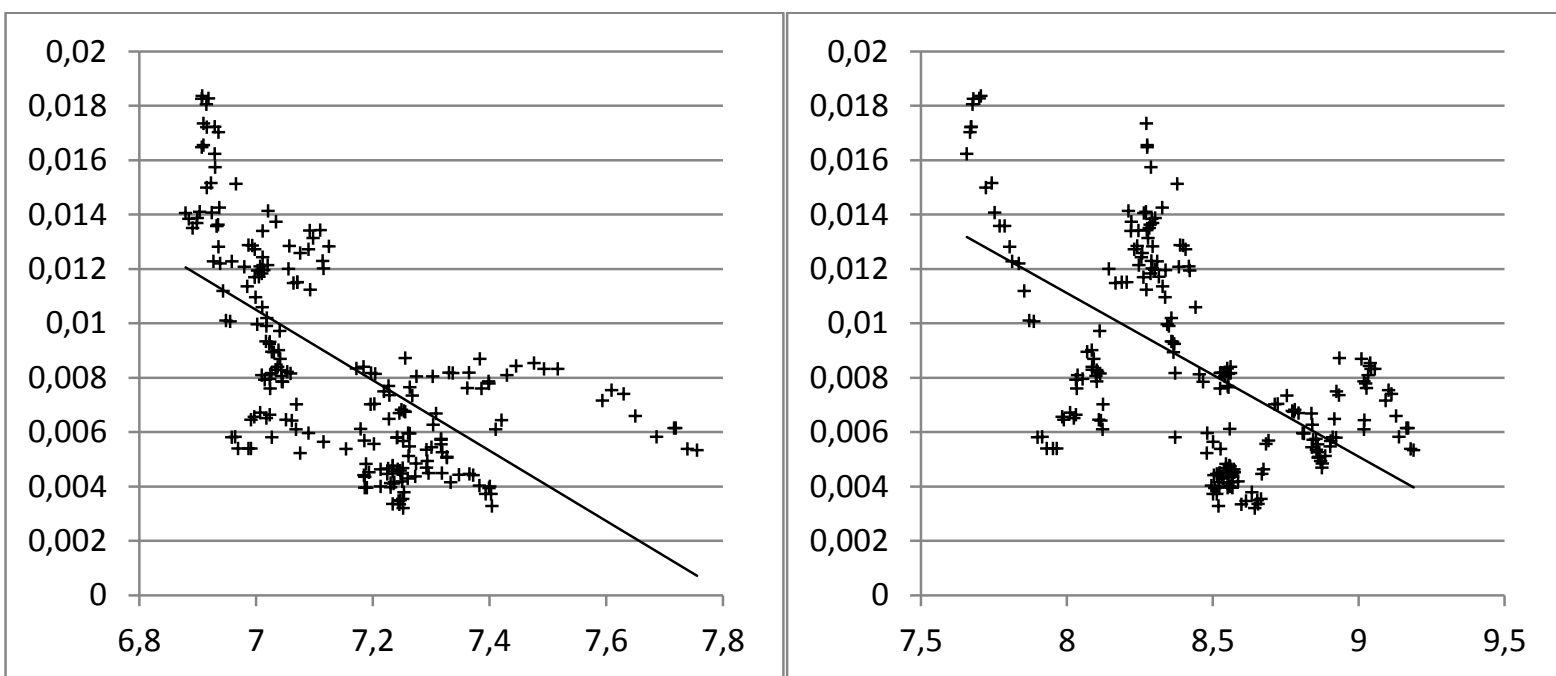

Figura 8 - Gráficos de dispersão: Vol_PIB $t_{t}$ vs. $\log (\mathrm{M1})$ (esquerda) e $\log (\mathrm{M} 2)$ (direita)

Por fim, nos modelos propostos será também usada a variável de risco Spread $_{t}$, que constitui a diferença entre as taxas de juros de dois ativos de diferentes níveis de risco selecionados de acordo com algum aspecto de interesse. Serão usados três spreads de cálculos distintos, que denominaremos Spread-loan, TED-Spread, e Spread-T30. A evolução temporal, com valores trimestrais (fim do trimestre), das três variáveis é exibida na Figura 9 abaixo. Observe que a disponibilidade de dados de cada uma é distinta (e que os dados para o SpreadT30 não existem para o período entre 2002 e 2005). 


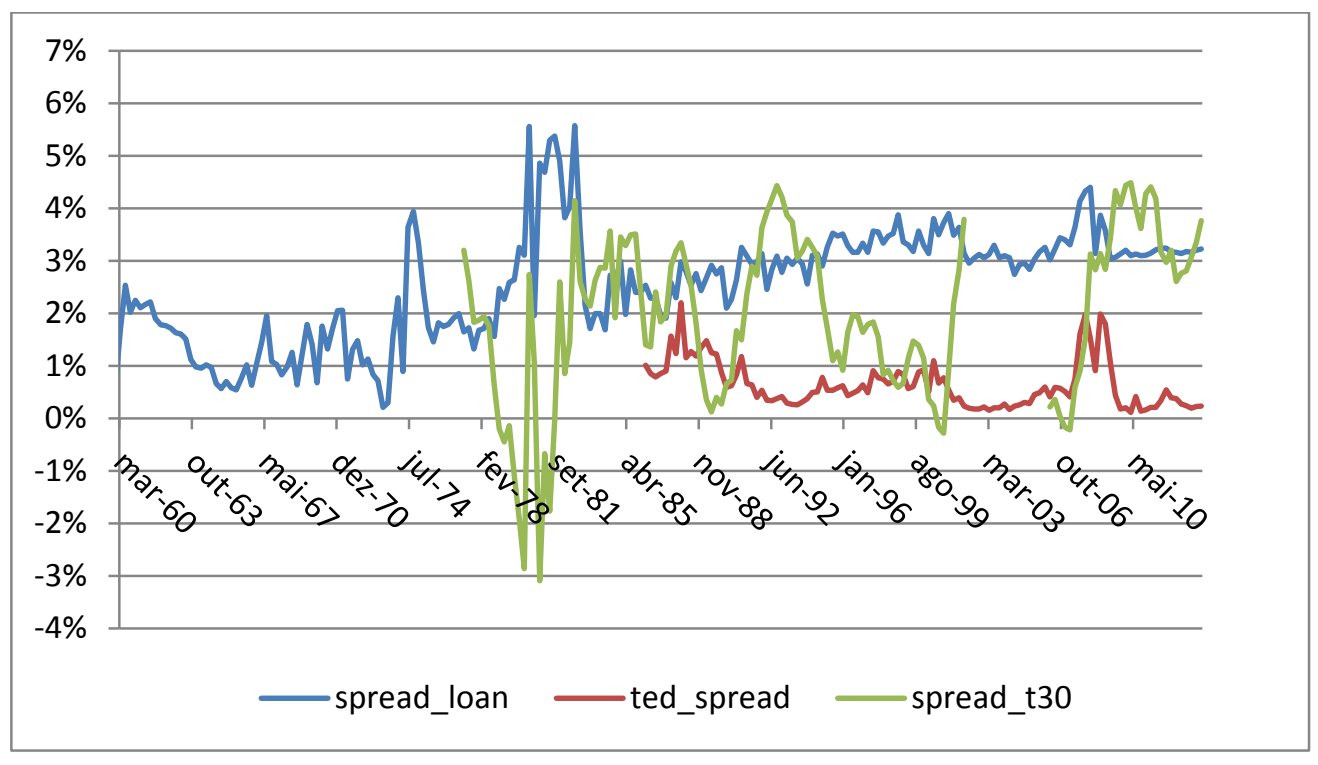

Figura 9 - Spread-loan, Ted-Spread e Spread-T30 - 1960 a 2013

As três variáveis de spread utilizadas foram calculadas sobre a taxa de juros (no mercado secundário) dos títulos do tesouro norte-americano de vencimento em três meses, $r_{t}$, que é a variável de juros risk-free mais tradicionalmente usada e selecionada também como variável de custo de oportunidade no presente trabalho (ver seção 3.3), e são dadas por:

$$
\begin{aligned}
& \text { TED_Spread }{ }_{t}=i_{t}^{L I B O R}-r_{t} \\
& \text { Spread_loan }_{t}=i_{t}^{L O A N}-r_{t} \\
& \text { Spread_T } 30_{t}=i_{t}^{T 30}-r_{t}
\end{aligned}
$$

A taxa $\mathrm{i}_{\mathrm{t}}^{\mathrm{LIBOR}}$ (London Interbank Offered Rate) é a taxa de juros cobrada sobre empréstimos interbancários de 3 meses baseados em dólares norte-americanos (US\$). Os valores do TED-Spread e seus componentes estão exibidos na Figura 10 abaixo (a partir de 1986, ano em que a taxa LIBOR começou a ser calculada).

A taxa $i_{t}^{L O A N}$ (Bank Prime Loan Rate), por sua vez, é a média das taxas de juros cobradas pelos maiores bancos dos EUA sobre empréstimos a entidades avaliadas como de baixo risco. Já a variável $i_{t}^{T 30}$ é a taxa de juros sobre papéis do tesouro com validade de 30 anos, não indexados e ajustados para maturidades constantes.

A título de ilustração da relação das variáveis de spread e dos agregados monetários M1 e M2, a Figura 11, a Figura 12 e a Figura 13 abaixo contêm os gráficos de dispersão destas variáveis, bem como suas linhas de tendência lineares simples. 


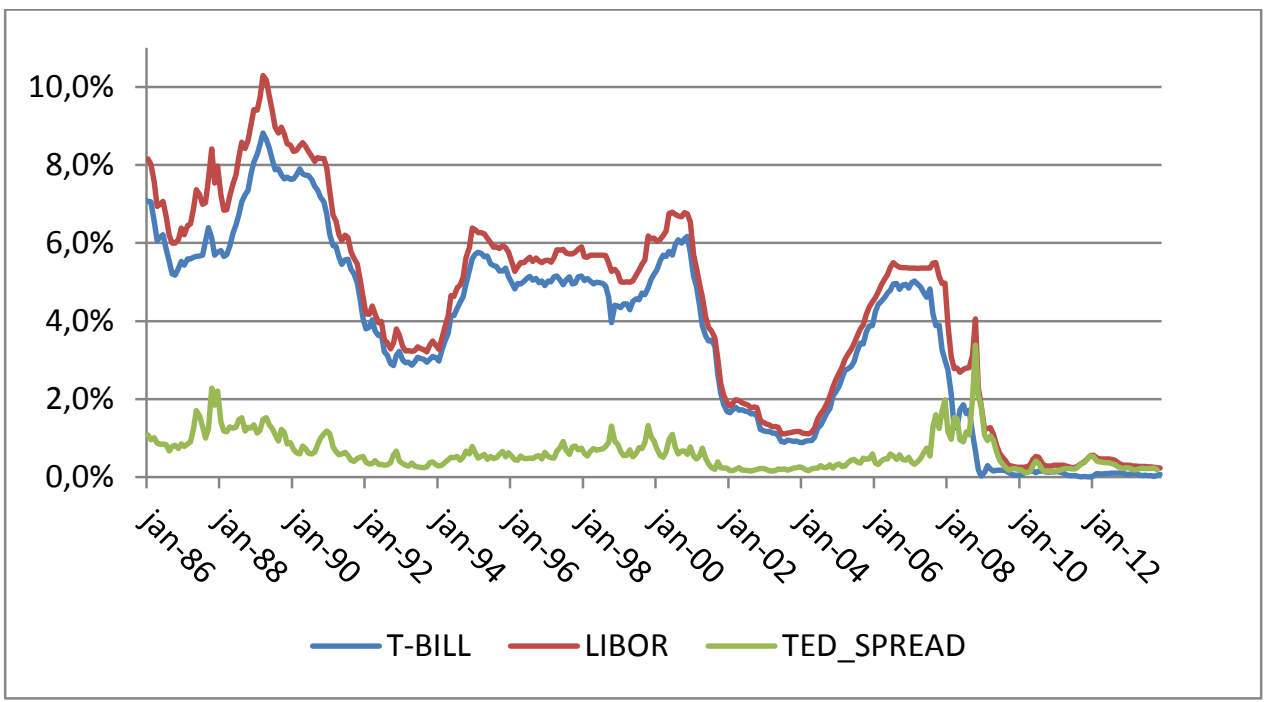

Figura 10 - Ted-Spread e componentes - dados mensais de 1986 a 2013
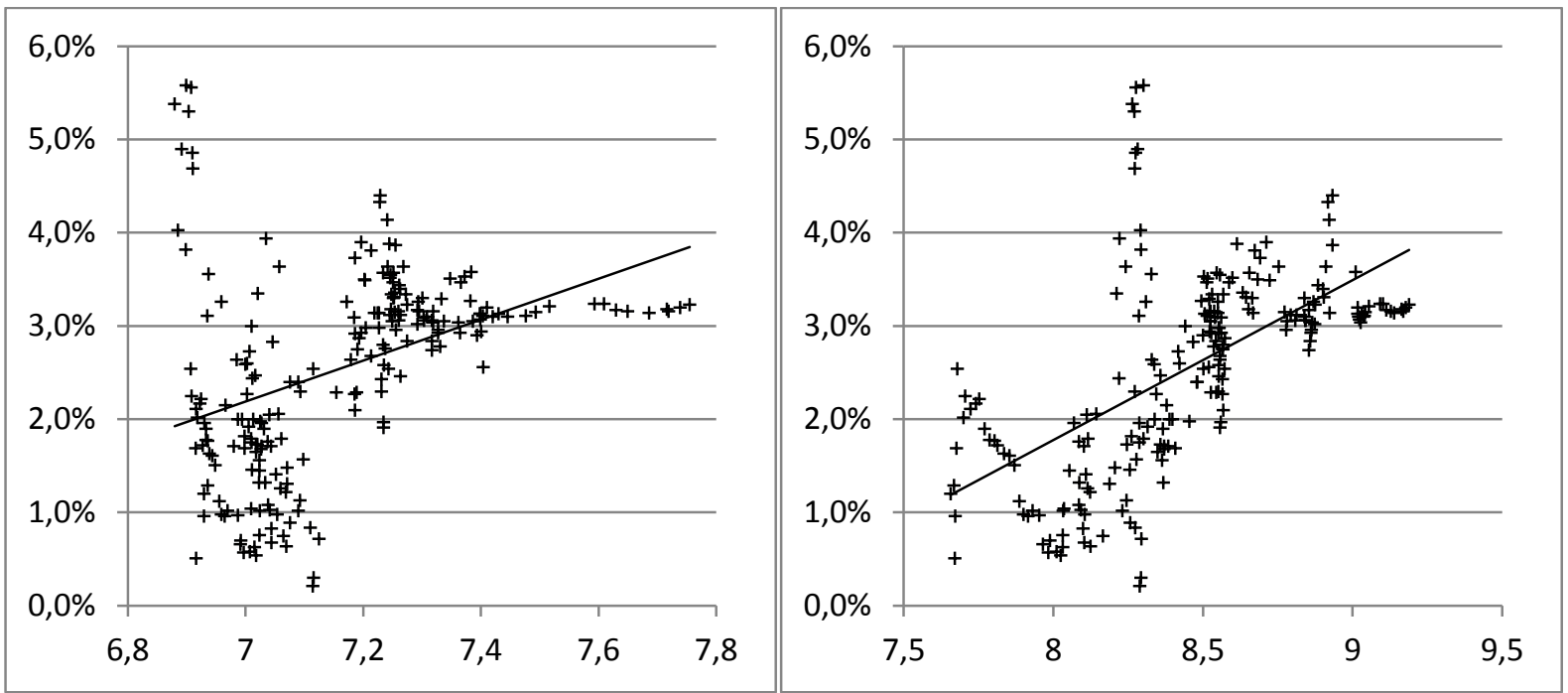

Figura 11- Gráficos de dispersão: Spread-loan vs. $\log (\mathrm{M1})$ (esquerda) e $\log (\mathrm{M} 2)$ (direita)

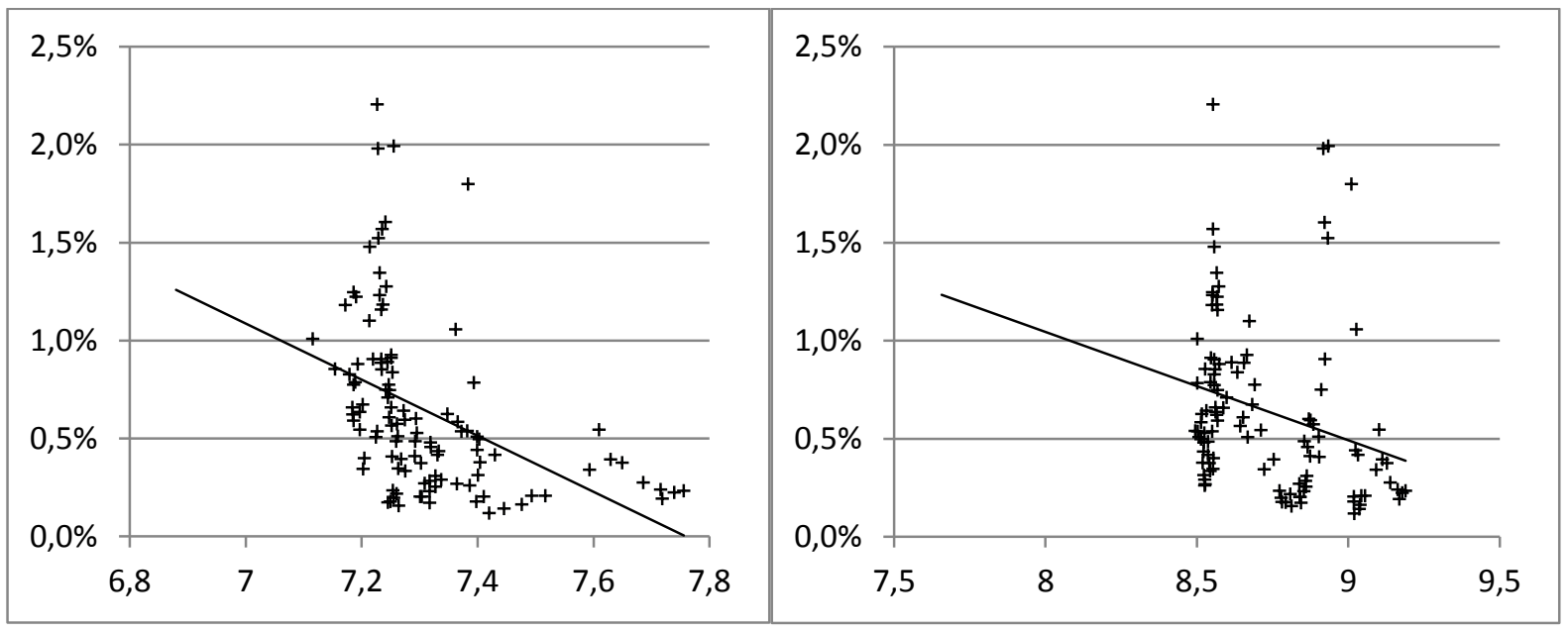

Figura 12- Gráficos de dispersão: TED Spread vs. $\log (\mathrm{M1})$ (esquerda) e $\log (\mathrm{M} 2)$ (direita) 


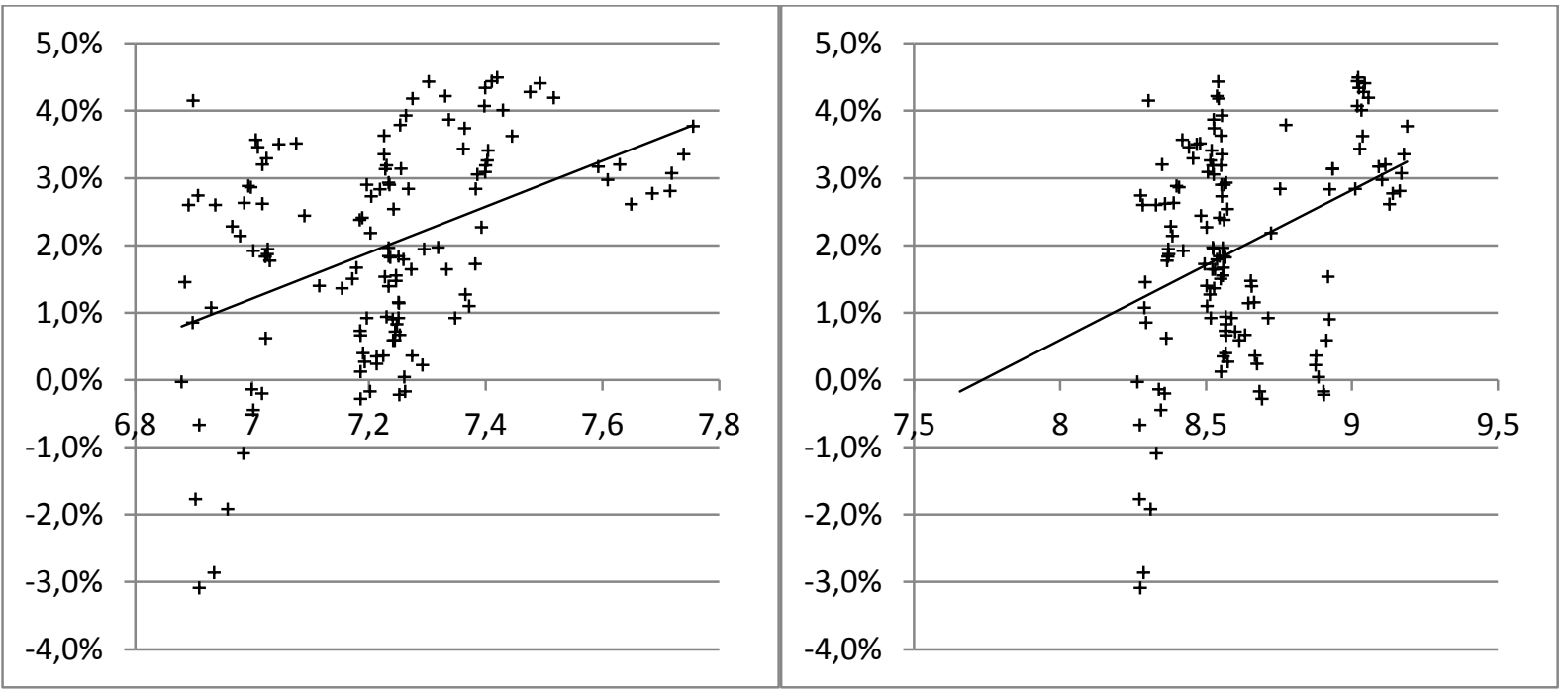

Figura 13- Gráficos de dispersão: T30 Spread vs. $\log ($ M1) (esquerda) e $\log ($ M2) (direita)

Apresentadas as variáveis a serem utilizadas neste estudo, a Tabela 1, abaixo, exibe os valores das correlações entre pares das mesmas (com M1 representando os agregados monetários). As correlações estatisticamente significativas, a 5\%, estão destacadas com asterisco.

Tabela 1 - Correlações das variáveis, em pares $(*=5 \%$ sign.)

\begin{tabular}{|c|c|c|c|c|c|c|c|c|}
\hline & $M 1 / P_{t}$ & $Y_{t}$ & $r_{t}$ & Sharpe $_{t}$ & Spread_loan $_{t}$ & TED_Spread & Spread_T30 & Vol_r $r_{t}$ \\
\hline$M 1 / P_{t}$ & 1 & & & & & & & \\
\hline$Y_{t}$ & $0,8172 *$ & 1 & & & & & & \\
\hline$r_{t}$ & $-0,5727^{*}$ & $-0,0305$ & 1 & & & & & \\
\hline Sharpe $_{t}$ & $0,3633^{*}$ & 0,0113 & $-0,3063^{*}$ & 1 & & & & \\
\hline Spread_loan $_{t}$ & $0,3828^{*}$ & 0,7094* & 0,2099* & $-0,0985$ & 1 & & & \\
\hline TED_Spread $t$ & $-0,4127^{*}$ & $-0,2921^{*}$ & $0,4772 *$ & 0,0438 & 0,1207 & 1 & & \\
\hline Spread_T30 & $0,4250^{*}$ & $0,2271^{*}$ & $-0,6437^{*}$ & 0,0931 & $-0,1794^{*}$ & $-0,3066^{*}$ & 1 & \\
\hline Vol_r $r_{t}$ & $-0,3948 *$ & 0,0619 & 0,6196* & $-0,4208^{*}$ & $0,3471^{*}$ & 0,1228 & $-0,2241^{*}$ & 1 \\
\hline Vol_PIB ${ }_{t}$ & $-0,5788 *$ & $-0,6931^{*}$ & 0,0335 & $-0,0318$ & $-0,3285^{*}$ & $-0,2110 *$ & $-0,077$ & $0,2423^{*}$ \\
\hline
\end{tabular}




\subsection{Especificação do modelo}

A teoria econômica não fornece nenhuma conclusão com relação à forma matemática correta da função de demanda por moeda. Portanto, de posse das variáveis exploradas até este ponto, é interessante questionarmos se as variáveis exerceriam influência sobre os agregados monetários modeláveis estatisticamente de forma linear ou não-linear (no caso de estudos da demanda por moeda, a forma não-linear de maior interesse na literatura atual é a logarítmica). Utilizando a nomenclatura das variáveis já apresentadas, os seguintes modelos de demanda por moeda podem, assim, ser inicialmente propostos para que possamos prosseguir à investigação da importância das variáveis de risco ${ }^{1415}$ :

$$
\begin{aligned}
& \text { A1 } \\
& \ln \left(M_{t} / P_{t}\right)=\alpha_{0}+\alpha_{1} Y_{t}+\alpha_{2} r_{t}+\alpha_{3} \text { Sharpe }_{t}+\alpha_{4} \text { Spread }_{t}+\alpha_{5} \text { Vol_r }_{t} \\
& +\alpha_{6} V_{o l} P I B_{t}+\varepsilon_{t} \\
& \text { A2 } \\
& \ln \left(M_{t} /_{P_{t}}\right)=\alpha_{0}+\alpha_{1} \ln \left(Y_{t}\right)+\alpha_{2} r_{t}+\alpha_{3} \text { Sharpe }_{t}+\alpha_{4} \text { Spread }_{t}+\alpha_{5} \text { Vol }_{-} r_{t} \\
& +\alpha_{6} \text { Vol_PIB } B_{t}+\varepsilon_{t} \\
& \text { A3 } \\
& \ln \left(M_{t} / P_{t}\right)=\alpha_{0}+\alpha_{1} Y_{t}+\alpha_{2} \ln \left(r_{t}\right)+\alpha_{3} \text { Sharpe }_{t}+\alpha_{4} \text { Spread }_{t}+\alpha_{5} \text { Vol }_{-} r_{t} \\
& +\alpha_{6} \text { Vol_PIB } B_{t}+\varepsilon_{t} \\
& \ln \left(M_{t} / P_{t}\right)=\alpha_{0}+\alpha_{1} \ln \left(Y_{t}\right)+\alpha_{2} \ln \left(r_{t}\right)+\alpha_{3} \text { Sharpe }_{t}+\alpha_{4} \text { Spread }_{t} \\
& +\alpha_{5} \text { Vol_r } r_{t}+\alpha_{6} \text { Vol_PIB } B_{t}+\varepsilon_{t} \\
& \ln \left(M_{t} / P_{t}\right)=\alpha_{0}+\alpha_{1} \ln \left(Y_{t}\right)+\alpha_{2} \ln \left(r_{t}\right)+\alpha_{3} \text { Sharpe }_{t}+\alpha_{4} \ln \left(\text { Spread }_{t}\right) \\
& +\alpha_{5} V o l \_r_{t}+\alpha_{6} V o l \_P I B_{t}+\varepsilon_{t} \\
& \ln \left(M_{t} / P_{t}\right)=\alpha_{0}+\alpha_{1} \ln \left(Y_{t}\right)+\alpha_{2} \ln \left(r_{t}\right)+\alpha_{3} \text { Sharpe }_{t}+\alpha_{4} \ln \left(\text { Spread }_{t}\right) \\
& +\alpha_{5} \ln \left(V o l_{-} r_{t}\right)+\alpha_{6} \text { Vol_PIB }{ }_{t}+\varepsilon_{t} \\
& +\alpha_{5} \ln \left(V o l_{-} r_{t}\right)+\alpha_{6} \ln \left(V o l_{-} P I B_{t}\right)+\varepsilon_{t}
\end{aligned}
$$

${ }^{14}$ Para pequenos valores de uma variável $\mathrm{x}$, sabemos que a seguinte aproximação será válida: $x \approx \ln (1+x)$. Portanto, não foi testada a forma funcional em que o termo da taxa de juros se soma à unidade. A teoria sugere também outras formas como $r_{t} / 1+r_{t}$ ou o uso dos juros acumulados no trimestre, porém, para mantermos a comparabilidade com a maior parte da literatura existente, estas formas funcionais não foram testadas.

${ }^{15}$ Observe que o Índice de Sharpe pode apresentar valores não-positivos e, portanto, a transformação logarítmica não é aplicável a esta variável. 
Adicionalmente, denominaremos por "B1",,..,"B7" os modelos análogos aos apresentados acima, porém sem a aplicação da transformação logarítmica ao agregado monetário utilizado como variável dependente (i.e, com a variável dependente $\mathrm{M}_{t} / \mathrm{P}_{\mathrm{t}}$ ).

A especificação log-linear da demanda por moeda "padrão" (equivalente ao modelo A4 acima com a restrição $\alpha_{3}=\alpha_{4}=\alpha_{5}=\alpha_{6}=0$ ) é a mais utilizada em estudos empíricos de modelagem da demanda pelo agregado M1 nos EUA (Sriram, 2001; Lucas, 2000; Ireland, 2009). Uma debatida desvantagem dessa especificação, entretanto, é que a mesma restringe as elasticidades de longo prazo da renda e da taxa de juros a serem constantes. ${ }^{16}$ Para escolhermos o modelo mais adequado ao atual estudo, entretanto, utilizaremos a seguir alguns testes de forma funcional, aplicados aos modelos acima utilizando os dados para o agregado monetário M1 como variável dependente e o Spread da taxa de empréstimos bancária (loanrate; ver seção 4.1).

\subsubsection{Transformação de Box-Cox}

Um dos métodos ainda hoje mais populares para o teste da forma funcional mais adequada dentre as citadas é a transformação de Box-Cox, proposta por Box \& Cox (1964) e cuja aplicação ao estudo da demanda por moeda foi adaptada por Zarembka (1968). Tal transformação visa obter uma forma funcional empiricamente estimável que apresenta as formas linear e logarítmica das variáveis envolvidas como casos especiais.

O procedimento consiste em aplicar a uma variável genérica $x$ a seguinte transformação:

$$
x^{(\lambda)}=\frac{x^{\lambda}-1}{\lambda}
$$

Cujo interesse empírico no teste de formas funcionais se baseia na observação de que:

${ }^{16}$ Isto é, em A4, elasticidade-renda: $\eta\left(\frac{M^{d}}{P}, Y\right)=\frac{d \log \left(M^{d} / P\right)}{d \log (Y)}=\alpha_{1}$. Analogamente, elasticidade-juros $=\alpha_{2}$. 


$$
x^{(\lambda)}=\left\{\begin{array}{cc}
x-1 & \text { se } \lambda=1 \\
\ln (x) & \text { se } \lambda=017 \\
1-\frac{1}{x} & \text { se } \lambda=-1
\end{array}\right.
$$

Observe que, aplicando a transformação às variáveis não-negativas em estudo, o uso dos dados para decisão entre as formas $\operatorname{com} \lambda=1$ e $\lambda=0$ auxiliaria-nos na escolha do uso mais adequado de cada variável em nosso modelo. Portanto, para testar a forma funcional mais adequada dentre as propostas acima, efetuaremos a estimação do seguinte modelo, utilizando um estimador de máxima verossimilhança ${ }^{18}$ :

$$
\begin{aligned}
M_{t} /_{P_{t}}{ }^{(\lambda)}=\alpha_{0} & +\alpha_{1} Y_{t}{ }^{(\lambda)}+\alpha_{2} r_{t}{ }^{(\lambda)}+\alpha_{3} \text { Sharpe }_{t}+\alpha_{4} \text { Spread }_{t}{ }^{(\lambda)} \\
& +\alpha_{5} \text { Vol_ }_{-}{ }^{(\lambda)}+\alpha_{6} \text { Vol_PIB }_{t}{ }^{(\lambda)}+\varepsilon_{t}
\end{aligned}
$$

Observe que o procedimento de estimação retorna um valor estimado de $\lambda$ único, aplicável a todas as variáveis. Levando em conta tal fato, utilizaremos as regressões de BoxCox nos modelos A1 a A6 e B1 a B7 descritos acima, em que a transformação definida em (3.15) foi aplicada apenas às variáveis que o modelo considera como lineares, sendo as outras variáveis do modelo deixadas não transformadas no processo de estimação, de modo que testaremos a relevância da transformação logarítmica de algumas variáveis considerandose dada a aplicação da mesma a outras variáveis do modelo ${ }^{19}$. Como exemplo, a regressão de Box-Cox associada ao modelo B3 será constituída então pelo estimador de máxima verossimilhança de $\lambda$ do modelo:

$$
\begin{aligned}
\left(M_{t} P_{t}\right)^{(\lambda)}= & \alpha_{0}+\alpha_{1} Y_{t}^{(\lambda)}+\alpha_{2} \ln \left(r_{t}\right)+\alpha_{3} \text { Sharpe }_{t}+\alpha_{4} \operatorname{Spread}_{t}{ }^{(\lambda)} \\
& +\alpha_{5} \text { Vol_r }_{t}{ }^{(\lambda)}+\alpha_{6} \text { Vol_PIB }_{t}{ }^{(\lambda)}+\varepsilon_{t}
\end{aligned}
$$

Os resultados encontrados para as regressões de Box-Cox definidas acima são apresentados na Tabela 2, abaixo. Suas primeiras duas linhas apresentam a estimativa de $\lambda$

\footnotetext{
${ }^{17}$ Esta aproximação provém da aplicação da regra de l'Hospital: $\lim _{\lambda \rightarrow 0} \frac{x^{\lambda}-1}{\lambda}=\ln (x)$

18 Observe que os testes são obtidos sob a hipótese de que o modelo está corretamente especificado. Detalhes sobre o procedimento de estimação podem ser encontrados em Box \& Cox (1964).

${ }^{19}$ Observe que o procedimento descrito não é, portanto, aplicável a A7.
} 
encontrada para cada modelo, bem como o p-valor do teste LR associado. As próximas três linhas da tabela apresentam a log-verossimilhança, a estatística LR e seu p-valor (destacado com asterisco quando menores que 5\%) para a especificação funcional com restrição $\lambda=1$, enquanto as três últimas linhas apresentam os mesmos valores considerando-se a forma funcional $\operatorname{com} \lambda=0 .{ }^{20}$

Tabela 2 - Resultados das regressões com transformações de Box-Cox

\begin{tabular}{|lrcccccc|}
\hline & & A1 & A2 & A3 & A4 & A5 & A6 \\
\hline Lambda & Coef. estimado & 1,719 & 1,616 & 5,213 & 1,312 & 1,280 & 2,849 \\
\hline H0: Lambda=1 & Log Likelihood & 622,336 & 623,543 & 642,666 & 644,580 & 639,700 & 639,661 \\
& Estat. LR (chi2) & 1,146 & $-0,072$ & 2,100 & $-0,730$ & $-0,320$ & 1,138 \\
& p-valor LR & 0,284 & 1,000 & 0,147 & 1,000 & 1,000 & 0,286 \\
\hline H0: Lambda=0 & Log Likelihood & 620,845 & 622,801 & 642,040 & 643,943 & 639,013 & 639,029 \\
& Estat. LR (chi2) & 4,129 & 1,412 & 3,350 & 0,545 & 1,054 & 2,402 \\
& p-valor LR & $0,042^{*}$ & 0,235 & 0,067 & 0,460 & 0,305 & 0,121 \\
\hline
\end{tabular}

\begin{tabular}{|lrccccccc|}
\hline & & B1 & B2 & B3 & B4 & B5 & B6 & B7 \\
\hline Lambda & Coef. estimado & 1,758 & 1,598 & $-3,844$ & 1,637 & 1,680 & $-2,554$ & 1,930 \\
\hline H0: Lambda=1 & Log Likelihood & $-962,33$ & $-962,25$ & $-931,54$ & $-931,19$ & $-934,40$ & $-934,90$ & $-934,56$ \\
& Estat. LR (chi2) & 0,401 & $-0,827$ & 2,611 & $-0,936$ & $-0,627$ & 0,806 & $-0,714$ \\
& p-valor LR & 0,527 & 1,000 & 0,106 & 1,000 & 1,000 & 0,369 & 1,000 \\
\hline H0: Lambda=0 & Log Likelihood & $-962,57$ & $-961,78$ & $-932,55$ & $-931,78$ & $-935,04$ & $-935,05$ & $-934,75$ \\
& Estat. LR (chi2) & 0,869 & $-1,762$ & 4,626 & 0,237 & 0,669 & 1,104 & $-0,322$ \\
& p-valor LR & 0,351 & 1,000 & $0,031^{*}$ & 0,627 & 0,413 & 0,293 & 1,000 \\
\hline
\end{tabular}

De modo geral, observamos que os estimadores acima apresentam valores de $\hat{\lambda}>1$ significativos (a 5\% de confiança) para os modelos A1, A2 e A3. Desconsiderando o valor negativo encontrado para $\lambda$ no modelo $\mathrm{B} 3$ (entretanto, a especificação $\lambda=0$ é rejeitada a $5 \%$ de confiança nesse modelo), pode-se dizer que padrão similar foi observado entre os modelos B1 e B2. Por outro lado, na maioria das estimações, os modelos não são capazes de rejeitar tanto a especificação logarítmica $\lambda=0$ quanto a especificação linear $\lambda=1$. As regressões foram, portanto, pouco conclusivas, sugerindo a utilização de metodologias adicionais para a definição da forma funcional a ser utilizada.

\footnotetext{
${ }^{20}$ Os testes desta e das seguintes seções foram realizados utilizando o formato $\operatorname{ARDL}(2,0,0,0,0,0,0)$ dos modelos em análise, considerando-se que as variáveis apresentam evidência de cointegração. Este tópico será detalhado no capítulo 4.
} 


\subsubsection{Testes "nonnested"}

Além da metodologia de Box-Cox, usaremos também testes para modelos "nonnested", que ocorrem quando o modelo da hipótese nula não pode ser representado como um caso especial de um modelo geral representado pela hipótese alternativa (i.e., um modelo que impõe alguma restrição a um modelo geral). Um dos testes de forma funcional que seguem tal abordagem é o teste J, de Davidson \& MacKinnon (1981), que é apropriado para o caso em que os modelos considerados contam com a mesma variável dependente. Portanto, para testarmos a forma A4 com relação à forma A1 (i.e., testarmos se o uso de A4 seria preferível ao uso de A1), por exemplo, nos basearemos nas hipóteses:

$$
\begin{aligned}
& H_{0}: \ln \left(M_{t} /_{t}\right)=\alpha_{0}+\alpha_{1} \ln \left(Y_{t}\right)+\alpha_{2} \ln \left(r_{t}\right)+\Pi \text { Risco }_{t}+v_{0 t} \\
& H_{A}: \ln \left(M_{t} /_{P_{t}}\right)=\alpha_{0}+\alpha_{1} Y_{t}+\alpha_{2} r_{t}+\Pi \text { Risco }_{t}+v_{1 t}
\end{aligned}
$$

Em que, para fins de exposição, as variáveis de risco estão representadas pela matriz $\boldsymbol{R i s c o}_{\boldsymbol{t}}$. O teste consiste em estimar a equação representada pela hipótese alternativa $\mathrm{H}_{\mathrm{A}}$ (via OLS) e adicionar o vetor dos valores previstos da variável dependente pelo modelo estimado ao modelo $\mathrm{H}_{0}$. Este modelo aumentado é, então, estimado via OLS e o valor da estatística t referente à variável adicionada é analisado.

$\mathrm{Na}$ Tabela 3 a seguir estão apresentados os valores encontrados para o teste $\mathbf{J}$ aplicados aos modelos em investigação, bem como os p-valores associados (destacados com asterisco quando menores que 5\%). O modelo utilizado como base de comparação para os modelos A foi o modelo A4 (i.e., os modelos A1, A2, A3, A5, A6 e A7 foram testados contra o modelo A4), e, para os modelos B, o modelo B4. As primeiras duas colunas de resultados apresentam os testes utilizando-se os modelos A4/B4 como hipótese alternativa, enquanto as duas colunas seguintes os utilizam como hipótese nula.

Observando-se a tabela, vemos que o teste $\mathrm{J}$ apresenta conclusões ambíguas para os testes A1xA4 e A2xA4, bem como seus correspondentes do tipo B (os testes são significativos a 5\% para as estruturas de hipóteses inversas). Por outro lado, os outros testes rejeitam, de modo geral e a 95\% de confiança, a hipótese nula de que o modelo A4 é o mais adequado, em oposição aos modelos A3 a A7 (individualmente), mas não o fazem quando a estrutura de hipóteses é invertida. Observações análogas podem ser feitas com relação aos modelos do tipo B correspondentes (exceto B3). 
Tabela 3 - Teste J: resultados para modelos selecionados

\begin{tabular}{cccccc}
\hline & & \multicolumn{2}{c}{ H0: M1 / HA:M2 } & \multicolumn{2}{c}{ H0: M2 / HA:M1 } \\
\hline Modelo 1 & Modelo 2 & $\mathbf{t}$ & $\mathbf{p}>|\mathbf{t}|$ & $\mathbf{t}$ & $\mathbf{p}>|\mathbf{t}|$ \\
A1 & A4 & 4,28 & $0,000^{*}$ & 8,62 & $0,000^{*}$ \\
A2 & A4 & 4,42 & $0,000^{*}$ & 8,28 & $0,000^{*}$ \\
A3 & A4 & $-0,21$ & 0,837 & 2,38 & $0,018^{*}$ \\
A5 & A4 & $-1,15$ & 0,251 & 3,25 & $0,001^{*}$ \\
A6 & A4 & $-0,88$ & 0,378 & 3,25 & $0,001^{*}$ \\
A7 & A4 & $-0,88$ & 0,381 & 3,52 & $0,001^{*}$ \\
\hline B1 & B4 & 2,90 & $0,004^{*}$ & 9,29 & $0,000^{*}$ \\
B2 & B4 & 2,89 & $0,004^{*}$ & 9,13 & $0,000^{*}$ \\
B3 & B4 & 0,85 & 0,394 & 1,44 & 0,153 \\
B5 & B4 & $-0,75$ & 0,454 & 2,57 & $0,011^{*}$ \\
B6 & B4 & $-0,78$ & 0,436 & 2,86 & $0,005^{*}$ \\
B7 & B4 & $-0,08$ & 0,935 & 2,81 & $0,005^{*}$ \\
\hline
\end{tabular}

Para testarmos os modelos com variáveis dependentes distintas, utilizaremos o teste PE, desenvolvido por MacKinnon, White e Davidson (1983). Como exemplo de sua aplicação, a seguinte estrutura de hipóteses seria usada para testarmos o modelo A4 (loglinear) em contraposição ao modelo B1 (linear):

$$
\begin{aligned}
& H_{0}: \ln \left(M_{t} /_{t}\right)=\alpha_{0}+\alpha_{1} \ln \left(Y_{t}\right)+\alpha_{2} \ln \left(r_{t}\right)+\Pi \text { Risco }_{t}+v_{0 t} \\
& H_{A}:{ }^{M} /_{P_{t}}=\alpha_{0}+\alpha_{1} Y_{t}+\alpha_{2} r_{t}+\Pi \text { Risco }_{t}+v_{1 t}
\end{aligned}
$$

Representando por $\widehat{d e p}_{t}$ e $\widetilde{d e p}_{t}$ os valores previstos para as variáveis dependentes nos modelos de $\mathrm{H}_{0}$ e $\mathrm{H}_{\mathrm{A}}$ estimados via OLS, respectivamente, baseamos o teste PE na seguinte regressão simples:

$$
\hat{v}_{0 t}=\theta_{0}+\theta_{1} \ln \left(Y_{t}\right)+\theta_{2} \ln \left(r_{t}\right)+\boldsymbol{\Xi} \boldsymbol{R i s c o}+\kappa\left[\overline{\operatorname{dep}_{t}}-\exp \left(\widehat{\operatorname{dep}_{t}}\right)\right]+u_{0 t}
$$

Sendo $\hat{v}_{0 t}$ o resíduo da estimação do modelo $\mathrm{H}_{0}$. O teste consistirá, portanto, na observação do teste $t$ associado à estimativa do coeficiente $\kappa$.

A Tabela 4 abaixo exibe os resultados obtidos para os testes cujos procedimentos foram descritos acima, os quais foram aplicados entre pares de modelos com variável dependente logarítmica e linear (isto é, modelos tipo A contra modelos do tipo B de mesmo 
número, segundo a terminologia apresentada). As primeiras duas colunas de resultados apresentam os testes em que os modelos de tipo A foram utilizados como hipótese nula, enquanto as duas próximas colunas apresentam os resultados em que os modelos B foram utilizados como hipótese nula.

Tabela 4 - Teste PE, modelos selecionados

\begin{tabular}{cccccc}
\hline & & \multicolumn{2}{c}{ H0:M1 / HA:M2 } & \multicolumn{2}{c}{ H0:M2 / HA:M1 } \\
\hline Modelo 1 & Modelo 2 & $\mathbf{t}$ & $\mathbf{p}>|\mathbf{t}|$ & $\mathbf{t}$ & $\mathbf{p}>\mathbf{| t |}$ \\
A1 & B1 & $-0,16$ & 0,873 & 0,91 & 0,363 \\
A2 & B2 & $-0,64$ & 0,520 & 1,32 & 0,187 \\
A3 & B3 & $-0,70$ & 0,486 & 1,48 & 0,139 \\
A4 & B4 & $-0,93$ & 0,355 & 1,89 & 0,060 \\
A5 & B5 & $-0,89$ & 0,373 & 1,86 & 0,065 \\
A6 & B6 & $-1,07$ & 0,288 & 2,08 & $0,038^{*}$ \\
A7 & B7 & $-1,16$ & 0,246 & 2,12 & $0,035^{*}$ \\
\hline
\end{tabular}

Os p-valores encontrados para os testes com os modelos A como hipótese nula são altos, indicando que os modelos A em geral só deveriam ser rejeitados em favor dos modelos B se fossem adotados níveis de significância bastante altos. A um nível de significância de $5 \%$, entretanto, os modelos de tipo B só são rejeitados (como hipótese nula) em favor dos modelos A nos casos B6 e B7, ainda que os p-valores associados a B4 e B5 sejam também baixos.

\subsubsection{Seleção por critérios de informação e ajuste dos modelos}

Finalmente, devemos atentar-nos às dificuldades implícitas na definição do modelo adequado através do uso de testes cuja conclusão apresentada é de formato binário (i.e., a aplicação é feita em pares de modelos), como os utilizados acima. Mais especificamente, se temos $m$ modelos, e com eles realizamos $m(m-1)$ testes em pares, não seria razoável esperar que apenas um dos modelos nunca fosse rejeitado. Para contornar essa questão, deveríamos utilizar procedimento específicos para seleção de modelos (Davidson \& MacKinnon, 1999, Cap. 15). 
Os critérios de informação como AIC (Akaike Information Criterion), introduzido por Akaike (1973), e BIC (Schwarz's Bayesian Information Criterion), introduzido por Schwarz (1978), têm utilização recomendável, portanto, na escolha de modelos alternativos em tal contexto de possibilidades múltiplas. Os mesmos podem ser vistos como medidas da qualidade do ajuste de um modelo aos dados, ao mesmo tempo em que incluem uma "penalidade" pelo uso de parâmetros adicionais (sendo, assim, mais adequados que a simples observação do valor da função de verossimilhança associada ao modelo) (Davidson \& MacKinnon, 1999).

Os valores dos critérios de informação a serem apresentados para os modelos A1 a A7 e B1 a B7 são obtidos pelas seguintes relações:

$$
\begin{gathered}
A I C=-2 \ln (L)+2 k \\
B I C=-2 \ln (L)+k \ln (N)
\end{gathered}
$$

Em que $\ln (L)$ é a log-verossimilhança maximizada ${ }^{21}$ do modelo avaliado, $k$ é o número de parâmetros estimados e $N$ é o tamanho da amostra utilizada ${ }^{22}$. Observe que, da definição utilizada acima, o modelo que classificaremos, pelo uso destes critérios, como o mais adequado, é aquele que apresentar o menor valor de AIC e/ou BIC. Vale observar também que, como para amostras de tamanho razoável têm-se $\ln (N)>2$, o critério BIC impõe uma penalidade maior para o uso de variáveis adicionais e, portanto, seu uso para seleção de modelos pode ser considerado mais parcimonioso em relação ao uso de AIC.

A Tabela 5 abaixo exibe, além dos valores do $\mathrm{R}^{2}$ ajustado para as regressões, os valores dos critérios AIC e BIC para os modelos em análise, expressos em formato ARDL para que se considere corretamente a cointegração entre as variáveis, estimados via OLS (ver capítulo 4).

Observe que, pelos valores obtidos, os modelos que minimizam ambos os critérios AIC e BIC (e maximizam o $\mathrm{R}^{2}$ ajustado) entre os grupos de modelos A e B são, respectivamente, os modelos que representamos por A4 e B4. Como afirmado acima, a comparação entre os modelos dos grupos A e B não é adequada, e, para isso, podemos recorrer aos resultados já obtidos pelo uso do teste PE. Observando novamente a Tabela 4, de resultados deste teste, lembramos que o mesmo retornou o resultado de que é possível, de

\footnotetext{
${ }^{21}$ Portanto, os critérios não serão úteis para compararmos os modelos do tipo A com os modelos do tipo B.

${ }^{22}$ As fórmulas apresentadas, utilizadas pelos softwares estatísticos, são o negativo das fórmulas apresentadas originalmente pelos respectivos autores, e que, portanto, eram originalmente maximizadas na escolha do modelo.
} 
acordo com a evidência dos dados, rejeitar a hipótese nula de que o modelo B4 é preferível ao modelo A4 em favor da hipótese alternativa de que o modelo A4 é preferível ao modelo B4, se adotado um nível de significância estatística de 10\%. Na estrutura de hipóteses inversa, entretanto, a hipótese nula não pôde ser rejeitada ao mesmo nível de significância.

Tabela 5 - Critérios de informação para modelos no formato ARDL (agregado M1)

\begin{tabular}{cccc}
\hline Modelo & AIC & BIC & $\overline{\boldsymbol{R}^{\mathbf{2}}}$ \\
\hline A1 & $-1206,67$ & $-1142,45$ & 0,2631 \\
\hline A2 & $-1209,09$ & $-1144,87$ & 0,2743 \\
A3 & $-1247,33$ & $-1183,11$ & 0,5153 \\
\hline A4 & $\mathbf{- 1 2 5 1 , 1 6}$ & $\mathbf{- 1 1 8 6 , 9 4}$ & $\mathbf{0 , 5 2 1 5}$ \\
A5 & $-1241,40$ & $-1177,18$ & 0,4938 \\
\hline A6 & $-1241,32$ & $-1177,10$ & 0,4948 \\
\hline A7 & $-1240,09$ & $-1175,87$ & 0,4936 \\
\hline B1 & 1962,67 & 2026,88 & 0,2582 \\
B2 & 1962,50 & 2026,72 & 0,2654 \\
\hline B3 & 1901,08 & 1965,30 & 0,5591 \\
\hline B4 & $\mathbf{1 9 0 0 , 3 8}$ & $\mathbf{1 9 6 4 , 6 0}$ & $\mathbf{0 , 5 6 1 3}$ \\
\hline B5 & 1906,79 & 1971,01 & 0,5448 \\
B6 & 1907,80 & 1972,02 & 0,5464 \\
B7 & 1907,11 & 1971,33 & 0,5479 \\
\hline
\end{tabular}

Em adição a esta análise, outra questão que se observa naturalmente é com relação a qual dos modelos melhor descreve os dados utilizados. Como veremos no capítulo seguinte, a metodologia de estimação a ser utilizada retorna uma relação de equilíbrio de longo prazo para os modelos estimados. A Tabela 6 abaixo exibe os valores da soma dos quadrados dos termos de correção de erro de cada modelo em análise, isto é, das diferenças entre os valores previstos pela relação de equilíbrio da demanda por moeda associada a cada um dos modelos e os valores efetivamente observados no mesmo período. Nela observamos que, dentre os modelos do "tipo A", os menores valores desta soma são, na ordem, dos modelos A6 e A4. Já entre os modelos do "tipo B", os menores valores (dados em milhares de trilhões de US\$) correspondem, na ordem, aos modelos B6, B7 e B4. Considerando que as somas constituem uma medida de aderência a uma relação de longo prazo, cuja porção do desvio advinda de eventuais erros de especificação desejamos minimizar, os resultados mostram que os modelos 
A4/B4 têm bom desempenho neste quesito, apesar de, por pequenas diferenças, não serem os modelos com os menores valores desta soma de erros de previsão.

Tabela 6 - Soma dos quadrados dos termos de erro

\begin{tabular}{ccccccc}
\hline A1 & A2 & A3 & A4 & A5 & A6 & A7 \\
\hline 33,733 & 21,088 & 4,404 & 3,676 & 4,085 & $\mathbf{3 , 6 6 6}$ & 4,313 \\
\hline B1 & B2 & B3 & B4 & B5 & B6 & B7 \\
\hline 660,58 & $1.771,44$ & 30,53 & 23,89 & 24,30 & $\mathbf{1 8 , 2 3}$ & 23,15 \\
\hline
\end{tabular}

\subsubsection{Variáveis de interação}

Em complemento à questão da forma funcional adequada ao uso das variáveis em estudo, uma questão adicional deve ser considerada. Tendo em vista as variáveis a serem incluídas no modelo, exploradas nas seções anteriores, podemos esperar, de acordo com a teoria macroeconômica, interações entre pares de algumas das variáveis no mesmo instante temporal. Deste modo, visando buscar o melhor ajuste possível para o modelo a ser estimado, utilizaremos variáveis de interação ${ }^{23}$, definidas como o produto simples dos valores de duas variáveis X e Y no instante $t$ :

$$
I T_{i, t}[X, Y]=X_{i, t} * Y_{i, t}
$$

As variáveis calculadas foram, com base nos pares de variáveis com interação prevista, as seguintes:

- $\quad I T_{t}[r, \operatorname{Vol}(r)]$;

- $\quad I T_{t}[\operatorname{Vol}(P I B)$, Sharpe $]$;

- $\quad I T_{t}[\operatorname{Vol}(P I B), \operatorname{Vol}(r)]$;

- $I T_{t}[\operatorname{Vol}(P I B)$, Spread $]$

De modo que obtemos o vetor $\mathbf{I T}_{\mathrm{t}}$ de observações das variáveis de interação no período $t$, a ser incluído nos modelos a serem estimados:

\footnotetext{
${ }^{23}$ Para detalhes sobre o uso de tais variáveis, ver, por exemplo, Ozer-Balli \& Sørensen (2010).
} 


$$
\boldsymbol{I T}_{\boldsymbol{t}}=\left[\begin{array}{l}
I T_{t}[r, \operatorname{Vol}(r)] \\
I T_{t}[\operatorname{Vol}(P I B), \text { Sharpe }] \\
I T_{t}[\operatorname{Vol}(P I B), \operatorname{Vol}(r)] \\
I T_{t}[\operatorname{Vol}(P I B), \text { Spread }]
\end{array}\right]
$$

A significância da inclusão das variáveis acima no modelo estimado será analisada individualmente no próximo capítulo, com o auxílio dos testes estatísticos relevantes.

Em suma, neste capítulo analisamos e selecionamos sete agregados monetários a serem utilizados como variável dependente das estimações seguintes, incluindo agregados de definição mais ampla e outros de definição mais restrita. As variáveis independentes a serem utilizadas foram definidas, e, de posse das mesmas, foram realizados testes estatísticos de forma funcional para seleção do modelo teórico mais apropriado para estimação no capítulo seguinte. Tomando como base os resultados obtidos, em especial, pela aplicação dos critérios de informação e do teste PE, concluímos que o modelo selecionado, a ser utilizado no procedimento de estimação detalhado no próximo capítulo, é dado pela equação (3.24) abaixo.

$$
\begin{aligned}
\ln \left(M_{t} / P_{t}\right)=\alpha_{0} & +\alpha_{1} \ln \left(Y_{t}\right)+\alpha_{2} \ln \left(r_{t}\right)+\alpha_{3} \text { Sharpe }_{t}+\alpha_{4} \text { Spread }_{t}+\alpha_{5} \text { Vol_r }_{t} \\
& +\alpha_{6} \text { Vol_Y }_{t}+\boldsymbol{\rho} \boldsymbol{I T}_{\boldsymbol{t}}+\varepsilon_{t}
\end{aligned}
$$




\section{ESTIMAÇÃO DO MODELO E RESULTADOS}

Neste capítulo, procedemos à estimação do modelo de demanda por moeda com fatores de risco definido no capítulo anterior. Os resultados desta estimação serão apresentados em comparação ao que denominaremos por "modelo de demanda por moeda padrão", isto é, que conta apenas com variáveis de escala e custo de oportunidade. Os resultados serão apresentados em sua forma mais simples, e algumas extensões aos mesmos, em termos de dados utilizados e modelagem das variáveis de risco distintos serão exploradas no próximo capítulo.

$\mathrm{Na}$ primeira seção deste capítulo, serão apresentados detalhes sobre os dados utilizados nas estimações, como suas definições precisas, periodicidade e fontes dos dados. A seguir, será discutida a metodologia econométrica de estimação do modelo, que consistirá no uso de modelos ARDL (Autoregressive Distributed Lags) para variáveis cointegradas. Na terceira seção, utilizaremos a metodologia apresentada para a estimação do modelo de demanda por moeda padrão, cujos resultados serão utilizados na quarta e última seção, que apresenta os resultados da estimação do modelo com variáveis de risco, com o objetivo de comparar as duas abordagens e analisar a relevância do uso deste último, o qual consiste o objeto central desta dissertação.

\subsection{Dados analisados}

Para analisarmos o efeito das variáveis de risco sobre diferentes conceitos de moeda $\boldsymbol{M}_{\boldsymbol{t}}$, serão analisados sete agregados distintos do mercado monetário dos Estados Unidos:

- $\quad M 1_{t}$, o agregado monetário de maior liquidez M1; definido pelo "Board of Governors of the Federal Reserve System" como fundos prontamente acessíveis ao gasto, constituídos por 1) depósitos à vista, 2) traveler's checks, 3) moeda exterior ao U.S. Treasury, aos Federal Reserve Banks e às outras instituições de depósito e 4) outros depósitos observáveis ("other checkable deposits" - OCDs). Os dados com ajuste sazonal são calculados pela soma de seus componentes já dessazonalizados. 
- $\quad M 1 R S_{t}$, que consiste no agregado M1 ajustado para inclusão das sweep accounts (disponibilizados a partir de 1967 por Richard Anderson e Barry Jones, através da base de dados do Federal Reserve Bank of St. Louis).

- $\quad M 2_{t}$, agregado que inclui, além de M1, depósitos a prazo de menor valor, depósitos em poupança e saldos em fundos mútuos do mercado monetário (Money Market Mutual Funds).

- $\quad D V_{t}$, definido também pelo "Board of Governors of the Federal Reserve System" como "demand deposits at commercial banks";

- $\quad P M P P_{t}$, definido pela mesma instituição como "currency component of $M I$ ";

- $\quad B M_{t}$, a base monetária ("total monetary base") no mês $t$.

- $R E S_{t}$, as reservas (balanços) totais mantidos no sistema. Os dados desta variável foram calculados a partir da definição de base monetária, da qual possuímos os valores divulgados de $B M_{t}$ e $P M P P_{t}$ :

$$
B M_{t}=\text { Reservas }_{t}+P M P P_{t}
$$

As regressões com este último agregado devem, naturalmente, ser interpretadas com cautela, visto que a demanda pelo mesmo não é diretamente controlada pelos indivíduos, e, portanto, as relações parciais com as variáveis envolvidas não seguirão a mesma lógica dos casos anteriores.

Todos os agregados monetários acima (exceto Reservas $\mathrm{t}_{\mathrm{t}}$ e $M 1 R S_{t}$,) são divulgados mensalmente pelo "Board of Governors of the Federal Reserve System", em sua base de dados H.6 - "Money Stock Measures" (exceto a base monetária, componente da base H.3 "Aggregate Reserves of Depository Institutions and the Monetary Base"). Todos os dados são ajustados para sazonalidade e divulgados em bilhões de US\$.

Para a variável de nível de preços $\boldsymbol{P}_{\boldsymbol{t}}$, foram utilizados os dados do Índice de Preços ao Consumidor para consumidores urbanos em geral (CPI), cujos dados mensais são divulgados pelo “U.S. Department of Labor: Bureau of Labor Statistics”. Os dados, com ajuste sazonal e base Jan/1982=100, foram alterados para a base Jan/2009=1 (para que utilizemos a mesma base em que os dados para o PIB real são denominados). Como indicado no capítulo anterior, todos os agregados monetários foram denotados em termos reais pela razão entre o valor nominal divulgado pela autoridade monetária e o índice de preços CPI, após alteração do ano- 
base. Para ambas as variáveis, os valores utilizados são os observados ao final do mês que compõe o trimestre ao qual representará.

A variável de taxa de juros $\boldsymbol{r}_{\boldsymbol{t}}$ utilizada foi a taxa de retorno, no mercado secundário, sobre os papéis do tesouro norte-americano com três meses de vencimento (3-month treasury bill). Os dados, em \% ao ano e em médias mensais, são divulgados pelo "Board of Governors of the Federal Reserve System" na base de dados "H.15 - Selected Interest Rates".

A variável de escala $\boldsymbol{Y}_{\boldsymbol{t}}$ utilizada no estudo é o produto interno bruto calculado pela abordagem de dispêndio ("Gross domestic product - expenditure approach"), divulgado pela base "Quarterly national accounts" da "OECD.Stat". Os dados são trimestrais, com ajuste sazonal e em milhões de US\$ a preços correntes. Antes de serem utilizados, portanto, os dados são denominados em bilhões de US\$ (assim como os agregados monetários) e em termos reais, via divisão pelo índice de preços CPI com base 2009 (cuja disponibilidade de dados é maior em relação ao deflator do PIB). Como estes são os dados de menor periodicidade a serem utilizados, todas as outras variáveis a serem utilizadas foram denominadas trimestralmente (exceto na seção 5.1), pelo seu valor ao final do período de três meses.

Para compor as variáveis de produto e de agregados monetários em termos per capita, foram usados dados do "U.S. Department of Commerce: Census Bureau" para a população total (todas as idades) dos Estados Unidos, os quais são divulgados em termos mensais sem ajuste sazonal, em milhares. As variáveis per capita são dadas, naturalmente, pela divisão entre a variável original já denominada em termos reais e a população total (após as devidas multiplicações para que as variáveis fossem denominadas em unidades).

O índice da bolsa de valores a ser utilizado no cálculo do índice de Sharpe, $\boldsymbol{S h a r p e}_{\boldsymbol{t}}$, é o "Dow Jones Industrial Average", que é componente da base "S\&P Dow Jones Indices LLC" da Standard \& Poors. Os dados foram coletados a nível mensal, a partir de 1947.

Como explorado no capítulo anterior, para a variável Spread $_{\boldsymbol{t}}$ foram utilizados três tipos distintos:

- Spread-loan, dado pela diferença entre a taxa prime de empréstimos bancários dos 25 maiores bancos em termos de ativos "bank prime loan rate" (divulgada em termos mensais na base "H.15 Selected Interest Rates" do "Board of Governors of the Federal Reserve System") e a T-Bill $\boldsymbol{r}_{\boldsymbol{t}}$ já utilizada acima. Esta série é disponível a partir de 1949.

- TED-Spread, dado pela diferença entre a taxa LIBOR (“3-Month London Interbank Offered Rate (LIBOR), based on U.S. Dollar"), divulgada pela “British Bankers' 
Association", e a T-Bill $\boldsymbol{r}_{\boldsymbol{t}}$. Esta variável de spread tem a desvantagem de ter dados disponíveis apenas a partir de 1986.

- Spread-T30, dado pela diferença entre a taxa de juros sobre papéis do tesouro com validade de 30 anos, não indexados e ajustados para maturidades constantes (“30-Year Treasury Constant Maturity Rate", divulgada em termos mensais na base "H.15 Selected Interest Rates" do "Board of Governors of the Federal Reserve System") e a T-Bill $\boldsymbol{r}_{\boldsymbol{t}}$. O cálculo dos dados para aquela taxa de juros, iniciado em 1977, foi descontinuado em Fevereiro de 2002, e reintroduzido em Fevereiro de 2006.

Os dados utilizados nas regressões abaixo correspondem ao período do primeiro trimestre de 1959 ao terceiro trimestre de 2013 (exceto para M1RS e quando indicado).

\subsection{Metodologia de estimação do modelo}

A seguir, será apresentado o procedimento econométrico geral para estimação de nosso modelo de demanda por moeda, sendo consideradas as peculiaridades empíricas envolvidas. Os modelos ARDL (Autoregressive Distributed Lags) e sua aplicação ao estudo de séries temporais cointegradas são apresentados e detalhados já tendo em vista sua aplicação a um vetor de cointegração de demanda por moeda de equilíbrio (longo prazo).

\subsubsection{Testes de raiz unitária}

Um passo inicial importante em estudos econométricos que envolvem séries temporais é a observação e teste dos dados utilizados para checagem de evidências da existência de raiz unitária nas variáveis em estudo. Tal procedimento tem sua importância derivada do fato de que o modelo de regressão clássico utiliza de hipóteses que não são satisfeitas quando do uso de variáveis não-estacionárias no modelo estimado (Hamilton, 1994).

Para testar a presença de raiz unitária nas variáveis, utilizamos o teste ADF (Augmented Dickey-Fuller), que consiste na estimação e teste estatístico, utilizando valores críticos apropriados, do coeficiente $\alpha$ na equação 4.1 (Hamilton, 1994). 


$$
\Delta y_{t}=\alpha_{0}+\beta t+\alpha y_{t-1}+\sum_{j=1}^{k} c_{j} \Delta y_{t-j}+e_{t}
$$

A Tabela 7 a seguir apresenta os p-valores do teste ADF aplicado às variáveis a serem utilizadas no presente estudo. $\mathrm{O}$ teste foi aplicado em duas variações: considerando-se a modelagem apenas com constante (i.e., com $\beta=0$ na equação (4.1)) e com constante e tendência temporal linear. As primeiras duas colunas correspondem aos p-valores dos testes aplicados às variáveis em nível, e as duas últimas colunas estão associadas aos testes aplicados à primeira diferença das variáveis (para eliminar também a possibilidade de variáveis $\mathrm{I}(2))$.

Considerando o nível de confiança padrão de 5\% (os valores que não superam este nível na tabela estão destacados com asterisco), podemos afirmar que há fortes indícios da existência de raiz unitária entre as variáveis de agregados monetários, bem como nas variáveis de escala e de custo de oportunidade. Entre as variáveis de risco, o teste evidencia haver tanto variáveis $\mathrm{I}(0)$ quanto $\mathrm{I}(1)$. A próxima seção levará em conta estes resultados para aplicarmos a correta base teórica a ser utilizada na estimação da demanda por moeda. ${ }^{24}$

Tabela 7 - Teste ADF: p-valores estimados

\begin{tabular}{ccccc}
\hline \multirow{2}{*}{ Variável/Modelo } & \multicolumn{2}{c}{ Nível } & \multicolumn{2}{c}{ 1a diferença } \\
\cline { 2 - 5 } & Const. & Tend. & Const. & Tend. \\
\hline BM_P & 1,000 & 1,000 & $0,000^{*}$ & $0,000^{*}$ \\
DV_P & 0,689 & 1,000 & $0,000^{*}$ & $0,000^{*}$ \\
M1_P & 0,999 & 0,993 & $0,000^{*}$ & $0,000^{*}$ \\
PMPP_P & 1,000 & 1,000 & $0,000^{*}$ & $0,000^{*}$ \\
RES_P & 1,000 & 1,000 & $0,000^{*}$ & $0,000^{*}$ \\
M2/P & 0,998 & 0,997 & $0,001^{*}$ & $0,002^{*}$ \\
\hline M1RS/P & 0,999 & 0,987 & $0,000^{*}$ & $0,001^{*}$ \\
\hline RGDP_Q & 0,995 & 0,459 & $0,000^{*}$ & $0,000^{*}$ \\
\hline TBILL & 0,202 & 0,515 & $0,000^{*}$ & $0,000^{*}$ \\
\hline SHARPE_DOW & $0,047^{*}$ & 0,181 & $0,000^{*}$ & $0,000^{*}$ \\
SPREAD_T30 & $0,006^{*}$ & $0,007^{*}$ & $0,000^{*}$ & $0,000^{*}$ \\
SPREAD_LOAN & $0,023^{*}$ & $0,001^{*}$ & $0,000^{*}$ & $0,000^{*}$ \\
TED_SPREAD & $0,007^{*}$ & $0,016^{*}$ & $0,000^{*}$ & $0,000^{*}$ \\
V_I & $0,007^{*}$ & $0,043^{*}$ & $0,000^{*}$ & $0,000^{*}$ \\
V_RGDP & 0,315 & 0,300 & $0,000^{*}$ & $0,000^{*}$ \\
\hline
\end{tabular}

\footnotetext{
${ }^{24}$ Os teste aplicados às variáveis per capita geraram iguais conclusões e, portanto, não serão exibidos.
} 


\subsubsection{Cointegração e equilíbrio de longo prazo}

$\mathrm{Na}$ discussão da seção 3.5, argumentamos pela seleção do seguinte modelo de demanda por moeda a ser estimado:

$$
\begin{aligned}
\ln \left(M_{t} / P_{t}\right)= & \alpha_{0}+\alpha_{1} \ln \left(Y_{t}\right)+\alpha_{2} \ln \left(r_{t}\right)+\alpha_{3} \text { Sharpe }_{t}+\alpha_{4} \text { Spread }_{t}+\alpha_{5} \text { Vol_r }_{t} \\
& +\alpha_{6} \text { Vol_Y }_{t}+\boldsymbol{\rho I T _ { \boldsymbol { t } }}+\varepsilon_{t}
\end{aligned}
$$

A equação acima é uma equação de demanda por moeda de longo prazo, pois, como visto, é esperado que ao menos as três primeiras variáveis sejam cointegradas. Os movimentos de curto prazo entre as variáveis, por sua vez, podem ser capturados por um modelo de correção de erros, que leva em consideração a dinâmica de absorção de choques entre as variáveis no sentido de retomada do equilíbrio de longo prazo.

Como visto acima, as variáveis em estudo são uma combinação de variáveis I(1) e I(0), de modo que o procedimento para cointegração mais amplamente difundido de EngleGranger não seria perfeitamente indicado para a estimação neste caso.

A abordagem de "Bounds Testing" com modelos autoregressive distributed lags (ARDL), proposta por M. Pesaran, Y. Shin \& R. Smith (2001) para o teste da existência de uma relação única de longo prazo entre um conjunto de variáveis, por outro lado, apresenta grande relevância ao caso em estudo por não exigir que se conjecture a existência ou não de raiz unitária dentre as variáveis consideradas. Em outras palavras, a metodologia é aplicável não só para o caso padrão de um conjunto de variáveis I(1), como também para um conjunto com variáveis $\mathrm{I}(0)$ e I(1), como as evidências dos testes anteriores sugerem ser nosso caso.

Nos últimos anos, muitos trabalhos empíricos com a finalidade de estimar a relação de demanda por moeda em países em desenvolvimento e/ou com adição de variáveis adicionais I(0) passaram a utilizar tal metodologia, tendo em vista esta sua maior aplicabilidade, de modo que podemos afirmar, com alguma segurança, que a aplicação de modelos ARDL à estimação da demanda por moeda já conta com posição relativamente consolidada na literatura (podemos citar como exemplos: Dritsakis (2011), Samreth (2008), Akinlo (2006), Sharifi-Renani (2007), Hossain (2012), Bahmani-Oskooee \& Ng (2002) e Baharumshah et al. (2009)). 
Para discutirmos o embasamento teórico da técnica ${ }^{25}$, em um contexto de demanda por moeda, sejam $m_{t}$ e $\boldsymbol{x}_{t}$, respectivamente, a demanda por saldos monetários reais e um vetor das séries temporais determinantes da variável anterior. Fazendo $\boldsymbol{Z}_{t}=\left[m_{t} \boldsymbol{x}_{t}\right]^{\prime}$, seja a seguinte autoregressão vetorial geradora de dados:

$$
\boldsymbol{Z}_{t}=\boldsymbol{\mu}+\boldsymbol{\delta} t+\sum_{j=1}^{p} \boldsymbol{\phi}_{j} \boldsymbol{Z}_{t-j}+\boldsymbol{\varepsilon}_{t}
$$

Em que $\boldsymbol{\phi}_{j}$ é uma matriz de parâmetros VAR, $\boldsymbol{\mu}$ e $\boldsymbol{\delta}$ são vetores de termos constantes e $t$ é o termo temporal linear. Sendo o vetor de erros $\boldsymbol{\varepsilon}_{t}=\left[\begin{array}{ll}\varepsilon_{m, t} & \boldsymbol{\varepsilon}_{\boldsymbol{x}, t}\end{array}\right]^{\prime} \sim \operatorname{IN}(\mathbf{0}, \boldsymbol{\Omega})$, em que $\boldsymbol{\Omega}$ é positiva definida, dada por:

$$
\boldsymbol{\Omega}=\left[\begin{array}{ll}
\omega_{m m} & \omega_{m x} \\
\omega_{m x} & \omega_{x \boldsymbol{x}}
\end{array}\right]
$$

De modo que podemos expressar $\varepsilon_{m, t}$ em termos de $\boldsymbol{\varepsilon}_{\boldsymbol{x}, t}$ :

$$
\varepsilon_{m, t}=\frac{\omega_{m x}}{\omega_{x x}} \varepsilon_{x, t}+u_{t}
$$

Com $u_{t} \sim \operatorname{IN}\left(0, \omega_{m m}\right)$. Manipulando a equação (4.3) de modo a expressá-la como um modelo vetorial de correção de erros:

$$
\Delta \boldsymbol{Z}_{t}=\boldsymbol{\mu}+\boldsymbol{\delta} t+\lambda \boldsymbol{Z}_{t-1}+\sum_{j=1}^{p-1} \boldsymbol{\gamma}_{\boldsymbol{j}} \Delta \boldsymbol{Z}_{t-j}+\boldsymbol{\varepsilon}_{t}
$$

Em que:

$$
\boldsymbol{\gamma}_{\boldsymbol{j}}=\left[\begin{array}{ll}
\gamma_{m m, j} & \gamma_{m x, j} \\
\gamma_{m x, j} & \gamma_{x \boldsymbol{x}, j}
\end{array}\right]=-\sum_{k=j+1}^{p} \phi_{k}
$$

E $\lambda$ é o multiplicador de longo prazo matricial dado por:

\footnotetext{
${ }^{25}$ Esta discussão se baseia em Serletis (2007) e Pesaran et al. (2001).
} 


$$
\lambda=\left[\begin{array}{cc}
\lambda_{m m} & \lambda_{m x} \\
\lambda_{x m} & \lambda_{x x}
\end{array}\right]=-\left(\boldsymbol{I}-\sum_{j=1}^{p} \phi_{j}\right)
$$

Em que $I$ é a matriz identidade. Para permitir que cada uma das séries temporais possam ser $\mathrm{I}(0)$ ou $\mathrm{I}(1)$, os elementos diagonais da matriz $\lambda$ são deixados irrestritos. $\mathrm{O}$ procedimento permite o teste da existência de uma única relação de longo prazo entre $m_{t}$ e $\boldsymbol{x}_{t}$, de modo que apenas um dos componentes $\lambda_{\boldsymbol{x} m}$ e $\lambda_{m \boldsymbol{x}}$ pode ser não nulo. Como nosso interesse atual é com relação à demanda por moeda (i.e., os efeitos de longo prazo das variáveis em $\boldsymbol{x}_{t}$ sobre a demanda por saldos monetários reais), será imposta a restrição:

$$
\lambda_{x m}=0
$$

Ou, na terminologia utilizada por Pesaran et al. (2001), as variáveis em $\boldsymbol{x}_{t}$ são longrun forcing para os saldos monetários.

Finalmente, sob a hipótese em (4.9), e utilizando (4.5), a equação de demanda por moeda de (4.6) pode ser descrita por:

$$
\Delta m_{t}=\alpha_{0}+\alpha_{1} t+\varphi m_{t-1}+\boldsymbol{\psi} \boldsymbol{x}_{t-1}+\sum_{j=1}^{p} \gamma_{j} \Delta m_{t-j}+\sum_{j=0}^{q} \beta_{\boldsymbol{x}, j} \Delta \boldsymbol{x}_{t-j}+u_{t}
$$

Em que $\alpha_{0}=\mu_{m}-\omega^{\prime} \mu_{x}, \alpha_{1}=\delta_{m}-\omega^{\prime} \delta_{x}, \varphi=\lambda_{m m}, \boldsymbol{\psi}=\lambda_{m x}-\omega^{\prime} \lambda_{x \boldsymbol{x}}$. A equação acima é um modelo de correção de erros irrestrito, que pode ser interpretado como um modelo $\operatorname{ARDL}(\mathrm{p}, \mathrm{q})$ (autoregressive distributed lags). Observe também que o modelo (4.10) pode ser estimado por mínimos quadrados ordinários (OLS).

No caso de interesse, em que $\varphi \neq 0$ e $\boldsymbol{\psi} \neq \mathbf{0}$, à equação (4.10) corresponderá uma relação estável de longo prazo entre $m_{t}$ e $\boldsymbol{x}_{t}$, dada por:

$$
m_{t}=\theta_{0}+\theta_{1} t+\boldsymbol{\theta}_{2}^{\prime} \boldsymbol{x}_{t}+v_{t}
$$

Em que $v_{t}$ é um processo estacionário de média zero. 
Para investigar a presença de uma relação de longo prazo entre as variáveis de $\boldsymbol{Z}_{t}$, portanto, o procedimento de bounds-testing consiste em um teste F padrão com as estimativas OLS obtidas para (4.10), e que constituirá um teste com a hipótese de inexistência de cointegração entre as variáveis contra a existência de cointegração entre as mesmas:

$$
\begin{aligned}
& H_{0}: \varphi=\psi_{1}=\psi_{2}=\cdots=0 ; \text { i.e., não há cointegração entre as variáveis } \\
& H_{A}: \varphi \neq \psi_{1} \neq \psi_{2} \neq \cdots \neq 0 ; \text { i.e., há cointegração entre as variáveis }
\end{aligned}
$$

Em que os valores $\left(\psi_{1}, \psi_{2}, \ldots\right)$ são os componentes do vetor $\boldsymbol{\psi}$ na representação da equação (4.10).

A distribuição da estatística F, no entanto, não é padrão, independentemente da combinação entre variáveis I(0) e I(1) utilizada (ver Pesaran et al., 1999). Os valores críticos da estatística F estão, porém, disponíveis em Pesaran \& Pesaran (1997) e Pesaran et al. (2001), os quais foram calculados pelos autores utilizando procedimento de Monte-Carlo. Os autores disponibilizam dois conjuntos de valores críticos: o primeiro calculado sob a hipótese de que todas as variáveis no modelo ARDL são I(1), e o segundo sob a hipótese de que são $\mathrm{I}(0)$. Portanto, para aplicações práticas, estes conjuntos fornecem bandas (bounds) de valores críticos que cobrirão todas as combinações entre variáveis $\mathrm{I}(0)$ e I(1) possíveis. Desse modo, se o valor $\mathrm{F}$ encontrado situa-se acima da banda superior (upper bound) de valores críticos, a hipótese nula de inexistência de cointegração é rejeitada (ao nível de significância escolhido); se o valor está abaixo da banda inferior (lower bound), a hipótese nula não deve ser rejeitada. Se o valor de F está entre os dois valores de banda, entretanto, o teste é inconclusivo.

A seguir, será descrito em termos práticos o procedimento de aplicação do arcabouço teórico descrito acima ao nosso caso de interesse de estimação da demanda por moeda com variáveis explicativas de risco incluídas.

O primeiro estágio da aplicação do procedimento consiste em testarmos a existência de uma relação de longo prazo entre as variáveis. Após checarmos, na subseção anterior, que as mesmas não são integradas de segunda ordem (i.e., não são I(2)), o primeiro passo é a formulação e estimação do Unrestricted Error Correction Model (UECM) definido pela equação (4.10). Tendo em vista as variáveis de risco em estudo, e inserindo o vetor de variáveis iteradas $\boldsymbol{I} \boldsymbol{T}_{\boldsymbol{t}-\mathbf{1}}$, o modelo apresentará a forma ARDL(p,q1,q2,..,q6) abaixo: ${ }^{26}$

\footnotetext{
${ }^{26}$ Para uma justificativa da inclusão de defasagens na especificação de curto prazo da demanda por moeda, via formação de expectativas, ver Feige (1967).
} 


$$
\begin{aligned}
\Delta \ln \left(M_{t} /_{P_{t}}\right)= & \beta_{0}+\sum_{i=1}^{p} \gamma_{0 i} \Delta \ln (M / P)_{t-i}+\sum_{j=0}^{q 1} \gamma_{1 i} \Delta(\ln (Y))_{t-j}+\sum_{j=0}^{q 2} \gamma_{2 j} \Delta(\ln (r))_{t-j} \\
& +\sum_{j=0}^{q 3} \gamma_{3 j} \Delta(\text { Sharpe })_{t-j}+\sum_{j=0}^{q 4} \gamma_{4 j} \Delta(\text { Spread })_{t-j}+\sum_{j=0}^{q 5} \gamma_{5 j} \Delta\left(\operatorname{Vol}_{\mathrm{r}}\right)_{t-j} \\
& +\sum_{j=0}^{q 6} \gamma_{6 j} \Delta\left(\operatorname{Vol}_{\mathrm{PIB}}\right)_{t-j}+\varphi \ln \left(M_{t-1} /_{P_{t-1}}\right)+\beta_{1} \ln \left(Y_{t-1}\right) \\
& +\beta_{2} \ln \left(r_{t-1}\right)+\beta_{3} \operatorname{Sharpe}_{t-1}+\beta_{4} \operatorname{Spread}_{t-1}+\beta_{5} \operatorname{Vol}(r)_{t-1} \\
& +\beta_{6} \operatorname{Vol}(\mathrm{PIB})_{t-1}+\text { pIT }_{t-1}+\varepsilon_{t}
\end{aligned}
$$

Utilizando de procedimento seguido pela literatura (ver, por exemplo, Dritsakis (2011)), inicialmente realizamos o teste F para a hipótese nula de que os coeficientes para as relações de longo prazo $\left(\beta_{i}\right.$, na representação da equação (4.13)) são iguais a 0 , para diferentes defasagens hipotéticas na equação acima. Em outras palavras, as seguintes hipóteses são testadas pelo cômputo da estatística $\mathrm{F}$ para os modelos $\operatorname{ARDL}(1,1,1,1,1,1,1)$, $\operatorname{ARDL}(2,2,2,2,2,2,2), \ldots$, etc:

$$
\begin{aligned}
& H_{0}: \beta_{1}=\beta_{2}=\beta_{3}=\beta_{4}=\beta_{5}=\beta_{6}=0 \\
& H_{A}: \beta_{1} \neq 0, \beta_{2} \neq 0, \beta_{3} \neq 0, \beta_{4} \neq 0, \beta_{5} \neq 0, \beta_{6} \neq 0
\end{aligned}
$$

O objetivo deste procedimento é confirmar a existência de uma relação de longo prazo entre as variáveis desejadas, antes que o modelo com a estrutura de defasagens mais adequada seja estimado. Caso os resultados obtidos pela aplicação do teste $\mathrm{F}$ evidenciem a hipótese de existência de cointegração entre as variáveis, passamos então à estimação do modelo ARDL adequado e à obtenção e interpretação dos coeficientes de longo prazo.

Para determinarmos o número de defasagens apropriado, efetuamos regressões OLS para os casos possíveis e selecionamos os valores de $(p, q 1 \ldots, q 6)$ que minimizam o critério de informação de Schwarz (BIC) ou Akaike (AIC) ${ }^{27}$ para cada um dos diferentes agregados monetários utilizados como variável dependente. Tendo em vista a utilização de dados trimestrais em nosso estudo, o número máximo de defasagens testadas foi de seis.

Como visto, uma das hipóteses utilizadas na derivação do modelo da equação (4.10) é de que o mesmo apresenta ausência de correlação serial nos resíduos e, portanto, é de grande 
importância que esta hipótese seja testada nas estimações a seguir. Para isso, utilizamos o teste LM de Breusch-Godfrey para correlação serial, o qual possui como hipótese nula a ausência de correlação serial de qualquer ordem igual ou menor que o parâmetro $p$ utilizado no teste.

De posse dos resultados obtidos pela estimação do modelo ARDL selecionado, podemos calcular os coeficientes para a relação de equilíbrio no longo prazo da relação de demanda por moeda da maneira a seguir. Observe que, em um equilíbrio de longo prazo, por definição, teremos:

$$
\begin{aligned}
\Delta \ln (M / P)_{t-i}= & \Delta(\ln (Y))_{t-j}=\Delta(\ln (r))_{t-j}=\Delta(\text { Sharpe })_{t-j}=\Delta(\text { Spread })_{t-j} \\
& =\Delta(\text { Vol_r })_{t-j}=\Delta(\text { Vol_PIB })_{t-j}=0 ; \quad \forall(i, j)<\infty
\end{aligned}
$$

Substituindo na equação (4.13):

$$
\begin{gathered}
\beta_{0}+\varphi \ln \left(M_{t-1} / P_{t-1}\right)+\beta_{1} \ln \left(Y_{t-1}\right)+\beta_{2} \ln \left(r_{t-1}\right)+\beta_{3} \text { Sharpe }_{t-1}+\beta_{4} \text { Spread }_{t-1} \\
+\beta_{5} \operatorname{Vol}(r)_{t-1}+\beta_{6} \operatorname{Vol}(P I B)_{t-1}+\boldsymbol{p I T}_{\boldsymbol{t}-\mathbf{1}}+\varepsilon_{t}=0
\end{gathered}
$$

E expressando-a em termos do agregado monetário:

$$
\begin{aligned}
\ln \left(M_{t-1} P_{P_{t-1}}\right) & =-\frac{\beta_{0}}{\varphi}-\frac{\beta_{1}}{\varphi} \ln \left(Y_{t-1}\right)-\frac{\beta_{2}}{\varphi} \ln \left(r_{t-1}\right)-\frac{\beta_{3}}{\varphi} \text { Sharpe }_{t-1}-\frac{\beta_{4}}{\varphi} \text { Spread }_{t-1} \\
& -\frac{\beta_{5}}{\varphi} \operatorname{Vol}(r)_{t-1}-\frac{\beta_{6}}{\varphi} \operatorname{Vol}(P I B)_{t-1}-\frac{1}{\varphi} \boldsymbol{p I T}_{\boldsymbol{t}-\mathbf{1}}+e_{t}
\end{aligned}
$$

Em que $e_{t}=-\varphi^{-1} \varepsilon_{t}$. Comparando esta relação com a equação de demanda por moeda proposta em (4.2), temos que os coeficientes estimados pela abordagem ARDL desta podem ser expressos por:

$$
\widehat{\alpha_{J}}=-\left(\frac{\widehat{\beta}_{J}}{\hat{\varphi}}\right) ; \widehat{\boldsymbol{\rho}}=-\left(\frac{1}{\hat{\varphi}}\right) \widehat{\boldsymbol{p}}
$$

Em que $j \in[0, \ldots, 6]$. Portanto, de posse das estimativas do modelo ARDL, teremos, por consequência, as estimativas de interesse da equação de demanda por moeda de longo prazo, com as quais buscaremos realizar inferências a respeito do papel das variáveis de risco: 


$$
\begin{aligned}
\ln \left(M_{t} / P_{t}\right)=\widehat{\alpha_{0}} & +\widehat{\alpha_{1}} \ln \left(Y_{t}\right)+\widehat{\alpha_{2}} \ln \left(r_{t}\right)+\widehat{\alpha_{3}} \text { Sharpe }_{t}+\widehat{\alpha_{4}} \operatorname{Spread}_{t}+\widehat{\alpha_{5}} \text { Vol }_{-} r_{t} \\
& +\widehat{\alpha_{6}} V_{\text {ol }} Y_{t}+\widehat{\boldsymbol{\rho} I T_{\boldsymbol{t}}}+e_{t}
\end{aligned}
$$

\subsubsection{Relação de curto prazo e modelo de correção de erros}

O ECM correspondente ao modelo ARDL aqui utilizado é análogo ao modelo estimado no início do procedimento (equação (4.13)), porém com as variáveis defasadas substituídas por um termo de correção de erros $E C_{t-1}$, ao que se deriva o nome de ECM restrito. Observe que, se o modelo de correção de erros representa a dinâmica de retorno a um equilíbrio de longo prazo, é esperado que o coeficiente $\theta$, associado a $E C_{t-1}$, tenha sinal negativo, e seu módulo seja menor que a unidade. Além disso, note que o coeficiente $\theta$ também pode ser interpretado como o parâmetro de velocidade de ajuste ao equilíbrio.

Representando por $E C_{t-1}$ o erro, em $t-1$, dado pela diferença entre o valor do agregado monetário observado e seu valor previsto pela equação de equilíbrio de longo prazo, isto é, dado pelo resíduo da equação (4.19) estimada por OLS:

$$
\begin{aligned}
& \widehat{E C_{t}}=\ln \left(M_{t} / P_{t}\right)-\left\{\widehat{\alpha_{0}}+\widehat{\alpha_{1}} \ln \left(Y_{t}\right)+\widehat{\alpha_{2}} \ln \left(r_{t}\right)+\widehat{\alpha_{3}} \text { Sharpe }_{t}+\widehat{\alpha_{4}} \text { Spread }_{t}\right. \\
& \left.+\widehat{\alpha_{5}} V o l_{r_{t}}+\widehat{\alpha_{6}} V o l_{Y_{t}}+\widehat{\boldsymbol{\rho} I T_{t}}\right\}
\end{aligned}
$$

O modelo de correção de erros correspondente ao modelo (4.2) estimado será dado por:

$$
\begin{aligned}
\Delta\left(M_{t} / P_{t}\right)=\beta_{0} & +\sum_{i=1}^{p} \gamma_{0 i} \Delta(M / P)_{t-i}+\sum_{j=0}^{q 1} \gamma_{1 i} \Delta(\ln (Y))_{t-j}+\sum_{j=0}^{q 2} \gamma_{2 j} \Delta(\ln (r))_{t-j} \\
& +\sum_{j=0}^{q 3} \gamma_{3 j} \Delta(\text { Sharpe })_{t-j}+\sum_{j=0}^{q 4} \gamma_{4 j} \Delta(\text { Spread })_{t-j} \\
& +\sum_{j=0}^{q 5} \gamma_{5 j} \Delta(\text { Vol_r })_{t-j}+\sum_{j=0}^{q 6} \gamma_{6 j} \Delta(\text { Vol_PIB })_{t-j}+\theta \widehat{E C_{t-1}}+u_{t}
\end{aligned}
$$




\subsection{Resultados: demanda por moeda padrão}

Como exemplo de aplicação da metodologia acima, e com o intuito de realizar comparações com os modelos com variáveis de risco, procedemos a seguir à estimação de um modelo "padrão" de demanda pelo agregado monetário M1 (i.e., apenas com variáveis de escala e custo de oportunidade) para os EUA. A equação de longo prazo, seguindo a forma funcional utilizada até aqui, pode ser escrita como:

$$
\ln \left(M_{t} / P_{t}\right)=\alpha_{0}+\alpha_{1} \ln \left(Y_{t}\right)+\alpha_{2} \ln \left(r_{t}\right)+\varepsilon_{t}
$$

Prosseguindo à aplicação do primeiro passo do procedimento, descrito na seção anterior, a função de demanda por moeda especificada pode, por sua vez, ser representada como o modelo de correção de erros não-restrito na forma ARDL abaixo:

$$
\begin{aligned}
\Delta \ln \left(M_{t} / P_{t}\right)= & \beta_{0}+\sum_{i=1}^{p} \gamma_{0 i} \Delta \ln (M / P)_{t-i}+\sum_{j=0}^{q 1} \gamma_{1 i} \Delta(\ln (Y))_{t-j}+\sum_{j=0}^{q 2} \gamma_{2 j} \Delta(\ln (r))_{t-j} \\
& +\varphi \ln \left(M_{t-1} / P_{t-1}\right)+\beta_{1} \ln \left(Y_{t-1}\right)+\beta_{2} \ln \left(r_{t-1}\right)+\varepsilon_{t}
\end{aligned}
$$

Para testarmos a existência de uma relação de longo prazo entre as variáveis, a Tabela 8 , abaixo, exibe os valores do teste $\mathrm{F}\left(\varphi=\beta_{1}=\beta_{2}=0\right.$ ) para o modelo acima estimado, com até seis defasagens.

Tabela 8 - Valores do teste F com diferentes defasagens no modelo ARDL padrão - M1

\begin{tabular}{ccccccc}
\hline Lags & $\mathbf{1}$ & $\mathbf{2}$ & $\mathbf{3}$ & $\mathbf{4}$ & $\mathbf{5}$ & $\mathbf{6}$ \\
\hline & $8,18^{*}$ & 3,87 & 3,26 & 3,54 & 2,53 & 2,2 \\
\hline
\end{tabular}

Intervalo de valores críticos relevantes (intercepto irrestrito e sem tendência, com dois regressores, $\mathrm{k}=2):[3,17 ; 4,14]$ a $90 \%$ de confiança; $[3,79 ; 4,85]$ a $95 \%$; e $[4,41 ; 5,52]$ a $99 \%$. ***, **, * indicam valores significativos, respectivamente, a 90\%, 95\% e 99\%. (ver Tabela CI, Pesaran et al.(2001))

Portanto, o procedimento de bounds-testing utilizado rejeita a hipótese nula de ausência de relação de longo prazo entre as variáveis ao menos para a relação com um nível de defasagem para as variáveis do modelo. 
O número de defasagens adequado à estimação do modelo, por sua vez, selecionado simultaneamente pelos critérios de seleção AIC e BIC, é o modelo ARDL(2,0,0) seguinte:

$$
\begin{aligned}
\Delta \ln \left(M_{t} / P_{t}\right)= & \beta_{0}+\gamma_{01} \Delta \ln (M / P)_{t-1}+\gamma_{02} \Delta \ln (M / P)_{t-2}+\gamma_{10} \Delta(\ln (Y))_{t} \\
& +\gamma_{20} \Delta(\ln (r))_{t}+\varphi \ln \left(M_{t-1} /_{P_{t-1}}\right)+\beta_{1} \ln \left(Y_{t-1}\right)+\beta_{2} \ln \left(r_{t-1}\right)+\varepsilon_{t}
\end{aligned}
$$

A estimação do modelo acima retorna os seguintes resultados:

\begin{tabular}{|c|c|c|c|c|}
\hline \multicolumn{5}{|c|}{ A: Coeficientes de longo-prazo } \\
\hline & & Constante & $\ln (Y)$ & $\ln (r)$ \\
\hline & Coef. * & 4,4872 & 0,2874 & $-0,1294$ \\
\hline & Teste $\mathrm{t}$ & 2,61 & 2,12 & $-3,79$ \\
\hline & P-valor & $0,010^{*}$ & $0,035^{*}$ & $0,000 *$ \\
\hline \multicolumn{5}{|c|}{ B: Coeficientes de curto-prazo } \\
\hline Lag & & $\Delta(\ln (M / P))$ & $\Delta \ln (Y)$ & $\Delta \ln (r)$ \\
\hline \multirow[t]{2}{*}{0} & & & 0,3654 & $-0,0240$ \\
\hline & Teste $\mathrm{t}$ & & 3,64 & $-10,52$ \\
\hline \multirow[t]{2}{*}{1} & & 0,1775 & & \\
\hline & Teste $\mathrm{t}$ & 3,12 & & \\
\hline \multirow[t]{2}{*}{2} & & 0,2676 & & \\
\hline & Teste $\mathrm{t}$ & 4,77 & & \\
\hline \multicolumn{5}{|c|}{ C: Testes } \\
\hline \multicolumn{2}{|c|}{$\chi_{B G}^{2}(2)^{* *}:$} & 1,415 & \multicolumn{2}{|c|}{ (p-valor: 0,493$)$} \\
\hline
\end{tabular}

Tabela 9 - Resultados: Estimação do modelo ARDL(2,0,0)

De posse dos resultados exibidos na Tabela 9, acima, podemos, portanto, exibir a seguinte relação de longo prazo:

$$
\ln \left(M_{t} / P_{t}\right)=4,4872+0,2874 * \ln \left(Y_{t}\right)-0,1294 * \ln \left(r_{t}\right)+\widehat{\varepsilon_{t}}
$$

Observe que a relação de demanda por moeda de longo prazo nos EUA obtida possui coeficientes significativos e com o sinal esperado. De posse desta relação, obtemos os valores 
dos resíduos $\widehat{\varepsilon_{t}}$, os quais utilizaremos como o termo $\widehat{E C}_{t}$ na estimação do modelo de correção de erros restrito a seguir:

$$
\Delta \ln \left(M_{t} / P_{t}\right)=\beta_{0}+\sum_{i=1}^{2} \gamma_{0 i} \Delta \ln (M / P)_{t-i}+\gamma_{10} \Delta(\ln (Y))_{t}+\gamma_{20} \Delta(\ln (r))_{t}+\theta \widetilde{E C_{t-1}}+u_{t}
$$

Efetuando a estimação, via OLS, do modelo de correção de erros acima, obtemos os seguintes resultados:

\begin{tabular}{|c|c|c|c|}
\hline Regressor & Coeficiente & $\begin{array}{c}\text { Erro } \\
\text { padrão }\end{array}$ & p-valor \\
\hline$\widehat{E C_{t-1}}$ & $-0,0315$ & 0,0079 & $0,000^{*}$ \\
\hline$\Delta \ln (M / P)_{t-1}$ & 0,1775 & 0,0549 & $0,001^{*}$ \\
\hline$\Delta \ln (M / P)_{t-2}$ & 0,2676 & 0,0537 & $0,000^{*}$ \\
\hline$\Delta(\ln (\boldsymbol{Y}))_{t}$ & 0,3654 & 0,0973 & $0,000 *$ \\
\hline$\Delta(\ln (\boldsymbol{r}))_{t}$ & $-0,0240$ & 0,0023 & $0,000^{*}$ \\
\hline Intercepto & 0,0000 & 0,0011 & 1,000 \\
\hline$\overline{R^{2}}$ : & 0,4861 & & \\
\hline$\chi_{B G}^{2}(2):$ & 1,407 & & 0,495 \\
\hline
\end{tabular}

*Em que $\overline{\boldsymbol{R}^{2}}$ é o coeficiente R-quadrado ajustado da estimação

Observando-se os resultados obtidos, vemos que o coeficiente associado ao termo de correção de erros defasado é negativo e significativo, a 95\% de confiança; o que constitui mais um forte indicativo de cointegração entre as variáveis ${ }^{28}$. Seu valor, entretanto, indica uma relativamente lenta dinâmica de retorno ao equilíbrio de longo prazo em resposta a choques de curto-prazo: apenas 3,15\% dos desequilíbrios causados por choques no período anterior convergem novamente ao equilíbrio de longo-prazo no período posterior. De modo geral, portanto, podemos afirmar que a aplicação do procedimento ARDL proposto para análise de cointegração obteve resultados satisfatórios.

\footnotetext{
${ }^{28}$ Segundo Kremers et al.(1992) um termo de correção de erros significativo é um modo bastante eficiente de estabelecer uma relação de cointegração.
} 
A seguir, reproduzimos o procedimento acima para os outros seis agregados monetários de interesse, representados pelas siglas apresentadas na seção 4.1 (M2, M1RS, DV, PMPP, RES e BM).

As estruturas de defasagens escolhidas pela minimização dos critérios BIC e AIC estão apresentadas na Tabela 12 a seguir. A Tabela 13, por sua vez, contém os coeficientes estimados para os modelos ARDL selecionados pelo critério BIC para cada agregado monetário, apresentados na tabela anterior. O painel A exibe os coeficientes de maior interesse, correspondentes à relação de equilíbrio de longo prazo da demanda por moeda. Os coeficientes significativos (a 5\%) são destacados com asterisco, e o termo $M$ representa o agregado monetário utilizado (em termos reais) em cada modelo.

Tabela 11 - Teste F (“bounds-testing”): modelo padrão

\begin{tabular}{lcccccc}
\hline \multicolumn{1}{r}{ Lags } & $\mathbf{1}$ & $\mathbf{2}$ & $\mathbf{3}$ & $\mathbf{4}$ & $\mathbf{5}$ & $\mathbf{6}$ \\
\hline M1RS & $8,736^{*}$ & $6,430^{*}$ & $4,250^{* * *}$ & $4,227^{* * *}$ & 2,922 & 2,333 \\
M2 & 3,579 & 3,321 & 3,295 & 2,967 & 2,368 & 2,474 \\
DV & $15,16^{*}$ & $6,48^{*}$ & $5,12^{* *}$ & $7,53^{*}$ & $5,38^{* *}$ & 3,65 \\
PMPP & $10,14^{*}$ & $6,37^{*}$ & $4,97^{* *}$ & $6,92^{*}$ & $4,88^{* *}$ & $4,26^{* * *}$ \\
BM & $9,97^{*}$ & $10,50^{*}$ & $11,01^{*}$ & $7,44^{*}$ & $6,18^{*}$ & $4,87^{* *}$ \\
RES & $4,19^{* * *}$ & 3,46 & 2,96 & 2,63 & 1,71 & 1,28 \\
\hline
\end{tabular}

Intervalo de valores críticos relevantes (intercepto irrestrito e sem tendência, com dois regressores, $\mathrm{k}=2):[3,17 ; 4,14]$ a $90 \%$ de confiança; $[3,79 ; 4,85]$ a $95 \%$; e $[4,41 ; 5,52]$ a $99 \%$. *,**, *** indicam valores significativos, respectivamente, a 99\%, 95\% e 90\%. (ver Tabela CI, Pesaran et al.(2001))

Tabela 12 - Defasagens selecionadas: modelo padrão

\begin{tabular}{lcc}
\hline & BIC & AIC \\
\hline M1 & $\operatorname{ARDL}(2,0,0)$ & $\operatorname{ARDL}(2,0,0)$ \\
M1RS & $\operatorname{ARDL}(3,0,0)$ & $\operatorname{ARDL}(3,5,1)$ \\
M2 & $\operatorname{ARDL}(1,0,0)$ & $\operatorname{ARDL}(1,0,0)$ \\
DV & $\operatorname{ARDL}(2,0,0)$ & $\operatorname{ARDL}(2,0,0)$ \\
PMPP & $\operatorname{ARDL}(1,0,0)$ & $\operatorname{ARDL}(1,0,1)$ \\
RES & $\operatorname{ARDL}(4,0,4)$ & $\operatorname{ARDL}(5,0,5)$ \\
BM & $\operatorname{ARDL}(4,5,4)$ & $\operatorname{ARDL}(4,5,4)$ \\
\hline
\end{tabular}


Tabela 13 - Coeficientes estimados para os modelos ARDL selecionados

\begin{tabular}{|c|c|c|c|c|c|c|}
\hline Agregado M: & M1RS & $\mathrm{M2}$ & DV & PMPP & BM & RES \\
\hline \multicolumn{7}{|c|}{ Painel A: Coeficientes de longo prazo } \\
\hline Constante & 1,0240 & $2,5625^{*}$ & 13,8010 & $-3,4869 *$ & 0,2642 & 6,6541 \\
\hline $\ln (Y)$ & $0,7606^{*}$ & $0,7407 *$ & $-1,3784$ & 1,1929* & $0,6646^{*}$ & $-0,5405$ \\
\hline $\ln (r)$ & $-0,1104^{*}$ & $-0,0779 *$ & $-0,8323 *$ & $-0,1491^{*}$ & $-0,2984 *$ & $-0,7222 *$ \\
\hline \multicolumn{7}{|c|}{ Painel B: Coeficientes de curto prazo } \\
\hline$\Delta(\ln (M))_{t-1}$ & $0,2081^{*}$ & $0,4502 *$ & $-0,0582$ & $0,3816^{*}$ & $0,176^{*}$ & $0,172^{*}$ \\
\hline$\Delta(\ln (M))_{t-2}$ & $0,1683^{*}$ & & 0,2078 & & $-0,049$ & $-0,047$ \\
\hline$\Delta(\ln (M))_{t-3}$ & 0,0902 & & & & $-0,214^{*}$ & $-0,232 *$ \\
\hline$\Delta(\ln (M))_{t-4}$ & & & & & $0,417^{*}$ & $0,383^{*}$ \\
\hline$\Delta(\ln (M))_{t-5}$ & & & & & $-0,054$ & $-0,175^{*}$ \\
\hline$\Delta(\ln (M))_{t-6}$ & & & & & $-0,041$ & \\
\hline$\Delta(\ln (Y))_{t}$ & $0,3980^{*}$ & $0,2989 *$ & 0,4095 & $0,2691^{*}$ & 0,403 & 0,425 \\
\hline$\Delta(\ln (Y))_{t-1}$ & & & & & $-0,272$ & \\
\hline$\Delta(\ln (Y))_{t-2}$ & & & & & 0,288 & \\
\hline$\Delta(\ln (Y))_{t-3}$ & & & & & 0,060 & \\
\hline$\Delta(\ln (Y))_{t-4}$ & & & & & $-0,576^{*}$ & \\
\hline$\Delta(\ln (Y))_{t-5}$ & & & & & 0,388 & \\
\hline$\Delta(\ln (\boldsymbol{r}))_{t}$ & $-0,0164^{*}$ & $-0,0147^{*}$ & $-0,0616^{*}$ & $-0,0097^{*}$ & $-0,094^{*}$ & $-0,248 *$ \\
\hline$\Delta(\ln (r))_{t-1}$ & & & & & 0,005 & $-0,005$ \\
\hline$\Delta(\ln (\boldsymbol{r}))_{t-2}$ & & & & & 0,014 & $-0,018$ \\
\hline$\Delta(\ln (r))_{t-3}$ & & & & & $-0,021 *$ & $-0,098^{*}$ \\
\hline$\Delta(\ln (\boldsymbol{r}))_{t-4}$ & & & & & $0,047^{*}$ & 0,091* \\
\hline$\Delta(\ln (r))_{t-5}$ & & & & & & $-0,075^{*}$ \\
\hline \multicolumn{7}{|c|}{ Painel C: Estatísticas relevantes } \\
\hline$\chi_{B G}^{2}(2)$ & 1,128 & 1,682 & 0,882 & 1,964 & 3,633 & 3,265 \\
\hline p-valor & 0,569 & 0,431 & 0,643 & 0,375 & 0,163 & 0,195 \\
\hline$\overline{R^{2}}$ & 0,449 & 0,469 & 0,467 & 0,456 & 0,599 & 0,502 \\
\hline \multicolumn{7}{|c|}{ Painel D: Modelos de correção de erros associados } \\
\hline$\widehat{E C_{t-1}}$ & $-0,0362$ & $-0,0246$ & $-0,0121$ & $-0,0140$ & $-0,122$ & $-0,048$ \\
\hline Teste $t$ & $-3,98$ & $-3,01$ & $-4,51$ & $-5,98$ & $-4,92$ & $-2,39$ \\
\hline p-valor & $0,000 *$ & $0,003 *$ & $0,000 *$ & $0,000 *$ & $0,000 *$ & $0,018^{*}$ \\
\hline$\overline{R^{2}}$ & 0,456 & 0,474 & 0,472 & 0,461 & 0,603 & 0,507 \\
\hline$\chi_{B G}^{2}(2)$ & 1,126 & 1,652 & 0,861 & 1,958 & 3,370 & 3,142 \\
\hline p-valor & 0,569 & 0,438 & 0,650 & 0,376 & 0,185 & 0,208 \\
\hline
\end{tabular}

De modo geral, os resultados acima apresentam um ajuste bastante favorável e com valores dentro do esperado. Vale destacar a elasticidade-renda próxima a 0,75 e a elasticidade-juros próxima a 0,10 obtidas para M2 e M1RS. Para os agregados DV e RES encontramos estimativas negativas (porém não significativas a 95\% de confiança) para a elasticidade-renda, o que também ocorrerá em algumas estimativas com variáveis de risco. Com relação aos modelos de correção de erros (restritos), todos os modelos apresentaram 
coeficientes associados ao termo de erro significativos (a 5\%), negativos e de baixo valor absoluto, refletindo a dinâmica de absorção de choques, em termos trimestrais, implícita no modelo. O modelo com agregado BM apresenta a absorção de desvios da relação de equilíbrio mais rápida: cerca de $12,2 \%$ dos mesmos convergem ao equilíbrio de longo prazo no período seguinte.

Em face ao objetivo central deste trabalho, de observarmos eventuais efeitos de variáveis de risco sobre a demanda por moeda, podemos argumentar também em favor do uso das variáveis de produto e de agregados monetários denominados em termos per capita. $\mathrm{O}$ argumento relacionado é de que, como a formação de expectativas e, de modo geral, a percepção de risco, se dá em termos individuais, as variáveis consideradas (porque de interesse direto) pelo indivíduo nesse processo são aquelas denominadas em termos per capita; i.e., o produto per capita e a demanda per capita de determinado agregado monetário. Observe que, com relação às variáveis de risco, por representarem a percepção de risco no ambiente econômico geral, seu uso na relação de demanda por moeda em análise permanece sendo em termos agregados ${ }^{29}$. Tendo em vista o exposto, e com o objetivo de nas próximas seções utilizarmos os resultados para análises comparativas, realizaremos a seguir a estimação do modelo padrão denominado por:

$$
\ln \left(m_{t} / p_{t}\right)=\alpha_{0}+\alpha_{1} \ln \left(y_{t}\right)+\alpha_{2} \ln \left(r_{t}\right)+\varepsilon_{t}
$$

Em que as variáveis em letras minúsculas representam as mesmas variáveis utilizadas nas regressões acima, porém dadas em termos per capita.

Procedendo à realização de novas estimações para o modelo per capita, temos, nas tabelas abaixo, os resultados dos testes $F$ para cointegração e as estruturas de defasagens selecionadas para cada agregado monetário, desta vez denominado em termos per capita.

A Tabela 16 exibe os resultados encontrados na estimação. As principais diferenças com relação aos resultados anteriores ficam por conta da elasticidade-renda, agora negativa para o agregado M1 per capita e assumindo valores menores para M2 e M1RS per capita.

\footnotetext{
29 Observe, portanto, que apesar de estar sendo proposto o uso do PIB em termos per capita no modelo, os valores da variável de volatilidade do produto permanecem sendo determinados pela variável de produto agregado, já que nosso interesse é a obtenção de uma variável que represente o risco no ambiente econômico geral. Ver Seção 3.4.
} 
Tabela 14 - Teste F ("bounds-testing"): modelo padrão com variáveis per capita

\begin{tabular}{lcccccc}
\hline \multicolumn{1}{c}{ Lags } & $\mathbf{1}$ & $\mathbf{2}$ & $\mathbf{3}$ & $\mathbf{4}$ & $\mathbf{5}$ & $\mathbf{6}$ \\
\hline M1 & $8,07^{*}$ & 3,79 & 3,26 & 3,52 & 2,60 & 2,21 \\
M2 & 2,52 & 2,37 & 2,67 & 3,25 & 3,36 & 2,86 \\
M1RS & $6,13^{*}$ & 3,56 & 2,91 & 2,9 & 2,31 & 2,16 \\
DV & $14,85^{*}$ & $6,18^{*}$ & $4,82^{* * *}$ & $7,18^{*}$ & $5,2 * *$ & 3,45 \\
PMPP & $8,6^{*}$ & $6,23^{*}$ & $5,45^{* *}$ & $6,56^{*}$ & $4,62^{* * *}$ & 3,85 \\
BM & $9,74^{*}$ & $10,22^{*}$ & $10,76^{*}$ & $6,95^{*}$ & $5,85^{*}$ & $4,68^{* * *}$ \\
RES & 3,79 & 3,11 & 2,74 & 2,2 & 1,5 & 1,14 \\
\hline
\end{tabular}

Intervalo de valores críticos relevantes (intercepto irrestrito e sem tendência, com dois regressores, $\mathrm{k}=2):[3,17 ; 4,14]$ a $90 \%$ de confiança; $[3,79 ; 4,85]$ a $95 \%$; e $[4,41 ; 5,52]$ a $99 \%$. *,**, *** indicam valores significativos, respectivamente, a 99\%, 95\% e 90\%. (ver Tabela CI, Pesaran et al.(2001))

Tabela 15 - Defasagens selecionadas: modelo padrão com variáveis per capita

\begin{tabular}{lcc}
\hline & BIC & AIC \\
\hline M1 & ARDL $(2,0,0)$ & $\operatorname{ARDL}(2,0,0)$ \\
M2 & $\operatorname{ARDL}(1,0,0)$ & $\operatorname{ARDL}(1,0,1)$ \\
M1RS & $\operatorname{ARDL}(1,0,0)$ & $\operatorname{ARDL}(2,0,1)$ \\
DV & $\operatorname{ARDL}(2,0,0)$ & $\operatorname{ARDL}(2,0,0)$ \\
PMPP & $\operatorname{ARDL}(1,0,0)$ & $\operatorname{ARDL}(1,0,1)$ \\
BM & $\operatorname{ARDL}(4,0,4)$ & $\operatorname{ARDL}(4,0,4)$ \\
RES & ARDL $(4,0,4)$ & $\operatorname{ARDL}(5,0,6)$ \\
\hline
\end{tabular}

Tabela 16 - Resultados: modelo padrão com variáveis per capita

\begin{tabular}{|c|c|c|c|c|c|c|c|}
\hline Agregado $\mathrm{M}$ : & M1 & M2 & M1RS & DV & PMPP & BM & RES \\
\hline \multicolumn{8}{|c|}{ Painel A: Coeficientes de longo prazo } \\
\hline Constante & $9,703^{*}$ & $4,511^{*}$ & 2,975 & 34,400 & $-5,951 *$ & $2,553^{*}$ & 16,390 \\
\hline $\ln (Y)$ & $-0,174$ & 0,564 & $0,582^{*}$ & $-3,508$ & $1,422^{*}$ & $0,466^{*}$ & $-1,370$ \\
\hline $\ln (r)$ & $-0,120 *$ & $-0,078 *$ & $-0,113^{*}$ & $-1,338 *$ & $-0,161^{*}$ & $-0,294^{*}$ & $-0,702$ \\
\hline \multicolumn{8}{|c|}{ Painel B: Coeficientes de curto prazo } \\
\hline$\Delta(\ln (M))_{t-1}$ & $0,181^{*}$ & $0,451^{*}$ & $0,184^{*}$ & $-0,056$ & $0,348^{*}$ & $0,160 *$ & $0,154^{*}$ \\
\hline$\Delta(\ln (M))_{t-2}$ & $0,273^{*}$ & & $0,227^{*}$ & $0,210^{*}$ & & $-0,049$ & $-0,055$ \\
\hline$\Delta(\ln (M))_{t-3}$ & & & & & & $-0,215^{*}$ & $-0,250 *$ \\
\hline$\Delta(\ln (M))_{t-4}$ & & & & & & $0,409 *$ & $0,369 *$ \\
\hline$\Delta(\ln (M))_{t-5}$ & & & & & & $-0,049$ & $-0,189 *$ \\
\hline$\Delta(\ln (M))_{t-6}$ & & & & & & $-0,037$ & \\
\hline$\Delta(\ln (Y))_{t}$ & $0,358^{*}$ & $0,305^{*}$ & $0,403 *$ & $0,412^{*}$ & $0,328^{*}$ & 0,342 & 0,426 \\
\hline \multicolumn{8}{|l|}{$\Delta(\ln (Y))_{t-1}$} \\
\hline \multicolumn{8}{|l|}{$\Delta(\ln (Y))_{t-2}$} \\
\hline \multicolumn{8}{|l|}{$\Delta(\ln (Y))_{t-3}$} \\
\hline \multicolumn{8}{|l|}{$\Delta(\ln (Y))_{t-4}$} \\
\hline$\Delta(\ln (Y))_{t-5}$ & & & & & & & \\
\hline
\end{tabular}




\begin{tabular}{|c|c|c|c|c|c|c|c|}
\hline Agregado M: & M1 & M2 & M1RS & DV & PMPP & BM & RES \\
\hline$\Delta(\ln (\boldsymbol{r}))_{t}$ & $-0,024^{*}$ & $-0,015^{*}$ & $-0,017^{*}$ & $-0,061^{*}$ & $-0,010^{*}$ & $-0,093 *$ & $-0,248^{*}$ \\
\hline$\Delta(\ln (r))_{t-1}$ & & & $-0,004$ & & & 0,002 & $-0,019$ \\
\hline$\Delta(\ln (\boldsymbol{r}))_{t-2}$ & & & & & & 0,013 & $-0,022$ \\
\hline$\Delta(\ln (r))_{t-3}$ & & & & & & $-0,023 *$ & $-0,107 *$ \\
\hline$\Delta(\ln (r))_{t-4}$ & & & & & & $0,046^{*}$ & $0,079 *$ \\
\hline$\Delta(\ln (r))_{t-5}$ & & & & & & & $-0,088^{*}$ \\
\hline$\Delta(\ln (r))_{t-6}$ & & & & & & & $-0,037$ \\
\hline \multicolumn{8}{|c|}{ Painel C: Estatísticas relevantes } \\
\hline$\overline{R^{2}}$ & 0,487 & 0,470 & 0,456 & 0,466 & 0,439 & 0,595 & 0,504 \\
\hline$\chi_{B G}^{2}(2)$ & 1,592 & 1,792 & 1,418 & 0,675 & 1,764 & 3,686 & 1,191 \\
\hline p-valor & 0,451 & 0,408 & 0,492 & 0,714 & 0,414 & 0,158 & 0,551 \\
\hline \multicolumn{8}{|c|}{ Painel D: Modelos de correção de erros associados } \\
\hline$\widehat{E C_{t-1}}$ & $-0,029$ & $-0,022$ & $-0,032$ & $-0,007$ & $-0,014$ & $-0,114$ & $-0,036$ \\
\hline Teste $\mathrm{t}$ & $-3,971$ & $-2,975$ & $-3,609$ & $-4,400$ & $-5,515$ & $-4,841$ & $-1,919$ \\
\hline p-valor & $0,000 *$ & $0,003^{*}$ & $0,000 *$ & $0,000 *$ & $0,000^{*}$ & $0,000^{*}$ & 0,056 \\
\hline$\overline{R^{2}}$ & 0,492 & 0,475 & 0,463 & 0,471 & 0,443 & 0,599 & 0,509 \\
\hline$\chi_{B G}^{2}(2)$ & 1,58 & 1,752 & 1,412 & 0,663 & 1,757 & 3,545 & 1,112 \\
\hline p-valor & 0,454 & 0,416 & 0,494 & 0,718 & 0,415 & 0,170 & 0,574 \\
\hline
\end{tabular}

\subsection{Resultados: demanda por moeda com fatores de risco}

Nesta seção, apresentaremos os resultados obtidos pela regressão, com a metodologia explicitada acima, do modelo de demanda por moeda com variáveis de risco. Como vimos no capítulo 2, alguns autores propõem que o resultado insatisfatório da estimação da demanda por moeda nas últimas décadas poderia ser corrigido (ou melhorado) por meio da adição de variáveis de risco/incerteza selecionadas. Assim, a título introdutório, a Figura 14 abaixo exibe a evolução temporal das variáveis de risco a serem usadas, em comparação com os valores do termo de erro estimados acima para a demanda por moeda agregada em sua forma padrão.

\subsubsection{Abordagem de "bounds-testing" para cointegração}

Como primeiro passo para a estimação do modelo dado pela equação (4.2), a Tabela 17 a seguir apresenta os valores obtidos para o teste F ("bounds-testing"), utilizando-se até cinco defasagens, para os diferentes agregados monetários sob análise. 


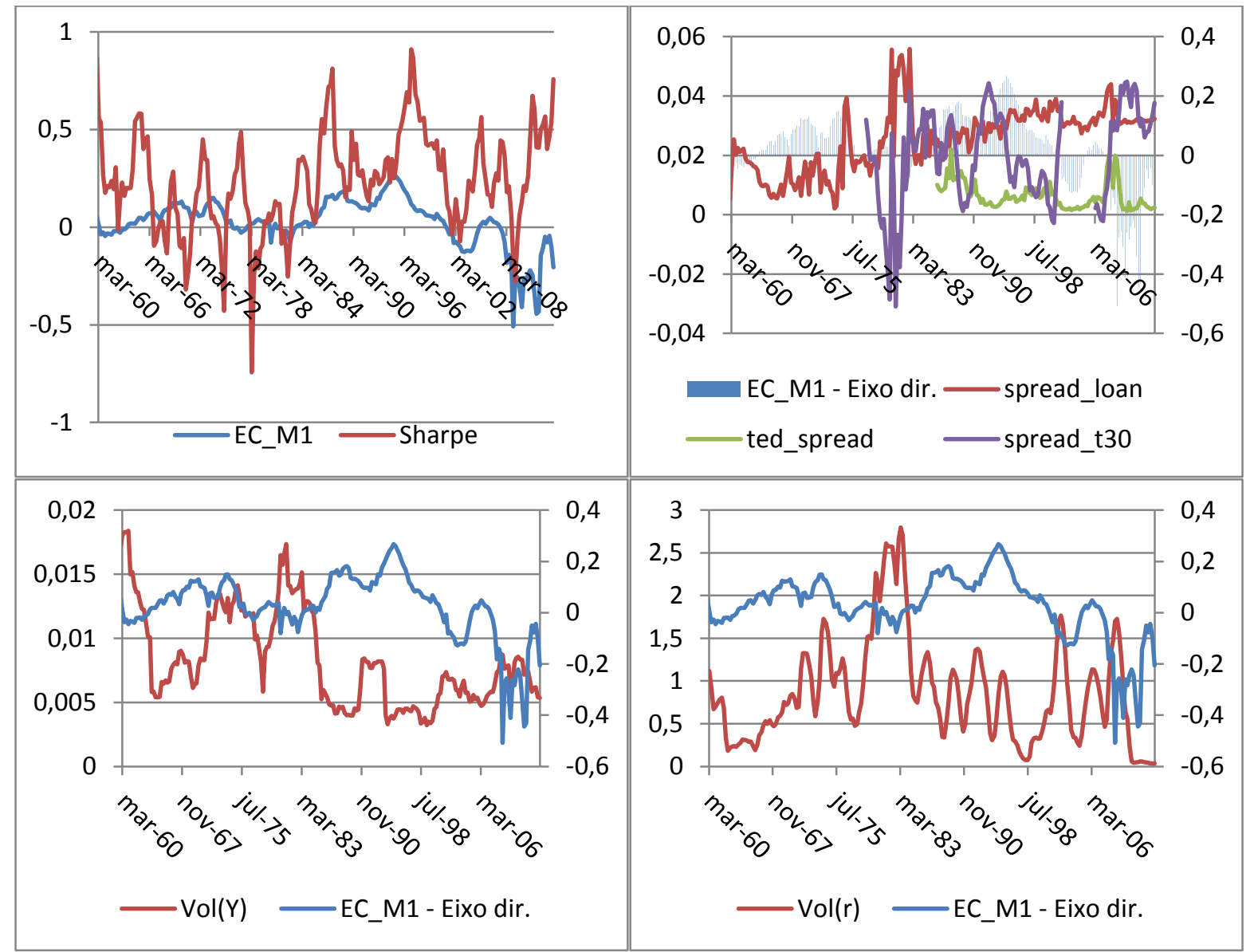

Figura 14 - Termo de erro do modelo padrão para M1 e variáveis de risco

Tabela 17 - Teste F ("bounds-testing"): modelo com variáveis de risco

\begin{tabular}{lccccc}
\hline Lags & $\mathbf{1}$ & $\mathbf{2}$ & $\mathbf{3}$ & $\mathbf{4}$ & $\mathbf{5}$ \\
\hline M1 & $3,59^{* * *}$ & 1,67 & 1,44 & 1,52 & 0,99 \\
M2 & 1,88 & 1,53 & 2,20 & 1,74 & 2,38 \\
\hline M1RS & 2,62 & 1,66 & 1,81 & 1,51 & 1,01 \\
DV & $6,51^{*}$ & 2,96 & 2,29 & 3,00 & 1,90 \\
\hline PMPP & $4,07^{* *}$ & $3,35^{* * *}$ & $3,76^{* *}$ & $4,33^{* *}$ & 2,76 \\
BM & $4,57^{*}$ & $5,15^{*}$ & $6,03^{*}$ & $4,73^{*}$ & $3,25^{* * *}$ \\
\hline RES & 2,90 & 2,38 & 2,07 & 1,52 & 1,33
\end{tabular}

*Intervalo de valores críticos relevantes (intercepto irrestrito e sem tendência, com seis regressores, $\mathrm{k}=6)$ : $(2,12$; 3,23), a 90\% de confiança***; $(2,45 ; 3,61)$, a 95\% de confiança**, e $(3,15 ; 4,43)$, a 99\% de confiança*. (ver Tabela CI(iii), Pesaran et al.(2001))

Da observação dos valores acima, vemos que, exceto pelos agregados de reservas totais, M2 e M1RS, os modelos ARDL apresentam indícios de cointegração, a 95\% de 
confiança (o teste $\mathrm{F}$ para o agregado $\mathrm{M} 1$ apresenta valor próximo ao valor crítico correspondente à situação em que todas as variáveis são I(1), o que, por não esperarmos ser o caso, também pode ser interpretado como indício de cointegração). A ausência de cointegração nos modelos com reservas totais, M2 ou M1RS como variável dependente será testada novamente, porém, pelo correspondente modelo de correção de erros. A Tabela 18 contém os resultados, semelhantes aos acima, para os modelos com variáveis de risco e denominado em termos per capita.

Tabela 18 - Teste F ("bounds-testing"): modelo com risco e com variáveis per capita

\begin{tabular}{lcccccc}
\hline Lags & $\mathbf{1}$ & $\mathbf{2}$ & $\mathbf{3}$ & $\mathbf{4}$ & $\mathbf{5}$ & $\mathbf{6}$ \\
\hline M1 & $3,607^{* * *}$ & 1,600 & 1,363 & 1,480 & 0,974 & 0,931 \\
M2 & 1,744 & 1,474 & 2,140 & 1,660 & 2,289 & 2,371 \\
M1RS & 2,860 & 1,791 & 1,909 & 1,630 & 1,071 & 0,931 \\
DV & $6,529^{*}$ & 2,886 & 2,233 & 2,999 & 1,900 & 1,451 \\
PMPP & $4,986^{*}$ & $4,375^{* *}$ & $4,748^{*}$ & $5,332^{*}$ & $3,669^{* *}$ & $3,746^{* *}$ \\
BM & $4,645^{*}$ & $5,173^{*}$ & $6,057^{*}$ & $4,615^{*}$ & 3,196 & 1,928 \\
RES & 2,822 & 2,300 & 2,035 & 1,452 & 1,287 & 0,919 \\
\hline
\end{tabular}

*Intervalo de valores críticos relevantes (intercepto irrestrito e sem tendência, com seis regressores, $\mathrm{k}=6):(2,12$; $3,23)$, a $90 \%$ de confiança***; $(2,45 ; 3,61)$, a $95 \%$ de confiança**, e $(3,15 ; 4,43)$, a $99 \%$ de confiança*. (ver Tabela CI(iii), Pesaran et al.(2001))

\subsubsection{Estrutura de lags do modelo ARDL}

Prosseguindo com a aplicação do procedimento descrito anteriormente, é feita a seleção da estrutura ótima de defasagens, pelos critérios BIC e AIC, que definirá o modelo ARDL a ser estimado para cada um dos cinco agregados monetários. Os modelos selecionados para cada agregado, tanto pelo critério BIC quanto pelo critério AIC, estão exibidos na Tabela 19 e na Tabela 20 (para modelo per capita) abaixo. Novamente, o valor máximo de defasagens considerado foi de seis, considerando o fato dos dados utilizados serem trimestrais.

Definidos, portanto, os valores de $(p, q 1, q 2, q 3, q 4, q 5, q 6)$ para cada agregado, passamos à estimação dos modelos ARDL na próxima subseção. Observe que, em alguns casos, os critérios AIC e BIC selecionaram estruturas de defasagem diferentes. Neste caso, daremos preferência ao critério BIC, que atribui maior penalidade à inclusão de novas variáveis e, portanto, tende a efetuar uma seleção com maior parcimônia, como vimos no capítulo anterior. 
Tabela 19 - Defasagens selecionadas: modelo com variáveis de risco

\begin{tabular}{lcc}
\hline & \multicolumn{1}{c}{ BIC } & AIC \\
\hline M1 & $\operatorname{ARDL}(2,0,0,0,0,0,0)$ & $\operatorname{ARDL}(2,0,0,0,0,0,0)$ \\
M2 & $\operatorname{ARDL}(1,0,0,0,0,0,0)$ & $\operatorname{ARDL}(1,0,0,0,0,0,1)$ \\
M1RS & $\operatorname{ARDL}(2,0,0,0,0,0,0)$ & $\operatorname{ARDL}(2,0,0,0,0,0,0)$ \\
DV & $\operatorname{ARDL}(2,0,0,0,0,0,0)$ & $\operatorname{ARDL}(2,0,0,0,1,0,0)$ \\
PMPP & $\operatorname{ARDL}(1,0,0,0,0,0,0)$ & $\operatorname{ARDL}(1,0,0,0,3,0,0)$ \\
RES & $\operatorname{ARDL}(4,0,4,0,2,0,0)$ & $\operatorname{ARDL}(5,0,4,0,2,0,0)$ \\
BM & $\operatorname{ARDL}(3,0,0,0,0,0,0)$ & $\operatorname{ARDL}(3,0,0,0,0,0,0)$ \\
\hline
\end{tabular}

Tabela 20 - Defasagens selecionadas: modelo com risco e com variáveis per capita

\begin{tabular}{lcc}
\hline & \multicolumn{1}{c}{ BIC } & AIC \\
\hline M1 & $\operatorname{ARDL}(2,0,0,0,0,0,0)$ & $\operatorname{ARDL}(2,0,0,0,0,0,0)$ \\
M2 & $\operatorname{ARDL}(1,0,0,0,0,0,0)$ & $\operatorname{ARDL}(1,0,0,0,0,0,1)$ \\
M1RS & $\operatorname{ARDL}(2,0,0,0,0,0,0)$ & $\operatorname{ARDL}(2,0,0,0,0,0,0)$ \\
DV & $\operatorname{ARDL}(2,0,0,0,0,0,0)$ & $\operatorname{ARDL}(2,0,0,0,1,0,0)$ \\
PMPP & $\operatorname{ARDL}(1,0,0,0,0,0,0)$ & $\operatorname{ARDL}(1,0,0,0,4,0,1)$ \\
RES & $\operatorname{ARDL}(1,0,0,0,0,0,0)$ & $\operatorname{ARDL}(1,0,0,0,0,0,0)$ \\
BM & $\operatorname{ARDL}(1,0,0,0,0,0,0)$ & $\operatorname{ARDL}(1,0,0,0,0,0,0)$ \\
\hline
\end{tabular}

\subsubsection{Estimação ECM irrestrito e equações de longo prazo}

Utilizando o procedimento detalhado anteriormente, são exibidos a seguir os resultados da estimação do modelo ARDL, para cada um dos agregados monetários em análise em termos agregados.

O procedimento geral utilizado foi de, inicialmente, efetuar a regressão por OLS do modelo com todas as variáveis. Caso alguma variável de interação não seja significativa a $10 \%$ de significância, a mesma é retirada e o modelo re-estimado. Quanto à estrutura de defasagens, inicialmente estimamos o modelo com a estrutura selecionada pelo critério BIC, e, caso o teste BG sugira a presença de correlação serial, utilizamos a estrutura selecionada por AIC. Caso o problema persista, alteramos o valor da defasagem $p$ até que não haja tal correlação. 
Tabela 21 - Resultados: modelo com variáveis de risco

\begin{tabular}{|c|c|c|c|c|c|c|c|}
\hline & M1 & M2 & M1RS & DV & PMPP & BM & RES \\
\hline \multicolumn{8}{|c|}{ Painel A: Coeficientes Padronizados de Longo Prazo } \\
\hline \multirow[t]{2}{*}{$\ln (Y)$} & 0,224 & 0,562 & 0,385 & $-0,227$ & 0,843 & 0,658 & $-0,114$ \\
\hline & 0,323 & 0,475 & 0,162 & 0,770 & $0,000^{*}$ & $0,002^{*}$ & 0,877 \\
\hline \multirow[t]{2}{*}{$\ln (r)$} & $-0,140$ & $-0,094$ & $-0,105$ & $-0,498$ & $-0,113$ & $-0,340$ & $-0,848$ \\
\hline & $0,005^{*}$ & 0,079 & $0,002^{*}$ & $0,002^{*}$ & $0,001^{*}$ & $0,000^{*}$ & $0,001 *$ \\
\hline \multirow[t]{2}{*}{ Sharpe } & $-0,047$ & 0,004 & 0,087 & $-0,131$ & 0,096 & $-0,156$ & $-0,495$ \\
\hline & 0,777 & 0,982 & 0,431 & 0,822 & 0,344 & 0,146 & 0,410 \\
\hline \multirow[t]{2}{*}{ Spread_loan } & 1,309 & 10,337 & 10,465 & $-39,983$ & 10,272 & $-6,051$ & $-38,539$ \\
\hline & 0,810 & 0,156 & $0,016^{*}$ & $0,050^{*}$ & $0,015^{*}$ & 0,112 & 0,075 \\
\hline \multirow[t]{2}{*}{ Vol_r $r$} & 0,009 & $-0,064$ & 0,116 & $-0,254$ & 0,114 & $-0,127$ & 0,631 \\
\hline & 0,926 & 0,547 & 0,116 & 0,425 & 0,165 & 0,336 & 0,074 \\
\hline \multirow[t]{2}{*}{ Vol_Y } & $-7,282$ & 10,214 & $-0,937$ & 31,341 & $-15,875$ & $-52,965$ & $-50,629$ \\
\hline & 0,666 & 0,591 & 0,933 & 0,590 & 0,156 & $0,001^{*}$ & 0,404 \\
\hline \multirow[t]{2}{*}{ Const. } & 4,977 & 3,633 & 3,723 & 7,296 & $-0,886$ & 0,772 & 3,951 \\
\hline & 0,093 & 0,062 & $0,006 *$ & 0,402 & 0,283 & 0,391 & 0,491 \\
\hline \multirow{2}{*}{$I T\left[\begin{array}{c}\operatorname{Vol}(P I B), \\
\operatorname{Vol}(r)\end{array}\right]$} & & & & & & 35,923 & \\
\hline & & & & & & $0,009 *$ & \\
\hline \multirow[t]{2}{*}{$\operatorname{IT}[r, \operatorname{Vol}(r)]$} & & & $-2,423$ & & $-2,030$ & $-1,893$ & \\
\hline & & & $0,002^{*}$ & & $0,014^{*}$ & $0,034^{*}$ & \\
\hline \multicolumn{8}{|c|}{ Painel B: Coeficientes de Curto Prazo Selecionados } \\
\hline \multirow[t]{2}{*}{$\Delta \ln (Y)$} & 0,314 & 0,318 & 0,320 & 0,172 & 0,267 & $-0,135$ & 0,211 \\
\hline & $0,003^{*}$ & $0,000^{*}$ & $0,002^{*}$ & 0,473 & $0,000 *$ & 0,665 & 0,853 \\
\hline \multirow[t]{2}{*}{$\Delta \ln (r)$} & $-0,026$ & $-0,015$ & $-0,017$ & $-0,064$ & $-0,010$ & $-0,093$ & $-0,261$ \\
\hline & $0,000^{*}$ & 0,709 & $0,000 *$ & $0,000^{*}$ & $0,000 *$ & $0,000^{*}$ & $0,000 *$ \\
\hline \multirow[t]{2}{*}{$\Delta$ Sharpe } & 0,003 & 0,002 & 0,007 & $-0,001$ & 0,000 & 0,000 & $-0,023$ \\
\hline & 0,672 & $0,002^{*}$ & 0,250 & 0,935 & 0,956 & 0,993 & 0,748 \\
\hline \multirow[t]{2}{*}{$\Delta$ Spread_loan } & $-0,654$ & $-0,368$ & $-0,291$ & $-1,292$ & $-0,050$ & $-0,102$ & $-0,069$ \\
\hline & $0,000^{*}$ & 0,706 & 0,095 & $0,001^{*}$ & 0,668 & 0,844 & 0,971 \\
\hline \multirow[t]{2}{*}{$\Delta V o l \_r$} & $-0,001$ & $-0,001$ & 0,000 & $-0,006$ & 0,001 & 0,012 & 0,066 \\
\hline & 0,913 & 0,974 & 0,944 & 0,630 & 0,726 & 0,422 & 0,241 \\
\hline \multirow[t]{2}{*}{$\Delta$ Vol_Y } & $-1,117$ & $-0,023$ & $-1,243$ & $-0,711$ & $-1,026$ & $-3,336$ & $-11,484$ \\
\hline & 0,271 & $0,000^{*}$ & 0,203 & 0,756 & 0,077 & 0,247 & 0,291 \\
\hline \multicolumn{8}{|c|}{ Painel C: Ajuste do modelo } \\
\hline$\overline{R^{2}}$ & 0,522 & 0,509 & 0,532 & 0,481 & 0,445 & 0,521 & 0,359 \\
\hline$\chi_{B G}^{2}(2)$ & 1,034 & 3,827 & 1,249 & 1,693 & 1,616 & 3,326 & 2,960 \\
\hline p-valor & 0,596 & 0,148 & 0,536 & 0,429 & 0,446 & 0,190 & 0,228 \\
\hline
\end{tabular}

Agregado M1 - O modelo para o agregado M1 apresenta valores para as elasticidades renda e juros próximos aos valores encontrados no modelo padrão, ainda que, aqui, o coeficiente associado à renda não seja significativo, a 5\%. Quanto às variáveis de risco, 
apenas o Spread aparenta ter efeito estatisticamente significativo sobre a demanda pelo agregado M1, no curto-prazo. A Figura 15, abaixo, exibe o valor do termo de correção de erros de ambos os modelos, no qual podemos ver que, de modo geral, o ajuste é satisfatório e o modelo com variáveis de risco tem desempenho preditivo pouco melhor que o modelo padrão na maioria dos períodos.

No período constituído pelos seis últimos anos da amostra, observamos claramente que ambos os modelos superestimam persistentemente a demanda por moeda. Este fenômeno será observado em todas as estimações a seguir, e será tratado com maior profundidade no capítulo seguinte.

Agregado M2 - As elasticidades renda e juros da demanda pelo M2 aparecem aqui bastante distintas da estimação com o modelo padrão. Duas variáveis de risco são estatisticamente significativas no curto prazo: o índice de Sharpe e a volatilidade do produto. Vale observar aqui a distinção entre as variáveis de risco que influenciam a demanda pelo agregado de maior liquidez M1 e que influenciam o agregado mais amplo M2. O comparativo entre os termos de erro dos modelos padrão e com variáveis de risco se encontra na Figura 16, na qual podemos observar que ambos os modelos produzem termos de erro de valor baixo, ainda que os erros do modelo com risco tenham maior variabilidade.

Agregado M1RS - Os resultados exibidos acima mostram uma elasticidade-renda menor que no modelo padrão, porém o coeficiente associado ao termo de longo prazo da variável de Spread é significativo a 5\%. Além disso, o coeficiente de longo prazo da variável de interação também é significativo, o que sugere que o termo de volatilidade dos juros, em associação ao valor desta taxa, é determinante da demanda pelo agregado M1RS. Na Figura 17, por sua vez, observamos a evolução do termo de correção de erros para o presente modelo e o modelo padrão associado a M1RS. Como se observa, apesar de este termo ter maior variância no modelo com variáveis de risco, o desempenho preditivo deste é superior em períodos de tempo maiores. ${ }^{30}$

Agregado DV - Assim como nos resultados obtidos para o modelo de demanda padrão, a elasticidade-renda da demanda pelo agregado DV estimada é negativa e nãosignificativa, ainda que de valor absoluto menor que naquele caso. Quanto às variáveis de risco, destaca-se o coeficiente negativo e significativo, a 5\%, para a variável de spread, tanto em sua denominação de longo quanto de curto prazo. A Figura 18 apresenta os termos de

\footnotetext{
${ }^{30}$ Em uma avaliação alternativa dos resultados, o apêndice deste trabalho mostra o gráfico de dispersão das variáveis dependentes estimadas nos modelos padrão e com variáveis de risco, divididas pela variável de produção e em relação à taxa de juros, analogamente à Figura 1.
} 
correção de erros associados, na qual podemos observar que o modelo com variáveis de risco tem desempenho preditivo claramente superior na maior parte do período, ainda que os valores absolutos desta variável sejam, em média, superiores aos modelos referentes aos agregados anteriores.

Agregado PMPP - Os resultados acima demonstram um ajuste bastante satisfatório, com elasticidades renda e juros significativas e de valor absoluto menor que no caso do modelo padrão. O coeficiente associado à variável de spread estimado é positivo e significativo, e o coeficiente associado à variável de interação entre taxa de juros e sua volatilidade significativo sugere que esta variável de risco também possuiria alguma relevância na determinação da demanda por papel moeda. Na Figura 19, por sua vez, observamos que o modelo com variáveis de risco tem desempenho superior, na maior parte do período, ao modelo padrão, pela análise do termo de correção de erros. Neste caso observamos também uma superestimação da demanda no período recente em nível relativamente menor que nos agregados anteriores.

Agregado BM - Nesta estimação observamos novamente coeficientes associados às variáveis de escala e custo de oportunidade significativos e com o sinal esperado. Quanto às variáveis de risco, destaca-se o coeficiente negativo e significativo associado à volatilidade do produto, em sua denominação de longo prazo. Adicionalmente, os coeficientes dos termos de interação da taxa de juros com sua volatilidade, e desta com a volatilidade do produto, são também significativos e fornecem evidências favoráveis a respeito da importância das duas variáveis de volatilidade na determinação da demanda pela base monetária.

Na Figura 20, por sua vez, vemos que o modelo com risco e o modelo padrão apresentam uma evolução temporal do termo de correção de erros similar, ainda que o primeiro tenha uma variabilidade bastante superior.

Agregado RES - Os resultados para o agregado de reservas totais apresentam novamente uma elasticidade-renda negativa, porém de menor valor absoluto que na estimação do modelo de demanda padrão. Quanto às variáveis de risco, observamos que os coeficientes de longo prazo das variáveis de spread e de volatilidade dos juros são significativos apenas a 90\% de confiança. Com o menor $\mathrm{R}^{2}$ ajustado dentre os diferentes agregados, o ajuste deste modelo, novamente analisado pelo termo de correção de erros, é exibido na Figura 21, na qual observamos que os modelos têm desempenho similar, ainda que por mais uma vez o termo de erro do modelo com risco tenha maior variabilidade. 


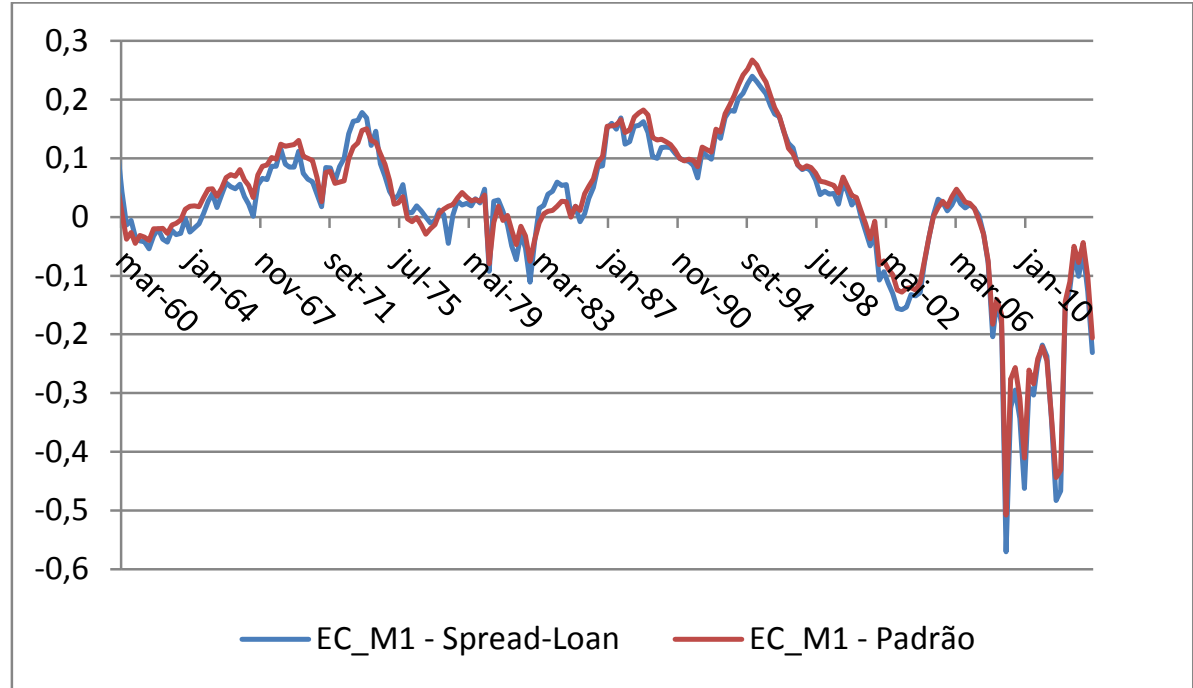

Figura 15 - Termo de correção de erros (logs), modelos com agregado M1

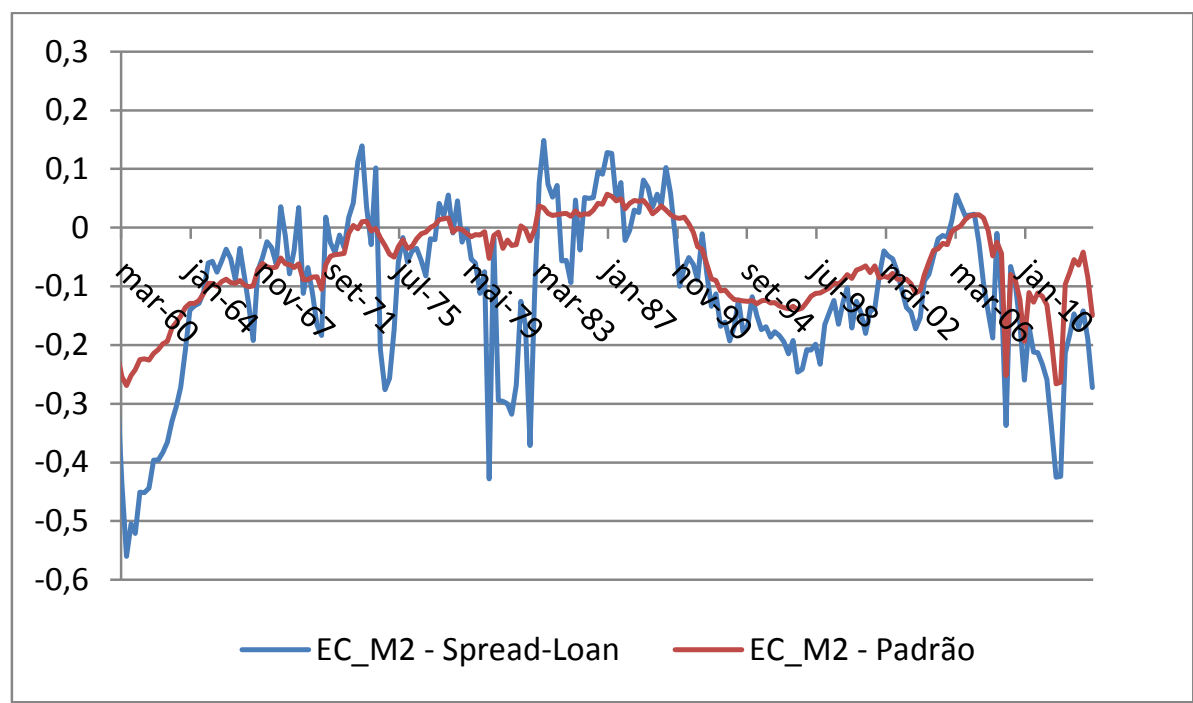

Figura 16 - Termo de correção de erros $(\operatorname{logs})$, modelos com agregado M2

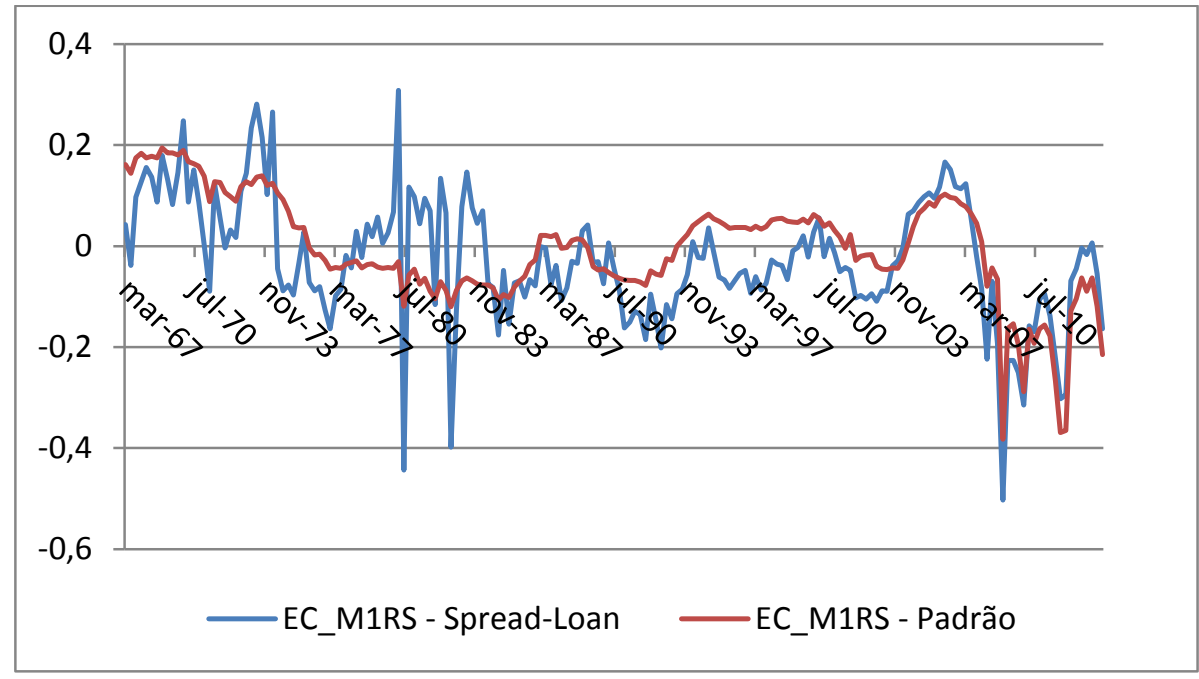

Figura 17 - Termo de correção de erros (logs), modelos com agregado M1RS 


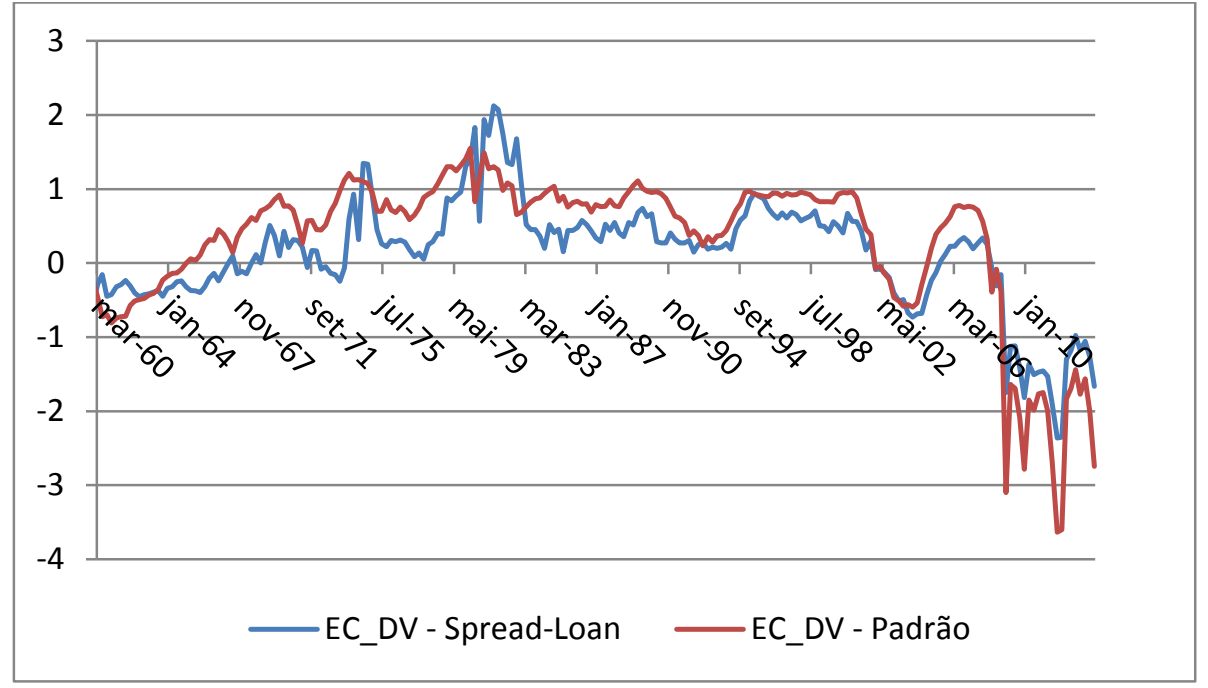

Figura 18 - Termo de correção de erros (logs), modelos com agregado DV

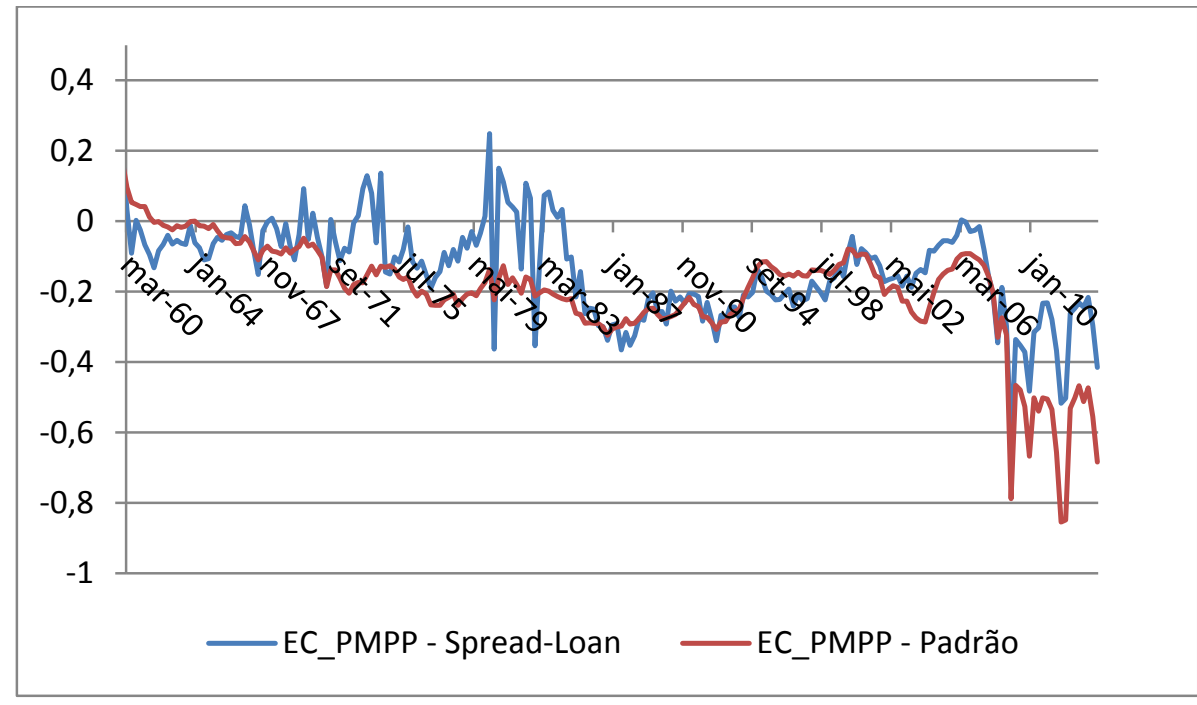

Figura 19 - Termo de correção de erros (logs), modelos com agregado PMPP

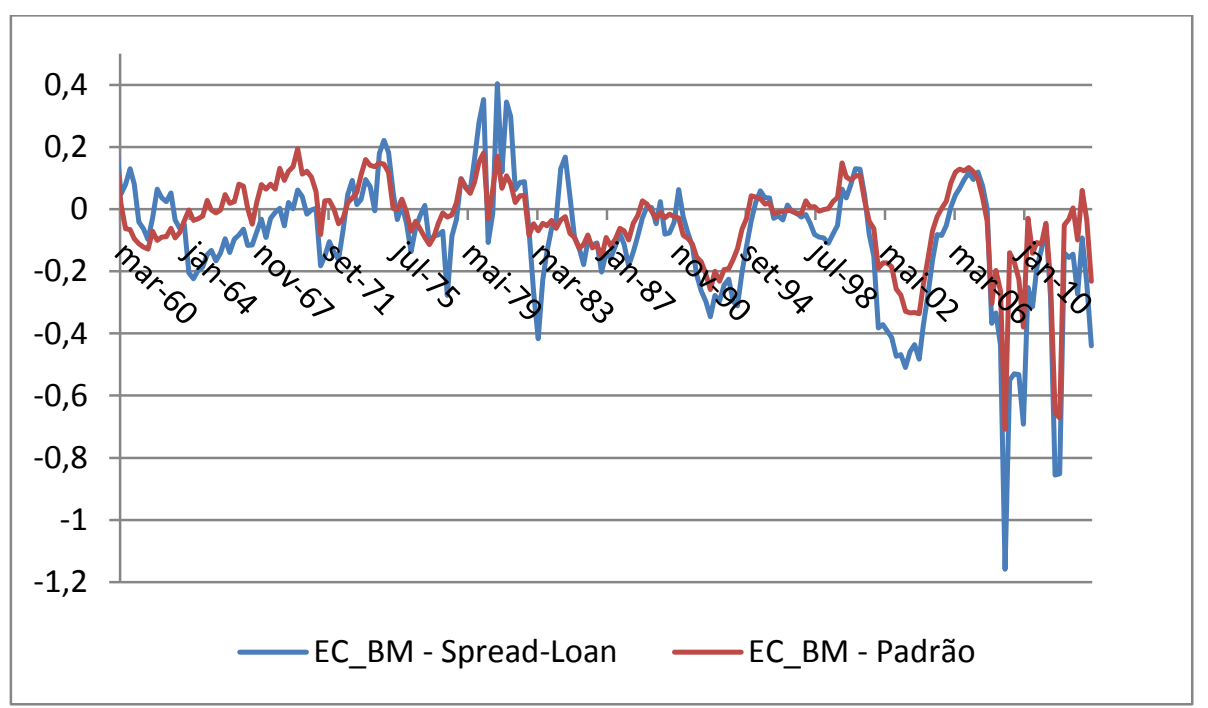

Figura 20 - Termo de correção de erros (logs), modelos com agregado BM 


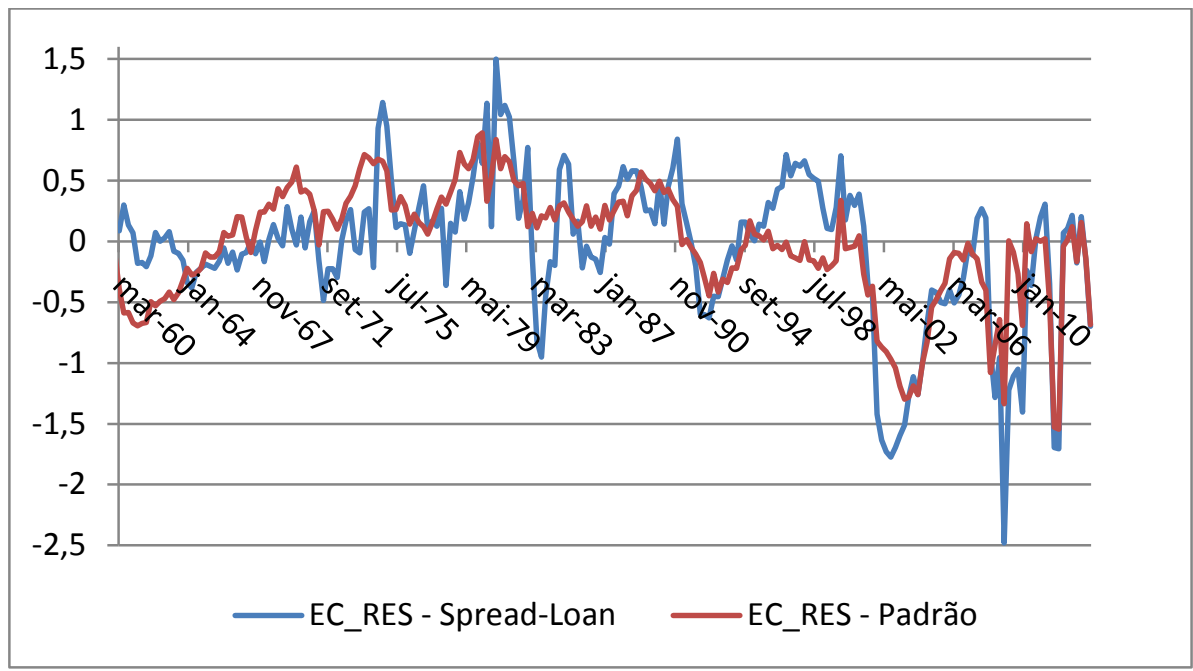

Figura 21 - Termo de correção de erros (logs), modelos com agregado RES

A Tabela 22, abaixo, exibe os resultados encontrados para os modelos com variáveis de risco denominados em termos per capita. Como exposto na seção anterior, tais modelos seriam mais adequados ao considerarmos a formação individual de expectativas. Os resultados obtidos são semelhantes aos explorados acima, com a exceção dos coeficientes da variável de spread, que passa a ser significativo e negativo para o agregado BM per capita, mas deixa de ser significativo, a 5\%, para M1RS per capita. Já para o curto prazo, observamos também coeficientes significativos associados ao termo de spread para mais agregados monetários. Os gráficos com a evolução temporal do termo de correção de erros obtido das estimações per capita, comparados aos termos de erro obtidos das estimações do modelo padrão estão exibidos, por sua vez, na Figura 22.

Tabela 22 - Resultados: modelo com risco e com variáveis per capita

\begin{tabular}{|c|c|c|c|c|c|c|c|}
\hline & M1 & M2 & M1RS & DV & PMPP & BM & RES \\
\hline \multicolumn{8}{|c|}{ Painel A: Coeficientes Padronizados de Longo Prazo } \\
\hline \multirow[t]{2}{*}{$\ln (Y)$} & 0,163 & 0,262 & 0,308 & $-0,700$ & 0,768 & 0,599 & $-0,840$ \\
\hline & 0,703 & 0,784 & 0,414 & 0,652 & $0,002 *$ & $0,006^{*}$ & 0,446 \\
\hline \multirow[t]{2}{*}{$\ln (r)$} & $-0,138$ & $-0,095$ & $-0,113$ & $-0,541$ & $-0,123$ & $-0,315$ & $-0,808$ \\
\hline & $0,013^{*}$ & 0,107 & $0,003 *$ & $0,002^{*}$ & $0,000 *$ & $0,000 *$ & $0,000 *$ \\
\hline \multirow[t]{2}{*}{ Sharpe } & $-0,020$ & $-0,011$ & $-0,017$ & $-0,185$ & 0,041 & $-0,098$ & $-0,507$ \\
\hline & 0,922 & 0,962 & 0,896 & 0,782 & 0,693 & 0,329 & 0,367 \\
\hline \multirow[t]{2}{*}{ Spread_loan } & $-24,85$ & 11,397 & 2,869 & $-49,217$ & 9,665 & $-8,455$ & $-34,057$ \\
\hline & 0,096 & 0,175 & 0,499 & $0,036^{*}$ & 0,019* & $0,015^{*}$ & 0,066 \\
\hline \multirow[t]{2}{*}{ Vol_r } & $-0,042$ & $-0,078$ & $-0,039$ & $-0,280$ & 0,112 & $-0,132$ & 0,521 \\
\hline & 0,722 & 0,533 & 0,574 & 0,444 & 0,179 & 0,298 & 0,095 \\
\hline
\end{tabular}




\begin{tabular}{|c|c|c|c|c|c|c|c|}
\hline & M1 & M2 & M1RS & DV & PMPP & BM & RES \\
\hline \multirow[t]{2}{*}{ Vol_Y } & $-45,899$ & 13,000 & $-10,21$ & 38,563 & $-20,961$ & $-29,230$ & $-34,185$ \\
\hline & 0,133 & 0,560 & 0,444 & 0,564 & 0,067 & $0,037^{*}$ & 0,546 \\
\hline \multirow[t]{2}{*}{ Const. } & 7,189 & 6,907 & 5,539 & 13,257 & $-0,004$ & 1,733 & 12,128 \\
\hline & 0,321 & 0,086 & 0,072 & 0,462 & 0,998 & 0,305 & 0,241 \\
\hline \multirow[t]{2}{*}{$I T\left[\begin{array}{c}\operatorname{Vol}(P I B), \\
\operatorname{Vol}(r)\end{array}\right]$} & - & - & - & - & - & 18,828 & - \\
\hline & - & - & - & - & - & 0,080 & - \\
\hline \multirow[t]{2}{*}{$\operatorname{IT}[r, \operatorname{Vol}(r)]$} & - & - & - & - & $-1,778$ & - & - \\
\hline & - & - & - & - & $0,035^{*}$ & - & - \\
\hline \multirow{2}{*}{$I T\left[\begin{array}{c}\operatorname{Vol}(P I B), \\
\text { Spread }\end{array}\right]$} & 2137,7 & - & - & - & - & - & - \\
\hline & 0,072 & - & - & - & - & - & - \\
\hline \multicolumn{8}{|c|}{ Painel B: Coeficientes de Curto Prazo Selecionados } \\
\hline \multirow[t]{2}{*}{$\Delta \ln (Y)$} & 0,319 & 0,324 & 0,314 & 0,169 & 0,312 & $-0,131$ & $-0,320$ \\
\hline & $0,003^{*}$ & $0,000^{*}$ & $0,002^{*}$ & 0,480 & $0,000^{*}$ & 0,678 & 0,767 \\
\hline \multirow[t]{3}{*}{$\Delta \ln (r)$} & $-0,025$ & $-0,015$ & $-0,018$ & $-0,064$ & $-0,010$ & $-0,094$ & $-0,252$ \\
\hline & $0,000^{*}$ & $0,000^{*}$ & $0,000 *$ & $0,000^{*}$ & $0,000^{*}$ & $0,000^{*}$ & $0,000^{*}$ \\
\hline & M1 & M2 & M1RS & DV & PMPP & BM & RES \\
\hline \multirow[t]{2}{*}{$\Delta$ Sharpe } & 0,003 & 0,001 & 0,006 & $-0,002$ & $-0,001$ & 0,005 & $-0,031$ \\
\hline & 0,623 & 0,760 & 0,386 & 0,903 & 0,779 & 0,819 & 0,662 \\
\hline \multirow[t]{2}{*}{$\Delta$ Spread_loan } & $-0,651$ & $-0,375$ & $-0,576$ & $-1,320$ & $-0,074$ & $-0,504$ & $-0,895$ \\
\hline & $0,000^{*}$ & $0,002^{*}$ & $0,000 *$ & $0,001^{*}$ & 0,507 & 0,309 & 0,607 \\
\hline \multirow[t]{2}{*}{$\Delta V o l \_r$} & $-0,001$ & $-0,001$ & $-0,001$ & $-0,006$ & 0,001 & 0,018 & 0,063 \\
\hline & 0,903 & 0,748 & 0,857 & 0,628 & 0,747 & 0,251 & 0,249 \\
\hline \multirow[t]{2}{*}{$\Delta V o l \_Y$} & $-0,981$ & $-0,002$ & $-1,352$ & $-0,711$ & $-0,671$ & $-3,174$ & $-7,040$ \\
\hline & 0,330 & 0,997 & 0,176 & 0,756 & 0,237 & 0,282 & 0,495 \\
\hline \multicolumn{8}{|c|}{ Painel C: Ajuste do modelo } \\
\hline$\overline{R^{2}}$ & 0,532 & 0,509 & 0,514 & 0,482 & 0,463 & 0,494 & 0,367 \\
\hline$\chi_{B G}^{2}(2)$ & 1,184 & 3,810 & 1,569 & 1,651 & 1,748 & 2,300 & 1,014 \\
\hline $\mathrm{p}$-valor & 0,553 & 0,149 & 0,456 & 0,438 & 0,417 & 0,317 & 0,602 \\
\hline
\end{tabular}

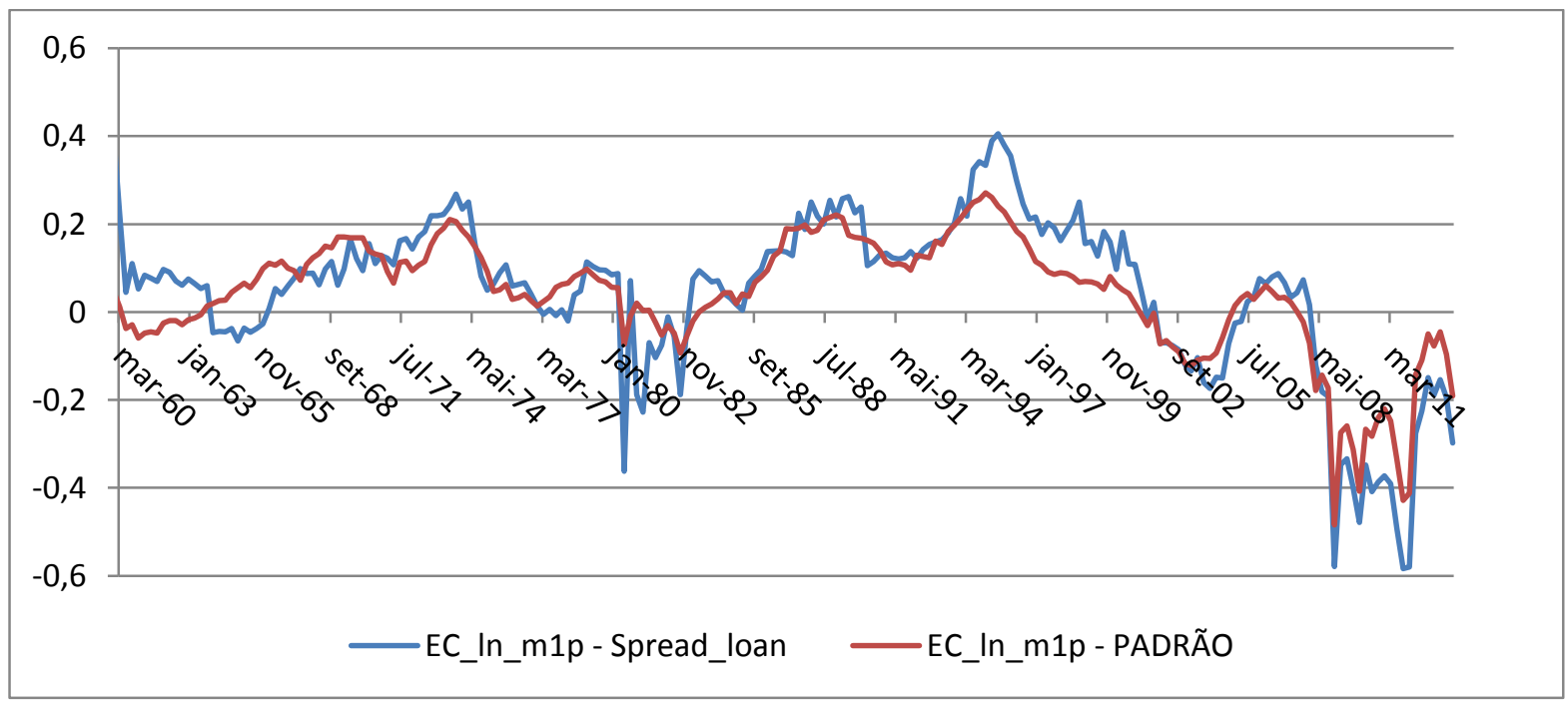




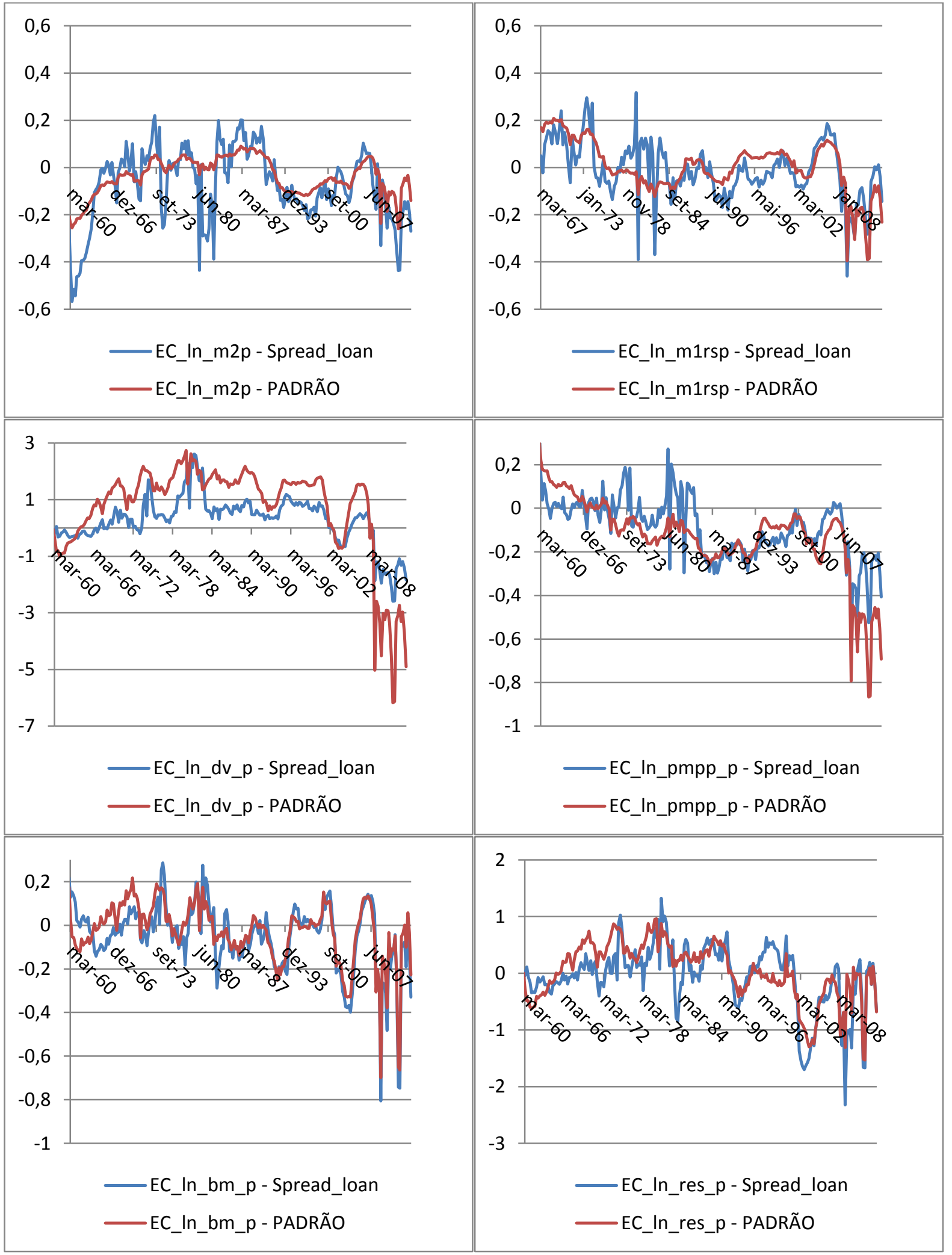

Figura 22 - Termo de correção de erros: modelos per capita com risco

$\mathrm{Na}$ Tabela 23, abaixo, realizamos o exercício alternativo de retirada das variáveis com nível de significância do coeficiente estimado acima menor que 15\%, formando modelos com 
variáveis de risco reduzidos a serem estimados novamente em termos per capita. Nos resultados observamos que as novas estimativas não diferem muito das anteriores, com o destaque novamente se voltando à variável de spread, que possuiria efeito negativo sob a demanda per capita sobre os agregados M1, DV, BM e RES.

Tabela 23 - Resultados: modelo per capita reduzido com risco

\begin{tabular}{|c|c|c|c|c|c|}
\hline & M1 & DV & PMPP & BM & RES \\
\hline \multicolumn{6}{|c|}{ Painel A: Coeficientes Padronizados de Longo Prazo } \\
\hline \multirow[t]{2}{*}{$\ln (Y)$} & 0,114 & $-1,199$ & 0,863 & 0,572 & $-0,482$ \\
\hline & 0,779 & 0,385 & $0,000 *$ & $0,010^{*}$ & 0,543 \\
\hline \multirow[t]{2}{*}{$\ln (r)$} & $-0,152$ & $-0,650$ & $-0,118$ & $-0,321$ & $-0,775$ \\
\hline & $0,002 *$ & $0,000 *$ & $0,000 *$ & $0,000 *$ & $0,000 *$ \\
\hline \multirow[t]{2}{*}{ Spread_loan } & $-24,737$ & $-52,217$ & 9,211 & $-8,078$ & $-37,408$ \\
\hline & 0,082 & $0,018^{*}$ & $0,029 *$ & $0,025^{*}$ & $0,032^{*}$ \\
\hline \multirow[t]{2}{*}{ Vol_r } & - & - & - & - & 0,486 \\
\hline & - & - & - & - & $0,030 *$ \\
\hline \multirow[t]{2}{*}{ Vol_Y } & $-48,996$ & - & $-15,423$ & $-22,478$ & - \\
\hline & 0,104 & - & 0,155 & 0,105 & - \\
\hline \multirow[t]{2}{*}{ Const. } & 7,579 & 17,523 & $-0,807$ & 1,833 & 8,703 \\
\hline & 0,295 & 0,308 & 0,609 & 0,324 & 0,258 \\
\hline \multirow[t]{2}{*}{$I T\left[\begin{array}{c}\operatorname{Vol}(P I B), \\
\operatorname{Vol}(r)\end{array}\right]$} & - & - & - & 8,967 & - \\
\hline & - & - & - & 0,074 & - \\
\hline \multirow{2}{*}{$\operatorname{IT}[\boldsymbol{r}, \operatorname{Vol}(\boldsymbol{r})]$} & - & - & $-1,115$ & - & - \\
\hline & - & - & 0,094 & - & - \\
\hline \multirow[t]{2}{*}{$I T\left[\begin{array}{c}\operatorname{Vol}(P I B), \\
\text { Spread }\end{array}\right]$} & 2090,9 & - & - & - & - \\
\hline & 0,062 & - & - & - & - \\
\hline \multicolumn{6}{|c|}{ Painel B: Coeficientes de Curto Prazo Selecionados } \\
\hline \multirow[t]{2}{*}{$\Delta \ln (Y)$} & 0,323 & 0,178 & 0,310 & $-0,101$ & $-0,387$ \\
\hline & $0,002 *$ & 0,436 & $0,000 *$ & 0,737 & 0,712 \\
\hline \multirow[t]{2}{*}{$\Delta \ln (r)$} & $-0,025$ & $-0,064$ & $-0,010$ & $-0,093$ & $-0,251$ \\
\hline & $0,000^{*}$ & $0,000^{*}$ & $0,000^{*}$ & $0,000 *$ & $0,000 *$ \\
\hline \multirow[t]{2}{*}{$\Delta$ Spread_loan } & $-0,661$ & $-1,334$ & $-0,105$ & $-0,510$ & $-1,212$ \\
\hline & $0,000 *$ & $0,000^{*}$ & 0,330 & 0,295 & 0,474 \\
\hline \multirow[t]{2}{*}{$\Delta V o l \_r$} & - & - & - & - & 0,069 \\
\hline & - & - & - & - & 0,188 \\
\hline \multirow[t]{2}{*}{$\Delta V o l \_Y$} & $-0,970$ & - & $-0,615$ & $-2,698$ & - \\
\hline & 0,313 & - & 0,261 & 0,352 & - \\
\hline \multicolumn{6}{|c|}{ Painel C: Ajuste do modelo } \\
\hline$\overline{R^{2}}$ & 0,540 & 0,495 & 0,468 & 0,493 & 0,375 \\
\hline$\chi_{B G}^{2}(2)$ & 1,056 & 1,959 & 2,676 & 1,872 & 1,088 \\
\hline p-valor & 0,590 & 0,376 & 0,262 & 0,392 & 0,581 \\
\hline
\end{tabular}




\subsubsection{Modelos ECM restritos e dinâmica de curto prazo}

De posse dos resultados obtidos para os coeficientes de longo prazo, podemos prosseguir à estimação do modelo de correção de erros representado pela equação (4.21) da seção anterior. A Tabela 24 e a Tabela 25 exibem os resultados obtidos com a estimação de tais modelos, respectivamente, para as formas agregada e per capita do modelo com variáveis de risco. As primeiras três linhas da tabela apresentam os valores dos coeficientes estimados de correção de erros, o valor do teste t associado ao mesmo e o p-valor deste teste. As demais linhas apresentam estatísticas do ajuste do modelo. Note que os coeficientes estimados para os termos de ajuste de curto prazo devem, necessariamente, ser os mesmos obtidos na estimação anterior e, portanto, não são exibidos novamente.

Tabela 24 - Resultados: ECMs modelo com risco

\begin{tabular}{cccccccc}
\hline & M1 & M2 & M1RS & DV & PMPP & BM & RES \\
\hline$\overline{\boldsymbol{E C} \boldsymbol{t}-\mathbf{1}}$ & $-0,027$ & $-0,015$ & $-0,040$ & $-0,017$ & $-0,023$ & $-0,122$ & $-0,076$ \\
Teste t & $-3,632$ & $-3,506$ & $-5,090$ & $-4,837$ & $-6,714$ & $-7,980$ & $-4,046$ \\
p-valor & $0,000^{*}$ & $0,001^{*}$ & $0,000^{*}$ & $0,000^{*}$ & $0,000^{*}$ & $0,000^{*}$ & $0,000^{*}$ \\
$\overline{\boldsymbol{R}^{\mathbf{2}}}$ & 0,535 & 0,523 & 0,551 & 0,496 & 0,461 & 0,540 & 0,379 \\
$\boldsymbol{\chi}_{\boldsymbol{B G}}^{2}(2)$ & 1,007 & 3,500 & 1,115 & 1,477 & 1,567 & 2,584 & 2,695 \\
p-valor & 0,604 & 0,174 & 0,573 & 0,478 & 0,457 & 0,275 & 0,260 \\
\hline
\end{tabular}

Tabela 25 - Resultados: ECMs modelo per capita com risco

\begin{tabular}{cccccccc}
\hline & M1 & M2 & M1RS & DV & PMPP & BM & RES \\
\hline$\overline{\boldsymbol{E C}_{\boldsymbol{t}-\mathbf{1}}}$ & $-0,021$ & $-0,013$ & $-0,042$ & $-0,015$ & $-0,022$ & $-0,128$ & $-0,078$ \\
Teste t & $-4,045$ & $-3,387$ & $-5,240$ & $-4,819$ & $-6,559$ & $-6,906$ & $-4,731$ \\
p-valor & $0,000^{*}$ & $0,001^{*}$ & $0,000^{*}$ & $0,000^{*}$ & $0,000^{*}$ & $0,000^{*}$ & $0,000^{*}$ \\
$\overline{\boldsymbol{R}^{\mathbf{2}}}$ & 0,548 & 0,524 & 0,558 & 0,497 & 0,479 & 0,511 & 0,386 \\
$\boldsymbol{\chi}_{\boldsymbol{B G}}^{2}(\mathbf{2})$ & 1,181 & 3,472 & 1,147 & 1,466 & 1,608 & 1,844 & 0,935 \\
p-valor & 0,554 & 0,176 & 0,564 & 0,480 & 0,448 & 0,398 & 0,627 \\
\hline
\end{tabular}

Observe que, para todos os agregados monetários em análise (inclusive reservas totais), o termo de correção de erros é negativo e de módulo menor que um, além de significativo a $1 \%$. Isso reafirma a existência de uma relação de longo prazo entre as variáveis, cuja dinâmica de curto prazo é dada pelo modelo de correção de erros associado. Dos valores da tabela acima podemos observar, entretanto, que alguns dos agregados (BM e RES) monetários têm uma dinâmica de absorção de choques (e, portanto, um retorno ao equilíbrio) mais veloz. 


\subsubsection{O impacto da variável de spread}

Na Tabela 1, apresentada no capítulo anterior, observamos que os dados para o TEDSpread e o Spread-Loan apresentam correlação positiva, porém não significativa. As correlações com o Spread-T30, por sua vez, apresentam valores negativos e estatisticamente significativos. Este fato, somado à grande diferença de disponibilidade dos dados para as três variáveis, nos mostra que a escolha da melhor variável de spread a ser utilizada neste estudo não constitui uma tarefa simples. Deste modo, realizaremos a seguir uma nova estimação do modelo de demanda por moeda com variáveis de risco, desta vez utilizando como variável de Spread as variáveis definidas acima como TED-Spread e Spread-T30, nesta ordem.

As tabelas Tabela 26 a Tabela 29 abaixo exibem a estrutura de defasagens selecionada pelos critérios BIC e AIC para o modelo ECM irrestrito com o uso dos dados para o TEDSpread, para cada agregado monetário; e o resultado da aplicação do procedimento de bounds-testing ao mesmo modelo, com diferentes níveis de defasagem; ambos para modelos agregados e per capita. Observe que os indícios de existência de cointegração para os agregados M2 (no modelo agregado) e PMPP são fracos, porém prosseguiremos à estimação com o intuito de analisar o resultado final.

Tabela 26 - Defasagens selecionadas: modelo com variáveis de risco e TED Spread

\begin{tabular}{llc}
\hline & \multicolumn{1}{c}{ BIC } & AIC \\
\hline M1 & $\operatorname{ARDL}(2,0,0,0,0,0,0)$ & $\operatorname{ARDL}(2,5,0,0,0,0,4)$ \\
M2 & $\operatorname{ARDL}(1,0,0,0,0,0,0)$ & $\operatorname{ARDL}(1,0,0,0,0,0,0)$ \\
M1RS & $\operatorname{ARDL}(2,0,0,0,0,0,0)$ & $\operatorname{ARDL}(2,5,0,0,0,0,1)$ \\
DV & $\operatorname{ARDL}(2,0,0,0,0,0,0)$ & $\operatorname{ARDL}(2,5,0,0,0,0,1)$ \\
PMPP & $\operatorname{ARDL}(1,0,0,0,0,0,0)$ & $\operatorname{ARDL}(1,0,0,0,0,0,0)$ \\
BM & $\operatorname{ARDL}(3,0,0,0,0,0,0)$ & $\operatorname{ARDL}(3,1,0,0,0,0,0)$ \\
RES & $\operatorname{ARDL}(3,0,0,0,0,0,0)$ & $\operatorname{ARDL}(3,0,0,0,0,0,0)$ \\
\hline
\end{tabular}

Tabela 27 - Defasagens selecionadas: modelo per capita com variáveis de risco e TED Spread

\begin{tabular}{lcc}
\hline & \multicolumn{1}{c}{ BIC } & AIC \\
\hline M1 & ARDL $(2,0,0,0,0,0,0)$ & $\operatorname{ARDL}(2,5,0,0,0,0,1)$ \\
M2 & $\operatorname{ARDL}(1,0,0,0,0,0,0)$ & $\operatorname{ARDL}(1,0,0,0,0,0,0)$ \\
M1RS & $\operatorname{ARDL}(2,0,0,0,0,0,0)$ & $\operatorname{ARDL}(2,5,0,0,0,0,2)$ \\
DV & $\operatorname{ARDL}(2,0,0,0,0,0,0)$ & $\operatorname{ARDL}(2,5,0,0,0,0,0)$ \\
PMPP & $\operatorname{ARDL}(1,0,0,0,0,0,0)$ & $\operatorname{ARDL}(1,0,0,0,0,0,0)$ \\
BM & $\operatorname{ARDL}(2,0,0,0,0,0,0)$ & $\operatorname{ARDL}(3,0,0,0,0,0,0)$ \\
RES & ARDL $(1,0,0,0,0,0,0)$ & $\operatorname{ARDL}(4,0,0,0,0,0,0)$ \\
\hline
\end{tabular}


Tabela 28 - Teste F ("bounds-testing"): modelo com variáveis de risco e TED Spread

\begin{tabular}{ccccccc}
\hline Lags & $\mathbf{1}$ & $\mathbf{2}$ & $\mathbf{3}$ & $\mathbf{4}$ & $\mathbf{5}$ & $\mathbf{6}$ \\
\hline M1 & $4,319^{* *}$ & 2,216 & 2,900 & $4,907^{*}$ & $3,318^{* * *}$ & 2,941 \\
M2 & 0,723 & 0,820 & 1,394 & 1,408 & 1,616 & $3,648^{* *}$ \\
M1RS & 3,093 & 2,531 & $3,363^{* * *}$ & $4,750^{*}$ & $3,484^{* * *}$ & $3,353^{* * *}$ \\
DV & $6,857^{*}$ & $3,244^{* * *}$ & $3,573^{* * *}$ & $5,040^{*}$ & $4,579^{*}$ & 2,940 \\
\hline PMPP & 1,689 & 1,284 & 1,473 & 1,504 & 0,495 & 0,770 \\
\hline BM & $4,518^{*}$ & $4,670^{*}$ & $4,734^{*}$ & $5,675^{*}$ & $5,039^{*}$ & $3,243^{* * *}$ \\
RES & $4,415^{* *}$ & $3,985^{* *}$ & $3,292^{* * *}$ & $3,369 * * *$ & 2,949 & 1,953
\end{tabular}

*Intervalo de valores críticos relevantes (intercepto irrestrito e sem tendência, com seis regressores, $\mathrm{k}=6)$ : $(2,12$; 3,23), a $90 \%$ de confiança***; $(2,45 ; 3,61)$, a 95\% de confiança**, e $(3,15 ; 4,43)$, a 99\% de confiança*. (ver Tabela CI(iii), Pesaran et al.(2001))

Tabela 29 - Teste F (“bounds-testing”): modelo per capita com risco e TED Spread

\begin{tabular}{ccccccc}
\hline Lags & $\mathbf{1}$ & $\mathbf{2}$ & $\mathbf{3}$ & $\mathbf{4}$ & $\mathbf{5}$ & $\mathbf{6}$ \\
\hline M1 & $6,20^{*}$ & 3,22 & $5,77^{*}$ & $5,69^{*}$ & $4,97^{*}$ & $5,69^{*}$ \\
M2 & 1,98 & 2,39 & $3,41^{* * *}$ & $4,11^{* *}$ & 1,76 & 1,66 \\
M1RS & $3,90^{* *}$ & 2,92 & $4,70^{*}$ & 3,17 & 2,49 & 2,65 \\
DV & $6,10^{*}$ & $3,46^{* * *}$ & $3,77^{* *}$ & $3,91^{* *}$ & $3,30^{* * *}$ & 2,64 \\
PMPP & 1,48 & 1,36 & 1,58 & 1,51 & 1,39 & 2,23 \\
BM & 2,60 & 2,93 & $4,90^{*}$ & $4,74^{*}$ & 2,44 & 1,84 \\
RES & $3,24^{* * *}$ & $3,45^{* * *}$ & $5,86^{*}$ & $5,23^{*}$ & 3,22 & 2,45
\end{tabular}

*Intervalo de valores críticos relevantes (intercepto irrestrito e sem tendência, com seis regressores, $\mathrm{k}=6)$ : $(2,12$; 3,23), a $90 \%$ de confiança***; $(2,45 ; 3,61)$, a $95 \%$ de confiança**, e $(3,15 ; 4,43)$, a $99 \%$ de confiança*. (ver Tabela CI(iii), Pesaran et al.(2001))

A Tabela 30, por sua vez, exibe os resultados da estimação, via OLS, dos modelos ARDL com variável TED-Spread, selecionados acima pelo critério BIC. Como anteriormente, nos casos em que os mesmos apresentavam indícios de autocorrelação nos resíduos pelo teste BG, os modelos eram substituídos por aqueles selecionados pelo critério AIC. A título de simplificação da apresentação dos resultados, alguns coeficientes de curto-prazo foram omitidos, e estão presentes no Apêndice deste trabalho. Os p-valores do teste t associado aos coeficientes são apresentados sob cada coeficiente estimado, com um asterisco para destacar coeficientes significativos a $95 \%$ de confiança. 
Tabela 30 - Resultados: modelo com risco e com TED_Spread

\begin{tabular}{|c|c|c|c|c|c|c|c|}
\hline & M1 & M2 & M1RS & DV & PMPP & BM & RES \\
\hline \multicolumn{8}{|c|}{ Painel A: Coeficientes Padronizados de Longo Prazo } \\
\hline \multirow[t]{2}{*}{$\ln (Y)$} & $-0,699$ & 1,197 & 0,936 & $-1,929$ & $-4,310$ & 0,890 & $-1,064$ \\
\hline & 0,054 & $0,007^{*}$ & $0,049^{*}$ & 0,063 & 0,813 & 0,071 & 0,401 \\
\hline \multirow[t]{2}{*}{$\ln (r)$} & $-0,158$ & $-0,073$ & $-0,051$ & $-0,316$ & $-0,643$ & $-0,347$ & $-0,964$ \\
\hline & $0,026 *$ & 0,081 & 0,055 & $0,024^{*}$ & 0,127 & $0,000 *$ & $0,002^{*}$ \\
\hline \multirow[t]{2}{*}{ Sharpe } & $-0,161$ & 0,036 & 0,059 & 0,382 & $-2,031$ & $-0,141$ & $-0,725$ \\
\hline & 0,570 & 0,855 & 0,527 & 0,520 & 0,359 & 0,600 & 0,456 \\
\hline \multirow[t]{2}{*}{ TED_Spread } & 4,531 & 18,777 & $-1,684$ & 4,010 & 21,461 & 27,192 & 177,018 \\
\hline & 0,714 & $0,036^{*}$ & 0,678 & 0,867 & 0,865 & $0,015^{*}$ & $0,000^{*}$ \\
\hline \multirow[t]{3}{*}{ Vol_r } & $-0,113$ & 0,018 & 0,000 & $-0,263$ & $-0,589$ & 0,081 & 0,322 \\
\hline & 0,368 & 0,842 & 0,997 & 0,284 & 0,552 & 0,504 & 0,466 \\
\hline & M1 & M2 & M1RS & DV & PMPP & BM & RES \\
\hline \multirow[t]{2}{*}{ Vol_Y } & 98,504 & 1,096 & 38,164 & 123,169 & 212,695 & $-28,932$ & 27,450 \\
\hline & $0,014^{*}$ & 0,967 & $0,015^{*}$ & 0,150 & 0,485 & 0,422 & 0,830 \\
\hline \multirow[t]{2}{*}{ Const. } & 11,844 & $-1,214$ & $-0,422$ & 19,654 & 39,541 & $-1,746$ & 8,394 \\
\hline & $0,045^{*}$ & 0,595 & 0,654 & 0,108 & 0,614 & 0,499 & 0,435 \\
\hline \multicolumn{8}{|c|}{ Painel B: Coeficientes de Curto Prazo Selecionados } \\
\hline \multirow[t]{2}{*}{$\Delta \ln (Y)$} & 0,476 & 0,272 & 0,583 & 0,259 & 0,466 & 0,892 & 3,225 \\
\hline & 0,078 & 0,084 & $0,005^{*}$ & 0,697 & $0,012^{*}$ & 0,280 & 0,258 \\
\hline \multirow[t]{2}{*}{$\Delta \ln (r)$} & $-0,024$ & $-0,012$ & $-0,018$ & $-0,065$ & $-0,009$ & $-0,100$ & $-0,266$ \\
\hline & $0,000^{*}$ & $0,000^{*}$ & $0,000^{*}$ & $0,000^{*}$ & $0,000^{*}$ & $0,000^{*}$ & $0,000^{*}$ \\
\hline \multirow[t]{2}{*}{$\Delta$ Sharpe } & $-0,004$ & $-0,007$ & 0,001 & 0,007 & $-0,011$ & 0,076 & 0,259 \\
\hline & 0,788 & 0,385 & 0,951 & 0,835 & 0,278 & 0,094 & 0,098 \\
\hline \multirow[t]{2}{*}{$\triangle T E D \_S p r e a d$} & 0,032 & $-0,043$ & $-0,222$ & 1,034 & 0,168 & 2,775 & 24,173 \\
\hline & 0,958 & 0,903 & 0,629 & 0,489 & 0,700 & 0,132 & $0,000^{*}$ \\
\hline \multirow[t]{2}{*}{$\Delta V o l \_r$} & $-0,003$ & 0,000 & $-0,002$ & $-0,005$ & 0,005 & 0,007 & $-0,007$ \\
\hline & 0,756 & 0,938 & 0,814 & 0,840 & 0,471 & 0,832 & 0,944 \\
\hline \multirow[t]{2}{*}{$\Delta$ Vol_Y } & 0,228 & $-0,582$ & $-0,124$ & 1,579 & 0,600 & $-1,655$ & $-3,512$ \\
\hline & 0,927 & 0,678 & 0,951 & 0,797 & 0,718 & 0,826 & 0,891 \\
\hline \multicolumn{8}{|c|}{ Painel C: Ajuste do modelo } \\
\hline$\overline{R^{2}}$ & 0,552 & 0,456 & 0,506 & 0,521 & 0,272 & 0,567 & 0,521 \\
\hline$\chi_{B G}^{2}(2)$ & 0,732 & 0,334 & 3,462 & 1,578 & 0,697 & 4,291 & 3,878 \\
\hline p-valor & 0,693 & 0,846 & 0,177 & 0,454 & 0,706 & 0,117 & 0,144 \\
\hline
\end{tabular}

$\mathrm{Na}$ Tabela 31, abaixo, estão exibidos os resultados das estimações dos modelos de correção de erros associados aos modelos acima. Todos os coeficientes associados aos termos de correção de erros defasados apresentaram valor negativo e significativo a 5\%. Observe, entretanto, que além de o ECM apresentar $\mathrm{R}^{2}$ ajustado bastante inferior aos outros modelos, o termo de correção de erros para o agregado PMPP apresenta valor muito baixo, o qual afirma 
que apenas $0,3 \%$ dos choques na demanda por moeda de equilíbrio são corrigidos no período seguinte. Tais resultados favorecem a evidência apresentada pelo procedimento de boundstesting, o qual não encontrara evidências de uma relação de cointegração para esse agregado.

Tabela 31 - Resultados: ECM modelo com risco e com TED_Spread

\begin{tabular}{cccccccc}
\hline & M1 & M2 & M1RS & DV & PMPP & BM & RES \\
\hline$\overline{\boldsymbol{E C}}$ & $-0,038$ & $-0,031$ & $-0,090$ & $-0,048$ & $-0,003$ & $-0,123$ & $-0,114$ \\
Teste t & $-5,022$ & $-3,704$ & $-4,566$ & $-4,498$ & $-3,245$ & $-5,362$ & $-5,831$ \\
p-valor & $0,000^{*}$ & $0,000^{*}$ & $0,000^{*}$ & $0,000^{*}$ & $0,002^{*}$ & $0,000^{*}$ & $0,000^{*}$ \\
$\overline{\boldsymbol{R}^{\mathbf{2}}}$ & 0,579 & 0,488 & 0,537 & 0,549 & 0,315 & 0,594 & 0,550 \\
$\boldsymbol{\chi}_{\boldsymbol{B} \boldsymbol{G}}^{\mathbf{2}}(\mathbf{2})$ & 0,711 & 0,305 & 3,31 & 1,192 & 0,645 & 3,164 & 3,07 \\
$\mathbf{p}$-valor & 0,701 & 0,859 & 0,191 & 0,551 & 0,724 & 0,206 & 0,215 \\
\hline
\end{tabular}

O uso da variável TED-Spread altera sensivelmente as estimativas dos coeficientes de longo prazo das variáveis de risco. No presente caso, os coeficientes associados à variável de Spread são significativos (a 5\%) nas equações de demanda pelos agregados M2, BM e RES: precisamente os agregados, somando-se a M1, para os quais isso não ocorria na seção anterior. Já com relação à volatilidade do produto, no presente caso obtemos estimativas positivas e significativas para seu coeficiente de longo prazo associado à demanda pelos agregados M1 e M1RS. Vale lembrar que, além de constituírem um spread entre taxas de conceitos diferentes, os dados para o TED-Spread estão disponíveis apenas a partir de 1986, e, portanto, as diferenças de resultados nas regressões com utilização dessa variável de spread, em relação aos da seção anterior, se devem não só à diferença conceitual da variável, mas também ao período amostral distinto.

Adicionalmente, a Figura 23 abaixo exibe o desempenho dos modelos com variável TED-Spread em comparação aos modelos anteriores com variável Spread-Loan, em termos dos erros da relação de longo prazo de demanda por moeda estimada em relação à demanda efetivamente observada no período. 


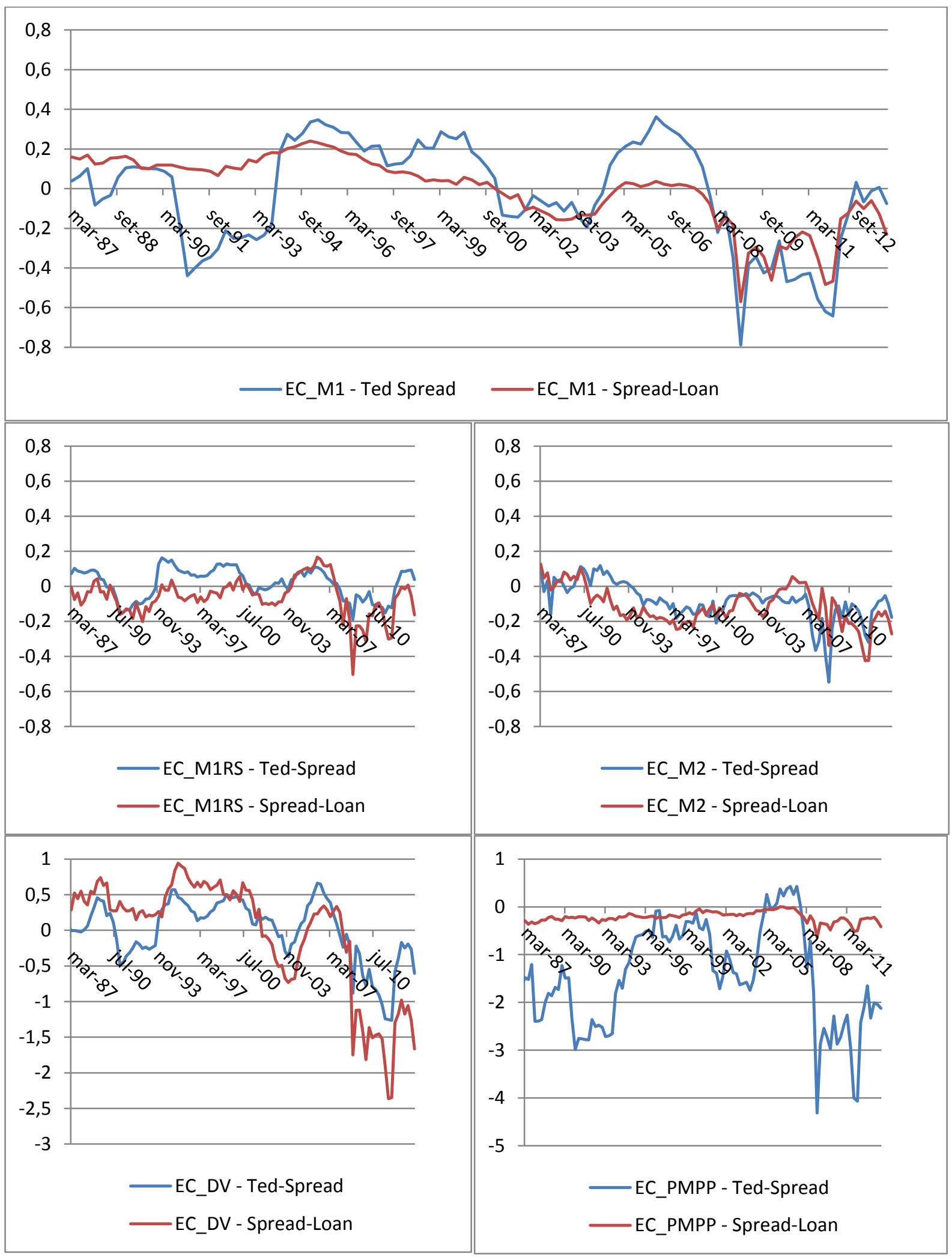




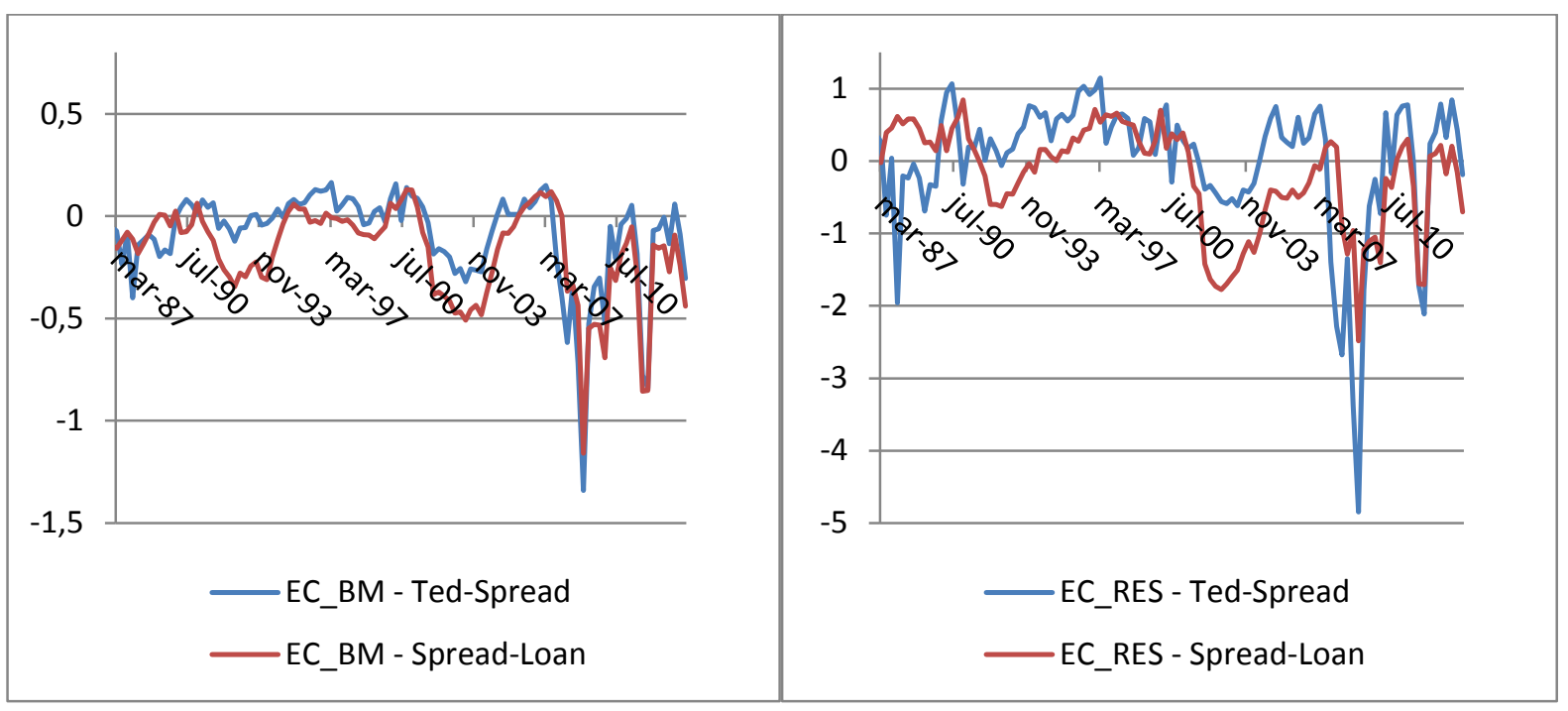

Figura 23 - Termo de correção de erros: modelos com Spread-Loan e TED-Spread

Na Tabela 32 e na Tabela 33 estão exibidos os resultados da estimação do modelo ARDL e do modelo de correção de erros para o modelo per capita com TED-Spread. Os resultados aqui incluem coeficientes significativos para mais coeficientes de variáveis de risco: o coeficiente associado ao índice de Sharpe aparece negativo e significativo para o agregado M1 per capita, e a variável de spread aparece significativa para M2, M1RS, PMPP, BM e RES (observe que, como o valor médio do TED-Spread é menor, tais coeficientes tem módulo maior em comparação aos da seção anterior). Os coeficientes associados à volatilidade do PIB aparecem significativos e negativos para três agregados per capita: PMPP, BM e RES. Vale destacar também a maior presença de variáveis de interação dentre estes modelos.

Tabela 32 - Resultados: modelo per capita com risco e com TED_Spread

\begin{tabular}{|c|c|c|c|c|c|c|c|}
\hline & M1 & M2 & M1RS & DV & PMPP & BM & RES \\
\hline \multicolumn{8}{|c|}{ Painel A: Coeficientes Padronizados de Longo Prazo } \\
\hline \multirow[t]{2}{*}{$\ln (Y)$} & $-1,804$ & 1,441 & 0,686 & $-3,810$ & $-2,739$ & $-0,964$ & $-6,832$ \\
\hline & $0,004^{*}$ & $0,006^{*}$ & 0,260 & $0,034 *$ & 0,607 & 0,518 & 0,119 \\
\hline \multirow[t]{2}{*}{$\ln (r)$} & $-0,113$ & $-0,077$ & $-0,054$ & $-0,249$ & $-0,223$ & $-0,520$ & $-1,499$ \\
\hline & $0,012^{*}$ & 0,051 & 0,061 & $0,010 *$ & 0,060 & $0,012^{*}$ & $0,010 *$ \\
\hline \multirow[t]{2}{*}{ Sharpe } & $-1,556$ & 0,054 & 0,089 & 0,302 & $-0,752$ & $-0,585$ & $-2,523$ \\
\hline & $0,011^{*}$ & 0,792 & 0,424 & 0,493 & 0,220 & 0,302 & 0,179 \\
\hline \multirow[t]{2}{*}{ TED_Spread } & $-43,934$ & 19,576 & $-30,704$ & 5,318 & $-302,061$ & $-252,993$ & $-722,963$ \\
\hline & 0,108 & $0,034^{*}$ & 0,039* & 0,757 & $0,001^{*}$ & $0,001^{*}$ & $0,008^{*}$ \\
\hline \multirow[t]{2}{*}{ Vol_r } & $-0,057$ & 0,024 & $-0,017$ & $-0,212$ & $-0,385$ & 0,051 & 0,554 \\
\hline & 0,525 & 0,799 & 0,732 & 0,250 & 0,163 & 0,838 & 0,514 \\
\hline
\end{tabular}




\begin{tabular}{|c|c|c|c|c|c|c|c|}
\hline & M1 & M2 & M1RS & DV & PMPP & BM & RES \\
\hline \multirow[t]{2}{*}{ Vol_Y } & $-73,284$ & 1,988 & 4,098 & 70,464 & $-271,736$ & $-385,815$ & $-1153,412$ \\
\hline & 0,213 & 0,942 & 0,843 & 0,290 & $0,021^{*}$ & $0,000^{*}$ & $0,002^{*}$ \\
\hline \multirow[t]{2}{*}{ Const. } & 25,398 & $-3,805$ & 2,240 & 41,389 & 34,923 & 17,172 & 69,197 \\
\hline & $0,007^{*}$ & 0,387 & 0,331 & $0,046^{*}$ & 0,271 & 0,124 & 0,104 \\
\hline \multirow[t]{2}{*}{$I T\left[\begin{array}{c}\operatorname{Vol}(P I B), \\
\text { Sharpe }\end{array}\right]$} & 257,58 & - & - & - & - & - & - \\
\hline & $0,014^{*}$ & - & - & - & - & - & - \\
\hline \multirow{2}{*}{$I T\left[\begin{array}{c}\operatorname{Vol}(P I B), \\
\text { Spread }\end{array}\right]$} & 8458,4 & - & 4448,3 & - & 49487,9 & 53631,7 & 184873,7 \\
\hline & 0,052 & - & 0,055 & - & $0,000^{*}$ & $0,000 *$ & $0,000 *$ \\
\hline \multicolumn{8}{|c|}{ Painel B: Coeficientes de Curto Prazo Selecionados } \\
\hline \multirow[t]{2}{*}{$\Delta \ln (Y)$} & 0,511 & 0,291 & 0,563 & 0,182 & 0,443 & 0,910 & 2,603 \\
\hline & 0,052 & 0,063 & $0,007^{*}$ & 0,782 & $0,009^{*}$ & 0,228 & 0,312 \\
\hline \multirow[t]{2}{*}{$\Delta \ln (r)$} & $-0,022$ & $-0,012$ & $-0,015$ & $-0,064$ & $-0,009$ & $-0,091$ & $-0,236$ \\
\hline & $0,000^{*}$ & $0,000 *$ & $0,000^{*}$ & $0,000^{*}$ & $0,000^{*}$ & $0,000^{*}$ & $0,000^{*}$ \\
\hline \multirow[t]{2}{*}{$\Delta$ Sharpe } & $-0,006$ & $-0,007$ & 0,001 & 0,008 & $-0,010$ & 0,069 & 0,223 \\
\hline & 0,685 & 0,393 & 0,937 & 0,827 & 0,272 & 0,102 & 0,116 \\
\hline \multirow[t]{2}{*}{$\Delta$ TED_Spread } & $-0,024$ & $-0,066$ & $-0,350$ & 1,084 & 0,094 & 3,204 & 20,670 \\
\hline & 0,968 & 0,852 & 0,454 & 0,463 & 0,814 & 0,059 & $0,001^{*}$ \\
\hline \multirow[t]{2}{*}{$\Delta V o l \_r$} & $-0,009$ & 0,000 & $-0,004$ & $-0,002$ & 0,002 & $-0,010$ & $-0,081$ \\
\hline & 0,402 & 0,954 & 0,607 & 0,927 & 0,789 & 0,726 & 0,405 \\
\hline \multirow[t]{3}{*}{$\Delta V o l \_Y$} & $-0,343$ & $-0,568$ & $-0,687$ & 0,782 & 0,277 & $-5,855$ & $-5,344$ \\
\hline & 0,889 & 0,686 & 0,731 & 0,899 & 0,857 & 0,403 & 0,826 \\
\hline & M1 & M2 & M1RS & DV & PMPP & BM & RES \\
\hline \multicolumn{8}{|c|}{ Painel C: Ajuste do modelo } \\
\hline$\overline{R^{2}}$ & 0,579 & 0,468 & 0,473 & 0,528 & 0,373 & 0,633 & 0,606 \\
\hline$\chi_{B G}^{2}(2)$ & 1,497 & 0,360 & 4,316 & 1,846 & 0,915 & 2,977 & 0,177 \\
\hline p-valor & 0,473 & 0,835 & 0,116 & 0,397 & 0,633 & 0,226 & 0,915 \\
\hline
\end{tabular}

Tabela 33 - Resultados: ECM modelo per capita com risco e com TED_Spread

\begin{tabular}{cccccccc}
\hline & M1 & M2 & M1RS & DV & PMPP & BM & RES \\
\hline$\widetilde{\boldsymbol{E C}_{\boldsymbol{t}-\mathbf{1}}}$ & $-0,054$ & $-0,030$ & $-0,076$ & $-0,064$ & $-0,011$ & $-0,055$ & $-0,055$ \\
Teste t & $-5,883$ & $-3,824$ & $-5,117$ & $-4,700$ & $-5,531$ & $-7,222$ & $-7,668$ \\
p-valor & $0,000^{*}$ & $0,000^{*}$ & $0,000^{*}$ & $0,000^{*}$ & $0,000^{*}$ & $0,000^{*}$ & $0,000^{*}$ \\
$\overline{\boldsymbol{R}^{\mathbf{2}}}$ & 0,613 & 0,500 & 0,510 & 0,557 & 0,417 & 0,659 & 0,634 \\
$\boldsymbol{\chi}_{\boldsymbol{B} \boldsymbol{G}}^{2}(\mathbf{2})$ & 1,068 & 0,326 & 3,676 & 1,375 & 0,824 & 2,818 & 0,173 \\
$\mathbf{p}$-valor & 0,586 & 0,849 & 0,159 & 0,503 & 0,662 & 0,244 & 0,917 \\
\hline
\end{tabular}

Em relação aos modelos que utilizam a variável de Spread-T30, novamente os resultados obtidos estarão relacionados ao período de disponibilidade de dados: só possuímos dados para este Spread a partir de 1977. Além disso, é importante notar que não existem dados para este Spread para o período entre 2002 e 2005. Novamente, da Tabela 34 à Tabela 
37 são exibidos, para modelos agregados e per capita, os resultados das estruturas de defasagens selecionadas para cada agregado pelos critérios BIC e AIC ao modelo de demanda por moeda com Spread-T30; e os valores do teste F representativo do procedimento de bounds testing, para diferentes defasagens no mesmo modelo. Observe que os resultados são semelhantes aos da metodologia anterior com variável TED-Spread, e novamente o modelo com agregado PMPP não apresenta evidências de cointegração.

Tabela 34 - Defasagens selecionadas: modelo com variáveis de risco e Spread T30

\begin{tabular}{llc}
\hline & \multicolumn{1}{c}{ BIC } & AIC \\
\hline M1 & $\operatorname{ARDL}(2,0,0,0,0,0,0)$ & $\operatorname{ARDL}(2,0,0,0,0,0,0)$ \\
M2 & $\operatorname{ARDL}(1,0,0,0,0,0,0)$ & $\operatorname{ARDL}(1,0,0,0,0,0,6)$ \\
M1RS & $\operatorname{ARDL}(1,0,0,0,0,0,0)$ & $\operatorname{ARDL}(2,0,0,0,0,0,0)$ \\
DV & $\operatorname{ARDL}(2,0,0,0,0,0,0)$ & $\operatorname{ARDL}(4,0,0,0,0,3,0)$ \\
PMPP & $\operatorname{ARDL}(1,0,0,0,0,0,0)$ & $\operatorname{ARDL}(1,0,0,0,0,0,1)$ \\
BM & $\operatorname{ARDL}(4,0,4,0,0,0,0)$ & $\operatorname{ARDL}(4,0,4,0,0,0,0)$ \\
RES & $\operatorname{ARDL}(1,0,0,0,0,0,0)$ & $\operatorname{ARDL}(1,0,0,0,0,0,0)$ \\
\hline
\end{tabular}

Tabela 35 - Defasagens selecionadas: modelo per capita com variáveis de risco e Spread T30

\begin{tabular}{lcc}
\hline & \multicolumn{1}{c}{ BIC } & AIC \\
\hline M1 & $\operatorname{ARDL}(2,0,0,0,0,0,0)$ & $\operatorname{ARDL}(2,0,0,0,0,0,0)$ \\
M2 & $\operatorname{ARDL}(1,0,0,0,0,0,0)$ & $\operatorname{ARDL}(5,0,0,0,0,0,6)$ \\
M1RS & $\operatorname{ARDL}(1,0,0,0,0,0,0)$ & $\operatorname{ARDL}(2,0,0,0,0,0,0)$ \\
\hline DV & $\operatorname{ARDL}(2,0,0,0,0,0,0)$ & $\operatorname{ARDL}(4,0,0,0,0,3,0)$ \\
PMPP & $\operatorname{ARDL}(1,0,0,0,0,0,1)$ & $\operatorname{ARDL}(1,0,0,0,0,0,1)$ \\
BM & $\operatorname{ARDL}(3,0,0,0,0,0,0)$ & $\operatorname{ARDL}(4,0,4,0,0,0,0)$ \\
RES & $\operatorname{ARDL}(1,0,0,0,0,0,0)$ & $\operatorname{ARDL}(5,0,6,0,0,0,0)$ \\
\hline
\end{tabular}

Tabela 36 - Teste F ("bounds-testing"): modelo com variáveis de risco e Spread T30

\begin{tabular}{ccccccc}
\hline Lags & $\mathbf{1}$ & $\mathbf{2}$ & $\mathbf{3}$ & $\mathbf{4}$ & $\mathbf{5}$ & $\mathbf{6}$ \\
\hline M1 & $4,319 * *$ & 2,216 & 2,900 & $4,907^{*}$ & $3,318 * * *$ & 2,941 \\
M2 & 0,723 & 0,820 & 1,394 & 1,408 & 1,616 & $3,648 * *$ \\
M1RS & 3,093 & 2,531 & $3,363 * * *$ & $4,750^{*}$ & $3,484 * * *$ & 3,353 \\
DV & $6,857^{*}$ & $3,244 * * *$ & $3,573 * * *$ & $5,040^{*}$ & $4,579 *$ & 2,940 \\
PMPP & 1,689 & 1,284 & 1,473 & 1,504 & 0,495 & 0,770 \\
BM & $4,518^{*}$ & $4,670^{*}$ & $4,734 *$ & $5,675^{*}$ & $5,039 *$ & $3,243 * * *$ \\
RES & $4,415^{* *}$ & $3,985^{* *}$ & $3,292^{* * *}$ & $3,369 * * *$ & 2,949 & 1,953
\end{tabular}

\footnotetext{
*Intervalo de valores críticos relevantes (intercepto irrestrito e sem tendência, com seis regressores, $\mathrm{k}=6)$ : $(2,12$; $3,23)$, a $90 \%$ de confiança***; $(2,45 ; 3,61)$, a $95 \%$ de confiança**, e $(3,15 ; 4,43)$, a $99 \%$ de confiança*. (ver Tabela CI(iii), Pesaran et al.(2001)).
} 
Tabela 37 - Teste F (“bounds-testing”): modelo per capita com variáveis de risco e Spread T30

\begin{tabular}{ccccccc}
\hline Lags & $\mathbf{1}$ & $\mathbf{2}$ & $\mathbf{3}$ & $\mathbf{4}$ & $\mathbf{5}$ & $\mathbf{6}$ \\
\hline M1 & $4,196^{* *}$ & 2,193 & 2,800 & $4,636^{*}$ & 3,076 & 2,646 \\
M2 & 0,758 & 0,852 & 1,437 & 1,429 & 1,657 & $3,698^{* *}$ \\
M1RS & 3,185 & 2,569 & $3,336^{* * *}$ & $4,681^{*}$ & $3,447^{* * *}$ & $3,309^{* * *}$ \\
\hline DV & $6,820^{*}$ & 3,220 & $3,647^{* *}$ & $4,999^{*}$ & $4,658^{*}$ & 2,968 \\
PMPP & 1,780 & 1,311 & 1,526 & 1,622 & 0,602 & 0,886 \\
\hline BM & $4,597^{*}$ & $4,796^{*}$ & $4,940^{*}$ & $5,906^{*}$ & $5,267^{*}$ & $3,388^{* * *}$ \\
RES & $3,811^{* *}$ & $3,377^{* * *}$ & 2,848 & 2,355 & 1,805 & 1,195 \\
\hline
\end{tabular}

*Intervalo de valores críticos relevantes (intercepto irrestrito e sem tendência, com seis regressores, $\mathrm{k}=6)$ : $(2,12$; 3,23), a $90 \%$ de confiança***; $(2,45 ; 3,61)$, a 95\% de confiança**, e $(3,15 ; 4,43)$, a 99\% de confiança*. (ver Tabela CI(iii), Pesaran et al.(2001)).

A Tabela 38 abaixo exibe os resultados obtidos para a estimação dos modelos agregados com Spread-T30 selecionados pelo critério BIC. Novamente, nos casos em que se observou evidência de autocorrelação nos resíduos, foi utilizado o modelo selecionado pelo critério AIC. Os coeficientes de curto prazo defasados estão mais uma vez exibidos no Apêndice deste trabalho. Na Tabela 39 estão exibidos os resultados da estimação dos modelos de correção de erros. Novamente, todos os coeficientes do termo de correção de erros são negativos e significativos a 5\%, porém o coeficiente para o ECM de PMPP é bastante baixo: $1,1 \%$ dos choques na demanda de equilíbrio da moeda são revertidos no período seguinte.

Tabela 38 - Resultados: modelo com risco e com Spread T30

\begin{tabular}{|c|c|c|c|c|c|c|c|}
\hline & M1 & M2 & M1RS & DV & PMPP & BM & RES \\
\hline \multicolumn{8}{|c|}{ Painel A: Coeficientes Padronizados de Longo Prazo } \\
\hline \multirow[t]{2}{*}{$\ln (Y)$} & 0,135 & 1,102 & 0,972 & $-1,485$ & 1,174 & 0,869 & $-1,604$ \\
\hline & 0,575 & 0,073 & $0,002 *$ & $0,023^{*}$ & 0,670 & $0,000 *$ & $0,004^{*}$ \\
\hline \multirow[t]{2}{*}{$\ln (r)$} & $-0,098$ & $-0,049$ & $-0,050$ & $-0,241$ & $-0,098$ & $-0,271$ & $-0,811$ \\
\hline & $0,047^{*}$ & 0,470 & $0,032 *$ & $0,006^{*}$ & 0,359 & $0,000^{*}$ & $0,000^{*}$ \\
\hline \multirow[t]{2}{*}{ Sharpe } & 0,098 & 0,196 & 0,079 & 0,216 & 0,227 & $-0,069$ & $-0,373$ \\
\hline & 0,548 & 0,383 & 0,202 & 0,330 & 0,571 & 0,183 & 0,165 \\
\hline \multirow[t]{2}{*}{ Spread } & 9,869 & 2,362 & 2,041 & 12,961 & 22,446 & $-2,950$ & $-9,647$ \\
\hline & $0,000^{*}$ & 0,519 & 0,085 & $0,007^{*}$ & $0,002^{*}$ & $0,005^{*}$ & $0,050 *$ \\
\hline \multirow[t]{2}{*}{ Vol_r } & 0,034 & 0,057 & $-0,011$ & $-0,419$ & 0,157 & 0,009 & 0,124 \\
\hline & 0,669 & 0,616 & 0,752 & $0,010^{*}$ & 0,450 & 0,725 & 0,372 \\
\hline \multirow[t]{2}{*}{ Vol_Y } & $-6,446$ & 21,332 & $-0,295$ & 39,140 & $-46,903$ & 3,085 & $-32,751$ \\
\hline & 0,723 & 0,349 & 0,967 & 0,143 & 0,309 & 0,625 & 0,241 \\
\hline \multirow[t]{2}{*}{ Const. } & 5,659 & $-0,471$ & $-0,503$ & 16,879 & $-3,322$ & $-1,235$ & 15,206 \\
\hline & 0,088 & 0,897 & 0,488 & $0,020^{*}$ & 0,778 & 0,060 & $0,002 *$ \\
\hline
\end{tabular}




\begin{tabular}{|c|c|c|c|c|c|c|c|}
\hline & M1 & M2 & M1RS & DV & PMPP & BM & RES \\
\hline \multicolumn{8}{|c|}{ Painel B: Coeficientes de Curto Prazo Selecionados } \\
\hline \multirow[t]{2}{*}{$\Delta \ln (Y)$} & 0,187 & 0,266 & 0,585 & $-0,020$ & 0,319 & 0,399 & $-0,206$ \\
\hline & 0,286 & $0,024^{*}$ & $0,000 *$ & 0,959 & $0,008 *$ & 0,355 & 0,908 \\
\hline \multirow{2}{*}{$\Delta \ln (r)$} & $-0,023$ & $-0,013$ & $-0,016$ & $-0,063$ & $-0,008$ & $-0,110$ & $-0,318$ \\
\hline & $0,000^{*}$ & $0,000^{*}$ & $0,000 *$ & $0,000 *$ & $0,000 *$ & $0,000 *$ & $0,000 *$ \\
\hline \multirow[t]{2}{*}{$\Delta$ Sharpe } & 0,007 & $-0,002$ & 0,001 & 0,001 & $-0,005$ & 0,018 & $-0,011$ \\
\hline & 0,510 & 0,746 & 0,950 & 0,965 & 0,441 & 0,506 & 0,920 \\
\hline \multirow[t]{2}{*}{$\Delta$ Spread } & $-0,011$ & 0,069 & 0,031 & $-0,577$ & 0,102 & $-1,304$ & $-3,939$ \\
\hline & 0,947 & 0,495 & 0,833 & 0,116 & 0,315 & $0,001^{*}$ & $0,015^{*}$ \\
\hline \multirow[t]{2}{*}{$\Delta V o l \_r$} & 0,010 & 0,005 & 0,006 & $-0,024$ & 0,005 & $-0,014$ & $-0,058$ \\
\hline & 0,229 & 0,368 & 0,512 & 0,317 & 0,346 & 0,534 & 0,501 \\
\hline \multirow[t]{2}{*}{$\Delta V o l \_Y$} & $-1,563$ & 0,206 & 0,295 & 1,483 & $-0,147$ & $-0,392$ & $-3,291$ \\
\hline & 0,323 & 0,839 & 0,838 & 0,664 & 0,881 & 0,923 & 0,832 \\
\hline \multicolumn{8}{|c|}{ Painel C: Ajuste do modelo } \\
\hline$\overline{R^{2}}$ & 0,539 & 0,434 & 0,519 & 0,606 & 0,398 & 0,677 & 0,481 \\
\hline$\chi_{B G}^{2}(2)$ & 3,289 & 1,456 & 0,529 & 3,119 & 1,192 & 1,034 & 0,545 \\
\hline p-valor & 0,193 & 0,483 & 0,767 & 0,210 & 0,551 & 0,596 & 0,762 \\
\hline
\end{tabular}

Tabela 39 - Resultados: ECM modelo com risco e com Spread T30

\begin{tabular}{cccccccc}
\hline & M1 & M1RS & M2 & DV & PMPP & BM & RES \\
\hline$\overline{\boldsymbol{E C}}$ & $-0,047$ & $-0,020$ & $-0,111$ & $-0,069$ & $-0,011$ & $-0,361$ & $-0,267$ \\
Teste t & $-5,213$ & $-2,618$ & $-4,338$ & $-6,548$ & $-4,513$ & $-6,319$ & $-5,921$ \\
p-valor & $0,000^{*}$ & $0,010^{*}$ & $0,000^{*}$ & $0,000^{*}$ & $0,000^{*}$ & $0,000^{*}$ & $0,000^{*}$ \\
$\overline{\boldsymbol{R}^{\mathbf{2}}}$ & 0,562 & 0,462 & 0,547 & 0,627 & 0,428 & 0,694 & 0,507 \\
$\boldsymbol{\chi}_{\boldsymbol{B} \boldsymbol{G}}^{\boldsymbol{R}}(\mathbf{2})$ & 2,609 & 1,254 & 0,502 & 2,138 & 1,039 & 0,846 & 0,529 \\
$\mathbf{p}$-valor & 0,271 & 0,534 & 0,778 & 0,343 & 0,595 & 0,655 & 0,768 \\
\hline
\end{tabular}

Nas novas estimações, observamos coeficiente de longo prazo associado à nova variável de Spread significativo (a 5\%) para os agregados M1, DV, PMPP, BM e RES (positivo para os três primeiros e negativo para os dois últimos, para os quais obtivemos também coeficiente de curto prazo significativo). Uma estimativa significativa e negativa foi também obtida para a variável de volatilidade de juros no longo prazo, na equação de demanda pelo agregado DV.

A Figura 24 abaixo exibe o desempenho dos modelos com variável Spread-T30 em comparação aos modelos anteriores com variável Spread-Loan, novamente em termos de erros da demanda por moeda prevista pelo modelo de longo prazo estimado em relação à demanda efetivamente observada no período (i.e.: o termo de erro utilizado nos modelos ECM). 


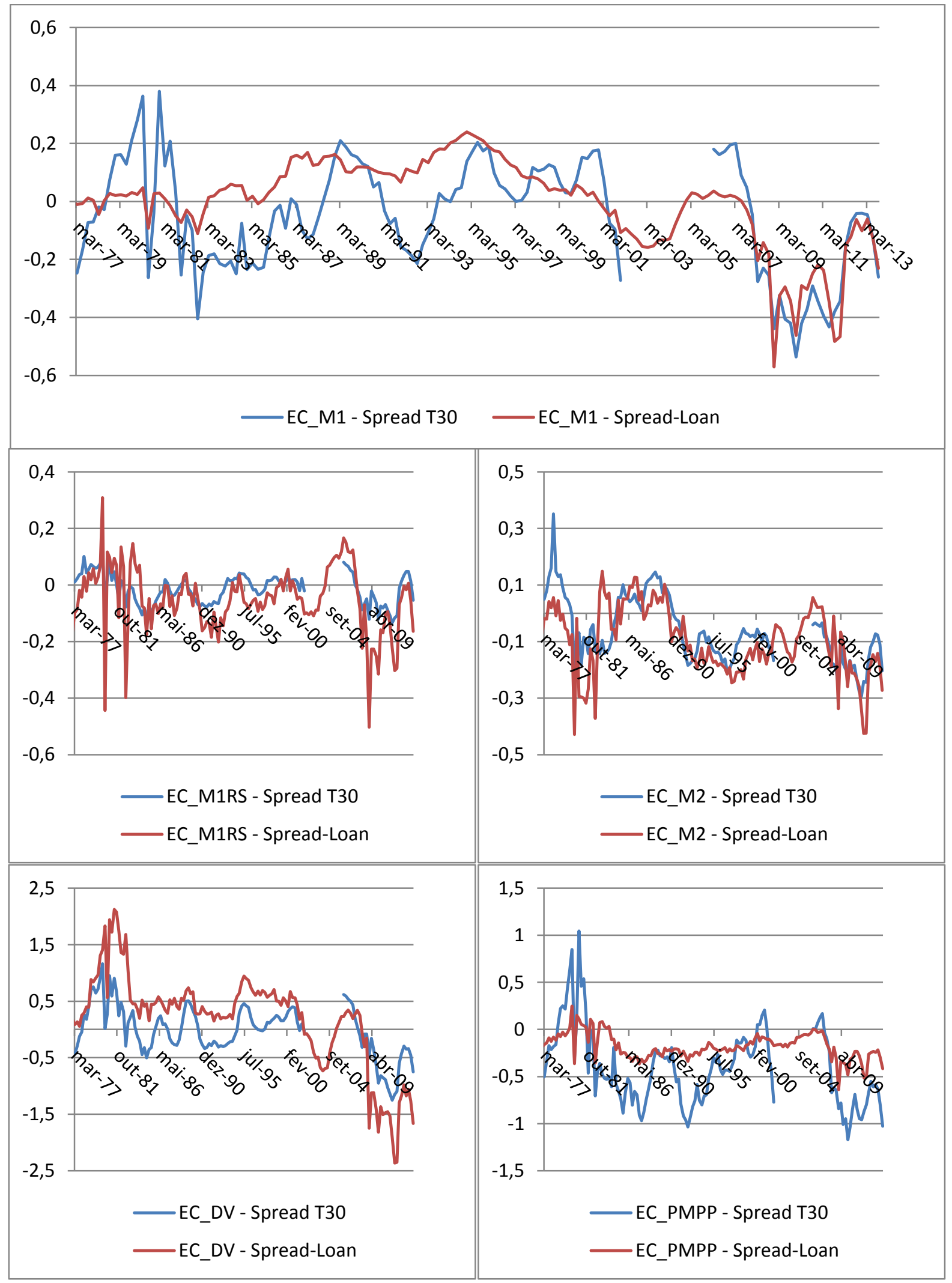




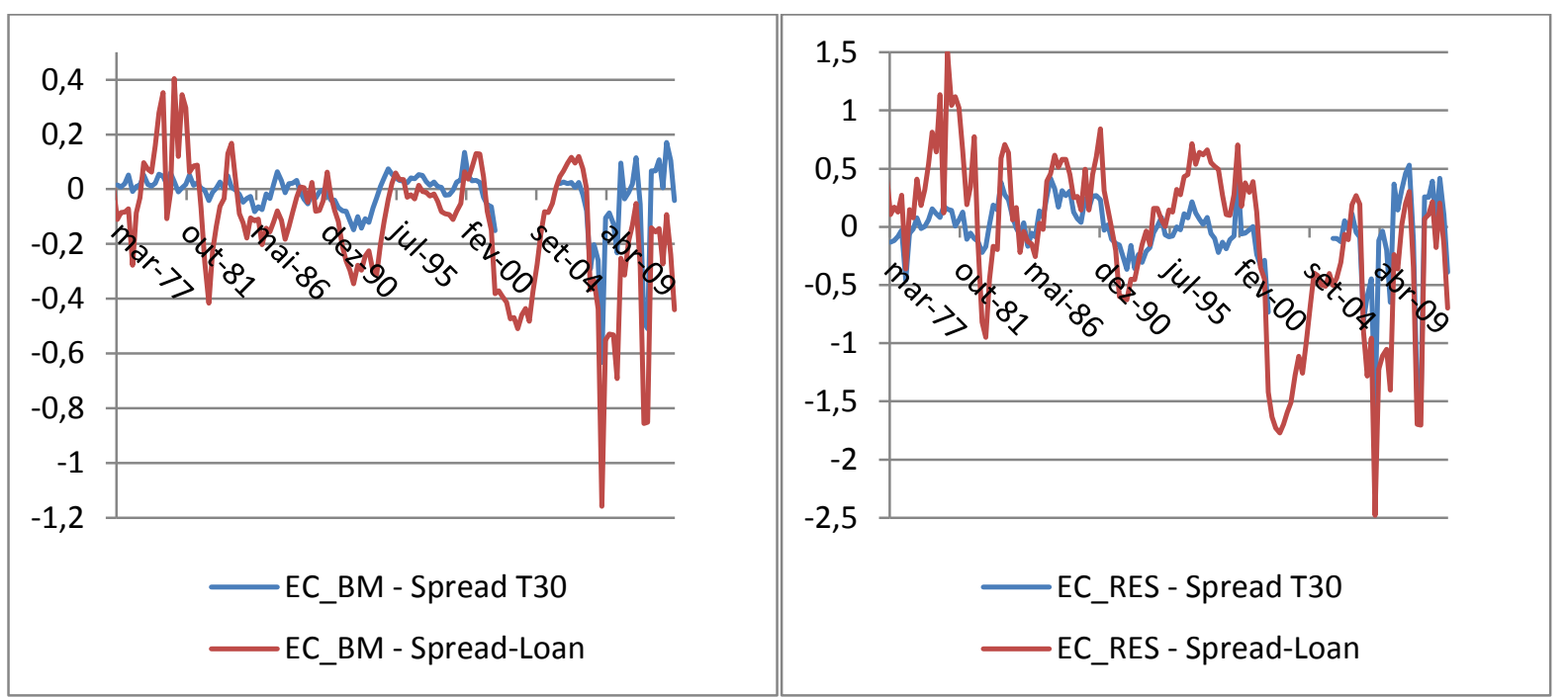

Figura 24 - Termo de correção de erros: modelos com Spread-Loan e Spread-T30

Para as estimações dos modelos per capita, temos os resultados exibidos na Tabela 40 abaixo, bem como os resultados dos modelos de correção de erros na Tabela 41. As maiores diferenças em relação ao modelo agregado ficam por conta dos coeficientes de spread, que aqui aparecem significativos apenas para M1, M2 (negativo neste caso) e PMPP. Para este último agregado, temos também um coeficiente significativo e negativo associado à volatilidade do PIB, bem como um coeficiente positivo e significativo para a variável de interação entre as duas volatilities.

Tabela 40 - Resultados: modelo per capita com risco e com Spread T30

\begin{tabular}{|c|c|c|c|c|c|c|c|}
\hline & M1 & M2 & M1RS & DV & PMPP & BM & RES \\
\hline \multicolumn{8}{|c|}{ Painel A: Coeficientes Padronizados de Longo Prazo } \\
\hline $\ln (Y)$ & $-0,549$ & 0,514 & 0,879 & $-3,500$ & 1,439 & 0,658 & $-3,564$ \\
\hline & 0,285 & 0,377 & $0,007^{*}$ & 0,116 & 0,442 & $0,018^{*}$ & $0,004 *$ \\
\hline \multirow[t]{2}{*}{$\ln (r)$} & $-0,089$ & $-0,122$ & $-0,061$ & $-0,275$ & $-0,086$ & $-0,301$ & $-0,788$ \\
\hline & 0,052 & $0,024^{*}$ & $0,005^{*}$ & $0,023^{*}$ & 0,151 & $0,000^{*}$ & $0,000 *$ \\
\hline \multirow[t]{2}{*}{ Sharpe } & 0,063 & 0,286 & 0,051 & $-0,088$ & $-0,058$ & $-0,165$ & $-0,521$ \\
\hline & 0,681 & 0,118 & 0,389 & 0,785 & 0,806 & 0,064 & 0,079 \\
\hline \multirow[t]{2}{*}{ Spread } & 9,095 & $-23,779$ & 1,316 & 10,918 & 14,605 & $-3,125$ & $-10,751$ \\
\hline & $0,001 *$ & $0,002^{*}$ & 0,275 & 0,140 & $0,000^{*}$ & 0,066 & 0,056 \\
\hline \multirow[t]{2}{*}{ Vol_r $r$} & 0,017 & 0,107 & $-0,007$ & $-0,191$ & $-0,361$ & 0,027 & 0,095 \\
\hline & 0,828 & 0,245 & 0,831 & 0,333 & 0,144 & 0,569 & 0,537 \\
\hline \multirow[t]{2}{*}{ Vol_Y } & $-9,233$ & $-26,725$ & $-2,914$ & $-10,075$ & $-92,166$ & $-9,313$ & $-42,853$ \\
\hline & 0,635 & 0,233 & 0,656 & 0,782 & $0,018^{*}$ & 0,353 & 0,179 \\
\hline \multirow[t]{2}{*}{ Const. } & 13,175 & 4,931 & 0,383 & 38,842 & $-5,514$ & 0,905 & 36,965 \\
\hline & 0,086 & 0,404 & 0,808 & 0,113 & 0,621 & 0,682 & $0,002 *$ \\
\hline
\end{tabular}




\begin{tabular}{|c|c|c|c|c|c|c|c|}
\hline & M1 & M2 & M1RS & DV & PMPP & BM & RES \\
\hline \multirow[t]{2}{*}{$I T\left[\begin{array}{c}\operatorname{Vol}(P I B), \\
\operatorname{Vol}(r)\end{array}\right]$} & & & & & 46,391 & & \\
\hline & & & & & $0,037^{*}$ & & \\
\hline$I T\left[\begin{array}{c}\operatorname{Vol}(P I B), \\
\text { Spread }\end{array}\right]$ & & 2696,64 & & & & & \\
\hline & & $0,000^{*}$ & & & & & \\
\hline \multicolumn{8}{|c|}{ Painel B: Coeficientes de Curto Prazo Selecionados } \\
\hline \multirow[t]{2}{*}{$\Delta \ln (Y)$} & 0,162 & 0,308 & 0,459 & $-0,237$ & 0,287 & 0,445 & $-0,282$ \\
\hline & 0,357 & $0,006^{*}$ & $0,002^{*}$ & 0,533 & $0,013^{*}$ & 0,350 & 0,875 \\
\hline \multirow[t]{2}{*}{$\Delta \ln (r)$} & $-0,023$ & $-0,013$ & $-0,016$ & $-0,065$ & $-0,009$ & $-0,107$ & $-0,312$ \\
\hline & $0,000^{*}$ & $0,000 *$ & $0,000^{*}$ & $0,000^{*}$ & $0,000^{*}$ & $0,000^{*}$ & $0,000 *$ \\
\hline \multirow[t]{2}{*}{$\Delta$ Sharpe } & 0,006 & $-0,003$ & 0,006 & $-0,010$ & $-0,006$ & 0,016 & $-0,029$ \\
\hline & 0,569 & 0,650 & 0,466 & 0,674 & 0,334 & 0,589 & 0,790 \\
\hline \multirow[t]{2}{*}{$\Delta$ Spread } & $-0,033$ & 0,192 & 0,067 & $-0,871$ & 0,100 & $-1,105$ & $-4,043$ \\
\hline & 0,838 & 0,059 & 0,615 & $0,019^{*}$ & 0,315 & $0,014^{*}$ & $0,014 *$ \\
\hline \multirow[t]{2}{*}{$\Delta V o l \_r$} & 0,010 & 0,012 & 0,009 & $-0,004$ & 0,004 & $-0,024$ & $-0,062$ \\
\hline & 0,255 & $0,031^{*}$ & 0,199 & 0,847 & 0,508 & 0,311 & 0,481 \\
\hline \multirow[t]{2}{*}{$\Delta$ Vol_Y } & $-1,579$ & 0,043 & $-1,017$ & 0,957 & $-0,218$ & $-2,461$ & $-4,196$ \\
\hline & 0,320 & 0,964 & 0,423 & 0,778 & 0,823 & 0,567 & 0,789 \\
\hline \multicolumn{8}{|c|}{ Painel C: Ajuste do modelo } \\
\hline$\overline{R^{2}}$ & 0,544 & 0,501 & 0,523 & 0,568 & 0,419 & 0,598 & 0,469 \\
\hline$\chi_{B G}^{2}(2)$ & 2,737 & 0,272 & 3,613 & 1,938 & 0,358 & 1,397 & 0,244 \\
\hline p-valor & 0,255 & 0,873 & 0,164 & 0,380 & 0,836 & 0,497 & 0,885 \\
\hline
\end{tabular}

Tabela 41 - Resultados: ECM modelo per capita com risco e com Spread T30

\begin{tabular}{cccccccc}
\hline & M1 & M2 & M1RS & DV & PMPP & BM & RES \\
\hline$\overline{E \boldsymbol{C}_{\boldsymbol{t}-\mathbf{1}}}$ & $-0,048$ & $-0,024$ & $-0,095$ & $-0,048$ & $-0,020$ & $-0,227$ & $-0,245$ \\
Teste t & $-5,205$ & $-4,791$ & $-4,186$ & $-5,353$ & $-5,171$ & $-6,920$ & $-5,609$ \\
$\mathbf{p}$-valor & $0,000^{*}$ & $0,000^{*}$ & $0,000^{*}$ & $0,000^{*}$ & $0,000^{*}$ & $0,000^{*}$ & $0,000^{*}$ \\
$\overline{\boldsymbol{R}^{\mathbf{2}}}$ & 0,567 & 0,530 & 0,548 & 0,590 & 0,453 & 0,619 & 0,495 \\
$\boldsymbol{\chi}_{\boldsymbol{B} \boldsymbol{G}}^{2}(\mathbf{2})$ & 2,243 & 0,263 & 2,892 & 1,378 & 0,299 & 1,224 & 0,238 \\
$\mathbf{p}$-valor & 0,326 & 0,877 & 0,235 & 0,502 & 0,861 & 0,542 & 0,888 \\
\hline
\end{tabular}

Os resultados obtidos neste capítulo são animadores: em várias estimações, as variáveis de risco adicionadas à relação de demanda por moeda propostas anteriormente apresentam coeficientes estimados significativos, e os termos de correção de erros relacionados estáveis ao longo do período da amostra sugerem que o modelo utilizado se associa a uma relação de longo prazo, conforme esperado. O uso de três diferentes variáveis de spread produziu resultados similares, de modo que, no capítulo seguinte, apresentaremos 
alguns complementos ao modelo geral proposto neste capítulo utilizando o spread-loan como variável de spread. 


\section{$5 \quad$ EXTENSÕES AO MODELO PROPOSTO}

Neste capítulo, serão apresentados alguns complementos à abordagem proposta no capítulo anterior, particularmente no sentido de investigar uma possível modificação do modelo anterior com vista a uma melhor adaptação do mesmo a eventos recentes e também na aplicação do modelo com metodologia alternativa de dados utilizados e abordagem para estimação.

Mais especificamente, na primeira seção realizaremos a estimação do modelo de demanda por moeda com variáveis de risco com periodicidade mensal dos dados, utilizando para isso uma variável de escala distinta. Em seguida, na segunda seção, será proposta uma modelagem alternativa para as variáveis de risco utilizadas (exceto spread), através do uso de um modelo GARCH; e a posterior estimação do modelo de demanda por moeda com tais variáveis. Finalmente, na terceira seção deste capítulo será explorado o forte efeito da crise financeira iniciada em 2008 sobre os modelos de demanda por moeda apresentados até então, bem como serão investigadas possíveis alternativas metodológicas para que o período posterior seja melhor entendido a partir do modelo com variáveis de risco proposto.

\subsection{Estimação do modelo com dados mensais}

As estimações obtidas no capítulo anterior contavam com aproximadamente 215 observações, dependendo do número de defasagens utilizado (nos modelos com Spread_loan; com a variável TED-Spread, foram em média 110 observações, e com o Spread-T30, foram 129 observações). Como vimos no capítulo 2, é esperado que o efeito das variáveis de risco sobre a demanda por moeda tenha começado a ganhar maior importância apenas por volta da década de 1980, e, portanto, é possível que a quantidade de observações (trimestres) utilizadas não tenha sido suficiente para observarmos satisfatoriamente a importância de tais efeitos. Além disso, dada a própria natureza das variáveis de volatilidade, desejamos ser capazes de captar os efeitos de eventuais movimentos de risco em nosso modelo utilizando a maior periodicidade de dados disponível. Nesta seção, portanto, propomos uma variável alternativa ao PIB real, cujos dados estão disponíveis apenas em termos trimestrais, para que possamos estimar o modelo de demanda por moeda com variáveis de risco em termos mensais. 


\subsubsection{Dados utilizados}

Nesta seção, utilizaremos os dados do Índice de Produção Industrial da economia dos EUA como variável de escala, de modo que todos os dados utilizados em nosso modelo de demanda por moeda com variáveis de risco estejam disponíveis para uso em uma estimação em termos mensais, que, consequentemente, será feita sob um número de observações maior, possivelmente permitindo-nos observar um ajuste melhor ao modelo.

O Índice de Produção Industrial (Industrial Production Index) mede o produto, em termos reais, de vários setores da economia dos Estados Unidos, e seus valores são divulgados em termos mensais (ajustados para sazonalidade) pelo "Board of Governors of the Federal Reserve System", em seu release G.17 (Industrial Production and Capacity Utilization), com dados disponíveis a partir de 1919. Para denomina-la em termos per capita, para os modelos com tais variáveis, foi efetuada a conversão da variável de população para número índice com a mesma data base utilizada para o IPI. Após o procedimento, denominamos por IPI per capita a razão entre as duas varáveis.

\subsubsection{Estrutura de lags e bounds-testing}

Denotando por $I P I_{t}$ os valores da nova variável no período (mês) $t$, e utilizando novamente esta variável de escala em termos de seu logaritmo natural, bem como utilizando o Spread-Loan como variável de spread, temos o seguinte modelo de demanda por moeda de longo prazo aumentado para variáveis de risco a ser estimado, em que todas as outras variáveis mantêm seu significado anterior, porém agora denominadas mensalmente:

$$
\begin{aligned}
\ln \left(M_{t} /_{P_{t}}\right)=\alpha_{0} & +\alpha_{1} \ln \left(I P I_{t}\right)+\alpha_{2} \ln \left(r_{t}\right)+\alpha_{3} \text { Sharpe }_{t}+\alpha_{4} \text { Spread }_{t}+\alpha_{5} \text { Vol_r }_{t} \\
& +\alpha_{6} \text { Vol_IPI }_{t}+\varepsilon_{t}
\end{aligned}
$$

Mantendo nossa metodologia apresentada na seção 4.2, e considerando a aplicação de modelos em termos agregado e per capita, a Tabela 42 e a Tabela 43 a seguir exibem os valores do teste $\mathrm{F}$ (bounds-testing) obtidos para diferentes defasagens aplicadas ao modelo de correção de erros irrestrito associado a (5.1). As duas tabelas seguintes apresentam a estrutura de defasagens selecionada pelos critérios BIC e AIC para cada agregado monetário em 
análise. ${ }^{31}$ Observe que, tendo em vista a maior periodicidade dos dados utilizados, foram testadas até 12 defasagens para o modelo de correção de erros irrestrito, visando uma melhor captação dos movimentos de curto-prazo. Em vista a essa possibilidade de seleção de um modelo com maior número de defasagens, os cálculos do teste $\mathrm{F}$ foram feitos também para um maior número de lags. Vale observar que, novamente, o modelo com o agregado PMPP apresenta fraca evidência de cointegração.

Tabela 42 - Teste F ("bounds-testing"): modelo com variáveis mensais

\begin{tabular}{|c|c|c|c|c|c|c|c|c|c|c|}
\hline Lags: & 1 & 2 & 3 & 4 & 5 & 6 & 7 & 8 & 9 & 10 \\
\hline M1 & $8,313^{*}$ & $6,031 *$ & $4,399 * *$ & $4,194 * *$ & $3,261 * * *$ & 2,292 & 2,152 & 2,027 & 2,049 & 1,679 \\
\hline M2 & 2,905 & 3,140 & $3,323 * * *$ & 2,716 & 2,040 & 2,178 & 2,011 & 2,307 & 2,510 & 2,253 \\
\hline M1RS & $5,309^{*}$ & $3,991 * *$ & 3,176 & 2,752 & 2,085 & 1,812 & 1,618 & 1,654 & 1,976 & 1,612 \\
\hline DV & $11,287 *$ & $9,925^{*}$ & $7,787 *$ & $8,699 *$ & $7,978 *$ & $4,122 * *$ & $3,790 * *$ & $3,431 * * *$ & 2,835 & 2,651 \\
\hline PMPP & 2,552 & 2,507 & 2,440 & 2,073 & 1,678 & 1,605 & 1,662 & 2,025 & 2,436 & 2,223 \\
\hline BM & 2,741 & $6,985^{*}$ & $4,149 * *$ & $4,042 * *$ & $3,521 * * *$ & $4,660 *$ & $5,3768 *$ & $5,641 *$ & $5,4811 *$ & $5,758^{*}$ \\
\hline RES & 2,575 & $4,960 *$ & $3,993 * *$ & $3,973 * *$ & $3,515 * * *$ & $3,883^{* *}$ & $3,864 * *$ & $3,652 * *$ & $3,822 * *$ & $4,103 * *$ \\
\hline
\end{tabular}

*Intervalo de valores críticos relevantes (intercepto irrestrito e sem tendência, com seis regressores, $\mathrm{k}=6)$ : $(2,12$; 3,23), a $90 \%$ de confiança***; $(2,45 ; 3,61)$, a $95 \%$ de confiança**, e $(3,15 ; 4,43)$, a 99\% de confiança*. (ver Tabela CI(iii), Pesaran et al.(2001))

Tabela 43 - Teste F (“bounds-testing"): modelo per capita com variáveis mensais

\begin{tabular}{ccccccccccc}
\hline Lags: & $\mathbf{1}$ & $\mathbf{2}$ & $\mathbf{3}$ & $\mathbf{4}$ & $\mathbf{5}$ & $\mathbf{6}$ & $\mathbf{7}$ & $\mathbf{8}$ & $\mathbf{9}$ & $\mathbf{1 0}$ \\
\hline M1 & $9,31^{*}$ & $6,71^{*}$ & $4,89^{*}$ & $4,73^{*}$ & $3,76^{* *}$ & 2,65 & 2,47 & 2,34 & 2,30 & 1,95 \\
M2 & 2,80 & 2,96 & 3,10 & 2,52 & 1,92 & 2,12 & 1,93 & 2,23 & 2,47 & 2,26 \\
M1RS & $6,09 *$ & $4,55^{*}$ & $3,54 * * *$ & 3,12 & 2,38 & 2,04 & 1,83 & 1,87 & 2,18 & 1,83 \\
DV & $11,49 *$ & $10,08^{*}$ & $7,83^{*}$ & $8,79 *$ & $8,09 *$ & $4,12^{* *}$ & $3,78^{* *}$ & $3,43 * * *$ & 2,83 & 2,69 \\
PMPP & 2,92 & 2,84 & 2,69 & 2,29 & 1,86 & 1,77 & 1,80 & 2,15 & 2,56 & 2,35 \\
BM & 2,85 & $7,25^{*}$ & $4,32^{* *}$ & $4,18^{* *}$ & $3,64 * *$ & $4,79 *$ & $5,52^{*}$ & $5,79 *$ & $5,62^{*}$ & $5,90^{*}$ \\
RES & 2,60 & $5,04^{*}$ & $4,06^{* *}$ & $4,02^{* *}$ & $3,54 * * *$ & $3,89 * *$ & $3,88^{* *}$ & $3,66^{* *}$ & $3,83^{* *}$ & $4,10^{* *}$ \\
\hline
\end{tabular}

*Intervalo de valores críticos relevantes (intercepto irrestrito e sem tendência, com seis regressores, $\mathrm{k}=6)$ : $(2,12$; 3,23), a $90 \%$ de confiança***; $(2,45 ; 3,61)$, a $95 \%$ de confiança**, e $(3,15 ; 4,43)$, a $99 \%$ de confiança*. (ver Tabela CI(iii), Pesaran et al.(2001))

31 Por motivos de viabilidade computacional, nesta seção a seleção do número de defasagens foi feita considerando um número de defasagens igual para as variáveis independentes no modelo de longo prazo, i.e., consideramos, no modelo de correção de erros irrestrito denominado na seção $4.2, q 1=q 2=\cdots=q 6$. 
Tabela 44 - Defasagens selecionadas: modelo com variáveis mensais

\begin{tabular}{ccc}
\hline & BIC & AIC \\
\hline M1 & $(6,0,0,0,0,0,0)$ & $(9,0,0,0,0,0,0)$ \\
M1RS & $(3,0,0,0,0,0,0)$ & $(3,0,0,0,0,0,0)$ \\
M2 & $(1,0,0,0,0,0,0)$ & $(5,0,0,0,0,0,0)$ \\
DV & $(6,0,0,0,0,0,0)$ & $(6,1,1,1,1,1,1)$ \\
PMPP & $(1,0,0,0,0,0,0)$ & $(5,0,0,0,0,0,0)$ \\
BM & $(3,0,0,0,0,0,0)$ & $(3,2,2,2,2,2,2)$ \\
RES & $(3,0,0,0,0,0,0)$ & $(4,0,0,0,0,0,0)$ \\
\hline
\end{tabular}

Tabela 45 - Defasagens selecionadas: modelo per capita com variáveis mensais

\begin{tabular}{ccc}
\hline & BIC & AIC \\
\hline M1 & $(6,0,0,0,0,0,0)$ & $(9,0,0,0,0,0,0)$ \\
M2 & $(1,0,0,0,0,0,0)$ & $(9,0,0,0,0,0,0)$ \\
M1RS & $(3,0,0,0,0,0,0)$ & $(3,0,0,0,0,0,0)$ \\
DV & $(6,0,0,0,0,0,0)$ & $(6,1,1,1,1,1,1)$ \\
PMPP & $(1,0,0,0,0,0,0)$ & $(5,0,0,0,0,0,0)$ \\
BM & $(11,0,0,0,0,0,0)$ & $(11,3,3,3,3,3,3)$ \\
RES & $(13,2,2,2,2,2,2)$ & $(24,2,2,2,2,2,2)$ \\
\hline
\end{tabular}

\subsubsection{Resultados da estimação}

Na Tabela 46, abaixo, observamos os resultados da estimação do modelo agregado de demanda por moeda com variáveis de risco denominado em termos mensais, para cada um dos agregados monetários em análise. Os p-valores do teste t associado aos coeficientes são apresentados sob cada coeficiente estimado, com destaque de um asterisco para coeficientes significativos a 95\% de confiança. Novamente, os coeficientes de curto prazo defasados são apresentados no Apêndice A. Observe que, como os dados neste caso são mensais, são esperados coeficientes dos termos de correção de erros menores que os de seções anteriores.

O destaque nas estimações fica por conta da variável de Spread, cujo coeficiente de longo prazo estimado é significativo (a 5\%) para os agregados de reservas totais e base monetária. O coeficiente de curto prazo desta mesma variável é também significativo e negativo, para todos os outros agregados utilizados. Ainda em termos de coeficientes de curto prazo, os resultados mostram um termo positivo e significativo para o Índice de Sharpe no modelo com o agregado M1RS e para a volatilidade da variável de escala (IPI) nos modelos com agregados DV e RES (para este último, o coeficiente de longo prazo é também significativo). 
Tabela 46 - Resultados: modelo com risco e variáveis mensais

\begin{tabular}{|c|c|c|c|c|c|c|c|}
\hline & M1 & M2 & M1RS & DV & PMPP & BM & RES \\
\hline \multicolumn{8}{|c|}{ Painel A: Coeficientes Padronizados de Longo Prazo } \\
\hline \multirow[t]{2}{*}{$\ln (Y)$} & 0,1033 & 0,2484 & 0,5669 & $-1,1632$ & 0,9404 & 0,8037 & 0,3621 \\
\hline & 0,4404 & 0,7201 & $0,0372^{*}$ & 0,0696 & 0,1018 & $0,0000^{*}$ & 0,5635 \\
\hline \multirow[t]{2}{*}{$\ln (r)$} & $-0,1312$ & $-0,1304$ & $-0,1459$ & $-0,6947$ & $-0,1434$ & $-0,3352$ & $-0,8790$ \\
\hline & $0,0004^{*}$ & 0,0817 & $0,0000^{*}$ & $0,0000^{*}$ & $0,0220^{*}$ & $0,0000^{*}$ & $0,0002^{*}$ \\
\hline \multirow{2}{*}{ Sharpe } & 0,2171 & 0,3778 & 0,2135 & 0,6256 & 0,1967 & 0,2166 & 0,7272 \\
\hline & 0,0776 & 0,1500 & 0,0519 & 0,2819 & 0,3412 & 0,0971 & 0,2958 \\
\hline \multirow{2}{*}{ Spread } & $-0,4882$ & 15,4349 & $-2,2415$ & $-32,5156$ & 3,9477 & $-11,3885$ & $-54,0071$ \\
\hline & 0,8952 & 0,0700 & 0,5557 & 0,0746 & 0,5263 & $0,0051^{*}$ & $0,0121^{*}$ \\
\hline \multirow[t]{2}{*}{ Vol_r $r$} & $-0,5646$ & $-10,1606$ & $-2,3856$ & 5,0940 & $-12,1466$ & 3,8886 & 38,0007 \\
\hline & 0,9223 & 0,4075 & 0,6418 & 0,8412 & 0,2123 & 0,4880 & 0,2174 \\
\hline \multirow[t]{2}{*}{ Vol_Y } & $-8,6816$ & 32,0346 & $-9,3404$ & $-39,4215$ & 6,0593 & 21,8035 & 128,6659 \\
\hline & 0,4693 & 0,1801 & 0,3944 & 0,4472 & 0,7536 & 0,0564 & 0,0376* \\
\hline \multirow[t]{2}{*}{ Const. } & 6,3845 & 6,6735 & 4,6583 & 9,6239 & 1,9004 & 2,1540 & 0,8793 \\
\hline & $0,0048^{*}$ & 0,1234 & $0,0017^{*}$ & 0,0857 & 0,0773 & $0,0077^{*}$ & 0,7552 \\
\hline \multicolumn{8}{|c|}{ Painel B: Coeficientes de Curto Prazo Selecionados } \\
\hline \multirow[t]{2}{*}{$\Delta \ln (Y)$} & $-0,0741$ & 0,0012 & $-0,0494$ & $-0,1771$ & 0,0015 & $-0,0135$ & $-0,6016$ \\
\hline & 0,0592 & 0,9573 & 0,1706 & 0,0702 & 0,9454 & 0,8792 & 0,0672 \\
\hline \multirow[t]{2}{*}{$\Delta \ln (r)$} & $-0,0164$ & $-0,0057$ & $-0,0105$ & $-0,0436$ & $-0,0036$ & $-0,0219$ & $-0,0602$ \\
\hline & $0,0000^{*}$ & $0,0000^{*}$ & $0,0000^{*}$ & $0,0000^{*}$ & $0,0000^{*}$ & $0,0000^{*}$ & $0,0000^{*}$ \\
\hline \multirow[t]{2}{*}{$\Delta$ Sharpe } & 0,0073 & 0,0014 & 0,0086 & 0,0013 & 0,0028 & $-0,0117$ & $-0,0368$ \\
\hline & 0,0653 & 0,5492 & $0,0153^{*}$ & 0,8964 & 0,2060 & 0,1916 & 0,2627 \\
\hline \multirow[t]{2}{*}{$\Delta$ Spread } & $-0,3963$ & $-0,1295$ & $-0,3733$ & $-0,4454$ & $-0,1370$ & 0,0043 & 0,4426 \\
\hline & $0,0000^{*}$ & $0,0035^{*}$ & $0,0000^{*}$ & $0,0170^{*}$ & $0,0009 *$ & 0,9800 & 0,4732 \\
\hline \multirow[t]{2}{*}{$\Delta V o l \_r$} & 0,2690 & 0,1105 & $-0,0325$ & 2,7318 & 0,0303 & 1,0314 & 7,9236 \\
\hline & 0,4945 & 0,6279 & 0,9243 & 0,1122 & 0,8895 & 0,5176 & 0,1639 \\
\hline \multirow[t]{2}{*}{$\Delta$ Vol_Y } & 0,7946 & 0,3986 & 0,8510 & 3,0590 & 0,1364 & 0,8956 & 15,0425 \\
\hline & 0,1226 & 0,1783 & 0,0999 & $0,0191^{*}$ & 0,6303 & 0,4415 & $0,0005^{*}$ \\
\hline \multicolumn{8}{|c|}{ Painel C: Ajuste do modelo } \\
\hline$\overline{R^{2}}$ & 0,3580 & 0,4296 & 0,3346 & 0,3237 & 0,3122 & 0,5342 & 0,4647 \\
\hline$\chi_{B G}^{2}(2)$ & 3,9320 & 3,3340 & 4,6070 & 2,5390 & 1,7300 & 2,6590 & 0,5240 \\
\hline p-valor & 0,1400 & 0,1890 & 0,0999 & 0,2810 & 0,4210 & 0,2650 & 0,7690 \\
\hline \multicolumn{8}{|c|}{ Painel D: Modelo de correção de erros } \\
\hline$\widehat{E C_{t-1}}$ & $-0,0111$ & $-0,0030$ & $-0,0111$ & $-0,0060$ & $-0,0036$ & $-0,0251$ & $-0,0165$ \\
\hline Teste $\mathbf{t}$ & $-4,26$ & $-4,46$ & $-5,00$ & $-5,74$ & $-3,34$ & $-6,09$ & $-5,04$ \\
\hline p-valor & $0,000 *$ & $0,000^{*}$ & $0,000^{*}$ & $0,000^{*}$ & $0,001^{*}$ & $0,000^{*}$ & $0,000^{*}$ \\
\hline$\overline{R^{2}}$ & 0,364 & 0,435 & 0,342 & 0,330 & 0,319 & 0,539 & 0,470 \\
\hline$\chi_{B G}^{2}(2)$ & 3,735 & 3,061 & 4,359 & 2,479 & 1,570 & 2,530 & 0,502 \\
\hline p-valor & 0,155 & 0,216 & 0,113 & 0,290 & 0,456 & 0,282 & 0,778 \\
\hline
\end{tabular}


A título de avaliação do ajuste obtido pelo modelo estimado, a Figura 25 exibe o termo de correção de erros associado aos modelos com dados mensais estimados, para alguns dos agregados utilizados e durante todo o período em que os dados foram obtidos.

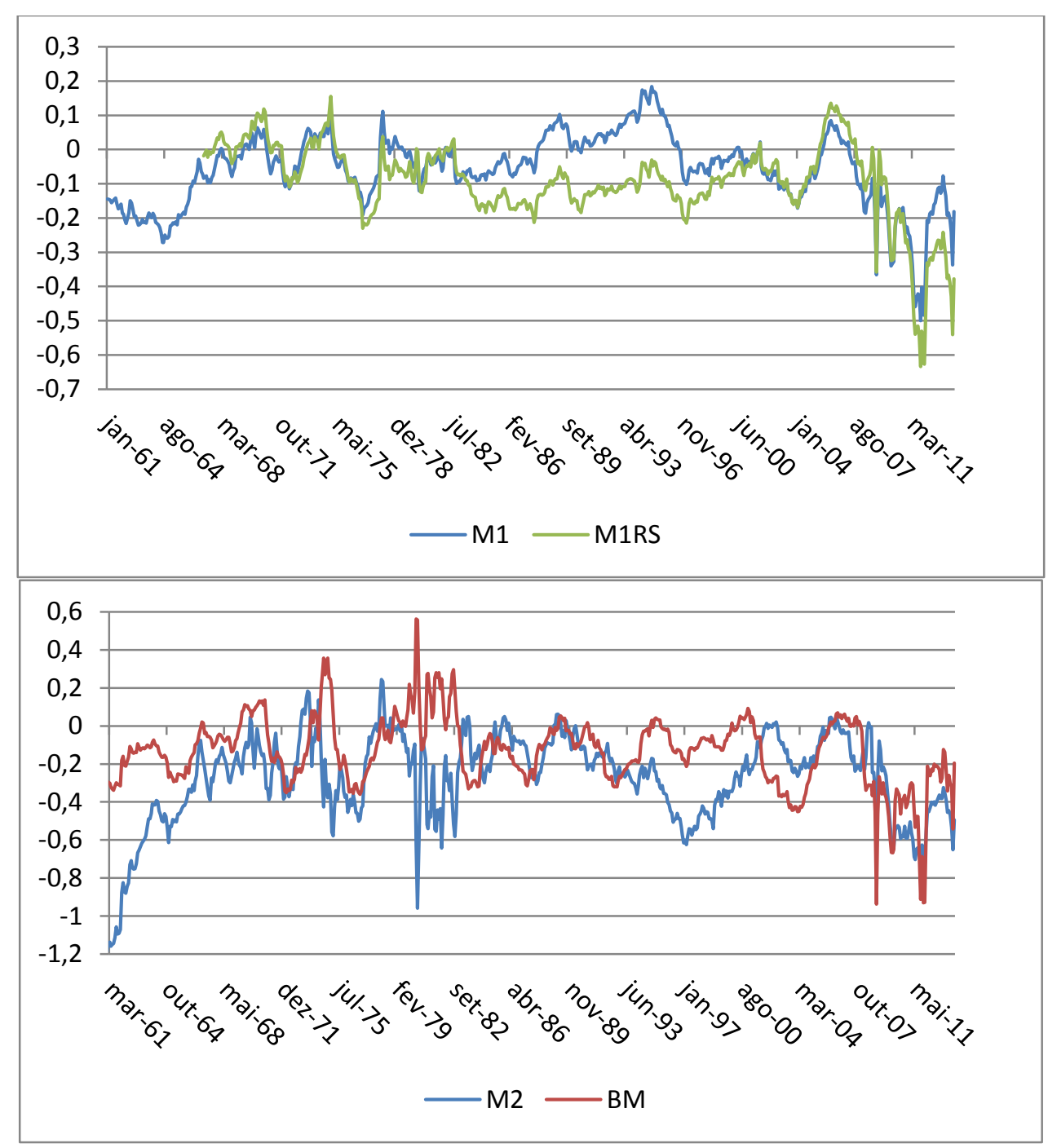

Figura 25 - Termo de correção de erros: modelos com dados mensais.

A Tabela 47, por sua vez, exibe os resultados obtidos para o modelo denominado em termos per capita. Neste caso, observamos coeficientes significativos para a variável de spread entre os agregados M2, DV, BM e RES, sendo o mesmo positivo no primeiro caso (ainda que, no curto prazo, ocorra coeficiente negativo e significativo) e negativo nos demais. A estimativa obtida para a volatilidade da variável de escala assume valores positivos e significativos para BM e RES, no longo prazo, e para DV e RES, no curto prazo. Novamente, os termos de correção de erros apresentam coeficientes menores, devido à maior periodicidade dos dados, porém significativos. 
Tabela 47 - Resultados: modelo per capita com risco e variáveis mensais

\begin{tabular}{|c|c|c|c|c|c|c|c|}
\hline & M1 & M2 & M1RS & DV & PMPP & BM & RES \\
\hline \multicolumn{8}{|c|}{ Painel A: Coeficientes Padronizados de Longo Prazo } \\
\hline \multirow[t]{2}{*}{$\ln (Y)$} & $-0,352$ & $-0,145$ & 0,292 & $-2,399$ & 0,905 & 0,826 & $-0,022$ \\
\hline & $0,024 *$ & 0,819 & 0,242 & 0,066 & 0,105 & $0,001^{*}$ & 0,979 \\
\hline \multirow[t]{2}{*}{$\ln (r)$} & $-0,106$ & $-0,097$ & $-0,137$ & $-0,794$ & $-0,148$ & $-0,334$ & $-0,858$ \\
\hline & $0,000 *$ & 0,149 & $0,000 *$ & $0,000^{*}$ & $0,010 *$ & $0,000 *$ & $0,000 *$ \\
\hline \multirow[t]{2}{*}{ Sharpe } & 0,182 & 0,270 & 0,198 & 0,722 & 0,196 & 0,274 & 1,190 \\
\hline & 0,091 & 0,283 & 0,051 & 0,316 & 0,305 & 0,079 & 0,051 \\
\hline \multirow[t]{2}{*}{ Spread } & $-2,212$ & 17,210 & $-2,676$ & $-44,499$ & 3,477 & $-15,262$ & $-61,883$ \\
\hline & 0,500 & $0,035^{*}$ & 0,444 & 0,049* & 0,535 & $0,001^{*}$ & $0,001^{*}$ \\
\hline \multirow[t]{2}{*}{ Vol_r $r$} & $-0,239$ & $-9,545$ & $-2,698$ & 7,841 & $-10,078$ & 3,809 & 48,675 \\
\hline & 0,963 & 0,415 & 0,574 & 0,804 & 0,262 & 0,567 & 0,067 \\
\hline \multirow[t]{2}{*}{ Vol_Y } & $-11,734$ & 25,761 & $-10,266$ & $-50,099$ & 4,132 & 29,571 & 128,221 \\
\hline & 0,290 & 0,265 & 0,317 & 0,438 & 0,818 & $0,030 *$ & $0,016^{*}$ \\
\hline \multirow[t]{2}{*}{ Const. } & 8,214 & 9,026 & 8,477 & 5,326 & 7,315 & 7,119 & 3,756 \\
\hline & $0,003^{*}$ & 0,262 & $0,002^{*}$ & 0,261 & $0,048^{*}$ & $0,001^{*}$ & $0,007^{*}$ \\
\hline \multicolumn{8}{|c|}{ Painel B: Coeficientes de Curto Prazo Selecionados } \\
\hline \multirow[t]{2}{*}{$\Delta \ln (Y)$} & $-0,079$ & $-0,006$ & $-0,053$ & $-0,184$ & 0,000 & 0,006 & $-0,567$ \\
\hline & $0,045^{*}$ & 0,798 & 0,144 & 0,061 & 0,988 & 0,950 & 0,087 \\
\hline \multirow[t]{2}{*}{$\Delta \ln (r)$} & $-0,016$ & $-0,005$ & $-0,011$ & $-0,043$ & $-0,004$ & $-0,019$ & $-0,050$ \\
\hline & $0,000 *$ & $0,000 *$ & $0,000^{*}$ & $0,000 *$ & $0,000 *$ & $0,000 *$ & $0,000^{*}$ \\
\hline \multirow[t]{2}{*}{$\Delta$ Sharpe } & 0,007 & 0,001 & 0,008 & 0,001 & 0,003 & $-0,011$ & $-0,039$ \\
\hline & 0,081 & 0,727 & $0,018^{*}$ & 0,938 & 0,210 & 0,215 & 0,239 \\
\hline \multirow[t]{2}{*}{$\Delta$ Spread } & $-0,403$ & $-0,115$ & $-0,375$ & $-0,457$ & $-0,137$ & 0,022 & 0,681 \\
\hline & $0,000 *$ & $0,010^{*}$ & $0,000 *$ & $0,014^{*}$ & $0,001^{*}$ & 0,900 & 0,283 \\
\hline \multirow[t]{2}{*}{$\Delta V o l \_r$} & 0,305 & 0,146 & $-0,001$ & 2,736 & 0,048 & 0,522 & 9,111 \\
\hline & 0,437 & 0,521 & 0,997 & 0,112 & 0,825 & 0,745 & 0,120 \\
\hline \multirow[t]{2}{*}{$\Delta$ Vol_Y } & 0,745 & 0,399 & 0,814 & 3,011 & 0,126 & 1,203 & 14,340 \\
\hline & 0,147 & 0,178 & 0,115 & $0,021 *$ & 0,656 & 0,303 & $0,001^{*}$ \\
\hline \multicolumn{8}{|c|}{ Painel C: Ajuste do modelo } \\
\hline$\overline{R^{2}}$ & 0,364 & 0,434 & 0,340 & 0,325 & 0,314 & 0,544 & 0,473 \\
\hline$\chi_{B G}^{2}(2)$ & 3,633 & 2,817 & 4,052 & 2,541 & 1,708 & 3,091 & 1,269 \\
\hline p-valor & 0,163 & 0,245 & 0,132 & 0,281 & 0,426 & 0,213 & 0,530 \\
\hline \multicolumn{8}{|c|}{ Painel D: Modelo de correção de erros } \\
\hline$\overline{E C_{t-1}}$ & $-0,012$ & $-0,003$ & $-0,012$ & $-0,005$ & $-0,004$ & $-0,022$ & $-0,020$ \\
\hline Teste $\mathbf{t}$ & $-4,528$ & $-4,446$ & $-5,295$ & $-5,756$ & $-3,535$ & $-5,674$ & $-5,955$ \\
\hline p-valor & $0,000 *$ & $0,000 *$ & $0,000^{*}$ & $0,000 *$ & $0,000 *$ & $0,000 *$ & $0,000^{*}$ \\
\hline$\overline{R^{2}}$ & 0,370 & 0,440 & 0,347 & 0,332 & 0,321 & 0,549 & 0,478 \\
\hline$\chi_{B G}^{2}(2)$ & 3,472 & 2,558 & 3,844 & 2,484 & 1,555 & 2,865 & 1,243 \\
\hline p-valor & 0,176 & 0,278 & 0,146 & 0,289 & 0,459 & 0,239 & 0,537 \\
\hline
\end{tabular}




\subsection{Modelagem GARCH de volatilidades}

Até este ponto, utilizamos o desvio padrão das variáveis (ou razão do desvio padrão pela média, no caso do Índice de Sharpe) como medida de sua volatilidade, como utilizado também por alguns dos trabalhos citados no segundo capítulo. Nesta seção, utilizaremos a variância condicional da primeira diferença das variáveis de retorno no mercado de ações, taxa de juros e PIB como medida de volatilidade (risco) associada a estes mercados. Os dados desta variância condicional serão estimados através do modelo GARCH (Generalized Autoregressive Conditional Heteroscedasticity) de Bollerslev (1986).

\subsubsection{Metodologia}

Nos modelos $\operatorname{GARCH}(r, m)$, a variância condicional de uma série temporal é função do quadrado dos resíduos do processo (termos $\mathrm{ARCH}$ ) e incorporam também a heterocedasticidade no procedimento de estimação da variância condicional, dada por $h_{t}$ (Bollerslev, 1986):

$$
h_{t}=\omega^{\prime}+\sum_{j=1}^{r} \beta_{j} h_{t-j}+\sum_{j=1}^{m} \alpha_{j} \varepsilon^{2}{ }_{t-j}
$$

Para as taxas de juros de curto prazo $r_{t}$ e PIB real $Y_{t}$, utilizaremos os mesmos dados trimestrais utilizados no capítulo anterior. A variável $R D O W_{t}$ representará o retorno no mercado de ações em excesso à taxa de juros, representado pela variação no índice Dow Jones, i.e.:

$$
R D O W_{t}=\Delta D O W_{t}-r_{t}
$$

Em que $\Delta D O W_{t}$ é a variação percentual anualizada do índice Dow Jones medida no período t em relação ao período anterior. Assim, representando por $y_{t}$ as variáveis $\ln \left(\frac{r_{t}}{r_{t-1}}\right)$, $\ln \left(\frac{Y_{t}}{Y_{t-1}}\right)$ e $\Delta R D O W_{t}$, e utilizando, de acordo com sugestão de Choudhry (1999), os valores de $r$ e $m$ iguais a 1 , o modelo $\operatorname{GARCH}(1,1)$ a ser utilizado pode ser descrito por: 


$$
\begin{gathered}
\left\{\begin{array}{c}
y_{t}=\mu_{t}+\varepsilon_{t} \\
\varepsilon_{t} \mid \Omega_{t-1} \sim N\left(0, h_{t}\right)
\end{array}\right. \\
h_{t}=\omega^{\prime}+\beta_{1} h_{t-1}+\alpha_{1} \varepsilon^{2}{ }_{t-1}
\end{gathered}
$$

Em que $y_{t}$ é uma das três variáveis citadas acima e $\mu_{t}$ é a média de $y_{t}$ condicionada às informações passadas $\Omega_{t-1}$.

\subsubsection{Variáveis obtidas}

Os modelos definidos pelas equações (5.4) e (5.5) foram estimados pelo método de máxima verossimilhança, de acordo com Bollerslev (1986), e os resultados obtidos estão exibidos na Tabela 48, abaixo.

Tabela 48 - Resultados: Estimação dos modelos GARCH(1,1)

$$
\begin{aligned}
& \ln \left(\frac{r_{t}}{r_{t-1}}\right)=0,0202^{*}+\varepsilon_{t} \\
& h_{t}=0,0032^{*}+0,311^{*} h_{t-1}+1,246^{*} \varepsilon_{t-1} \\
& (4,70) \quad(8,58) \\
& L=67,26476 ; \chi^{2}=41,66^{*} \text {; } \\
& \ln \left(\frac{Y_{t}}{Y_{t-1}}\right)=0,0075^{*}+\varepsilon_{t} \\
& (13,06) \\
& h_{t}=0,0001^{* * *}+0,712^{*} h_{t-1}+0,2616^{*} \varepsilon_{t-1} \\
& (1,78) \quad(13,9) \quad(4,38) \\
& L=857,687 ; \chi^{2}=0,33 \text {; } \\
& \triangle R D O W_{t}=0,007+\varepsilon_{t} \\
& (0,26) \\
& h_{t}=0,0557^{*}+0,5226^{*} h_{t-1}+0,325^{*} \varepsilon_{t-1}
\end{aligned}
$$


Os valores estimados $\hat{h}_{t}$ obtidos dos modelos acima constituirão, portanto, as variáveis de volatilidade $G A R C H \_r_{t}, G A R C H_{-} Y_{t}$ e $G A R C H \_d o w_{t}$, cuja evolução temporal está exibida na Figura 26, e serão utilizados no modelo de demanda por moeda com risco descrito a seguir.

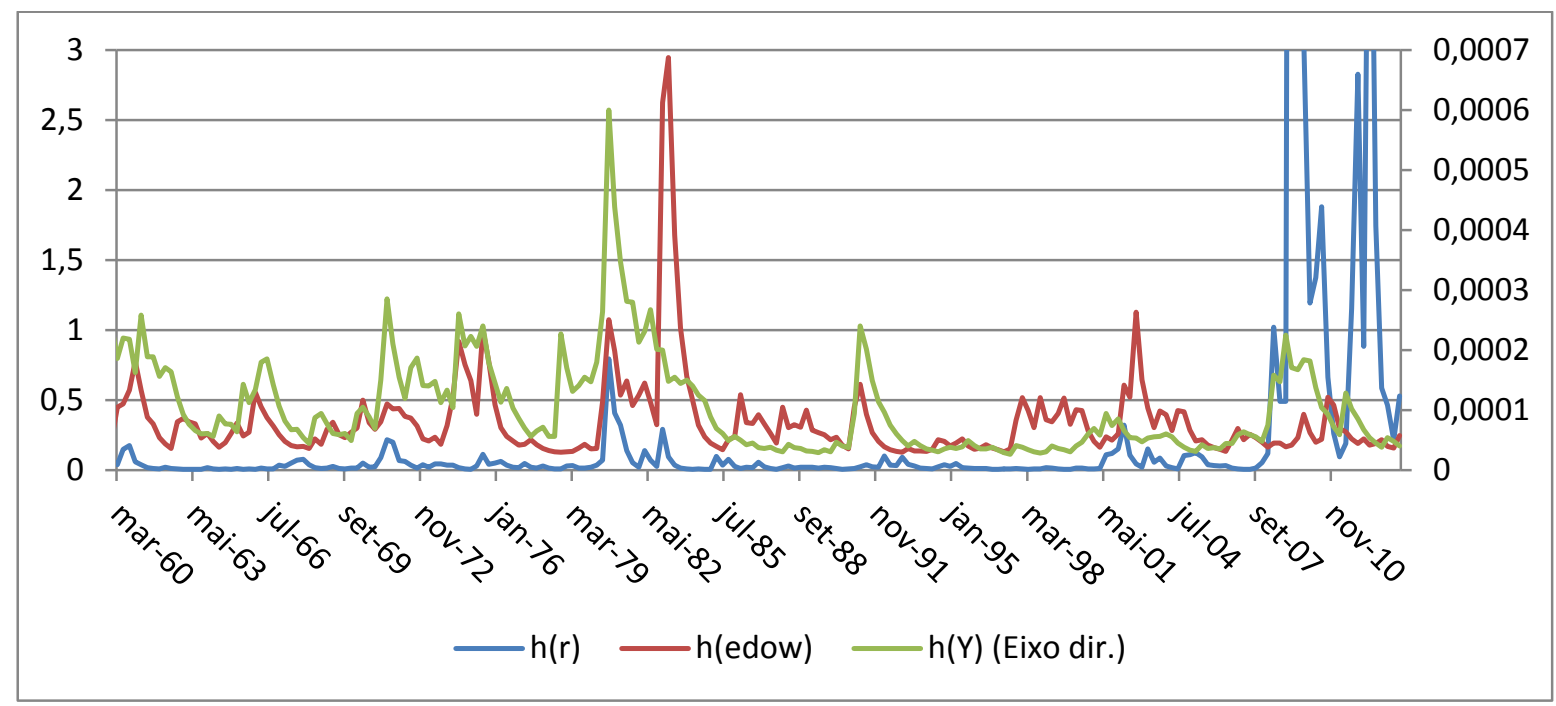

Figura 26 - Evolução temporal: $G A R C H_{-} r_{t}, G A R C H_{-} Y_{t}$ e $G A R C H_{-} d o w_{t}$

\subsubsection{Demanda por moeda com variáveis GARCH}

De posse das novas variáveis de volatilidade, podemos reescrever nosso modelo de demanda por moeda com variáveis de risco de longo prazo, novamente denominado em termos trimestrais e utilizando o PIB real como variável de escala, como:

$$
\begin{gathered}
\ln \left(M_{t} / P_{t}\right)=\alpha_{0}+\alpha_{1} \ln \left(Y_{t}\right)+\alpha_{2} \ln \left(r_{t}\right)+\alpha_{3} G A R C H_{-} \text {dow }_{t}+\alpha_{4} \text { Spread }_{t} \\
+\alpha_{5} G \text { GRCH_r } r_{t}+\alpha_{6} \text { GARCH_Y } Y_{t}+\varepsilon_{t}
\end{gathered}
$$

Utilizando mais uma vez o Spread-Loan como variável de spread, prosseguimos à obtenção dos valores do teste $\mathrm{F}$ (bounds-testing) para até seis defasagens, cujos resultados são exibidos na Tabela 49 e na Tabela 50.

Em seguida, prosseguimos à seleção do número de defasagens pelos critérios BIC e AIC, cujos resultados se encontram na Tabela 51 e na Tabela 52, e à estimação dos modelos selecionados, cujos resultados se encontram na Tabela 53. Os p-valores associados aos coeficientes são apresentados sob os mesmos, e destacados com um asterisco quando menores que 5\%. Alguns dos coeficientes de curto prazo de menor relevância à análise estão exibidos apenas no Apêndice A. 
Tabela 49 - Teste F ("bounds-testing"): modelo com variáveis GARCH

\begin{tabular}{ccccccc}
\hline Lags: & $\mathbf{1}$ & $\mathbf{2}$ & $\mathbf{3}$ & $\mathbf{4}$ & $\mathbf{5}$ & $\mathbf{6}$ \\
\hline M1 & $3,472 * * *$ & 2,503 & 2,182 & 1,993 & 1,709 & 2,044 \\
M2 & 1,844 & 2,440 & 2,058 & 2,324 & 2,470 & 3,147 \\
M1RS & $3,279 * * *$ & 2,197 & 2,075 & 1,651 & 1,436 & 1,820 \\
DV & $8,783 *$ & $4,319 * *$ & 2,591 & $3,279 * * *$ & 2,346 & 2,025 \\
PMPP & $4,836 *$ & $4,111 * *$ & $3,478 * * *$ & $3,656 * *$ & 3,107 & $3,456 * *$ \\
BM & $4,692 *$ & $6,565 *$ & $11,695 *$ & $5,122 *$ & $5,308 *$ & $4,317 * *$ \\
RES & 3,152 & $3,294 * * *$ & $6,990 *$ & 2,306 & 2,262 & 1,570 \\
\hline
\end{tabular}

*Intervalo de valores críticos relevantes (intercepto irrestrito e sem tendência, com seis regressores, $\mathrm{k}=6)$ : $(2,12$; $3,23)$, a $90 \%$ de confiança***; $(2,45 ; 3,61)$, a $95 \%$ de confiança**, e $(3,15 ; 4,43)$, a $99 \%$ de confiança*. (ver Tabela CI(iii), Pesaran et al.(2001)).

Tabela 50 - Teste F ("bounds-testing”): modelo per capita com variáveis GARCH

\begin{tabular}{ccccccc}
\hline Lags: & $\mathbf{1}$ & $\mathbf{2}$ & $\mathbf{3}$ & $\mathbf{4}$ & $\mathbf{5}$ & $\mathbf{6}$ \\
\hline M1 & $3,453^{* * *}$ & 2,480 & 2,156 & 2,005 & 1,751 & 2,027 \\
M2 & 1,730 & 2,311 & 1,958 & 2,212 & 2,313 & 2,972 \\
M1RS & $3,580^{* * *}$ & 2,369 & 2,206 & 1,777 & 1,542 & 1,935 \\
DV & $8,653^{*}$ & $4,189^{* *}$ & 2,469 & 3,200 & 2,314 & 1,999 \\
PMPP & $5,304^{*}$ & $4,832^{*}$ & $4,052^{* *}$ & $4,183^{* *}$ & $3,405^{* * *}$ & $4,061^{* *}$ \\
BM & $4,747^{*}$ & $6,523^{*}$ & $11,607^{*}$ & $5,049^{*}$ & $5,253^{*}$ & $4,263^{* *}$ \\
RES & 3,121 & $3,232^{* * *}$ & $6,915^{*}$ & 2,240 & 2,227 & 1,552 \\
\hline
\end{tabular}

*Intervalo de valores críticos relevantes (intercepto irrestrito e sem tendência, com seis regressores, $\mathrm{k}=6)$ : $(2,12$; $3,23)$, a $90 \%$ de confiança***; $(2,45 ; 3,61)$, a $95 \%$ de confiança**, e $(3,15 ; 4,43)$, a $99 \%$ de confiança*. (ver Tabela CI(iii), Pesaran et al.(2001)).

Tabela 51 - Defasagens selecionadas: modelo com variáveis GARCH

\begin{tabular}{ccc}
\hline & BIC & AIC \\
\hline M1 & $(2,0,0,0,0,1,0)$ & $(3,0,0,0,0,1,1)$ \\
M2 & $(1,0,0,0,0,0,0)$ & $(1,0,0,0,0,0,0)$ \\
M1RS & $(2,0,0,0,0,0,1)$ & $(2,0,0,0,0,1,1)$ \\
DV & $(1,0,0,0,0,1,2)$ & $(1,0,0,0,0,1,2)$ \\
PMPP & $(1,0,0,0,0,0,0)$ & $(4,1,0,0,0,0,0)$ \\
BM & $(3,0,0,0,0,0,0)$ & $(3,0,0,0,0,0,0)$ \\
RES & $(1,0,0,0,0,0,0)$ & $(1,0,0,0,0,0,0)$ \\
\hline
\end{tabular}


Tabela 52 - Defasagens selecionadas: modelo per capita com variáveis GARCH

\begin{tabular}{ccc}
\hline & BIC & AIC \\
\hline M1 & $(2,0,0,0,0,1,0)$ & $(3,0,0,0,0,1,1)$ \\
M2 & $(1,0,0,0,0,0,0)$ & $(1,0,0,0,0,0,0)$ \\
M1RS & $(2,0,0,0,0,0,1)$ & $(2,0,0,0,0,1,1)$ \\
DV & $(1,0,0,0,0,1,2)$ & $(2,0,0,0,0,4,2)$ \\
PMPP & $(1,0,0,0,0,0,0)$ & $(1,0,0,0,3,0,1)$ \\
BM & $(3,0,0,0,0,0,0)$ & $(3,0,0,0,0,0,0)$ \\
RES & $(1,0,0,0,0,0,0)$ & $(1,0,0,0,0,0,0)$ \\
\hline
\end{tabular}

Tabela 53 - Resultados: modelo com variáveis GARCH

\begin{tabular}{|c|c|c|c|c|c|c|c|}
\hline & M1 & M2 & M1RS & DV & PMPP & BM & RES \\
\hline \multicolumn{8}{|c|}{ Painel A: Coeficientes Padronizados de Longo Prazo } \\
\hline \multirow[t]{2}{*}{$\ln (Y)$} & 0,239 & 0,575 & 0,598 & $-0,318$ & 1,021 & 0,885 & 0,598 \\
\hline & 0,111 & 0,357 & 0,053 & 0,613 & $0,000^{*}$ & $0,000 *$ & 0,244 \\
\hline \multirow[t]{2}{*}{$\ln (r)$} & $-0,131$ & $-0,116$ & $-0,125$ & $-0,640$ & $-0,183$ & $-0,274$ & $-0,593$ \\
\hline & $0,000^{*}$ & $0,002^{*}$ & $0,001 *$ & $0,000^{*}$ & $0,000^{*}$ & $0,000^{*}$ & $0,000 *$ \\
\hline \multirow[t]{2}{*}{ GARCH_dow } & $-0,047$ & 0,191 & $-0,035$ & $-0,499$ & 0,013 & $-0,031$ & $-0,485$ \\
\hline & 0,604 & 0,137 & 0,679 & 0,197 & 0,923 & 0,652 & 0,210 \\
\hline \multirow[t]{2}{*}{ Spread } & 2,400 & 7,172 & 3,671 & $-33,356$ & 4,314 & $-8,695$ & $-39,503$ \\
\hline & 0,558 & 0,244 & 0,431 & 0,072 & 0,461 & $0,005^{*}$ & $0,024 *$ \\
\hline \multirow[t]{2}{*}{ GARCH_r } & $-0,083$ & $-0,048$ & $-0,015$ & $-0,443$ & $-0,084$ & 0,144 & 0,125 \\
\hline & $0,004^{*}$ & 0,160 & 0,491 & $0,000^{*}$ & $0,045^{*}$ & $0,000^{*}$ & 0,257 \\
\hline \multirow[t]{2}{*}{ GARCH_Y } & 3,810 & $-198,7$ & $-587,2$ & 2038,3 & $-921,3$ & 116,7 & 4775,5 \\
\hline & 0,994 & 0,742 & 0,231 & 0,320 & 0,100 & 0,727 & $0,009 *$ \\
\hline \multirow[t]{2}{*}{ Const. } & 4,830 & 3,502 & 2,218 & 7,461 & $-2,277$ & $-1,116$ & $-0,937$ \\
\hline & $0,012^{*}$ & $0,012 *$ & 0,093 & 0,302 & $0,015^{*}$ & 0,079 & 0,809 \\
\hline \multicolumn{8}{|c|}{ Painel B: Coeficientes de Curto Prazo Selecionados } \\
\hline \multirow[t]{2}{*}{$\Delta \ln (Y)$} & 0,301 & 0,276 & 0,366 & 0,159 & 0,299 & 0,392 & $-0,150$ \\
\hline & $0,003^{*}$ & $0,000 *$ & $0,000^{*}$ & 0,477 & $0,000^{*}$ & 0,188 & 0,891 \\
\hline \multirow[t]{2}{*}{$\Delta \ln (r)$} & $-0,025$ & $-0,016$ & $-0,018$ & $-0,062$ & $-0,010$ & $-0,097$ & $-0,269$ \\
\hline & $0,000^{*}$ & $0,000^{*}$ & $0,000^{*}$ & $0,000^{*}$ & $0,000^{*}$ & $0,000^{*}$ & $0,000^{*}$ \\
\hline \multirow[t]{2}{*}{$\triangle G A R C H \_d o w$} & 0,006 & 0,009 & 0,008 & $-0,001$ & 0,004 & 0,006 & $-0,014$ \\
\hline & 0,144 & $0,002 *$ & $0,037^{*}$ & 0,881 & 0,108 & 0,626 & 0,747 \\
\hline \multirow[t]{2}{*}{$\Delta$ Spread } & $-0,676$ & $-0,334$ & $-0,606$ & $-1,428$ & $-0,191$ & $-0,350$ & $-2,244$ \\
\hline & $0,000^{*}$ & $0,006^{*}$ & $0,000^{*}$ & $0,000^{*}$ & 0,073 & 0,489 & 0,228 \\
\hline \multirow[t]{2}{*}{$\triangle G A R C H \_r$} & $-0,002$ & 0,001 & 0,000 & $-0,007$ & 0,000 & 0,005 & 0,021 \\
\hline & $0,044^{*}$ & 0,259 & 0,754 & $0,001^{*}$ & 0,572 & 0,235 & 0,097 \\
\hline \multirow[t]{2}{*}{$\triangle G A R C H \_Y$} & $-1,071$ & $-2,364$ & $-17,991$ & 16,081 & $-10,740$ & 56,244 & 209,738 \\
\hline & 0,961 & 0,873 & 0,394 & 0,735 & 0,316 & 0,379 & 0,362 \\
\hline \multirow[t]{2}{*}{$\Delta G A R C H_{-} r_{t-1}$} & 0,002 & & & 0,007 & & & \\
\hline & $0,005^{*}$ & & & $0,000^{*}$ & & & \\
\hline \multirow{2}{*}{$\Delta G A R C H_{-} Y_{t-1}$} & 46,200 & & 44,954 & 109,942 & & & \\
\hline & $0,032^{*}$ & & $0,030^{*}$ & $0,021^{*}$ & & & \\
\hline \multirow[t]{2}{*}{$\Delta G A R C H_{-} Y_{t-2}$} & & & & $-116,012$ & & & \\
\hline & & & & $0,011^{*}$ & & & \\
\hline
\end{tabular}




\begin{tabular}{|c|c|c|c|c|c|c|c|}
\hline & M1 & M2 & M1RS & DV & PMPP & BM & RES \\
\hline \multicolumn{8}{|c|}{ Painel C: Ajuste do modelo } \\
\hline$\overline{R^{2}}$ & 0,565 & 0,549 & 0,530 & 0,558 & 0,475 & 0,551 & 0,382 \\
\hline$\chi_{B G}^{2}(2)$ & 0,464 & 1,938 & 4,429 & 3,095 & 0,399 & 0,683 & 2,434 \\
\hline p-valor & 0,793 & 0,379 & 0,109 & 0,213 & 0,819 & 0,711 & 0,296 \\
\hline \multicolumn{8}{|c|}{ Painel D: Modelo de correção de erros } \\
\hline$\widehat{E C_{t-1}}$ & $-0,037$ & $-0,018$ & $-0,035$ & $-0,019$ & $-0,015$ & $-0,136$ & $-0,089$ \\
\hline Teste $\mathbf{t}$ & $-4,794$ & $-3,987$ & $-4,116$ & $-6,089$ & $-5,972$ & $-8,671$ & $-5,258$ \\
\hline p-valor & $0,000 *$ & $0,000 *$ & $0,000^{*}$ & $0,000 *$ & $0,000 *$ & $0,000^{*}$ & $0,000 *$ \\
\hline$\overline{R^{2}}$ & 0,578 & 0,562 & 0,546 & 0,571 & 0,488 & 0,564 & 0,400 \\
\hline$\chi_{B G}^{2}(2)$ & 0,413 & 1,883 & 3,832 & 2,700 & 0,330 & 0,486 & 1,234 \\
\hline p-valor & 0,813 & 0,390 & 0,147 & 0,259 & 0,848 & 0,784 & 0,540 \\
\hline
\end{tabular}

Como podemos observar nas tabelas acima, a modelagem com variáveis GARCH retornou um número maior de coeficientes estatisticamente significativos associados às variáveis de risco, em comparação com os resultados anteriores. Os resultados sugerem que a variável relativa à volatilidade dos mercados de ações teria efeito de curto prazo positivo sobre a demanda pelos agregados M1RS e M2. Por sua vez, a variável de Spread teria efeito de longo prazo negativo sobre a demanda por BM e RES, e de curto prazo sobre a demanda por M1, M1RS, M2 e DV.

Já a volatilidade da taxa de juros seria determinante de longo prazo da demanda por M1, DV, PMPP e BM, além de influenciar os dois primeiros também no curto prazo. No caso do agregado DV, porém, obtivemos coeficientes iguais em módulo, mas de sinais opostos, para as diferenças contemporâneas e do período anterior, sugerindo que o efeito desta variável de risco se anularia após dois períodos. Com relação à volatilidade do produto, foram obtidos coeficientes de curto prazo positivos e significativos para M1, M1RS e DV para a primeira defasagem da diferença dessa volatilidade. Para o último caso, foi obtido um coeficiente negativo e significativo para a segunda defasagem, mas que poderia ser anulado no período seguinte. Dentre os termos de longo prazo, esta volatilidade aparenta entrar na determinação da demanda por RES com valor alto, possivelmente devido aos dados recentes do período de crise. Observe, pela análise da Figura 27 com os termos de erro associados e comparados aos modelos da seção 4.4.4, que os modelos com variáveis GARCH possuem erro de previsão expressivo nos períodos imediatamente seguintes ao desencadear da crise financeira de 2008 . 


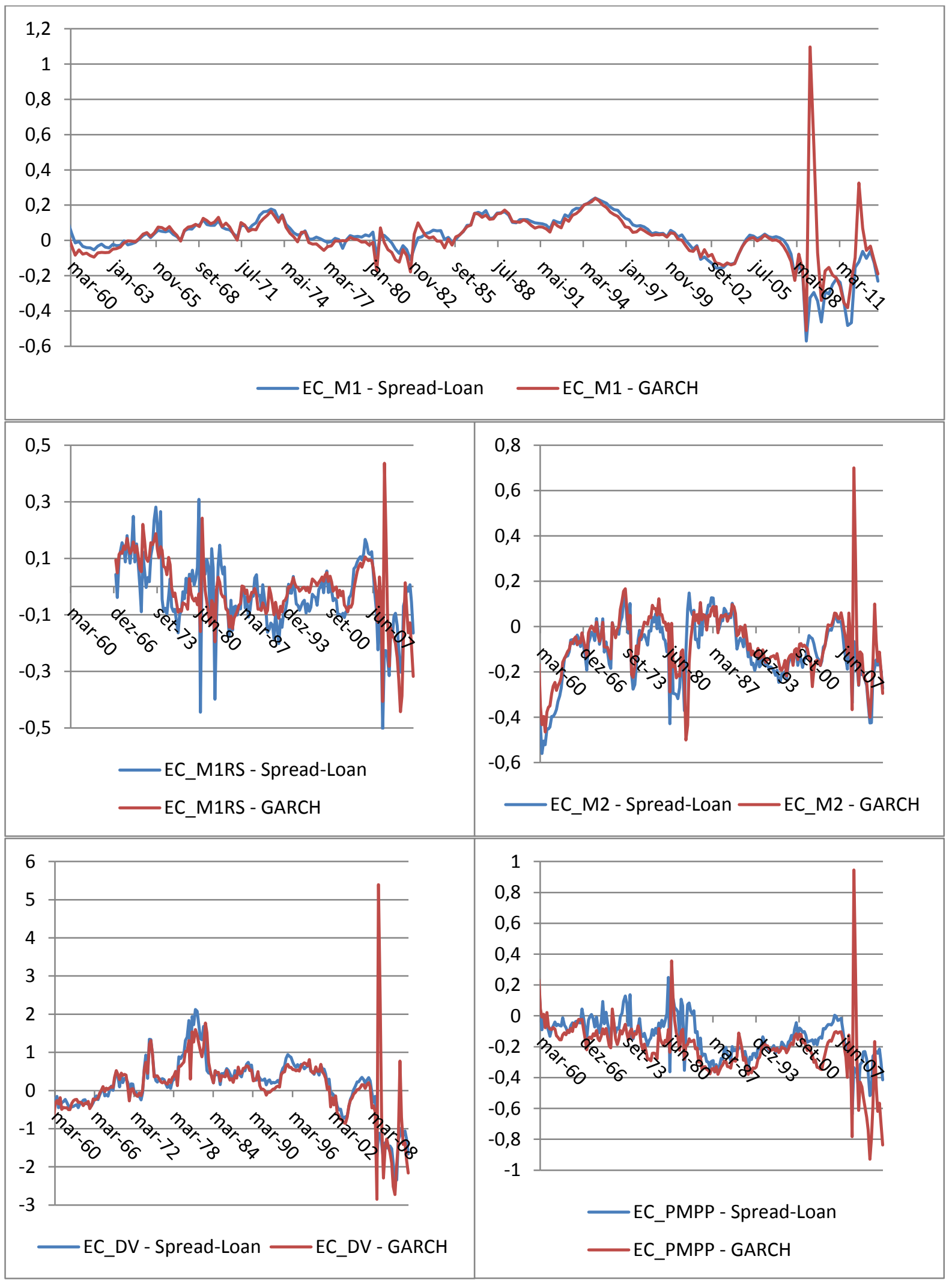




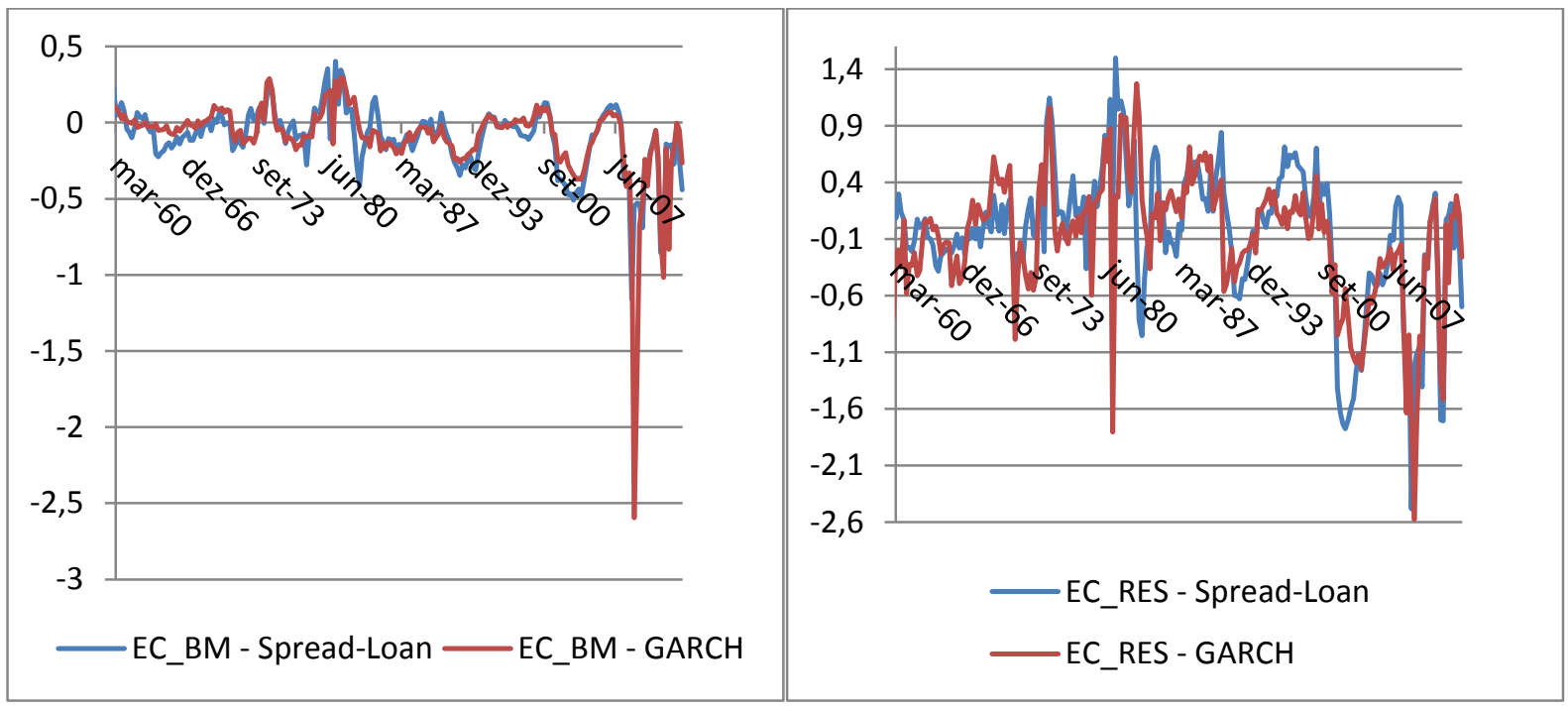

Figura 27 - Termos de erro: modelos com variáveis GARCH

Os resultados das estimações com modelos per capita, apresentados na Tabela 54, também apresentam resultados satisfatórios, similares aos obtidos para o modelo agregado. Vale destacar aqui o maior número de coeficientes significativos associados à variável de spread, no curto e no longo prazo.

Tabela 54 - Resultados: modelo per capita com variáveis GARCH

\begin{tabular}{|c|c|c|c|c|c|c|c|}
\hline & M1 & M2 & M1RS & DV & PMPP & BM & RES \\
\hline \multicolumn{8}{|c|}{ Painel A: Coeficientes Padronizados de Longo Prazo } \\
\hline \multirow[t]{2}{*}{$\ln (Y)$} & $-0,172$ & 0,284 & 0,295 & $-0,760$ & 0,738 & 0,761 & 0,568 \\
\hline & 0,406 & 0,702 & 0,385 & 0,569 & $0,003^{*}$ & $0,000^{*}$ & 0,511 \\
\hline \multirow[t]{2}{*}{$\ln (r)$} & $-0,119$ & $-0,120$ & $-0,121$ & $-0,725$ & $-0,154$ & $-0,270$ & $-0,587$ \\
\hline & $0,000^{*}$ & $0,005^{*}$ & $0,000^{*}$ & $0,000^{*}$ & $0,000^{*}$ & $0,000^{*}$ & $0,000^{*}$ \\
\hline \multirow[t]{2}{*}{ GARCH_dow } & $-0,061$ & 0,214 & $-0,040$ & $-0,567$ & $-0,095$ & $-0,037$ & $-0,501$ \\
\hline & 0,530 & 0,153 & 0,630 & 0,227 & 0,384 & 0,581 & 0,215 \\
\hline \multirow[t]{2}{*}{ Spread } & 0,185 & 7,448 & 3,020 & $-43,382$ & 13,138 & $-7,878$ & $-43,683$ \\
\hline & 0,964 & 0,285 & 0,478 & 0,051 & $0,005^{*}$ & $0,007^{*}$ & $0,013^{*}$ \\
\hline \multirow[t]{2}{*}{ GARCH_r } & $-0,090$ & $-0,057$ & $-0,015$ & $-0,593$ & $-0,043$ & 0,114 & 0,127 \\
\hline & $0,003^{*}$ & 0,156 & 0,490 & $0,004^{*}$ & 0,170 & $0,000^{*}$ & 0,272 \\
\hline \multirow[t]{2}{*}{ GARCH_Y } & 155,1 & $-182,61$ & $-616,53$ & 2832,53 & $-897,20$ & 237,85 & 5092,76 \\
\hline & 0,752 & 0,794 & 0,190 & 0,259 & 0,071 & 0,455 & $0,007^{*}$ \\
\hline \multirow[t]{2}{*}{ Const. } & 9,730 & 6,703 & 5,577 & 13,158 & 0,051 & 0,128 & $-0,018$ \\
\hline & $0,014^{*}$ & $0,017^{*}$ & $0,038^{*}$ & 0,402 & 0,976 & 0,922 & 0,998 \\
\hline \multicolumn{8}{|c|}{ Painel B: Coeficientes de Curto Prazo Selecionados } \\
\hline \multirow[t]{2}{*}{$\Delta \ln (Y)$} & 0,283 & 0,280 & 0,356 & 0,182 & 0,270 & 0,352 & $-0,193$ \\
\hline & $0,005^{*}$ & $0,000^{*}$ & $0,001^{*}$ & 0,416 & $0,000^{*}$ & 0,241 & 0,858 \\
\hline$\Delta \ln (\boldsymbol{r})$ & $-0,025$ & $-0,016$ & $-0,018$ & $-0,065$ & $-0,010$ & $-0,099$ & $-0,269$ \\
\hline
\end{tabular}




\begin{tabular}{|c|c|c|c|c|c|c|c|}
\hline & M1 & M2 & M1RS & DV & PMPP & BM & RES \\
\hline & $0,000^{*}$ & $0,000^{*}$ & $0,000 *$ & $0,000^{*}$ & $0,000^{*}$ & $0,000 *$ & $0,000 *$ \\
\hline \multirow[t]{2}{*}{$\triangle G A R C H \_d o w$} & 0,006 & 0,009 & 0,008 & 0,000 & 0,004 & 0,009 & $-0,013$ \\
\hline & 0,144 & $0,002^{*}$ & $0,041^{*}$ & 0,982 & 0,096 & 0,463 & 0,761 \\
\hline \multirow[t]{2}{*}{$\Delta$ Spread } & $-0,718$ & $-0,343$ & $-0,618$ & $-1,454$ & $-0,255$ & $-0,360$ & $-2,392$ \\
\hline & $0,000^{*}$ & $0,005^{*}$ & $0,000 *$ & $0,000^{*}$ & $0,018^{*}$ & 0,478 & 0,195 \\
\hline \multirow[t]{2}{*}{$\triangle G A R C H \_r$} & $-0,002$ & 0,001 & 0,000 & $-0,007$ & 0,001 & 0,005 & 0,021 \\
\hline & $0,049 *$ & 0,241 & 0,787 & $0,001^{*}$ & 0,105 & 0,189 & 0,096 \\
\hline \multirow[t]{2}{*}{$\Delta G A R C H \_Y$} & 1,501 & $-1,845$ & $-19,200$ & 17,420 & 7,574 & 77,160 & 211,200 \\
\hline & 0,945 & 0,901 & 0,362 & 0,713 & 0,518 & 0,220 & 0,359 \\
\hline \multicolumn{8}{|c|}{ Painel C: Ajuste do modelo } \\
\hline$\overline{R^{2}}$ & 0,569 & 0,550 & 0,537 & 0,565 & 0,507 & 0,551 & 0,382 \\
\hline$\chi_{B G}^{2}(2)$ & 0,479 & 1,947 & 4,419 & 2,832 & 2,707 & 4,566 & 2,428 \\
\hline p-valor & 0,787 & 0,378 & 0,110 & 0,243 & 0,258 & 0,102 & 0,297 \\
\hline \multicolumn{8}{|c|}{ Painel D: Modelo de correção de erros } \\
\hline$\widehat{E C_{t-1}}$ & $-0,035$ & $-0,015$ & $-0,036$ & $-0,015$ & $-0,019$ & $-0,139$ & $-0,085$ \\
\hline Teste $\mathbf{t}$ & $-4,744$ & $-3,895$ & $-4,256$ & $-4,937$ & $-6,137$ & $-7,303$ & $-5,242$ \\
\hline p-valor & $0,000^{*}$ & $0,000^{*}$ & $0,000^{*}$ & $0,000^{*}$ & $0,000^{*}$ & $0,000^{*}$ & $0,000^{*}$ \\
\hline$\overline{R^{2}}$ & 0,582 & 0,563 & 0,553 & 0,578 & 0,520 & 0,564 & 0,399 \\
\hline$\chi_{B G}^{2}(2)$ & 0,429 & 1,888 & 3,812 & 2,373 & 2,497 & 4,346 & 1,273 \\
\hline p-valor & 0,807 & 0,389 & 0,149 & 0,305 & 0,287 & 0,114 & 0,529 \\
\hline
\end{tabular}

\subsection{O impacto da crise financeira de 2008}

Como citado brevemente na seção 3.1, tendo em vista o relativo esgotamento das possibilidades de ação através da política monetária convencional, devido ao nível já próximo de zero da taxa de juros nominal, o período iniciado em 2008 foi caracterizado pela política de quantitative easing por parte do Federal Reserve, que consiste, basicamente, em mudanças no balanço de um banco central promovidas com o intuito de expandir as condições de liquidez e crédito de uma economia (Blinder, 2010).

A justificativa teórica utilizada para sustentar essa política é de que as decisões privadas de investimento e gasto dependem de taxas de juros com risco (como taxas para empréstimos bancários, hipotecas, etc.), compostas por um spread somado às taxas de política monetária dos T-Bills. Portanto, ainda que não seja possível reduzir ainda mais os juros livres de risco, o Federal Reserve ainda dispõe de instrumentos que podem ser usados para reduzir estes spreads, como a compra de ativos de menor liquidez do público (Blinder, 2010).

Iniciando sua ação lentamente nos primeiros meses de 2008, com a compra de ativos de menor liquidez em vista a reduzir os prêmios de liquidez, a atuação do FED a partir da 
quebra do banco Lehman Brothers (em 15 de Setembro de 2008) tomaria dimensão muito maior, expandindo seu balanço, operações de empréstimos e reservas bancárias drasticamente. Ainda de acordo com Blinder (2010), os ativos do FED passariam de US\$ 907 bilhões para US\$ 2,214 trilhões apenas entre 3 de setembro e 12 de novembro de 2008. Como o capital da instituição não se alterou significativamente, a maior parte deste aumento se traduziu em expansão das reservas bancárias, que passariam de US\$ 11 bilhões para US\$ 860 bilhões ainda em 2008. Este movimento pode ser observado na Figura 28 abaixo, na qual temos uma reprodução da Figura 2, dos agregados monetários em análise em termos reais, porém com foco no período iniciado em 2000.

Como pudemos observar claramente nos gráficos da evolução temporal dos termos de correção de erros dos modelos da seção anterior, tanto o modelo com variáveis de risco quanto o modelo padrão de demanda por moeda tendem a sobrestimar a demanda por vários dos agregados monetários em estudo no período dos anos finais de nossa amostra, isto é, no período da crise global iniciada em 2007/2008, que vem recebendo a denominação na literatura econômica de “Grande Recessão” (“Great Recession”).

Nesta seção, buscaremos redefinir nosso modelo de demanda por moeda com variáveis de risco desenvolvido anteriormente, de modo a considerar o impacto dos eventos da Grande Recessão. Iniciaremos esta investigação com a Figura 29 abaixo, que exibe a evolução temporal das variáveis de risco em uso neste trabalho entre 2006 e 2013, normalizadas utilizando o valor observado no primeiro trimestre de 2006 como base (i.e., o valor em 2006Q1=100). Nela podemos observar, por exemplo, pela evolução do TED-Spread em particular, que a política do FED especificamente voltada à redução dos spreads ativada pela quebra do banco Lehman Brothers surtiu o efeito desejado.

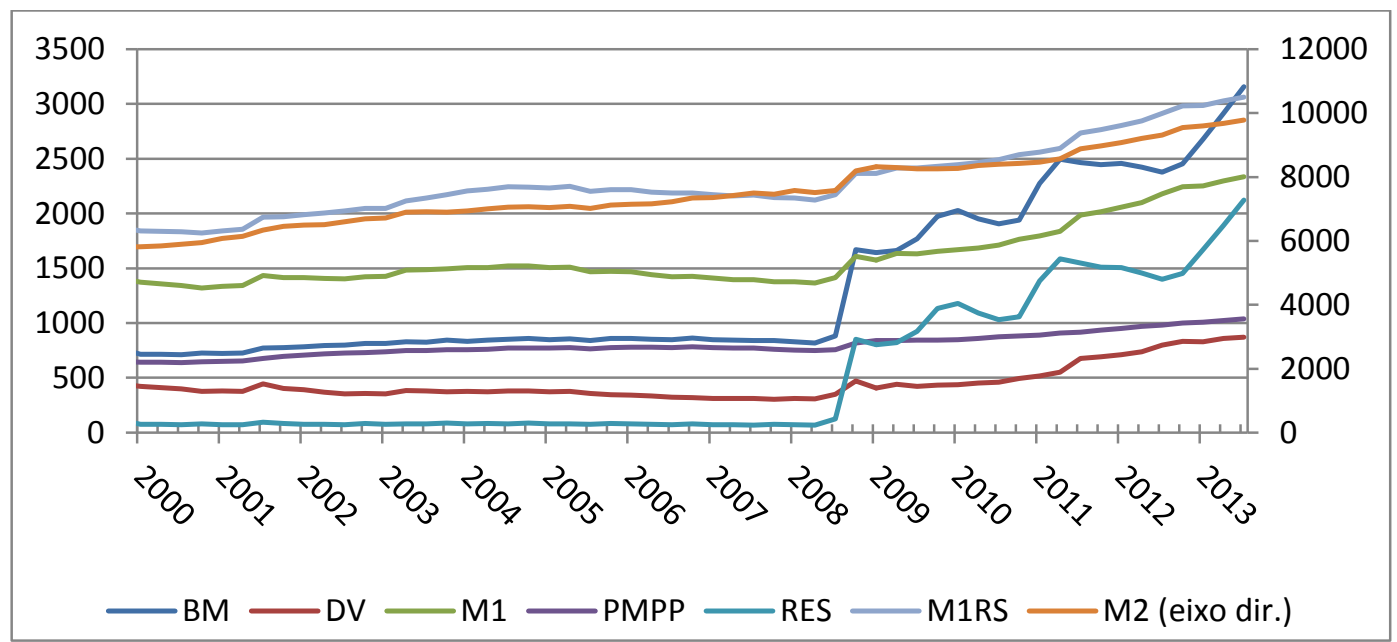

Figura 28 - Agregados Monetários - 2000 a 2013 (em US\$ bi de 2009) 


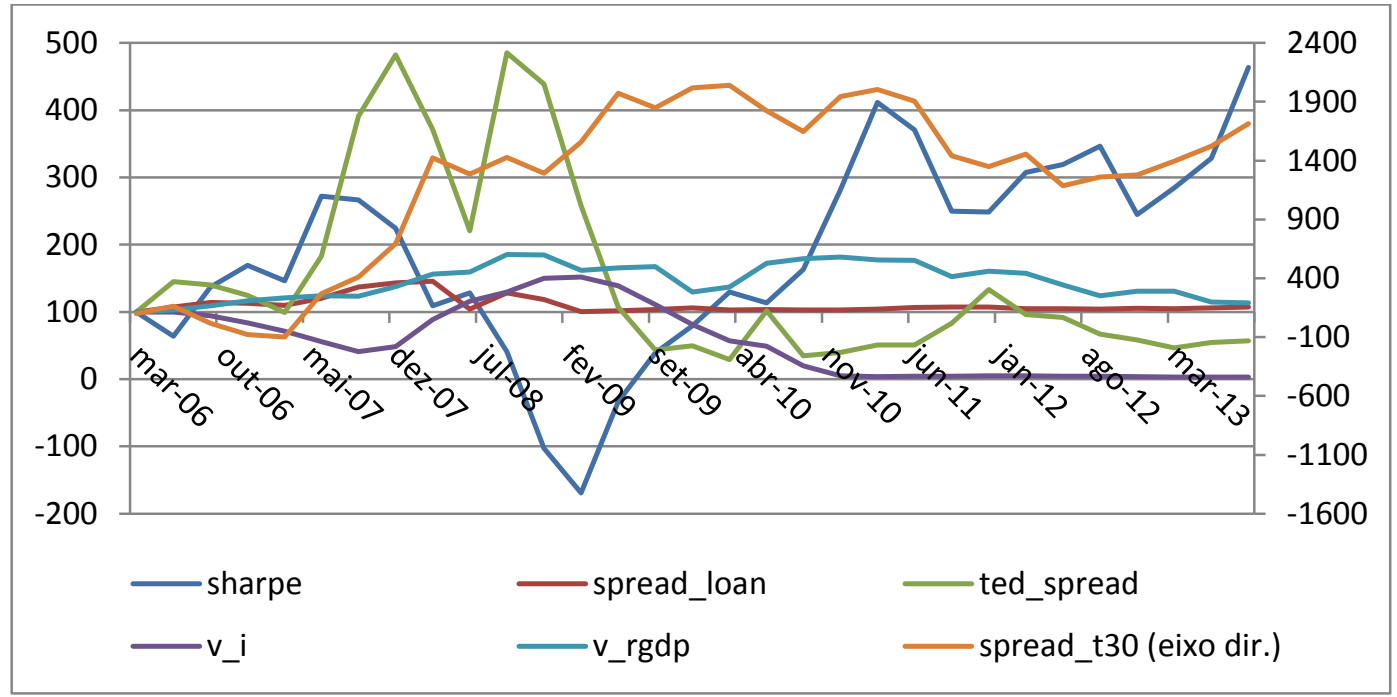

Figura 29 - Variáveis de risco - 2006 a 2013 (2006Q1=100)

\subsubsection{Variáveis dummy e forma funcional}

Com o objetivo de obter um melhor ajuste do modelo de demanda por moeda com variáveis de risco apresentado, buscaremos, inicialmente, identificar possíveis inclusões de variáveis binárias (dummy) ao modelo. Para isso, prosseguimos à estimação do modelo agregado com variáveis de risco para o agregado M1RS, adicionado de uma variável dummy representativa do período iniciado com a crise financeira de 2008, que assume valor unitário a partir do último trimestre de $2008^{32}$. O coeficiente padronizado estimado para esta dummy foi de $-0,392$, significativo ao nível de $5 \%$.

O termo de correção de erros deste modelo, comparado ao mesmo termo associado ao modelo sem dummy, é exibido na Figura 30, na qual observamos que o erro do novo modelo no período da crise financeira é inferior ao modelo sem dummy, até o final de 2011. Observe, entretanto, que os choques do último trimestre de 2008 e da segunda metade de 2011 persistem. $^{33}$

Levando em conta também o fato de que, em decorrência da política de expansão de liquidez no período, as taxas de juros se mantiveram em um nível próximo a zero durante vários trimestres, podemos argumentar também que a especificação funcional com elasticidade constante da taxa de juros utilizada até aqui não seria adequada a esta parte da

\footnotetext{
${ }^{32}$ De acordo com o procedimento adotado até aqui, a variável dummy será utilizada na estimação do modelo de correção de erros irrestrito com defasagem de um período.

${ }^{33}$ Foram estimados também modelos com a mesma variável dummy introduzida na forma de sua multiplicação pelas variáveis independentes do modelo, de modo a investigar uma possível quebra estrutural nos valores de algum dos coeficientes de longo prazo. Entretanto, a estimação de tais modelos não gerou coeficientes significativos associados a tais variáveis.
} 
amostra utilizada (que pode estar relacionada a uma armadilha de liquidez). Realizando uma nova estimação do modelo com a variável de juros denotada na forma linear (modelo semi-log A2, na terminologia do capítulo 3) observamos que, apesar de a performance do modelo nas décadas anteriores ser pouco satisfatório e o coeficiente da variável dummy estimado neste caso ser não-significativo (a 5\%), o desempenho do modelo é notavelmente superior no período iniciado em 2008, se avaliado de acordo com o termo de correção de erros derivado da nova estimação, como podemos observar novamente na Figura 30.

Apesar do resultado favorável, é importante observar que, com o uso da variável dummy, podemos encontrar evidências apenas em relação ao período em que algum choque pode ter ocorrido, sem que as suas causas ou variáveis envolvidas fiquem esclarecidas. $\mathrm{Na}$ próxima seção, buscaremos explorar algumas das possíveis variáveis que possam ser relevantes ao modelo no período recente.

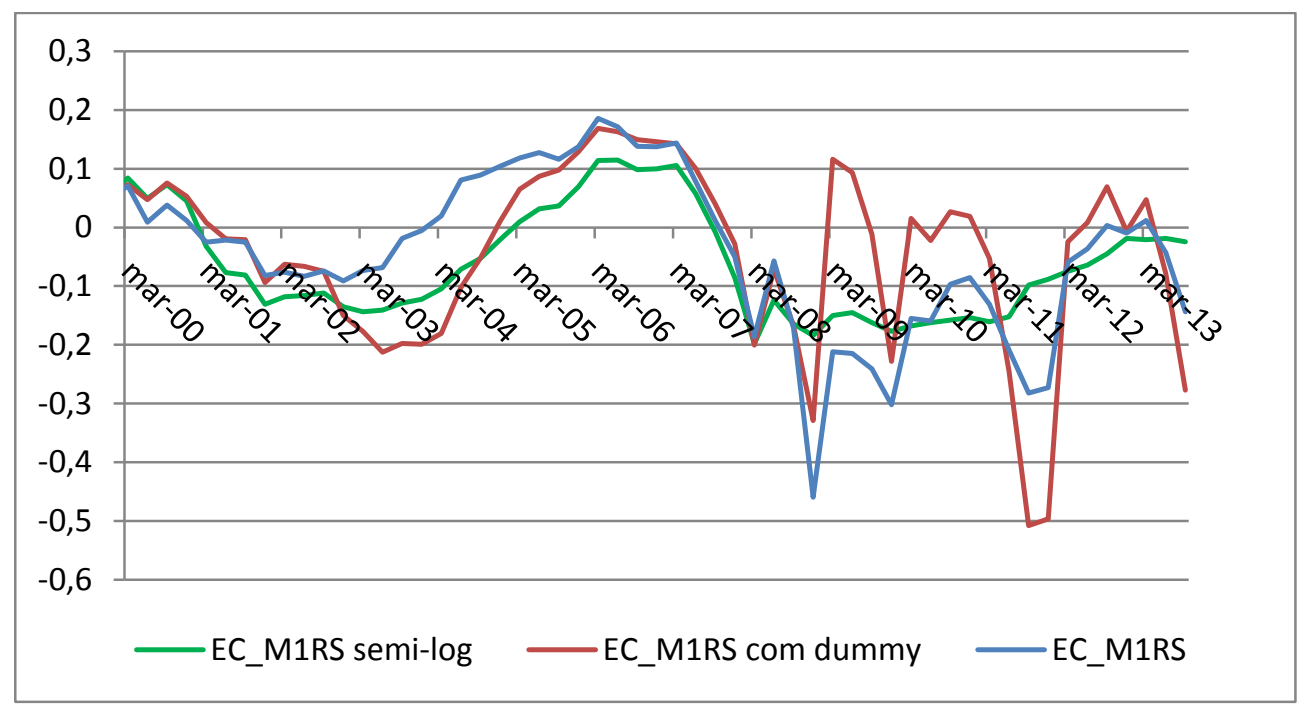

Figura 30 - Termo $E C_{t}$ do modelo com risco para M1RS com dummy da crise e semi-log

\subsubsection{Variáveis relacionadas à atuação do Federal Reserve}

Apesar da obtenção de termos de correção de erros menores para o período da crise obtidos no modelo anterior com variáveis dummy, tal modificação pouco explica sobre a origem dos desvios nos níveis de moeda demandados ocorridos no período, apenas o eventual momento em que algum choque possa ter ocorrido. Tomando como base a discussão anterior, testaremos a inclusão de algumas variáveis relacionadas à política de quantitative easing, que 
consistiriam na inclusão da(s) variável(is) $\mathbf{X}_{\mathbf{t}}$ na equação de demanda por moeda no longo prazo modificada, a seguir:

$$
\begin{aligned}
\ln \left(M_{t} /_{P_{t}}\right)=\alpha_{0} & +\alpha_{1} \ln \left(Y_{t}\right)+\alpha_{2} \ln \left(r_{t}\right)+\alpha_{3} \text { Sharpe }_{t}+\alpha_{4} \text { Spread }_{t}+\alpha_{5} \text { Vol_r }_{t} \\
& +\alpha_{6} \text { Vol_ }_{t}+e \boldsymbol{X}_{t}+\varepsilon_{t}
\end{aligned}
$$

Da discussão anterior, duas variáveis que potencialmente teriam influenciado as decisões de demanda por moeda são os níveis de reservas totais e a volatilidade destas, que pode ser vista como uma medida de incerteza sobre a política de quantitative easing. Para calcularmos esta última, utilizamos o mesmo procedimento adotado para a volatilidade das taxas de juros, consistindo na janela móvel do desvio padrão dos níveis de reservas totais (em $\log$ ) observados nos últimos 24 meses. A Figura 31 abaixo mostra a evolução temporal do termo de correção de erros obtido no modelo para M1RS com variáveis de risco do capítulo anterior e a volatilidade das reservas totais (eixo da direita), para o período iniciado em 2000.

A Tabela 55, abaixo, mostra os coeficientes e p-valores estimados para as novas variáveis inclusas no modelo. Os modelos V1, V2 e V3 consistem na substituição de $\mathrm{X}_{\mathrm{t}}$ em (5.10), respectivamente, pela volatilidade das reservas totais Vol_RES $\mathrm{t}_{\mathrm{t}}$, pelo logaritmo das reservas totais multiplicado pela dummy do período iniciado no último trimestre de 2008 RES $* D_{t}$, e por ambas as variáveis.

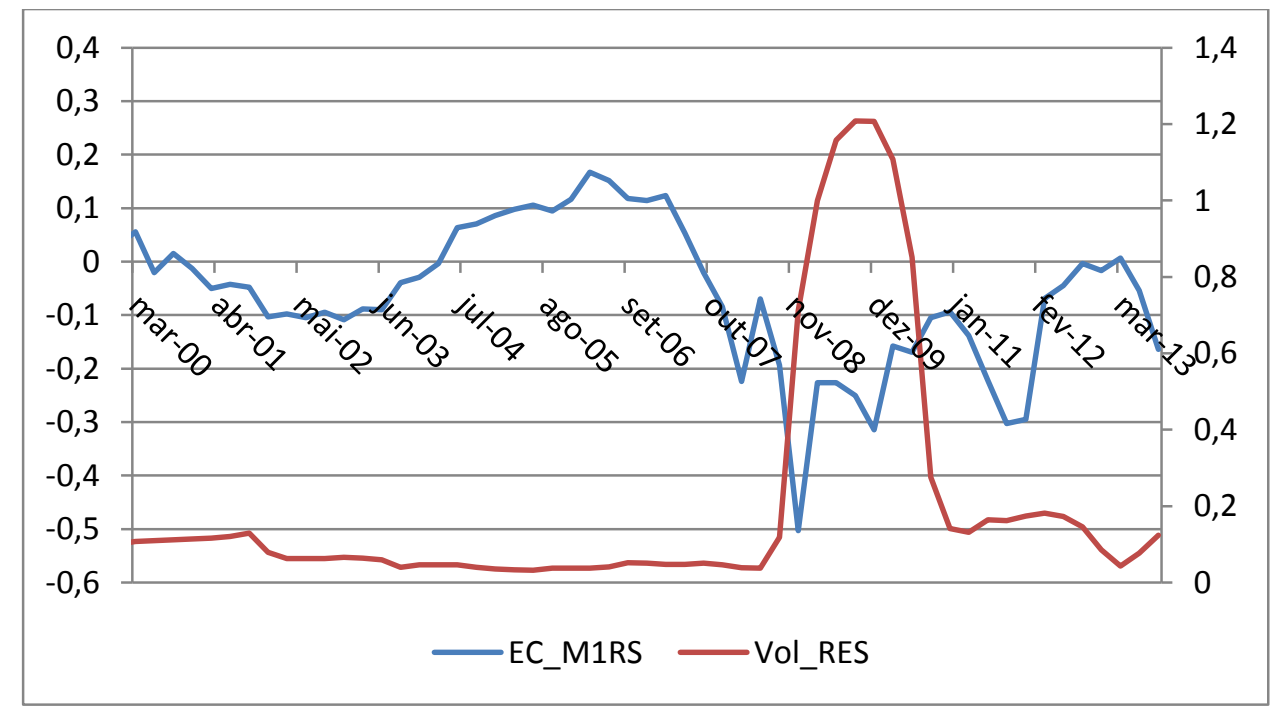

Figura 31 - Termo $E C_{t}$ do modelo com risco para M1RS e volatilidade das reservas totais 
Tabela 55 - Coeficientes e p-valores das variáveis incluídas

\begin{tabular}{|c|c|c|}
\hline & Coeficiente & p-valor \\
\hline \multicolumn{3}{|c|}{ Modelo V1 } \\
\hline Vol_RES & $-0,27193$ & 0,077 \\
\hline \multicolumn{3}{|c|}{ Modelo V2 } \\
\hline$R E S * D_{t}$ & $-0,07863$ & $0,001^{*}$ \\
\hline \multicolumn{3}{|c|}{ Modelo V3 } \\
\hline Vol_RES & $-0,05888$ & 0,675 \\
\hline$R E S * D_{t}$ & $-0,07303$ & $0,007^{*}$ \\
\hline
\end{tabular}

Na Figura 32, abaixo, observamos, por sua vez, a evolução temporal, a partir de 2000, do termo de erros da estimação do modelo com variáveis de risco do capítulo anterior, e dos modelos V1 e V2, com novas variáveis.

Observamos, portanto, que a inclusão da variável de reservas totais no modelo proposto retorna um erro associado à equação de longo prazo menor que no modelo com variáveis de risco do capítulo anterior na maioria dos trimestres do período iniciado com a crise financeira de 2008. Além disso, o coeficiente estimado associado à nova variável é estatisticamente significativo a $5 \%$ de confiança. Por outro lado, o desempenho do modelo com variável de volatilidade das reservas totais aparenta ser ainda melhor pela observação do termo de correção de erros, ainda que o coeficiente estimado associado a esta volatilidade não seja estatisticamente significativo a 5\% (mas sim a 10\%). A inclusão das duas variáveis no modelo, por sua vez, apresenta termo de erro similar ao modelo V2, e variável de volatilidade das reservas não significativa. Vale observar, ainda, que o desempenho dos modelos modificados no período correspondente aos três últimos trimestres de 2011 é destacadamente inferior ao do modelo com variáveis de risco utilizado anteriormente. ${ }^{34}$

\footnotetext{
${ }^{34}$ Este é o período correspondente à fase da política de Quantitative Easing denominada pela literatura como "Operation Twist", que consistiu na compra, por parte do FED, de grandes valores em títulos de longo prazo do tesouro americano, compensados pela venda de títulos de menor prazo, com o intuito de reduzir as taxas de juros de longo prazo na economia. O uso de dados para as taxas de juros de longo prazo (taxa de títulos do tesouro com prazo de 10 anos) em uma nova regressão, entretanto, não geraram resultados melhores para o período em questão.
} 


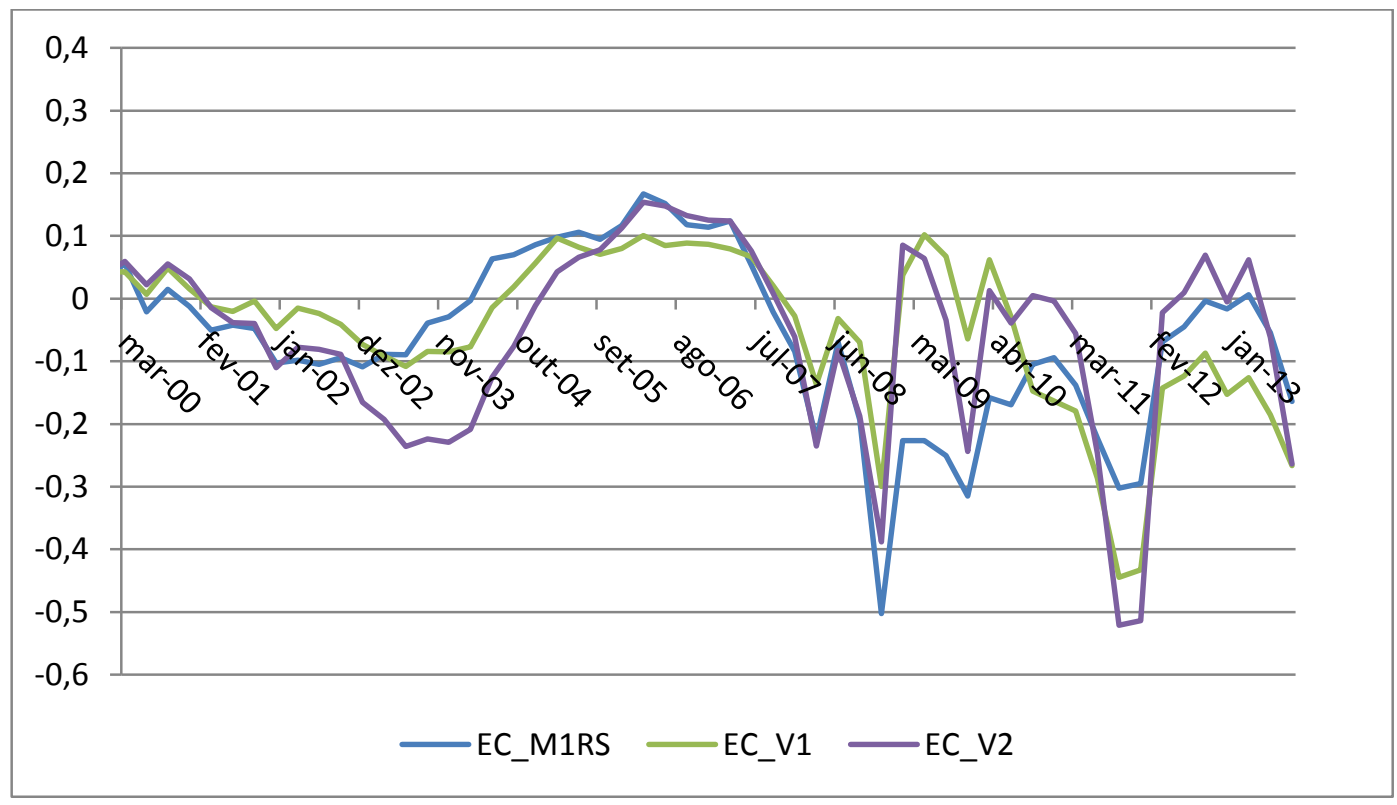

Figura 32 - Termos de correção de erros: modelo com risco anterior e modificado.

As próximas duas variáveis a serem testadas são disponibilizadas pelo Federal Reserve de St. Louis, que divulga periodicamente dados relativos aos valores, em milhões de US\$, das "Mortgage-Backed Securities" (MBST) e dos "Reverse Repurchase Agreements" (RRA) em posse de todos os bancos integrantes do Federal Reserve System. A compra de tais ativos foi uma das principais formas de atuação do FED constituintes de sua política de "quantitative easing" (Robinson \& El Nasser, 2013). A Tabela 56 abaixo exibe os coeficientes e p-valores estimados associados a estas variáveis, inclusas, em estimações separadas, no modelo da equação (5.10).

Tabela 56 - Coeficientes de modelos com inclusão de variáveis MBST e RRA

\begin{tabular}{ccc}
\hline & Coeficiente & p-valor \\
\hline MBST & $-0,00037$ & $0,041^{*}$ \\
RRA & $-0,00486$ & 0,103 \\
\hline
\end{tabular}

Apesar da inclusão da variável MBST retornar um coeficiente associado estatisticamente significativo (a 5\%), o ajuste dos novos modelos, em termos de erros de previsão da equação de longo prazo, não é tão satisfatório quanto os anteriores. 


\section{CONCLUSÕES}

Neste trabalho, foi avaliada a importância de fatores de risco na determinação da demanda por moeda, em diversas denominações, na economia dos Estados Unidos, durante o período de 1959 a 2013. Aplicando a relativamente recente técnica para cointegração com estimação de modelos ARDL aos dados trimestrais do período, em todos os casos analisados foi possível identificar a existência de uma relação de longo prazo entre agregados monetários, nível de produção, taxas de juros nominais e variáveis de risco; as quais argumentamos consistirem uma função de demanda por moeda aumentada para percepção de risco.

Entretanto, pela observação individual do desempenho das variáveis de risco utilizadas, não foi possível inferir maiores conclusões acerca da adequação das definições das variáveis utilizadas como representativas do ambiente de risco ao qual o indivíduo se depara em sua decisão de demanda por moeda ótima.

Dentre as variáveis de risco utilizadas, o Spread sobre a taxa de juros de política monetária, em suas distintas definições utilizadas neste trabalho, foi a que apresentou maiores evidências de impacto sobre os níveis de demanda por moeda. Particularmente para os agregados monetários mais restritos, foram obtidos coeficientes de longo prazo significativos em boa parte dos resultados expostos; e, como esperado pela discussão teórica, tais coeficientes eram frequentemente positivos, demonstrando uma relação em que os níveis de moeda demandados se elevavam conforme crescia o nível de risco representado pelos valores do spread.

Com relação às volatilities e ao Índice de Sharpe, os resultados expostos sugerem que seu possível efeito sobre a demanda por moeda se dê ainda no curto prazo. Vale sugerir aqui, porém, que o uso de metodologias distintas para cálculo do risco implícito nos mercados de ações, monetário e produtivo podem, por outro lado, virem a ser mais adequadas ao uso na relação de demanda investigada, no sentido de permitirem maiores conclusões acerca do papel do risco destes mercados e sua dinâmica. Em uma abordagem inicial neste sentido, foi possível observar resultados animadores com o uso de modelagem GARCH para a volatilidade nestes mercados. Nos modelos com uso destas variáveis, pôde-se observar uma maior importância das variáveis de risco nos resultados obtidos, tanto considerando-se a dinâmica de longo quanto de curto prazo. 
Uma particular atenção deve ser dada aos resultados obtidos relativos à volatilidade das taxas de juros. Os coeficientes estimados associados a essa variável foram também muitas vezes estatisticamente significativos, para a denominação de longo prazo. Nestes casos, porém, os coeficientes estimados retornaram valores negativos. Tal resultado pode se relacionar ao fato de que esta volatility, em particular, está diretamente relacionada com o risco em reter moeda, em oposição às outras variáveis de risco utilizadas, que representam os riscos envolvidos em mercados que se configuram como alternativas para a alocação de recursos, em comparação ao mercado monetário. Esta assertiva dá margem, naturalmente, a novos estudos empíricos com maior detalhamento na questão, já que os resultados obtidos aqui para esta questão não permitem maiores conclusões.

Em um complemento às estimações realizadas, foi também analisado o comportamento da demanda por moeda durante o período posterior à eclosão da crise global de 2008. O estudo realizado sugere que o nível de volatilidade nas reservas monetárias pode ter alguma importância na determinação da moeda demandada neste período (ainda vigente ao fim da amostra utilizada) de taxas de juros mantidas em seu limite inferior, possivelmente como indicativo da estabilidade da política monetária.

De modo geral, portanto, este trabalho pôde fornecer algumas novas evidências empíricas da importância da percepção de risco na determinação da demanda por moeda, ainda que tal importância aparente ter níveis variados para diferentes agregados monetários e diferentes abordagens metodológicas quanto ao modo de considerar tal risco. Possíveis investigações posteriores poderiam ser feitas, portanto, com foco na conceituação do agregado monetário mais adequada à captação da importância do risco, particularmente dando maior ênfase à nova ambientação do mercado monetário decorrente da intensa inovação financeira recente (o uso do agregado M1RS obteve algum sucesso neste sentido), e no maior desenvolvimento da modelagem da percepção de risco e sua forma funcional de interação com os níveis de demanda por moeda. 


\section{REFERÊNCIAS}

AKAIKE, Hirotugu. (1973). Information Theory as an Extension of the Maximum Likelihood Principle. Second International Symposium on Information Theory, editado por B. N. Petrov e F. Csaki. Pp. 267-81. Budapest: Akademiai Kiado.

AKINLO, A. Enisan. (2006). The stability of money demand in Nigeria: An autoregressive distributed lag approach. Journal of Policy Modeling, Elsevier, vol. 28(4), pag. 445-452, May.

BABA, Yoshihisa, HENDRY, David F., STARR, Ross M. (1992). The Demand for M1 in the U.S.A., 1960-1988. The Review of Economic Studies, Vol. 59, No. 1 (Jan., 1992), pp. 2561 .

BAHARUMSHAH, Ahmad Zubaidi, MOHD, Siti Hamizah \& MASIH, A. Mansur M. (2009) The stability of money demand in China: Evidence from the ARDL model. Economic Systems, Elsevier, vol. 33(3), pages 231-244, September.

BAHMANI-OSKOOEE, Mohsen; NG, Raymond Chi Wing. Long-run demand for money in Hong Kong: an application of the ARDL model. International Journal of Business and Economics, 2002, Vol. 1, No. 2, 147-155

BIANCONI, Marcelo; GHOSH, Subhajit \& YOSHINO, Joe A. (2014) Institutional and Risk Factors Effects on Money Demand Across Countries. 2014 Working Paper: Tufts University/ Faculdade de Economia, Administração e Contabilidade - Universidade de São Paulo.

BLINDER, Alan S. (2010) Quantitative easing: entrance and exit strategies. Federal Reserve Bank of St. Louis Review. November/December 2010, 92(6), pp. 465-79.

BOLLERSLEV, Tim. (1986) Generalized Autoregressive Conditional Heteroscedasticity. Journal of Econometrics 31:307-27. 
BOX, George E. P., \& D. R. Cox. (1964). An analysis of transformations. Journal of the Royal Statistical Society, Series B 26: 211-252.

BROWN, R. L.; DURBIN, J. \& EVANS, J. M. (1975). Techniques for testing the constancy of regression relationships over time. Journal of the Royal Statistical Society 1975; 37; 149163.

CARLSON, John B. \& SCHWARZ, Jeffrey C. (1999). Effects of movements in equities prices on M2 demand. Economic Review, Federal Reserve Bank of Cleveland, issue Q IV, pages 2-9.

CARPENTER, Seth B. \& LANGE, Joe,. (2003) Money Demand and Equity Markets. Finance and Economics Discussion Series 2003-03, Board of Governors of the Federal Reserve System (U.S.).

CHOI, Woon Gyu \& COOK, David. (2007). Financial Market Risk and U.S. Money Demand. IMF Working Papers 07/89, International Monetary Fund.

CHOI, Woon Gyu \& OH, Seonghwan. (2003). A Money Demand Function with Output Uncertainty, Monetary Uncertainty, and Financial Innovations. Journal of Money, Credit and Banking, Blackwell Publishing, vol. 35(5), pages 685-709, October.

CHOUDHRY, Taufiq. (1999). Does Interest Rate Volatility Affect the US M1 Demand Function? Evidence from Cointegration. Manchester School, University of Manchester, vol. 67(6), pages 621-48, December.

DAVIDSON, Russell \& MACKINNON, James G. (1981). Several tests for model specification in the presence of alternative hypotheses. Econometrica, 49 (1981), pp. 781793.

DRITSAKIS, Nikolaos. (2011). Demand for money in Hungary: an ARDL approach. Review of Economics and Finance, Better Advances Press, Canada, vol. 1, pages 01-16, November. 
DUCA, John V. \& VANHOOSE, David D., (2004). Recent developments in understanding the demand for money. Journal of Economics and Business, Elsevier, vol. 56(4), pages 247272.

DUTKOWSKY, D.H. \& CYNAMON, B.Z. (2003) Sweep Programs: The fall of M1 and rebirth of the medium of exchange. Journal of Money, Credit, and Banking, 35, pag. 263279.

ENGLE, Robert F \& GRANGER, Clive W. J., (1987). Co-integration and Error Correction: Representation, Estimation, and Testing. Econometrica, Econometric Society, vol. 55(2), pages 251-76, March.

FEIGE, Edgar L. (1967). Expectations and adjustments in the monetary sector. American Economic Review, Papers and Proceedings, 57: 462-473.

FRIEDMAN, Milton. (1956). The Quantity Theory of Money: A Restatement. Studies in the Quantity Theory of Money, M. Friedman (ed.), Chicago: University of Chicago Press.

GARNER, Alan C. (1986). Does interest rate volatility affect money demand? Economic Review, Federal Reserve Bank of Kansas City, issue Jan, pages 25-37.

GOLDFELD, Stephen M. (1973). The Demand for Money Revisited. Brookings Papers on Economic Activity, Economic Studies Program, The Brookings Institution, vol. 4(3), pages 577-646.

GOLDFELD, Stephen M. \& SICHEL, D.E. (1990) The Demand for Money. In: Handbook of Monetary Economics, Vol.1, Edited by B.M. Friedman and F.H. Hahn.

GRANGER, Clive W. J. (1981) Some Properties of Time Series Data and Their Use in Econometric Model Specification. Journal of Econometrics, 121-130.

GRANGER, Clive W. J. (1983) Co-Integrated Variables and Error-Correcting Models. Unpublished UCSD Discussion Paper 83-13. 
GRANGER, Clive W. J. (1986). Developments in the Study of Cointegrated Economic Variables. Oxford Bulletin of Economics and Statistics, Department of Economics, University of Oxford, vol. 48(3), pages 213-28, August.

GREIBER, Claus \& LEMKE, Wolfgang. (2005) Money demand and macroeconomic uncertainty. Discussion Paper Series 1: Economic Studies. No 26/2005, Deutsche Bundesbank Discussion Paper, Research Centre.

HAMILTON, James D. (1994) Time Series Analysis. Princeton University Press. Princeton, New Jersey.

HOSSAIN, Akhand Akhtar. (2012) Modelling of narrow money demand in Australia: an ARDL cointegration approach, 1970-2009. Springer, vol. 42(3), pages 767-790, June 2012.

IRELAND, Peter N. (2009). On the Welfare Cost of Inflation and the Recent Behavior of Money Demand. American Economic Review, 99(3): 1040-52.

JOHANSEN, Søren. (1988). Statistical analysis of cointegration vectors. Journal of Economic Dynamics and Control, Elsevier, vol. 12(2-3), pages 231-254.

JOHANSEN, Søren; JUSELIUS, Katarina. (1990). Maximum likelihood estimation and inference on cointegration - with applications to the demand for money. Oxford Bulletin of Economics and Statistics, 52, 2 (1990),

KEYNES, John Maynard. (1936). The General Theory of Employment, Interest, and Money. London and New York: Macmillan.

KREMERS, J.J., ERICSON, N.R. \& DOLADO, J.J. (1992) The power of cointegration tests. Oxford Bulletin of Economics and Statistics, 54, 325-347.

LEEPER, Eric M. \& ROUSH, Jennifer E. (2003) Putting “M” back in monetary policy. Journal of Money, Credit, and Banking, Vol. 35 (Part 2, December), pp. 1217-56. 
LEVINE, R., (2002) Bank-based or market-based financial systems: Which is better? Journal of Financial Intermediation 11, 398-428.

LUCAS Jr., Robert E. (1988). Money demand in the United States: A quantitative review. Carnegie-Rochester Conference Series on Public Policy, Elsevier, vol. 29(1), pages 137-167, January.

LUCAS Jr., Robert E. (2000). Inflation and Welfare. Econometrica, Econometric Society, vol. 68(2), pages 247-274, March.

MACKINNON, James G.; WHITE, Halbert \& DAVIDSON, Russell. (1983). Tests for model specification in the presence of alternative hypotheses: Some further results. Journal of Econometrics, 21, 53-70.

MANKIW, N. Gregory \& SUMMERS, Lawrence H. (1986). Money Demand and the Effects of Fiscal Policies. Journal of Money, Credit and Banking, Blackwell Publishing, vol. 18(4), pages $415-29$, November.

MUlligAN, Casey B. \& SALA-I-MARTIN, Xavier. (1992). U.S. Money Demand: Surprising Cross-Sectional Estimates. Brookings Papers on Economic Activity, Economic Studies Program, The Brookings Institution, vol. 23(2), pages 285-343.

MULLIGAN, Casey B. \& SALA-I-MARTIN, Xavier. (2000). Extensive Margins and the Demand for Money at Low Interest Rates. Journal of Political Economy. University of Chicago Press, vol. 108(5), pages 961-991, October.

OZER-BALLI, Hatice \& SØRENSEN, Bent E. (2010). Interaction Effects in Econometrics. CEPR Discussion Papers 7929, C.E.P.R. Discussion Papers.

PESARAN, M. Hashem; SHIN, Yongcheol \& SMITH, Richard J.. (1996). Testing for the Existence of a Long-Run Relationship. DAE Working Paper No. 9622, Department of Applied Economics, University of Cambridge. 
PESARAN, M. Hashem; SHIN, Yongcheol \& SMITH, Richard J.. (1999). Bounds Testing Approaches to the Analysis of Long-Run Relationships. DAE Working Paper No. 9907, Department of Applied Economics, University of Cambridge.

PESARAN, M. Hashem; SHIN, Yongcheol; SMITH, Richard J.. (2000). Structural analysis of vector error correction models with exogenous I(1) variables. Journal of Econometrics 97 (2000) 293-343.

PESARAN, M. Hashem; SHIN, Yongcheol; SMITH, Richard J.. (2001). Bounds testing approaches to the analysis of level relationships. Journal of Applied Econometrics, John Wiley \& Sons, Ltd., vol. 16(3), pages 289-326.

PESARAN, M. Hashem \& PESARAN, Bahram. (1997). Working with Microfit 4.0: Interactive Econometric Analysis. Oxford: Oxford University Press, Jan 31, $1997-505$ pages.

PESARAN, M. Hashem \& PESARAN, Bahram. (2009). Time Series Econometrics: Using Microfit 5.0. Oxford: Oxford University Press, 2009.

ROBINSON, Richard \& EL NASSER, Marwan. (2013). Decomposing US Money Supply Changes since the Financial Crisis. International Journal of Financial Studies. 2013; 1(2):32-44.

SAIKKONNEN, Pentti. (1992) Estimation and Testing of Cointegrated Systems by an Autoregressive Approximation. Econometric Theory, Vol. 8 (March), pp. 1-27.

SAMRETH, Sovannroeun. 2008. Estimating Money Demand Function in Cambodia: ARDL Approach. MPRA Paper 16274, University Library of Munich, Germany, revised Jun 2009.

SCHWARZ, Gideon E. (1978). Estimating the dimension of a model. Annals of Statistics 6 (2): 461-464.

SERLETIS, Apostolos. (2007). The demand for money - Theoretical and empirical approaches. Springer, 2007. 
SHARIFI-RENANI, Hosein. (2007). Demand for money in Iran: An ARDL approach. MPRA Paper 8224, University Library of Munich, Germany.

SHARPE, William F. (1966) Mutual Fund Performance. Journal of Business, January 1966, pp. 119-138.

SHARPE, William F. (1994) The Sharpe Ratio. The Journal of Portfolio Management: Fall 1994, Vol. 21, No. 1: pp. 49-58.

SIDRAUSKI, Miguel. (1967). Inflation and Economic Growth. Journal of Political Economy 75 (December, 1967): 796-810.

SLOVIN, Myron B. \& SUSHKA, Marie Elizabeth. (1983). Money, interest rates, and risk. Journal of Monetary Economics, Volume 12, Issue 3, September 1983, Pages 475-482.

SRIRAM, Subramanian S. (1999) Survey of Literature on Demand for Money: Theoretical and Empirical Work with Special Reference to Error-Correction Models. IMF Working Paper 99/64 (Washington: International Monetary Fund).

SRIRAM, Subramanian S. (2001) A Survey of Recent Empirical Money Demand Studies. IMF Staff Papers, Palgrave Macmillan, Vol. 47(3). International Monetary Fund. pp. 334-65

STOCK, James H. \& WATSON, Mark W. (1993) A Simple Estimator of Cointegrating Vectors in Higher Order Integrated Systems. Econometrica, Vol. 61 (July), pp. 783-820.

TELES, Pedro \& ZHOU, Ruilin. (2005). A stable money demand: Looking for the right monetary aggregate. Economic Perspectives, Federal Reserve Bank of Chicago, issue QI/2005, pages 50-63.

TOBIN, James. (1958) Liquidity Preference as Behavior Towards Risk. Review of Economic Studies, 25, 65-86.

WALSH, Carl E. (2010) Monetary Theory and Policy. The MIT Press, third edition. 
ZAREMBKA, Paul. (1968) Functional Form in the Demand for Money. Journal of the American Statistical Association, Vol. 63, No. 322 (Jun., 1968), pp. 502-511. 


\section{APÊNDICES}

APÊNDICE 1 - Coeficientes de curto prazo omitidos - modelo com risco

APÊNDICE 2 - Coeficientes de curto prazo omitidos - modelo com risco e com variáveis per capita

APÊNDICE 3 - Coeficientes de curto prazo omitidos - modelo com risco e com TED_Spread APÊNDICE 4 - Coeficientes de curto prazo omitidos - modelo per capita com risco e com TED_Spread

APENNDICE 5 - Coeficientes de curto prazo omitidos - modelo com risco e com Spread T30 APÊNDICE 6 - Coeficientes de curto prazo omitidos - modelo per capita com risco e com Spread T30

APÊNDICE 7 - Coeficientes de curto prazo omitidos - modelo com risco e variáveis mensais APÊNDICE 8 - Coeficientes de curto prazo omitidos - modelo per capita com risco e variáveis mensais

APÊNDICE 9 - Coeficientes de curto prazo omitidos - modelo per capita com variáveis GARCH

APÊNDICE 10 - Estatísticas descritivas das variáveis utilizadas

APÊNDICE 11 - Gráfico de dispersão: demandas estimadas por agregados sobre produto versus taxas de juros 
A.1 Coeficientes de curto prazo omitidos - modelo com risco

\begin{tabular}{|c|c|c|c|c|c|c|c|}
\hline & M1 & M2 & M1RS & DV & PMPP & BM & RES \\
\hline \multirow[t]{2}{*}{$\Delta(\ln (M))_{t-1}$} & 0,1519 & 0,4177 & 0,161 & $-0,0765$ & 0,3180 & $-0,020$ & $-0,011$ \\
\hline & $0,012 *$ & $0,000^{*}$ & $0,012^{*}$ & 0,198 & $0,000^{*}$ & 0,721 & 0,885 \\
\hline \multirow[t]{2}{*}{$\Delta(\ln (M))_{t-2}$} & 0,2771 & & 0,221 & 0,2031 & & $-0,160$ & $-0,029$ \\
\hline & $0,001 *$ & & $0,001 *$ & $0,001^{*}$ & & $0,003 *$ & 0,690 \\
\hline \multirow[t]{2}{*}{$\Delta(\ln (M))_{t-3}$} & & & & & & $-0,167$ & \\
\hline & & & & & & $0,002 *$ & \\
\hline \multirow[t]{2}{*}{$\Delta(\ln (\boldsymbol{r}))_{t-1}$} & & & & & & & $-0,028$ \\
\hline & & & & & & & 0,400 \\
\hline \multirow[t]{2}{*}{$\Delta(\ln (\boldsymbol{r}))_{t-2}$} & & & & & & & $-0,011$ \\
\hline & & & & & & & 0,746 \\
\hline \multirow[t]{2}{*}{$\Delta(\ln (r))_{t-3}$} & & & & & & & $-0,026$ \\
\hline & & & & & & & 0,339 \\
\hline \multirow[t]{2}{*}{$\Delta(\ln (r))_{t-4}$} & & & & & & & 0,024 \\
\hline & & & & & & & 0,349 \\
\hline \multirow{2}{*}{$\Delta$ Spread $_{t-1}$} & & & & & & & 1,450 \\
\hline & & & & & & & 0,489 \\
\hline \multirow[t]{2}{*}{$\Delta$ Spread $_{t-2}$} & & & & & & & 1,921 \\
\hline & & & & & & & 0,301 \\
\hline
\end{tabular}

A.2 Coeficientes de curto prazo omitidos - modelo com risco e com variáveis per capita

\begin{tabular}{lccccccc}
\hline & M1 & M2 & M1RS & DV & PMPP & BM & RES \\
\hline$\Delta(\ln (\boldsymbol{M}))_{t-1}$ & $\mathbf{0 , 1 5 1}$ & $\mathbf{0 , 4 1 9}$ & $\mathbf{0 , 1 9 4}$ & $-\mathbf{0 , 0 7 6}$ & $\mathbf{0 , 2 9 9}$ & $\mathbf{0 , 0 2 6}$ & $\mathbf{0 , 0 2 1}$ \\
& $0,009^{*}$ & $0,000^{*}$ & $0,003^{*}$ & 0,201 & $0,000^{*}$ & 0,645 & 0,734 \\
$\Delta(\ln (\boldsymbol{M}))_{t-2}$ & $\mathbf{0 , 2 6 5}$ & & $\mathbf{0 , 2 1 9}$ & $\mathbf{0 , 2 0 4}$ & & $\mathbf{- 0 , 1 1 9}$ & \\
& $0,000^{*}$ & & $0,001^{*}$ & $0,001^{*}$ & & $0,027^{*}$ & \\
\hline
\end{tabular}

A.3 Coeficientes de curto prazo omitidos - modelo com risco e com TED_Spread

\begin{tabular}{cccccccc}
\hline & M1 & M2 & M1RS & DV & PMPP & BM & RES \\
\hline$\Delta(\ln (M))_{t-1}$ & $\mathbf{0 , 0 1 3}$ & $\mathbf{0 , 3 0 0}$ & $\mathbf{0 , 1 3 8}$ & $-\mathbf{0 , 1 4 2}$ & $\mathbf{0 , 2 7 8}$ & $\mathbf{0 , 0 7 6}$ & $\mathbf{0 , 0 5 8}$ \\
& 0,881 & $0,001^{*}$ & 0,113 & 0,109 & $0,008^{*}$ & 0,371 & 0,515 \\
$\Delta(\ln (\boldsymbol{M}))_{t-2}$ & $\mathbf{0 , 2 0 8}$ & & $\mathbf{0 , 2 0 4}$ & $\mathbf{0 , 1 7 9}$ & & $-\mathbf{0 , 1 6 8}$ & $-\mathbf{0 , 0 8 1}$ \\
& $0,013^{*}$ & & $0,018^{*}$ & $0,041^{*}$ & & $0,021^{*}$ & 0,279 \\
$\Delta(\ln (\boldsymbol{M}))_{t-3}$ & & & & & & $-\mathbf{0 , 0 9 1}$ & \\
& & & & & & 0,207 & \\
$\Delta(\ln (\boldsymbol{Y}))_{t-1}$ & & & $\mathbf{0 , 2 5 7}$ & & & & \\
$\Delta(\ln (\boldsymbol{Y}))_{t-2}$ & & 0,225 & & & & \\
& & & $-0,138$ & & & & \\
\hline
\end{tabular}




\begin{tabular}{lc}
\hline$\Delta(\ln (\boldsymbol{Y}))_{t-3}$ & $\mathbf{0 , 4 8 3}$ \\
& $0,017^{*}$ \\
$\Delta(\ln (\boldsymbol{Y}))_{t-4}$ & $-\mathbf{0 , 3 4 8}$ \\
& 0,093 \\
$\Delta(\ln (\boldsymbol{Y}))_{t-5}$ & $\mathbf{0 , 3 4 6}$ \\
& 0,077 \\
$\Delta$ Vol_$_{\mathbf{t}} \boldsymbol{Y}_{-\mathbf{1}}$ & $\mathbf{- 2 , 3 9 1}$ \\
& 0,240 \\
\hline
\end{tabular}

A.4 Coeficientes de curto prazo omitidos - modelo per capita com risco e com TED_Spread

\begin{tabular}{lccccccc}
\hline & M1 & M2 & M1RS & DV & PMPP & BM & RES \\
\hline$\Delta(\ln (M))_{t-1}$ & $\mathbf{0 , 0 0 4}$ & $\mathbf{0 , 2 9 9}$ & $\mathbf{0 , 0 9 2}$ & $-\mathbf{0 , 1 4 2}$ & $\mathbf{0 , 1 8 8}$ & $-\mathbf{0 , 0 3 3}$ & $-\mathbf{0 , 1 2 1}$ \\
& 0,959 & $0,001^{*}$ & 0,306 & 0,106 & 0,052 & 0,685 & 0,195 \\
$\Delta(\ln (M))_{t-2}$ & $\mathbf{0 , 2 3 2}$ & & $\mathbf{0 , 2 1 1}$ & $\mathbf{0 , 1 7 7}$ & & $-\mathbf{0 , 2 1 3}$ & $-\mathbf{0 , 1 7 3}$ \\
& $0,005^{*}$ & & $0,014^{*}$ & $0,042^{*}$ & & $0,002^{*}$ & $0,021^{*}$ \\
$\Delta(\ln (M))_{t-3}$ & & & & & & & $-\mathbf{0 , 1 2 4}$ \\
& & & & & & & 0,073 \\
$\Delta(\ln (M))_{t-4}$ & & & & & & & 0,097 \\
& & & & & & & 0,165 \\
\hline
\end{tabular}

A.5 Coeficientes de curto prazo omitidos - modelo com risco e com Spread T30

\begin{tabular}{|c|c|c|c|c|c|c|c|}
\hline & M1 & M2 & M1RS & DV & PMPP & BM & RES \\
\hline \multirow[t]{2}{*}{$\Delta(\ln (M))_{t-1}$} & 0,041 & 0,447 & 0,194 & $-0,223$ & 0,295 & 0,250 & 0,004 \\
\hline & 0,615 & $0,000 *$ & $0,048 *$ & $0,004 *$ & $0,001 *$ & $0,008 *$ & 0,962 \\
\hline \multirow[t]{2}{*}{$\Delta(\ln (M))_{t-2}$} & 0,237 & & 0,350 & 0,199 & & $-0,041$ & \\
\hline & $\begin{array}{c}0,005 \\
*\end{array}$ & & $0,002 *$ & $0,012^{*}$ & & 0,638 & \\
\hline \multirow[t]{2}{*}{$\Delta(\ln (M))_{t-3}$} & & & & $-0,005$ & & $-0,204$ & \\
\hline & & & & 0,950 & & $0,019 *$ & \\
\hline \multirow[t]{2}{*}{$\Delta(\ln (M))_{t-4}$} & & & & $-0,142$ & & 0,319 & \\
\hline & & & & 0,054 & & $0,000 *$ & \\
\hline \multirow[t]{2}{*}{$\Delta(\ln (r))_{t-1}$} & & & 0,001 & & & 0,039 & \\
\hline & & & 0,683 & & & $0,014^{*}$ & \\
\hline \multirow[t]{2}{*}{$\Delta(\ln (\boldsymbol{r}))_{t-2}$} & & & 0,004 & & & 0,037 & \\
\hline & & & 0,180 & & & $0,011 *$ & \\
\hline \multirow[t]{2}{*}{$\Delta(\ln (r))_{t-3}$} & & & & & & $-0,005$ & \\
\hline & & & & & & 0,719 & \\
\hline \multirow[t]{2}{*}{$\Delta(\ln (r))_{t-4}$} & & & & & & 0,052 & \\
\hline & & & & & & $0,000 *$ & \\
\hline \multirow[t]{2}{*}{$\Delta(\ln (Y))_{t-1}$} & & & $-0,054$ & & & & \\
\hline & & & 0,756 & & & & \\
\hline
\end{tabular}




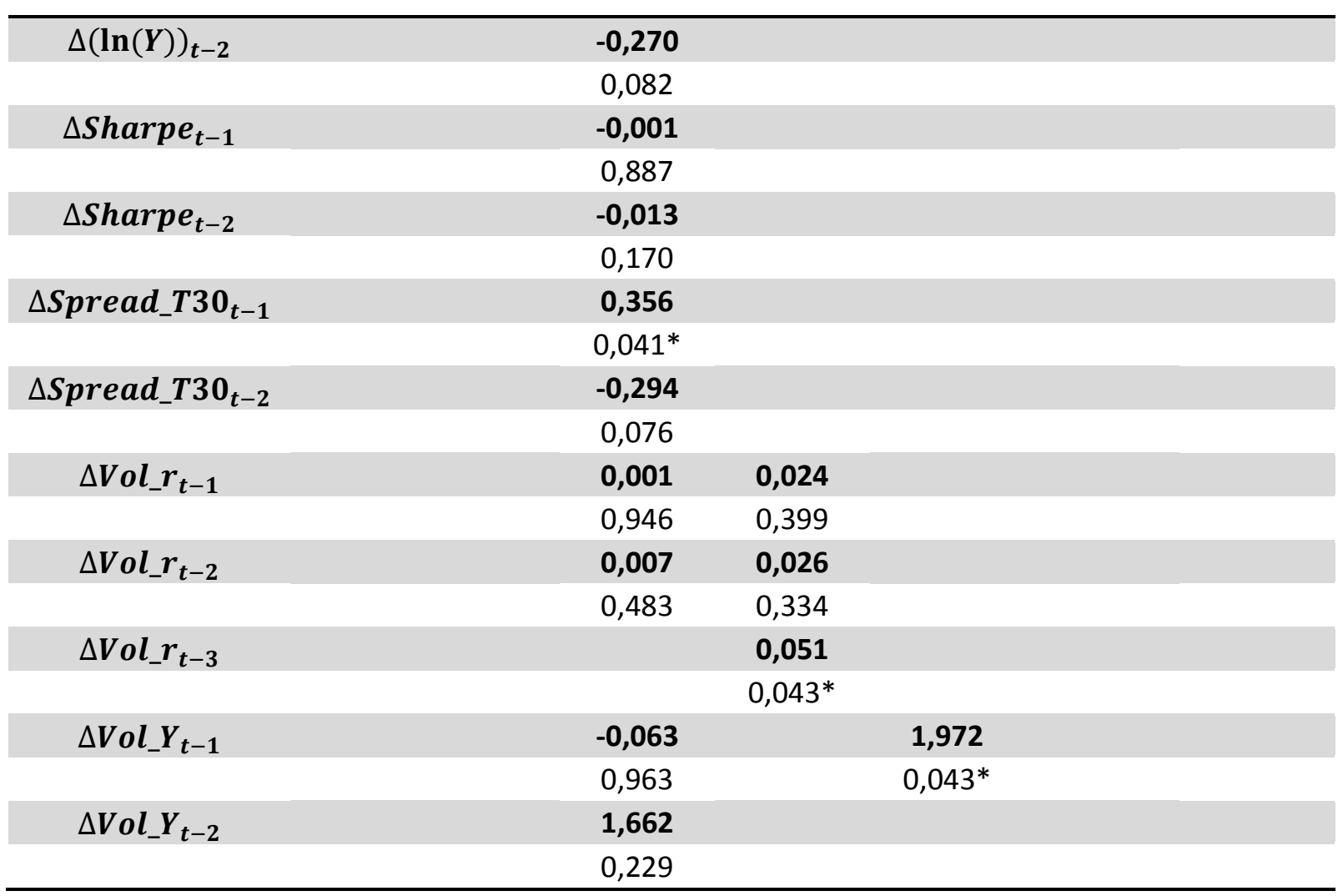

A.6 Coeficientes de curto prazo omitidos - modelo per capita com risco e com Spread T30

\begin{tabular}{|c|c|c|c|c|c|c|c|}
\hline & M1 & M2 & M1RS & DV & PMPP & BM & RES \\
\hline \multirow[t]{2}{*}{$\Delta(\ln (M))_{t-1}$} & 0,049 & 0,328 & 0,168 & $-0,171$ & 0,261 & 0,001 & 0,014 \\
\hline & 0,547 & $0,000^{*}$ & $0,038^{*}$ & $0,027^{*}$ & $0,003^{*}$ & 0,984 & 0,857 \\
\hline \multirow[t]{2}{*}{$\Delta(\ln (M))_{t-2}$} & 0,248 & & 0,261 & 0,223 & & $-0,157$ & \\
\hline & $0,003^{*}$ & & $0,003^{*}$ & $0,006^{*}$ & & $0,015^{*}$ & \\
\hline \multirow[t]{2}{*}{$\Delta(\ln (M))_{t-3}$} & & & & & & $-0,165$ & \\
\hline & & & & & & $0,012^{*}$ & \\
\hline \multirow[t]{2}{*}{$\Delta$ Spread $_{t-1}$} & & & 0,451 & & & & \\
\hline & & & $0,001^{*}$ & & & & \\
\hline \multirow[t]{2}{*}{$\Delta V o l_{-} Y_{t-1}$} & & & & & 2,075 & & \\
\hline & & & & & $0,031^{*}$ & & \\
\hline
\end{tabular}

A.7 Coeficientes de curto prazo omitidos - modelo com risco e variáveis mensais

\begin{tabular}{cccccccc}
\hline & M1 & M1RS & M2 & DV & PMPP & BM & RES \\
\hline$\Delta(\ln (\boldsymbol{M}))_{t-\mathbf{1}}$ & $\mathbf{0 , 1 2 7 5}$ & $\mathbf{0 , 2 2 2 5}$ & $\mathbf{0 , 4 7 2 7}$ & $-\mathbf{0 , 0 8 1 2}$ & $\mathbf{0 , 4 0 3 2}$ & $\mathbf{0 , 6 3 1 3}$ & $\mathbf{0 , 5 6 9 4}$ \\
& $0,0008^{*}$ & $0,0000^{*}$ & $0,0000^{*}$ & $0,0434^{*}$ & $0,0000^{*}$ & $0,0000^{*}$ & $0,0000^{*}$ \\
$\Delta(\ln (\boldsymbol{M}))_{\boldsymbol{t}-\mathbf{2}}$ & $\mathbf{0 , 0 9 4 9}$ & $\mathbf{0 , 0 7 5 9}$ & $\mathbf{0 , 0 5 5 3}$ & $\mathbf{0 , 0 1 3 6}$ & $\mathbf{0 , 0 3 9 1}$ & $-\mathbf{0 , 3 9 2 2}$ & $-\mathbf{0 , 3 1 3 8}$ \\
& $0,0127^{*}$ & 0,0666 & 0,2155 & 0,7113 & 0,3672 & $0,0000^{*}$ & $0,0000^{*}$ \\
$\Delta(\ln (\boldsymbol{M}))_{t-\mathbf{3}}$ & $\mathbf{0 , 1 1 9 5}$ & $\mathbf{0 , 1 9 3 4}$ & $\mathbf{0 , 0 4 9 8}$ & $\mathbf{0 , 0 6 6 7}$ & $\mathbf{0 , 0 8 6 1}$ & $\mathbf{0 , 1 3 6 9}$ & $\mathbf{0 , 0 7 7 3}$ \\
& $\mathbf{0 , 0 0 1 5 ^ { * }}$ & $\mathbf{0 , 0 0 0 0 ^ { * }}$ & 0,2644 & 0,0708 & $0,0485^{*}$ & $0,0046^{*}$ & 0,0974
\end{tabular}




\begin{tabular}{|c|c|c|c|c|c|c|c|}
\hline$\Delta(\ln (M))_{t-4}$ & $-0,0640$ & $-0,0373$ & $-0,0149$ & $-0,1010$ & $-0,0127$ & 0,0384 & $-0,0335$ \\
\hline & 0,0877 & 0,3507 & 0,7364 & $0,0051^{*}$ & 0,7673 & 0,4248 & 0,4658 \\
\hline \multirow{2}{*}{$\Delta(\ln (M))_{t-5}$} & 0,0770 & & 0,0829 & $-0,0089$ & 0,0895 & $-0,0427$ & $-0,0255$ \\
\hline & $0,0406^{*}$ & & $0,0342 *$ & 0,8061 & $0,0244 *$ & 0,3692 & 0,5782 \\
\hline \multirow[t]{2}{*}{$\Delta(\ln (M))_{t-6}$} & 0,1701 & & & 0,1944 & & 0,0269 & 0,0731 \\
\hline & $0,0000^{*}$ & & & $0,0000^{*}$ & & 0,5684 & 0,1089 \\
\hline \multirow[t]{2}{*}{$\Delta(\ln (M))_{t-7}$} & $-0,0229$ & & & & & $-0,1114$ & $-0,1123$ \\
\hline & 0,5449 & & & & & $0,0186^{*}$ & $0,0134 *$ \\
\hline \multirow[t]{2}{*}{$\Delta(\ln (M))_{t-8}$} & 0,0137 & & & & & $-0,0637$ & 0,0277 \\
\hline & 0,7170 & & & & & 0,1791 & 0,5413 \\
\hline \multirow[t]{2}{*}{$\Delta(\ln (M))_{t-9}$} & 0,1107 & & & & & 0,1081 & $-0,0159$ \\
\hline & $0,0031^{*}$ & & & & & $0,0228^{*}$ & 0,7279 \\
\hline \multirow[t]{2}{*}{$\Delta(\ln (M))_{t-10}$} & & & & & & $-0,2193$ & $-0,1193$ \\
\hline & & & & & & $0,0000^{*}$ & $0,0088^{*}$ \\
\hline \multirow[t]{2}{*}{$\Delta(\ln (M))_{t-11}$} & & & & & & 0,2195 & 0,0661 \\
\hline & & & & & & $0,0000^{*}$ & 0,1449 \\
\hline \multirow[t]{2}{*}{$\Delta(\ln (M))_{t-12}$} & & & & & & & 0,2509 \\
\hline & & & & & & & $0,0000^{*}$ \\
\hline \multirow[t]{2}{*}{$\Delta(\ln (M))_{t-13}$} & & & & & & & $-0,2344$ \\
\hline & & & & & & & $0,0000^{*}$ \\
\hline \multirow[t]{2}{*}{$\Delta(\ln (Y))_{t-1}$} & & & & 0,1477 & & $-0,0910$ & $-0,5974$ \\
\hline & & & & 0,1293 & & 0,3094 & 0,0687 \\
\hline \multirow[t]{2}{*}{$\Delta(\ln (\boldsymbol{r}))_{t-1}$} & & & & $-0,0168$ & & $-0,0181$ & $-0,0281$ \\
\hline & & & & $0,0002^{*}$ & & $0,0000 *$ & $0,0496 *$ \\
\hline \multirow[t]{2}{*}{$\Delta$ Sharpe $_{t-1}$} & & & & 0,0095 & & 0,0046 & 0,0137 \\
\hline & & & & 0,3465 & & 0,6235 & 0,6824 \\
\hline \multirow[t]{2}{*}{$\Delta$ Spread_loan $n_{t-1}$} & & & & $-0,4778$ & & $-0,0601$ & 0,0580 \\
\hline & & & & $0,0100^{*}$ & & 0,7259 & 0,9241 \\
\hline \multirow[t]{2}{*}{$\Delta V o l \_r_{t-1}$} & & & & $-2,8655$ & & $-0,1787$ & $-4,9517$ \\
\hline & & & & 0,0925 & & 0,9365 & 0,3788 \\
\hline \multirow[t]{2}{*}{$\Delta V o l_{-} Y_{t-1}$} & & & & 0,1247 & & 2,9310 & 11,6565 \\
\hline & & & & 0,9227 & & $0,0141^{*}$ & $0,0067^{*}$ \\
\hline \multirow[t]{2}{*}{$\Delta(\ln (Y))_{t-2}$} & & & & & & $-0,3033$ & \\
\hline & & & & & & $0,0007^{*}$ & \\
\hline \multirow[t]{2}{*}{$\Delta(\ln (\boldsymbol{r}))_{t-2}$} & & & & & & 0,0203 & \\
\hline & & & & & & $0,0000^{*}$ & \\
\hline \multirow[t]{2}{*}{$\Delta$ Sharpe $_{t-2}$} & & & & & & $-0,0039$ & \\
\hline & & & & & & 0,6710 & \\
\hline \multirow[t]{2}{*}{$\Delta$ Spread_loan $n_{t-2}$} & & & & & & 0,4052 & \\
\hline & & & & & & $0,0164 *$ & \\
\hline \multirow[t]{2}{*}{$\Delta V o l \_r_{t-2}$} & & & & & & 0,4819 & \\
\hline & & & & & & 0,7645 & \\
\hline \multirow[t]{2}{*}{$\Delta V o l \_Y_{t-2}$} & & & & & & 1,9366 & \\
\hline & & & & & & 0,0960 & \\
\hline
\end{tabular}


A.8 Coeficientes de curto prazo omitidos -modelo per capita com risco e variáveis mensais

\begin{tabular}{|c|c|c|c|c|c|c|c|}
\hline & M1 & M2 & M1RS & DV & PMPP & BM & RES \\
\hline \multirow[t]{2}{*}{$\Delta(\ln (M))_{t-1}$} & 0,123 & 0,464 & 0,217 & $-0,083$ & 0,399 & 0,658 & 0,575 \\
\hline & $0,001 *$ & $0,000 *$ & $0,000 *$ & $0,039 *$ & $0,000^{*}$ & $0,000^{*}$ & $0,000 *$ \\
\hline \multirow{2}{*}{$\Delta(\ln (M))_{t-2}$} & 0,091 & 0,063 & 0,073 & 0,013 & 0,040 & $-0,437$ & $-0,308$ \\
\hline & $0,017^{*}$ & 0,162 & 0,077 & 0,731 & 0,357 & $0,000^{*}$ & $0,000^{*}$ \\
\hline \multirow{2}{*}{$\Delta(\ln (M))_{t-3}$} & 0,115 & 0,044 & 0,189 & 0,066 & 0,083 & 0,123 & 0,087 \\
\hline & $0,002 *$ & 0,321 & $0,000^{*}$ & 0,075 & 0,056 & $0,010^{*}$ & 0,063 \\
\hline \multirow{2}{*}{$\Delta(\ln (M))_{t-4}$} & $-0,066$ & $-0,016$ & $-0,039$ & $-0,102$ & $-0,011$ & 0,020 & $-0,033$ \\
\hline & 0,079 & 0,724 & 0,330 & $0,005^{*}$ & 0,798 & 0,684 & 0,482 \\
\hline \multirow{2}{*}{$\Delta(\ln (M))_{t-5}$} & 0,075 & 0,062 & & $-0,010$ & 0,088 & $-0,055$ & $-0,038$ \\
\hline & $0,045^{*}$ & 0,161 & & 0,793 & $0,027^{*}$ & 0,250 & 0,412 \\
\hline \multirow{2}{*}{$\Delta(\ln (M))_{t-6}$} & 0,169 & 0,027 & & 0,194 & & 0,053 & 0,053 \\
\hline & $0,000 *$ & 0,549 & & $0,000^{*}$ & & 0,263 & 0,247 \\
\hline \multirow{2}{*}{$\Delta(\ln (M))_{t-7}$} & $-0,024$ & $-0,021$ & & & & $-0,114$ & $-0,107$ \\
\hline & 0,526 & 0,643 & & & & $0,015^{*}$ & $0,018^{*}$ \\
\hline \multirow[t]{2}{*}{$\Delta(\ln (M))_{t-8}$} & 0,013 & 0,026 & & & & $-0,063$ & 0,021 \\
\hline & 0,737 & 0,563 & & & & 0,182 & 0,650 \\
\hline \multirow[t]{2}{*}{$\Delta(\ln (M))_{t-9}$} & 0,110 & 0,082 & & & & 0,102 & $-0,016$ \\
\hline & $0,003^{*}$ & $0,038^{*}$ & & & & $0,031^{*}$ & 0,725 \\
\hline \multirow{2}{*}{$\Delta(\ln (M))_{t-10}$} & & & & & & $-0,219$ & $-0,124$ \\
\hline & & & & & & $0,000^{*}$ & $0,007^{*}$ \\
\hline \multirow[t]{2}{*}{$\Delta(\ln (M))_{t-11}$} & & & & & & 0,220 & 0,074 \\
\hline & & & & & & $0,000^{*}$ & 0,103 \\
\hline \multirow[t]{2}{*}{$\Delta(\ln (M))_{t-12}$} & & & & & & & 0,252 \\
\hline & & & & & & & $0,000 *$ \\
\hline \multirow[t]{2}{*}{$\Delta(\ln (M))_{t-13}$} & & & & & & & $-0,227$ \\
\hline & & & & & & & $0,000^{*}$ \\
\hline \multirow[t]{2}{*}{$\overline{\Delta(\ln (Y))_{t-1}}$} & & & & 0,147 & & $-0,093$ & $-0,657$ \\
\hline & & & & 0,132 & & 0,299 & $0,048 *$ \\
\hline \multirow[t]{2}{*}{$\Delta(\ln (\boldsymbol{r}))_{t-1}$} & & & & $-0,017$ & & $-0,023$ & $-0,030$ \\
\hline & & & & $0,000^{*}$ & & $0,000^{*}$ & $0,036^{*}$ \\
\hline \multirow[t]{2}{*}{$\Delta$ Sharpe $_{t-1}$} & & & & 0,009 & & 0,005 & 0,019 \\
\hline & & & & 0,356 & & 0,563 & 0,584 \\
\hline \multirow[t]{2}{*}{$\Delta$ Spread_loan ${ }_{t-1}$} & & & & $-0,468$ & & $-0,007$ & $-0,065$ \\
\hline & & & & $0,012^{*}$ & & 0,970 & 0,918 \\
\hline \multirow[t]{2}{*}{$\Delta$ Vol_r $r_{t-1}$} & & & & $-2,848$ & & 0,818 & $-6,745$ \\
\hline & & & & 0,094 & & 0,726 & 0,413 \\
\hline \multirow[t]{2}{*}{$\Delta V o l_{-} Y_{t-1}$} & & & & 0,105 & & 2,680 & 9,685 \\
\hline & & & & 0,935 & & $0,025^{*}$ & $0,029 *$ \\
\hline \multirow[t]{2}{*}{$\Delta(\ln (Y))_{t-2}$} & & & & & & $-0,274$ & $-0,816$ \\
\hline & & & & & & $0,002^{*}$ & $0,014^{*}$ \\
\hline \multirow[t]{2}{*}{$\Delta(\ln (r))_{t-2}$} & & & & & & 0,023 & 0,035 \\
\hline & & & & & & $0,000^{*}$ & $0,020^{*}$ \\
\hline$\Delta$ Sharpe $_{t-2}$ & & & & & & $-0,008$ & $-0,049$ \\
\hline & & & & & & 0,406 & 0,145 \\
\hline$\Delta$ Spread_loan ${ }_{t-2}$ & & & & & & 0,554 & 1,296 \\
\hline & & & & & & $0,002^{*}$ & $0,036^{*}$ \\
\hline$\Delta V o l \_r_{t-2}$ & & & & & & $-0,665$ & 1,841 \\
\hline
\end{tabular}




\begin{tabular}{|c|c|c|}
\hline & 0,775 & 0,755 \\
\hline \multirow[t]{2}{*}{$\Delta V o l_{-} Y_{t-2}$} & 1,994 & 0,222 \\
\hline & 0,094 & 0,959 \\
\hline \multirow[t]{2}{*}{$\Delta(\ln (Y))_{t-3}$} & $-0,098$ & \\
\hline & 0,283 & \\
\hline \multirow[t]{2}{*}{$\Delta(\ln (\boldsymbol{r}))_{t-3}$} & $-0,016$ & \\
\hline & $0,000^{*}$ & \\
\hline \multirow[t]{2}{*}{$\Delta$ Sharpe $_{t-3}$} & 0,004 & \\
\hline & 0,683 & \\
\hline \multirow[t]{2}{*}{$\Delta$ Spread_loan ${ }_{t-3}$} & $-0,087$ & \\
\hline & 0,607 & \\
\hline \multirow{2}{*}{$\Delta V o l r_{t-3}$} & 0,726 & \\
\hline & 0,651 & \\
\hline \multirow{2}{*}{$\Delta V o l_{-} Y_{t-3}$} & $-1,452$ & \\
\hline & 0,215 & \\
\hline
\end{tabular}

A.9 Coeficientes de curto prazo omitidos - modelo per capita com variáveis

\section{GARCH}

\begin{tabular}{|c|c|c|c|c|c|c|c|}
\hline & M1 & M2 & M1RS & DV & PMPP & BM & RES \\
\hline \multirow{2}{*}{$\Delta(\ln (M))_{t-1}$} & 0,173 & 0,327 & 0,173 & 0,021 & 0,184 & $-0,017$ & $-0,071$ \\
\hline & $0,007^{*}$ & $0,000^{*}$ & $0,012^{*}$ & 0,757 & $0,007^{*}$ & 0,847 & 0,420 \\
\hline \multirow[t]{2}{*}{$\Delta(\ln (M))_{t-2}$} & 0,281 & 0,171 & 0,287 & 0,217 & 0,156 & $-0,356$ & \\
\hline & $0,000^{*}$ & $0,007^{*}$ & $0,000^{*}$ & $0,002^{*}$ & $0,017^{*}$ & $0,000 *$ & \\
\hline \multirow{2}{*}{$\Delta(\ln (M))_{t-3}$} & 0,162 & & & & 0,097 & $-0,280$ & \\
\hline & $0,006^{*}$ & & & & 0,109 & $0,000 *$ & \\
\hline \multirow{2}{*}{$\Delta(\ln (M))_{t-4}$} & & & & & & 0,070 & \\
\hline & & & & & & 0,183 & \\
\hline \multirow[t]{2}{*}{$\Delta(\ln (M))_{t-5}$} & & & & & & 0,047 & \\
\hline & & & & & & 0,378 & \\
\hline \multirow{2}{*}{$\Delta G A R C H_{-} r_{t-1}$} & 0,002 & & & 0,007 & & & \\
\hline & $0,005^{*}$ & & & $0,009 *$ & & & \\
\hline \multirow[t]{2}{*}{$\Delta G A R C H \_r_{t-2}$} & & & & 0,001 & & & \\
\hline & & & & 0,546 & & & \\
\hline \multirow[t]{2}{*}{$\Delta G A R C H_{-} r_{t-3}$} & & & & $-0,001$ & & & \\
\hline & & & & 0,709 & & & \\
\hline \multirow[t]{2}{*}{$\Delta G A R C H \_r_{t-4}$} & & & & 0,003 & & & \\
\hline & & & & $0,050^{*}$ & & & \\
\hline \multirow[t]{2}{*}{$\Delta G A R C H_{-} Y_{t-1}$} & 42,760 & & 44,870 & 104,400 & 25,510 & & \\
\hline & $0,045^{*}$ & & $0,029 *$ & $0,029^{*}$ & $0,025^{*}$ & & \\
\hline \multirow[t]{2}{*}{$\Delta G A R C H_{-} Y_{t-2}$} & & & & $-127,000$ & & & \\
\hline & & & & $0,005^{*}$ & & & \\
\hline \multirow[t]{2}{*}{$\Delta$ Spread_loan ${ }_{t-1}$} & & & & & $-0,394$ & & \\
\hline & & & & & $0,001^{*}$ & & \\
\hline \multirow[t]{2}{*}{$\Delta$ Spread_loan ${ }_{t-2}$} & & & & & $-0,273$ & & \\
\hline & & & & & $0,019 *$ & & \\
\hline \multirow[t]{2}{*}{$\Delta$ Spread_loan ${ }_{t-3}$} & & & & & $-0,182$ & & \\
\hline & & & & & 0,064 & & \\
\hline
\end{tabular}


A.10 Estatísticas descritivas das variáveis utilizadas

\begin{tabular}{|c|c|c|c|c|c|}
\hline Variável & Obs & Média & $\begin{array}{l}\text { Desvio } \\
\text { Padrão }\end{array}$ & Min & $\operatorname{Max}$ \\
\hline ln_tbill & 267 & $-3,57834$ & 1,28310 & $-9,21034$ & $-1,86498$ \\
\hline$i t \_v p i b \_v i$ & 255 & 0,00803 & 0,00847 & 0,00018 & 0,04231 \\
\hline it_vpib_ted & 111 & 0,00004 & 0,00003 & 0,00001 & 0,00017 \\
\hline it_vpib_sharpedow & 255 & 0,00249 & 0,00336 & $-0,00606$ & 0,02161 \\
\hline it_vpib_loan & 255 & 0,00020 & 0,00014 & 0,00003 & 0,00092 \\
\hline$i t \_i \_v i$ & 259 & 0,04458 & 0,06382 & 0,00001 & 0,35871 \\
\hline sharpe_dow & 259 & 0,26975 & 0,26889 & $-0,74398$ & 1,36263 \\
\hline spread_loan & 259 & 0,02343 & 0,01093 & 0,00210 & 0,05580 \\
\hline ted_spread & 111 & 0,00637 & 0,00442 & 0,00118 & 0,02206 \\
\hline$v_{-} r g d p$ & 255 & 0,00929 & 0,00418 & 0,00322 & 0,01838 \\
\hline$v_{-} i$ & 259 & 0,79063 & 0,59656 & 0,03353 & 2,79558 \\
\hline spread_t30 & 131 & 0,01973 & 0,01567 & $-0,03090$ & 0,04490 \\
\hline ln_edow & 267 & $-0,00073$ & 0,41749 & $-1,73388$ & 1,14434 \\
\hline ln_tbill_garch & 267 & 0,25296 & 1,27180 & 0,00492 & 16,74673 \\
\hline ln_rgdp_garch & 267 & 0,00012 & 0,00010 & 0,00003 & 0,00060 \\
\hline ln_m1p & 219 & 7,15867 & 0,18907 & 6,87947 & 7,75538 \\
\hline$l n \_m 2 p$ & 219 & 8,44371 & 0,36844 & 7,65722 & 9,18878 \\
\hline ln_m1rsp & 187 & 7,31920 & 0,31396 & 6,87947 & 8,02719 \\
\hline$l n \_d v \_p$ & 219 & 6,38673 & 0,33008 & 5,71415 & 6,86227 \\
\hline$l n \_p m p p \_p$ & 267 & 5,87384 & 0,49375 & 5,31741 & 6,94512 \\
\hline$l n \_b m \_p$ & 219 & 6,34765 & 0,50669 & 5,83922 & 8,05804 \\
\hline ln_res_p & 219 & 4,96672 & 0,75240 & 4,21966 & 7,65965 \\
\hline ln_rgdp & 267 & 7,47702 & 0,55107 & 6,38112 & 8,25326 \\
\hline \multicolumn{6}{|c|}{ Per capita } \\
\hline ln_m1p & 219 & 8,57956 & 0,10263 & 8,34638 & 8,90466 \\
\hline $\ln \_m 2 p$ & 219 & 9,86460 & 0,20838 & 9,38936 & 10,33806 \\
\hline ln_m1rsp & 187 & 8,69692 & 0,19064 & 8,34638 & 9,17647 \\
\hline$l n \_d v \_p$ & 219 & 7,80762 & 0,47204 & 6,90722 & 8,43116 \\
\hline ln_pmpp_p & 247 & 7,37375 & 0,31389 & 7,01321 & 8,09440 \\
\hline$l n \_b m \_p$ & 219 & 7,76854 & 0,37995 & 7,38226 & 9,20732 \\
\hline ln_res_p & 219 & 6,38761 & 0,74455 & 5,41519 & 8,80893 \\
\hline ln_rgdp & 247 & 9,02319 & 0,28956 & 8,43499 & 9,41746 \\
\hline
\end{tabular}


A.11 Gráficos de dispersão: razão das demandas estimadas por agregados sobre PIB versus taxas de juros (modelos per capita)

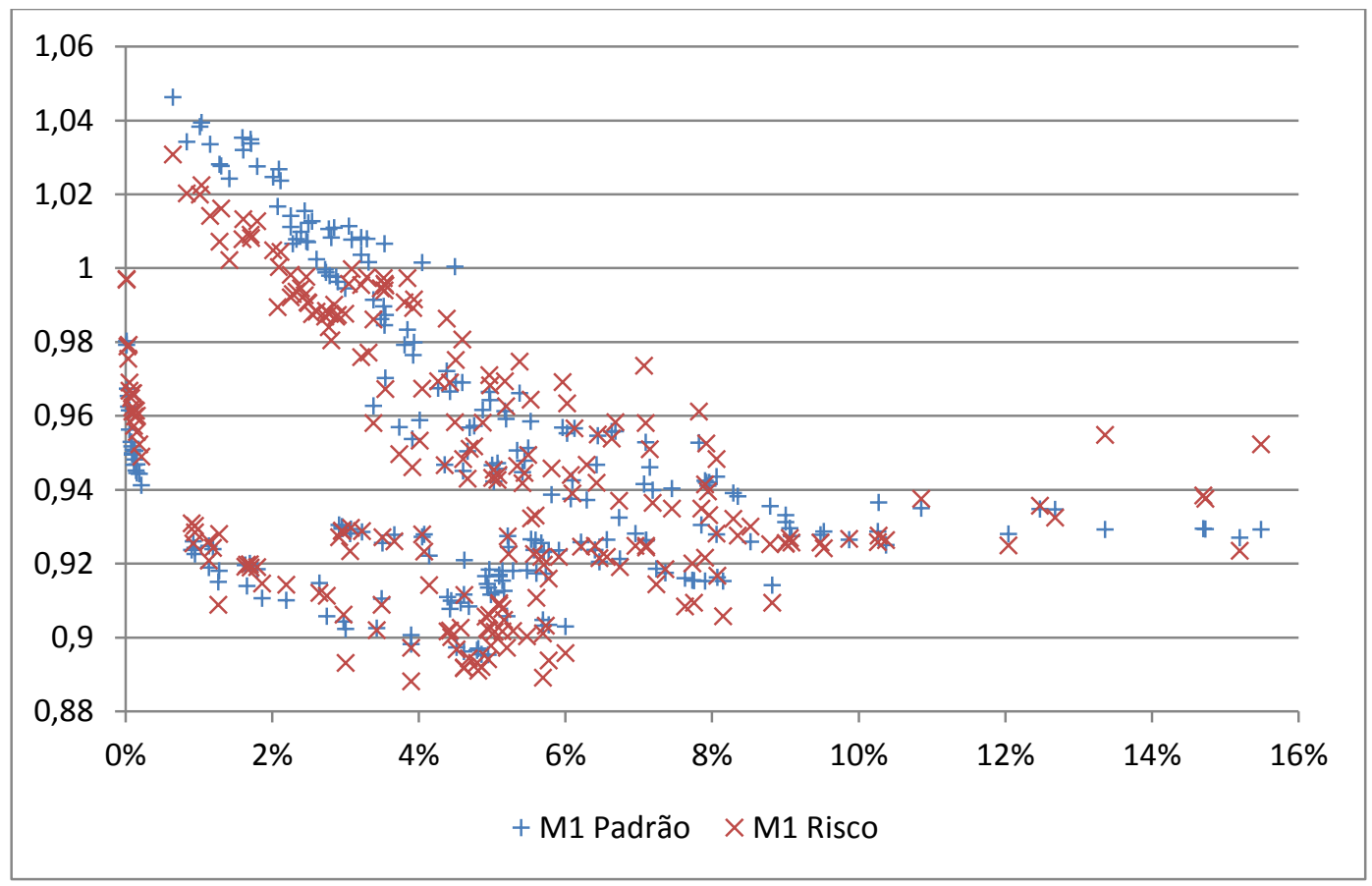

$\frac{\widehat{M 1 / P}}{P I B}$ vs. Taxa T-bill (abscissas) - Estimativas dos modelos padrão e com risco

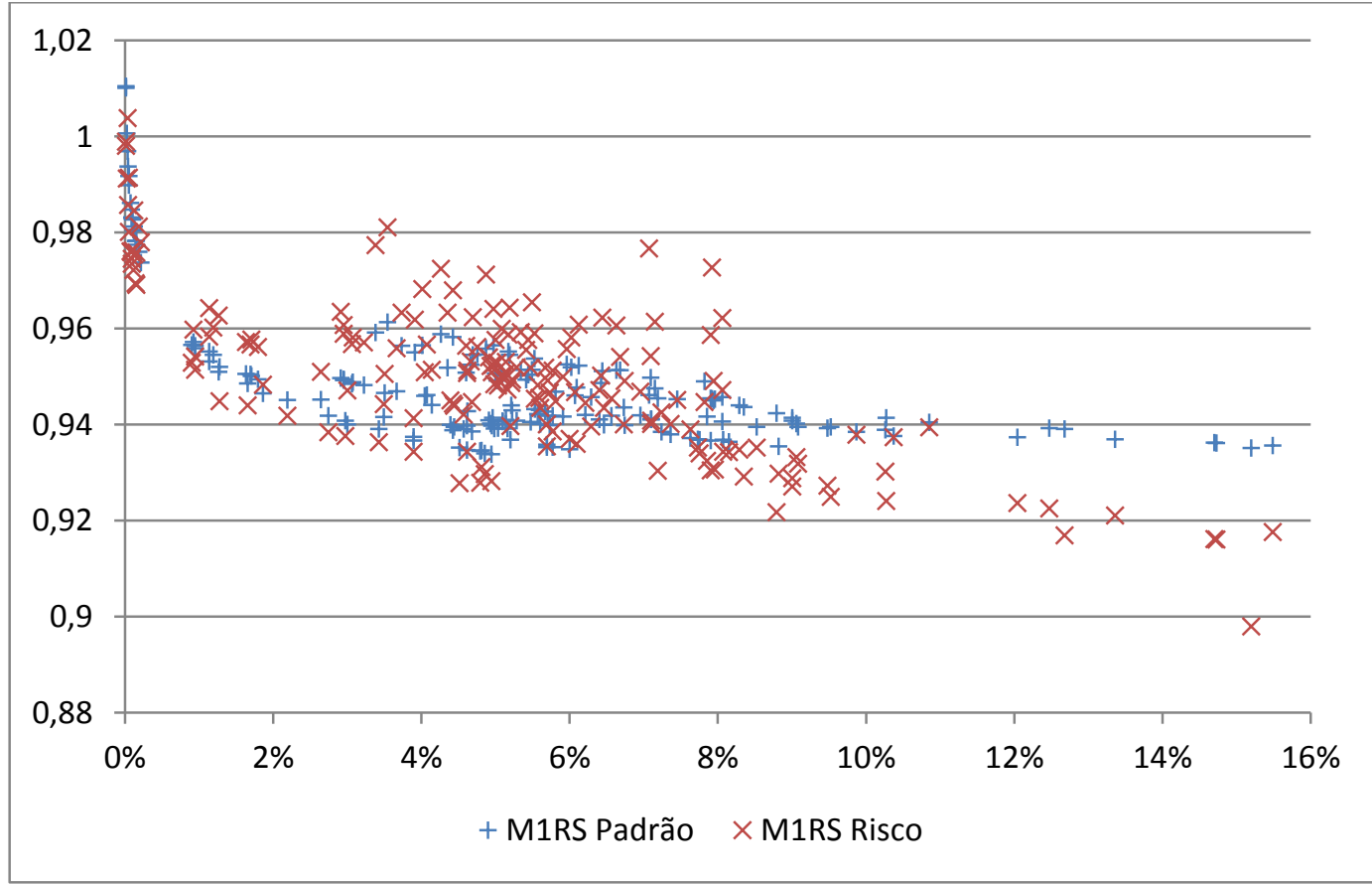

$\frac{M \widehat{1 R S} / P}{P I B}$ vs. Taxa T-bill (abscissas) - Estimativas dos modelos padrão e com risco 